The copyright of this thesis vests in the author. No quotation from it or information derived from it is to be published without full acknowledgement of the source. The thesis is to be used for private study or noncommercial research purposes only.

Published by the University of Cape Town (UCT) in terms of the non-exclusive license granted to UCT by the author. 


\section{AN EMPIRICAL STUDY ON THE DETERMINANTS OF}

Net INVESTMent Flows OF SOUTH AFRICAN

A dissertation presented to the

Faculty of Commerce

at the

University of Cape Town

in fulfilment of the requirements for the degree of

Master of Business Science

By

Riaan J Rudman 


\section{DECLARATION}

I declare that this research is my own, aided by my supervisors. I have used the Harvard convention for citation and referencing. Each significant contribution to and quotation in this research from the work, or works, of other people has been attributed, and has been cited and referenced. Neither the whole work, nor any part of it has been, is being or is to be submitted for another degree in this or any other university,

Riaan J Rudman

3: December 2004

"The insatiable craving for cash is proof that you and your fund manager have ultimately conflicting interests."

Zweig (1996, p.146) 


\section{ACKNOWLEDGMENTS}

I would like to expres5 my sincere thanks to:

4 Prof Michael Wormald (Head of Department of Accounting: UCD, for the advice and guidance during the preparation of the dissertation

4 Dr Richard Chivaka (Department of Accounting: UCD), for his tolerance, whole-hearted support, enthusiasm, constructive ideas and input throughout

1. Prof Dave Bradfield (Cadiz), for the use of the research 5tation and Mr Anton du Plooy (Profile Media) for providing the data utilised in the study

4. Prof Trevor Wegner (Department of Statistics: UC7), for his time and expertise to ensure that the formulae presented in this dișsertation are accurate and up to date

4 Ms Megan Riley (KPMG Writing Consuttant: UCJ), for the time-consuming and labour intenșlve task of proof-reading the dissertation several times

* Analysts, quantitative researchers and portfolio managers at

$\therefore \quad$ Edge Multi-managers

$* \quad$ Alexander Forbes

it Investment solutions

if. Cadiz, for the advice, planning tips, comments and insights given

* The Department of Accounting at the University of Cape Tows and Deloitte \& Touche: Financial Services Team for the opportunity to complete the Academic Articles

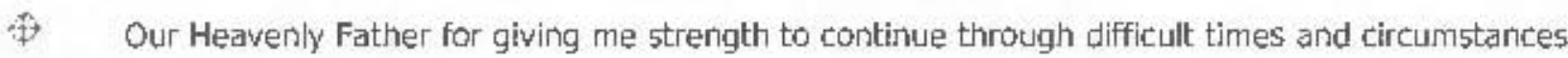

4. My parents for all the love and many years of support, understanding, patience and encouragement. 


\section{Abstract}

The unit trust industry is one of the fastest growing areas in the financial sector. This dramatic growth has raised concern regarding the level of investors' knowledge or lack thereof relating to costs, risks and other factors associated with inventment decisions. This dissertation empirically investigates the factors and the dynamics behind cash flows into and from General Equity unit trusts and the extent to which the following determinants explain the variation in cash flows:

1) Market factors - short- and long-term interest rates, local and international equity market returns.

2) Unit trust characteristics - transaction costs, past investors' contributions, fund category cash flows, risk classification, age, fund size and various performance measures.

The results are compared with research conducted in more established markets utilising similar methodologies to provide insight into the factors that might reflect investors' sentiment.

This dissertation reviews data from September 1996 to September 2001 . Using a $5 \%$ significance level, the timeseries and cross-5ectional regression anaiyses use monthly and annual data respectively. Fund performance and cash flows were examined by means of a piecewise cross-sectional regression analysis, attempting to establish whether investors are influenced by the magnitude of fund performances. A separate piecewise time-series analysis, using an interactive indicator variable approach, was performed to establish investors' reaction to the direction of performance changes. General Equity category data were aggregated into a single data-series. Timeseries multivariate and forward-stepwise regression analyses were performed on different independent variables and cash flows to establish which of these variables explain most of the variation in net cash flows at an aggregated level. This was supplemented by a cross-sectional analysis performed on the fund's characteristics for each year cowered, Multivariate and forward-stepwise time-series regression analyses were also performed for each unit trust, to mitigate the weaknesses of the aggregated testing.

The research reveals that top performing funds provide the strongest cash flow-performance relationship, indicating that investors are biased towards investing in top-performing funds. The aggregated regression analysis reflects a significant positive relationship between cash flows and contemporaneous returns of the General Equity unit trusts and the equity market, while being negatively related with lagged returns and cash flows. Initially, it appears that market returns contribute more explanatory power towards cash flows, however, further analysis shows that these findings are anomalous. This is attributable to the interaction between market returns and return earned by the General Equity category. Several of the determinants, including interest rates, fee structures, risk and fund size, identified by international literature, are found to be insignificant at a $5 \%$ significance level and do not contribute towards explainlng the movement in cash flows. The regression analysis performed on an individua! fund level, confirms the findings of the regression analysis performed on the aggregated data.

In conclusion, the results indicate that investors exhibit an element of profit maximisation, being driven by performances and irrationality, in that they give less consideration to fee structures et cetera. 


\section{TABLE OF CONTENTS}

DECLARATION I

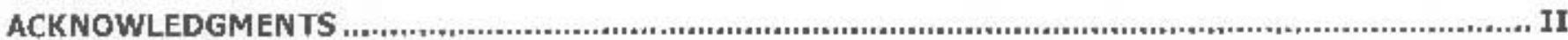

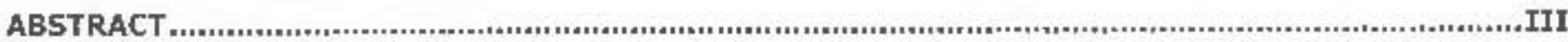

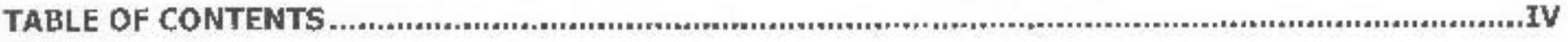

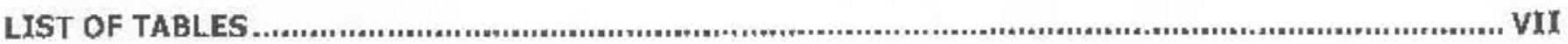

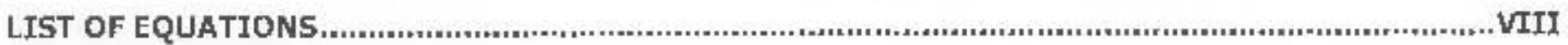

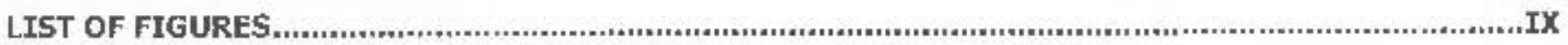

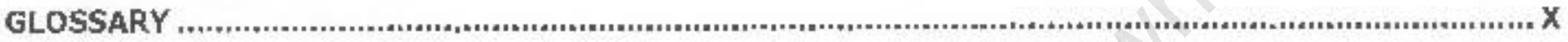

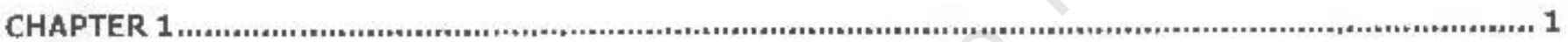

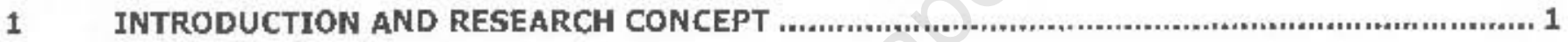

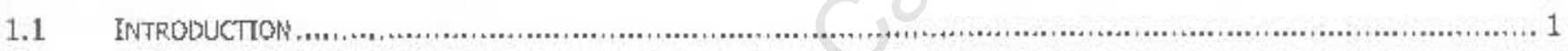

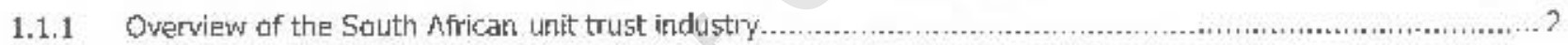

1.1.2 Differences in environmental factors locally and internaționally............................................................ 4

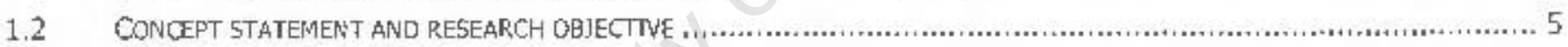

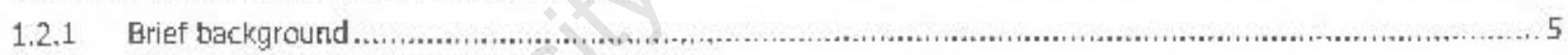

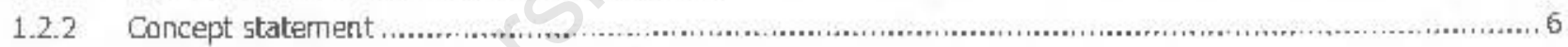

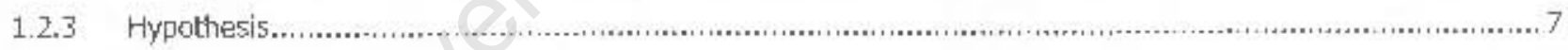

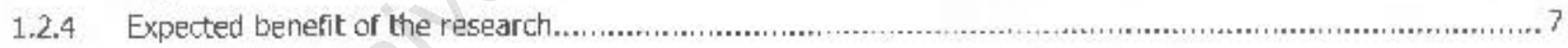

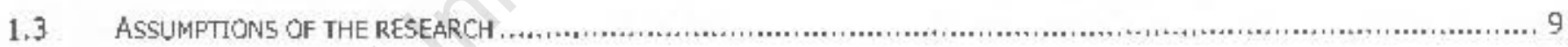

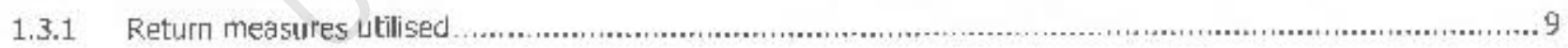

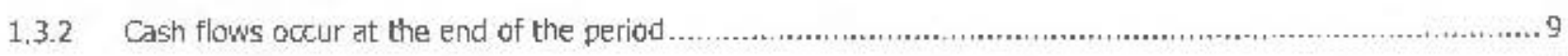

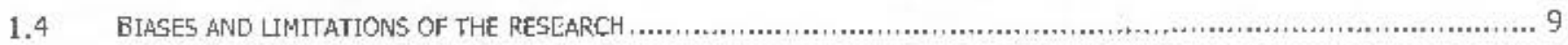

1.4.1 Reverse causality between cash flows and performances ............................................................... 9

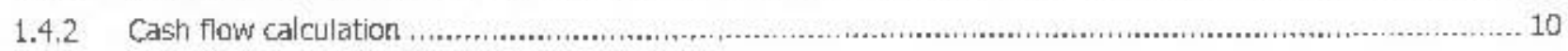

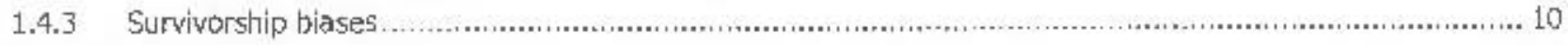

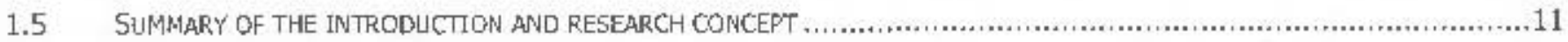

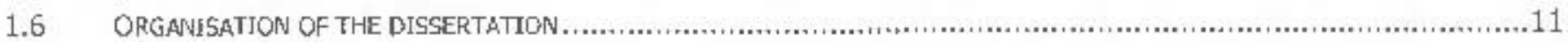




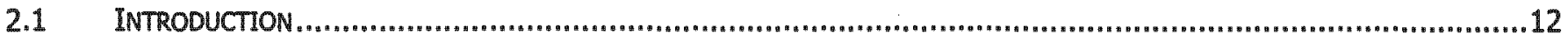

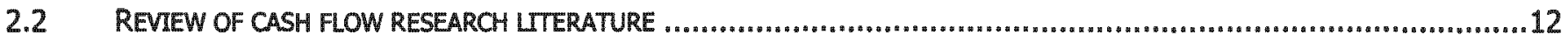

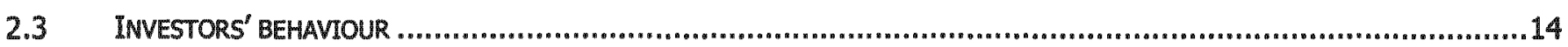

2.3.1 Common components of investors' behaviour ............................................................................. 14

2.3.2 Differences between retail and institutional investors .................................................................. 15

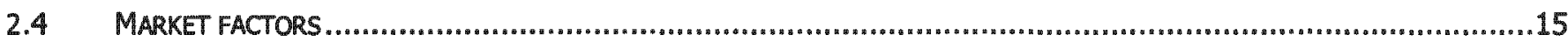

2.4.1 Impact of domestic market returns on investors' behaviour ........................................................... 16

2.4.2 Impact of international market returns on investors' behaviour.............................................................. 18

2.4.3 Impact of interest rates on investors' behaviour ............................................................................ 18

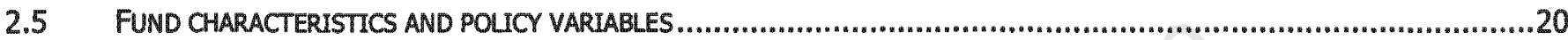

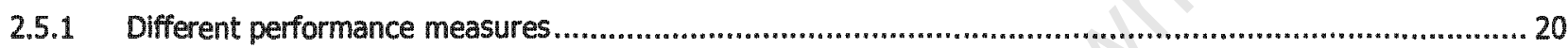

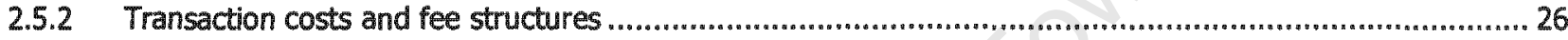

2.5.3 The influence of risk on the return-chasing behaviour.................................................................... 29

2.5.4 Past investors' capital contributions or net investment cash flows .................................................. 31

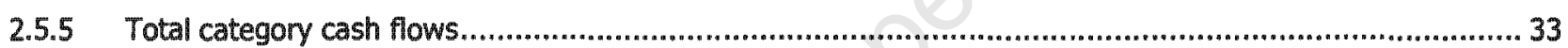

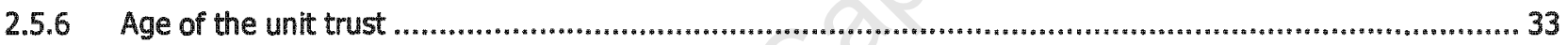

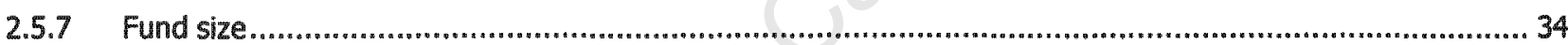

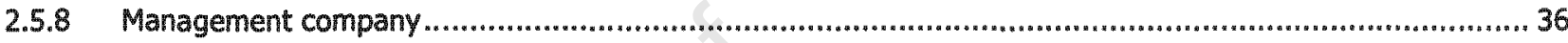

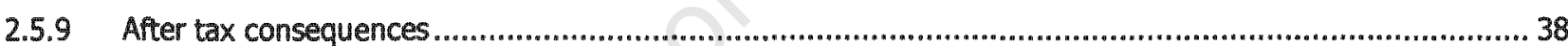

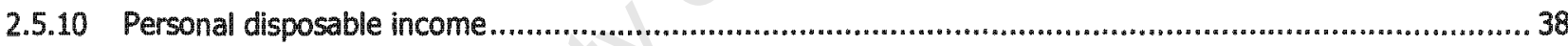

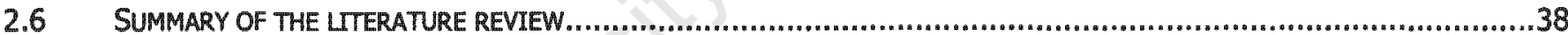

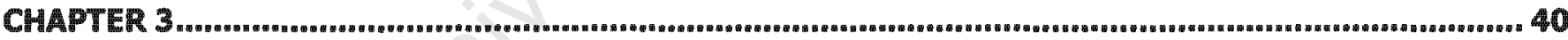

3 METHODOLOGY

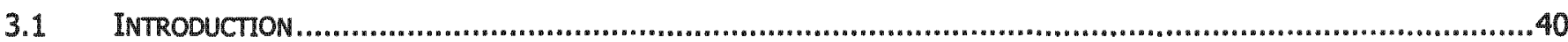

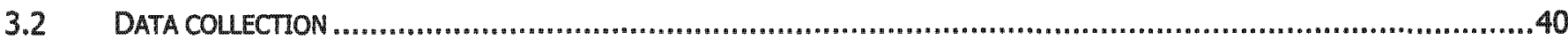

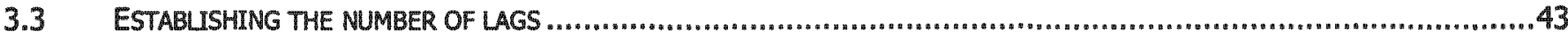

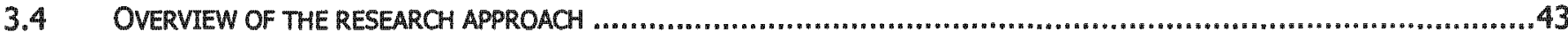

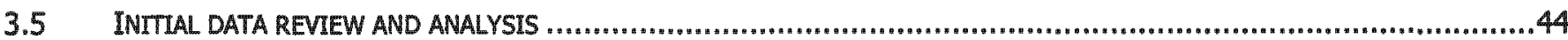

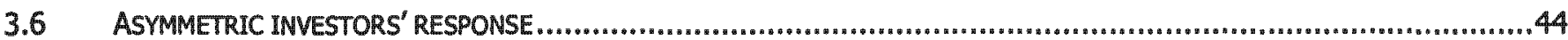

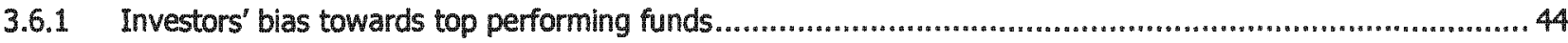

3.6.2 Investors' bias in respect of directional changes of performance ........................................................ 46

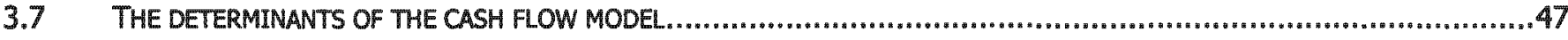

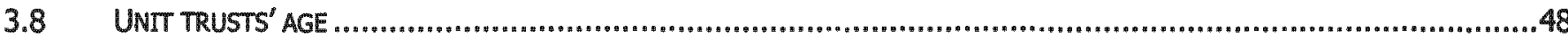




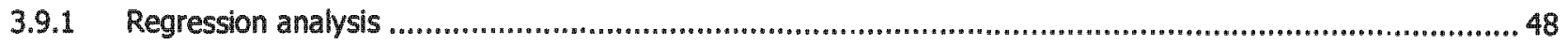

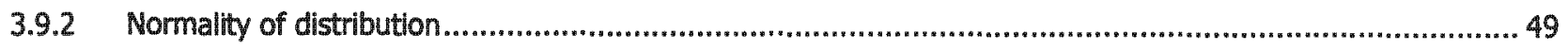

3.9.3 Regression analysis assumptions...................................................................................... 50

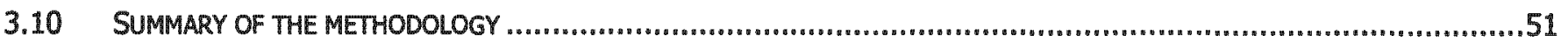

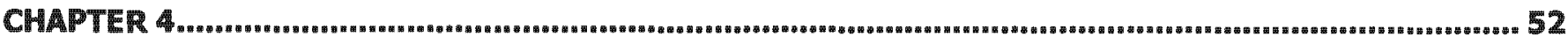

4. ANALYSIS AND DISCUSSTON OF FINDINGS .

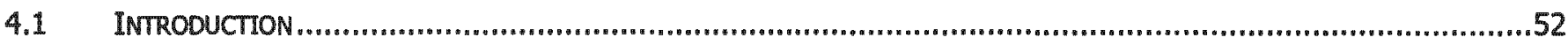

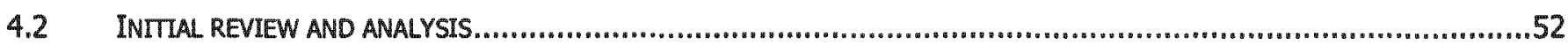

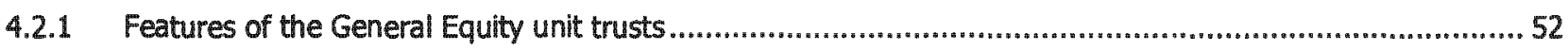

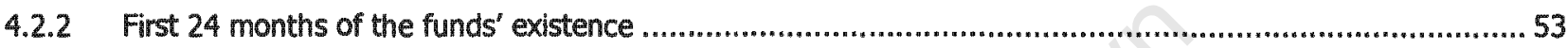

4.2.3 Interaction between the independent variables ...................................................................... 56

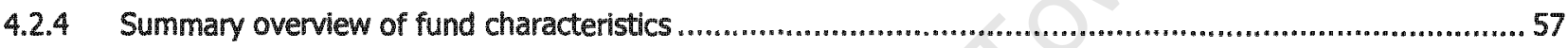

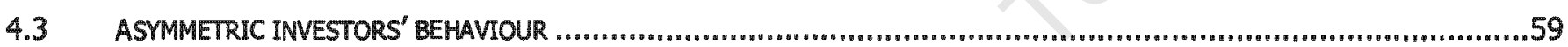

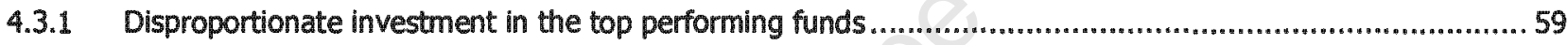

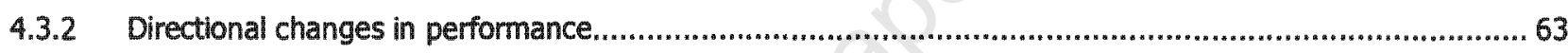

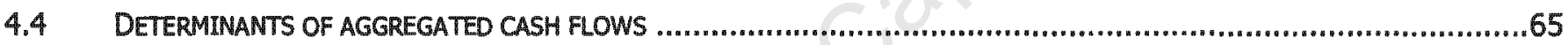

4.4.1 Interaction between market returns and General Equity returns ........................................................67

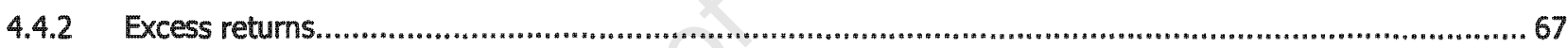

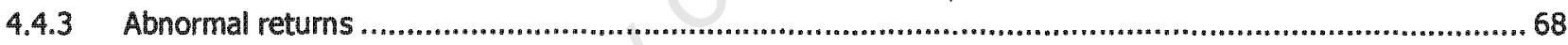

4.4.4 Lagged performance and cash flows ............................................................................................. 68

4.4.5 Interest rates, fee structures, risk and fund size ...................................................................... 69

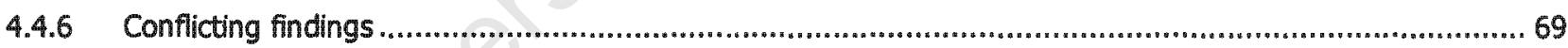

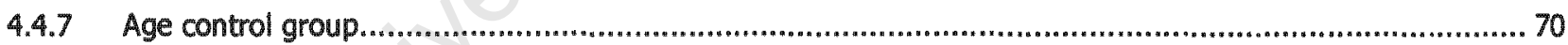

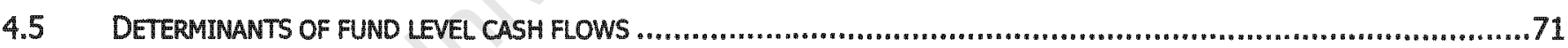

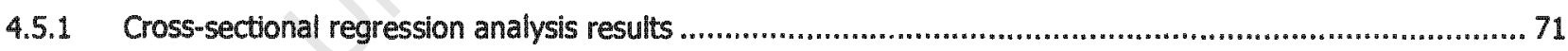

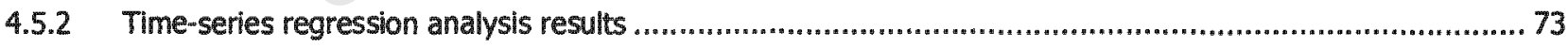

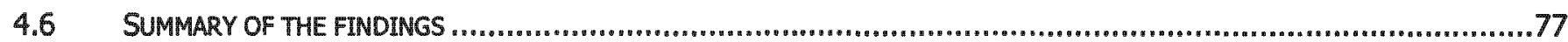

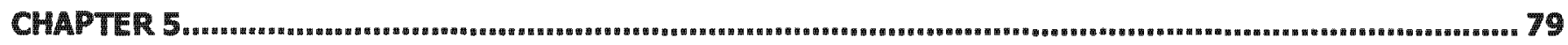

5 CONCLUSIONS AND RECOMMENDATIONS FOR FURTHER RESEARCH

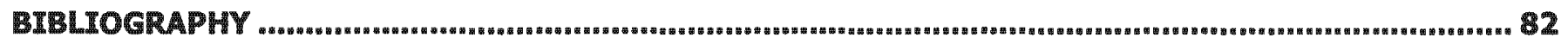

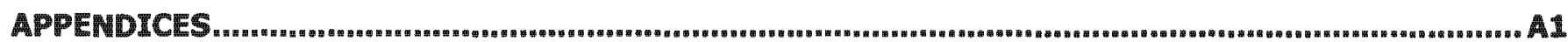




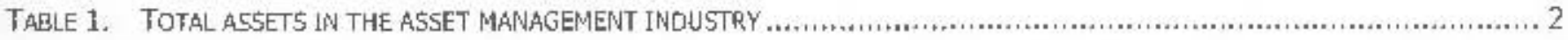

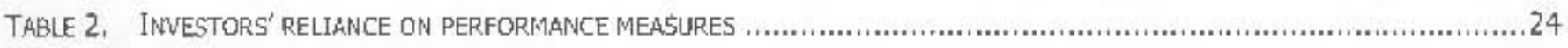

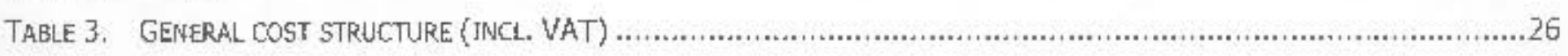

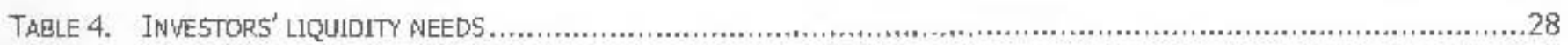

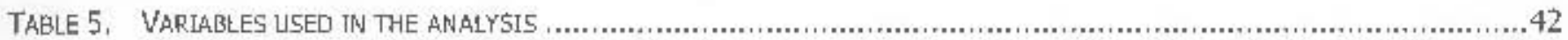

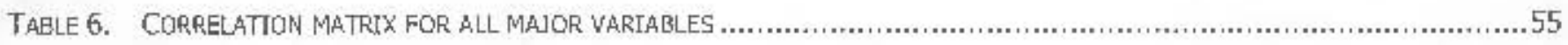

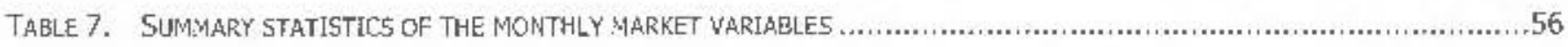

TAGLE 8. SUMMARY OVERVIEW OF FUND CHARACTERISTTCS RELATTVE TO CASH FLOWS ............................................58

TAGLE 9. REGRESSION RESULTS HIGHLIGHTING INVESTORS' ASYSMMETRIC RESPONSE THROUGH TIME FOR THE THREE PERFORMANCE

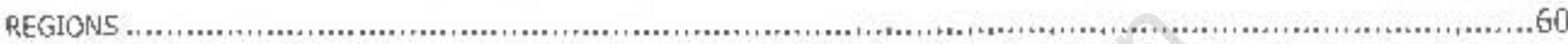

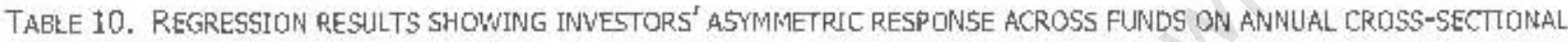

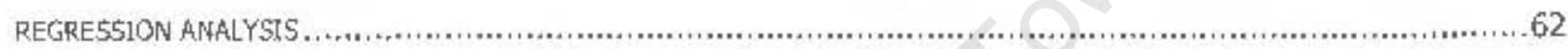

TAGLE 11. REGRESSION RESULTS INVESTIGATTNG THE INFLUENCE OF CHANGES IN PERFORMANCE ON CASH FIOWS..... .64

TABLE 12. REGRESSION RESULTS BETWEEN CASH FLOWS AND INDEPENDENT VARIAGLES USING A BIVARIATE REGRESSION TECHNIQUE

TAGLE 13. REGRESSION RESULTS BEIWEEN CASH FLOWS AND INDEPENDENT VARIABIES USING A MULTIVARIÁTE REGRESSION

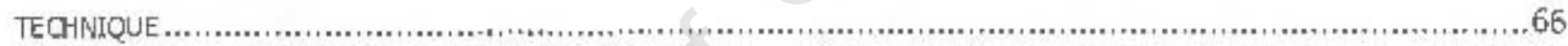

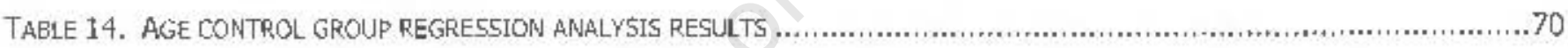

TABLE 15. CROSS-SECTIONAL REGRESSION RESULTS USING NORMAL RETURNS AS THE PERFORMANGE MEASURE ........................72

TABLE 16. MULTNARIATE REGRESSION ANALYSIS RESULTS SHOWING THE SGGNIFICANT INDEPENDENT VARIABLES THAT EXPLAIN A

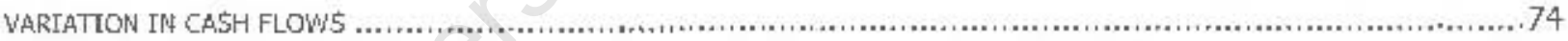

TABLE 17. INTERACTION BETWEEN THE INDEPENDENT VARIABLES AT DTFFERENT LFVELS OF CORRELATION ...........................77

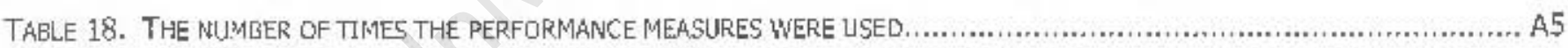

TAELE 19. TOTAL ASSETS MANAGGED EY THE TEN LARGEST MANAGEMENT COMPANIES ..............................................15 


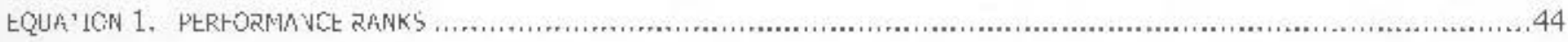

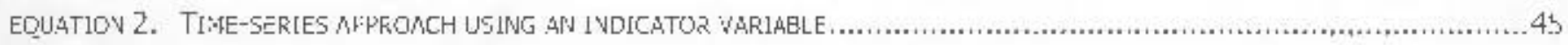

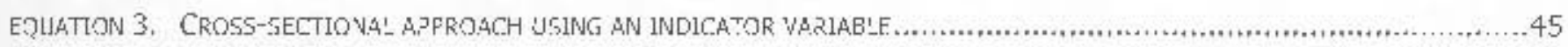

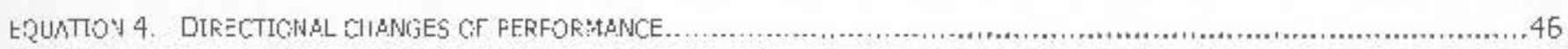

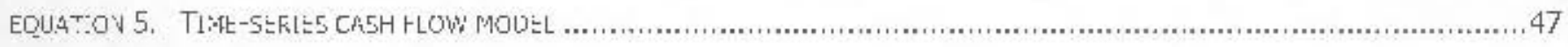

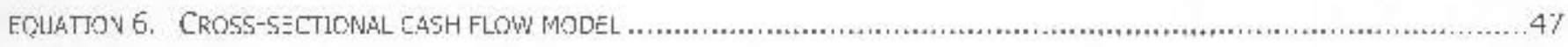

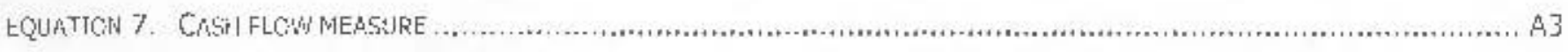

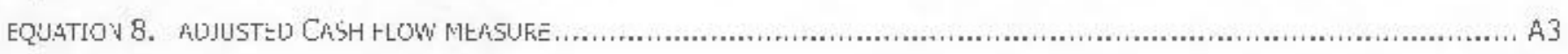

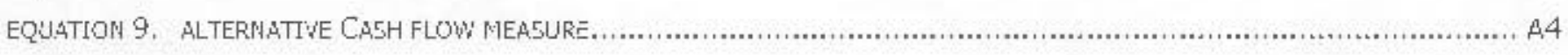

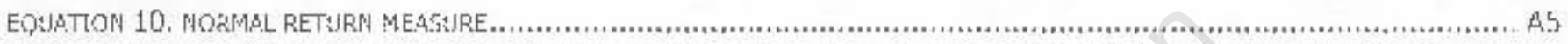

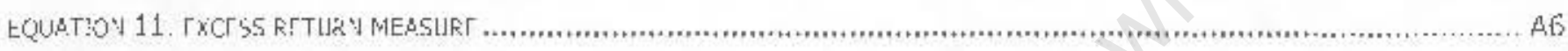

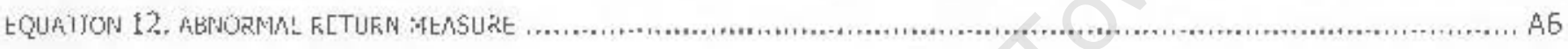

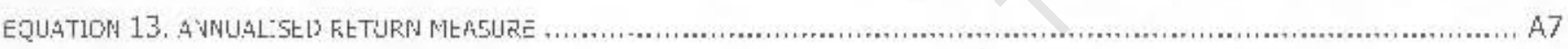

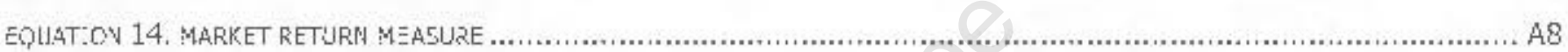

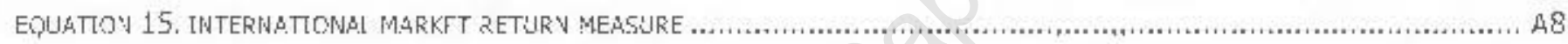




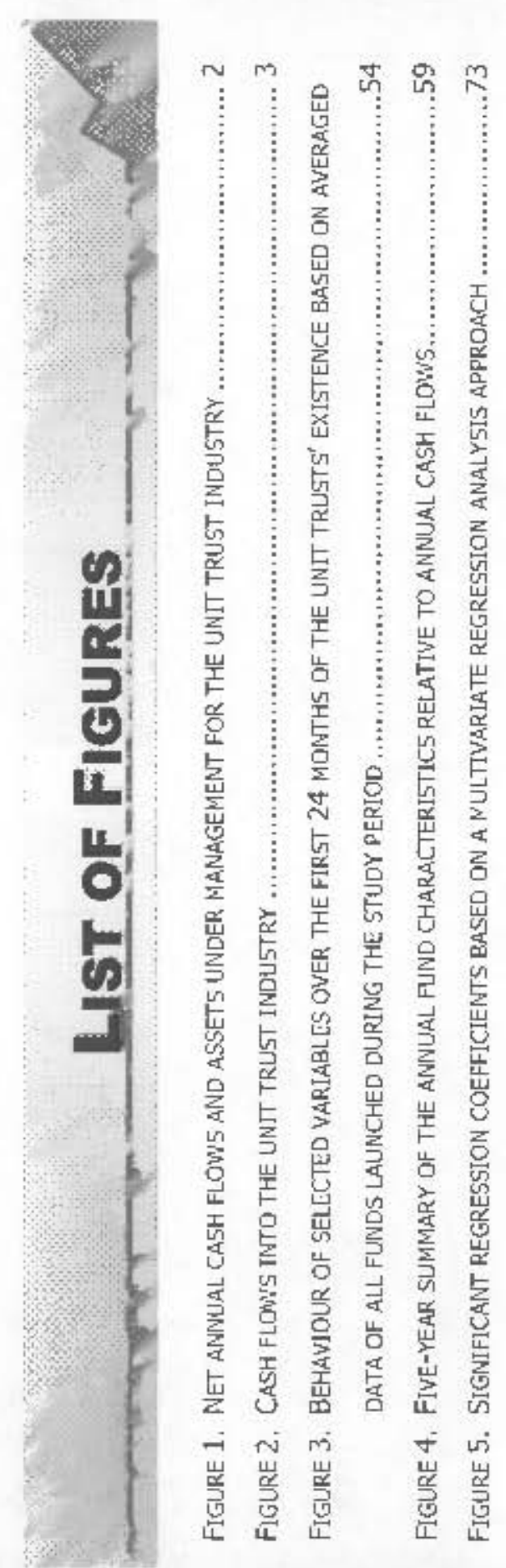




\section{Glossary}

The terms outlined below, are used in the context, of this research and when reference is made to the terms, these are defined and utilised as such.

1. Aggregated analysis: focuses on the influence of the independent variables on the cash flow of the whole sector and not on specific unit trusts. The determinants of individual funds are aggregated together into a single series.

2. Asymmetric response: Investors invest disproportionately in the top performing funds, while falling to divest from funds, which experience poor performances.

3. Correlation or relationship: A positive retationship implies that the dependent and the independent variables are related.

4. Dependent variable: refers to the variable being predicted, In this research, cash flow is the dependent variable.

5. Feedback-traders hypothesis: means that investors trade in response to recent signals in the market. These signals are reflected in either past returns, or cash flows. In other words, an investor will invest in a fund experiencing either high lagged performantes, or large cash flows.

6. Fund, mutual fund and unit trust: is a collective investment scheme where the investment contributions of a large number of relatively small investors are pooled and managed collectively by a furd manager. This pool of money is divided into identical units, each with the same value. The value of each unit reflects the performance of the underlying investments in which the fund has invested. The number of units in an investor's portfolto will depend on the amount invested and the unit price on the day of purthase. Money received by the unit trusts as dividends from ordinary shares held in their portfolio or as interest earned on their holdings of debt instruments, is paid out to unit-hoiders as dividends or reinvested. Investors share in funds' capital gains or losses, income and expenses on a proportional basis. These terms are used interchangeably.

7. Independent variable and determinant: means that the variable contributes towards prediuting another variable, in other words the potential explanatory variables under investigation.

8. Individual fund analysis: evaluates the influente of the dependent variables on the cash flows of specific unit trusts.

9. Institutional investors: consist of institutional money (held by fiduciaries, insurance companies, pension funds, trusts and corporate benefit plans) and life cycle money (for example, savings for retirement) looking for long-term investment returns rather than short-term gains.

10. Momentum traders: invest when the return on equities or the market rises. Conversely, value investors invest if the market dectines and sell units if the retum rises, thus detracting from the concurrent relationship.

11. Morningstar rating: The international rating system in the United States rates the individual mutual funds based on their risk-adjusted performances. 
12. Performance: refers to the return earned by the fund during the period under review, where returns are defined as either (i) normal returns (returns earned on capital appreciation and dividend income), (ii) excess returns (returns by which the investment out-performs the returns on the JSE All Share Index) or (iii) abnormal returns (returns on the funds in excess to those predicted by the Capital Asset Pricing Model).

13. Retail or private investors: act in their private capacity (or via a personal financial advisor or broker). Most retail investors do not have formal training in portfolio analysis and few has up-to-date information.

14. Reverse causality: is a process in which returns cause the cash flows at the same time as the cash flows cause the returns, referred to as the 'Chicken-or-the Egg' paradox. 


\section{ChAPTER 1}

\section{INTRODUCTION AND RESEARCH CONCEPT}

\subsection{Introduction}

Unit trust funds continue to be one of the fastest growing areas in the South African financial services sector (Association of Unit Trusts [AUT] $]^{1}, 2002$ ) and provide investors with flexibility, accessibility, transparency and regulatory protection (Sanlam, 2003). "This rapid growth signals that unit trusts are the favoured investment vehicle for the man in the street" (AUT, 2002); either by direct holdings or indirectly via, for example, pension funds (Lambrechts, 2003).

International literature suggests that the shift from "traditional forms of savings, particularfy bank deposits" (Remolona, Kleiman and Gruenstein, 1997, p.33), towards managed mutual funds resulted in a change in the focus in the structure and nature of financial services from "institutions to individual investors" (Fortune, 1997, p.58). This dramatic growth and the shift in risk bearing have raised concern regarding the "level of investor knowledge" (Alexander, Jones and Nigro, 1998, p.302), or lack thereof, relating to the costs, risks and other factors associated with local and international investment decisions.

Financial theories, such as the capital asset pricing model (CAPM) and mean-variance theory, have been used to explain investment decisions. The mean-variance theory rests on the assumption that purchasing decisions should be made on the basis of investors' beliefs regarding the future of the return and risk and the covariance of these assets with other financial assets (Markowitz, 1952). Other theories propose that investors (depending on their risk profile) should attempt to replicate the market index. In practice, this is not the case (Robertson, 2000$)^{2}$. Yet, by focusing only on risk and return, considerable understanding of investors' purchasing decisions is foregone. Since there appears to be no defined theory as to why investors invest their holdings in unit trusts, investors' behaviour may be somewhat irrational. This leads to the question: Which determinants guide investors when making unit trust investment decisions?

\footnotetext{
1 In March 2003, the AUT changed its name to Association of Collective Investment (AC).

${ }^{2}$ There is great investor concentration on actively managed funds. Other theories advocate investing strategies such as value or momentum investing.
} 


\subsubsection{Overview of the South African unit trust industry}

Unit trusts have existed іл Soth Africa since 1965 (Garvin, 1995). A noticeahle amount of cash unly started to flow into the industry after mid-1995: thereafler investors' interest in unit trusts grew exponentiaily (Duverihage; 2003) as graphically illustrated in Figure 1

\section{Figure 1. Net annual cash flows and assets under management for the unit trust industry}

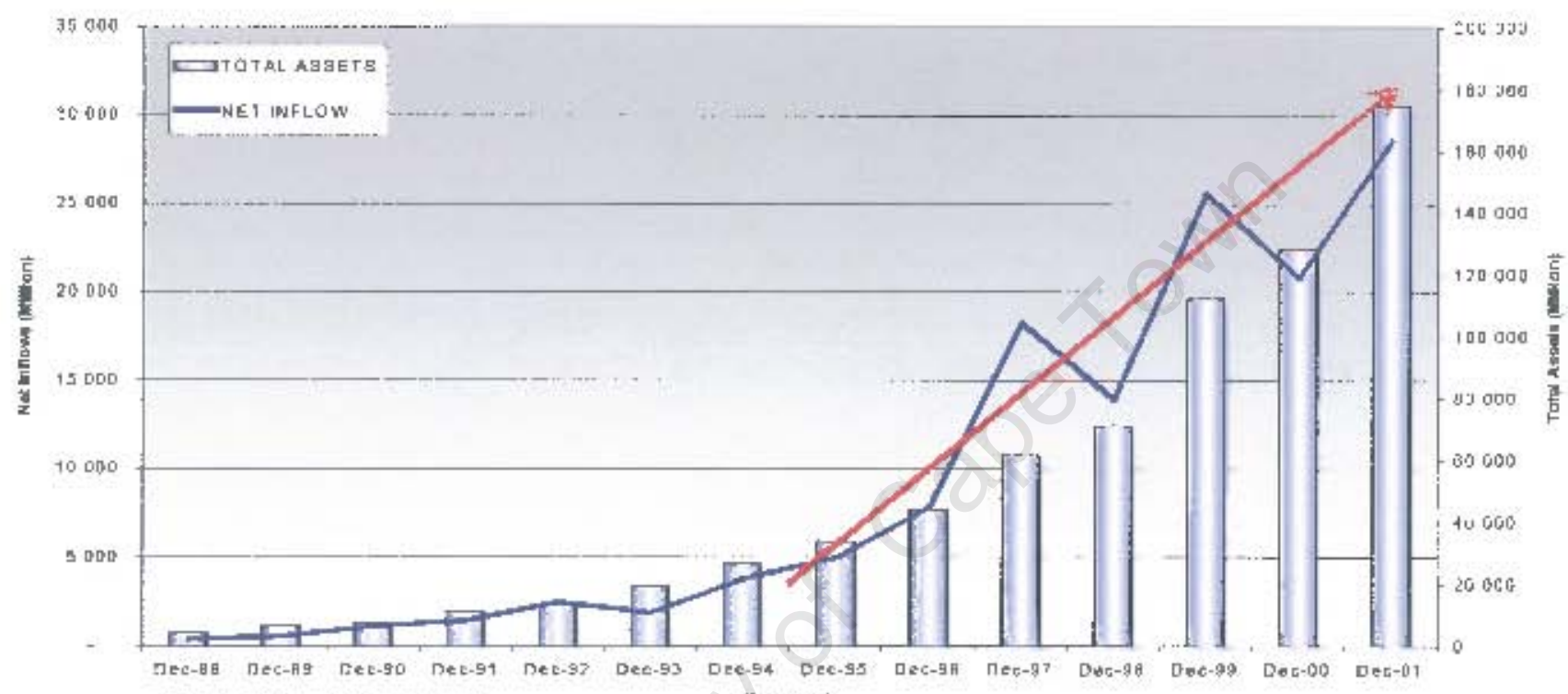

(SOURCE: AUT, 2002)

The South African industry grew by $279 \%$ from $R 33$ billion worth of assets in 1995 to $R$ 125 billion (i.e. $9 \%$ of the assets in the South African assed management industry of R 1418 billion) in 2000 as detailed in Table 1 (Coronation, 2002).

\section{Table 1. Total assets in the asset management industry}

\begin{tabular}{|c|c|}
\hline 2000 & Total $R$ billion \\
\hline Lite insulers & $\infty$ \\
\hline Private pension funas & 273 \\
\hline Pensior funds & 259 \\
\hline Ginit trusts & $125(i$, e. $9 \%)$ \\
\hline Short-term insurers & E: \\
\hline Total & 1418 \\
\hline
\end{tabular}

\footnotetext{
2 Figure 1 and Figure 2 (page 3 i refect nominal cash flows and fund sizes. Since buyirg power is erodea by inflation, it is concetvable that

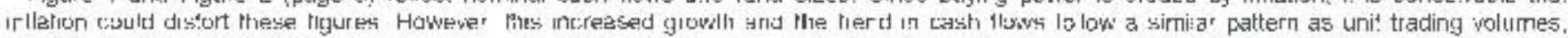

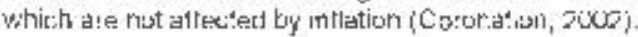


The industry experienced vecord growth, with gross sakes of R 137.4 billion during 2002 . Substantial total net new inflows of $R 19$ billion boosted assets to $R 178.8$ billion at the end of 2002 (Sanlam. 2003). From January 1996 to December 2001, the mumber of unit trust funds increased from 91 tunds (managing R 33695 million worth of assets) to 426 (with R 174585 million worth of assets under management) (AUT, 2002). This growth coujd be partialiy attributed to the shift by retirement funds from defined benefits to defined contributions. A large portion of growth in asset value was due to cash inflows in 1996 and 1999.

This growth occurred although the overall savings rate amongst South African investors showed a decline over the past couple of yoars arising from depressed economic conditions (Duverihage, 2003). The growth can be attributed to a number of factors. Fixed income and money market funds outperformod other types of funds. attracting a large portion of inflows mainly attributed to disappointing equity returns. Passive funds gained greater acceptance: due to pori and inconsistent performances by active funds. Unit trusts became more attractive due to lower management fees and transaction costs Therefore, management companies became mone competitive to increase the assets under management and this resulted in greater brand awareness and broader product ranges. Vatue funds out-performed growth funds in 2000 , and consequently made a come back during 2001. This reflewed islvestors attention (Cononation, 2002). From October to December 2001, assets increasct by R. 33178 million; one-third of the increase consisting of net cash isflows of $R 10256$ million, the remaining portion rolating to market appreciation (Figure 1).

\section{Figure 2. Cash flows into the unit trust industry}

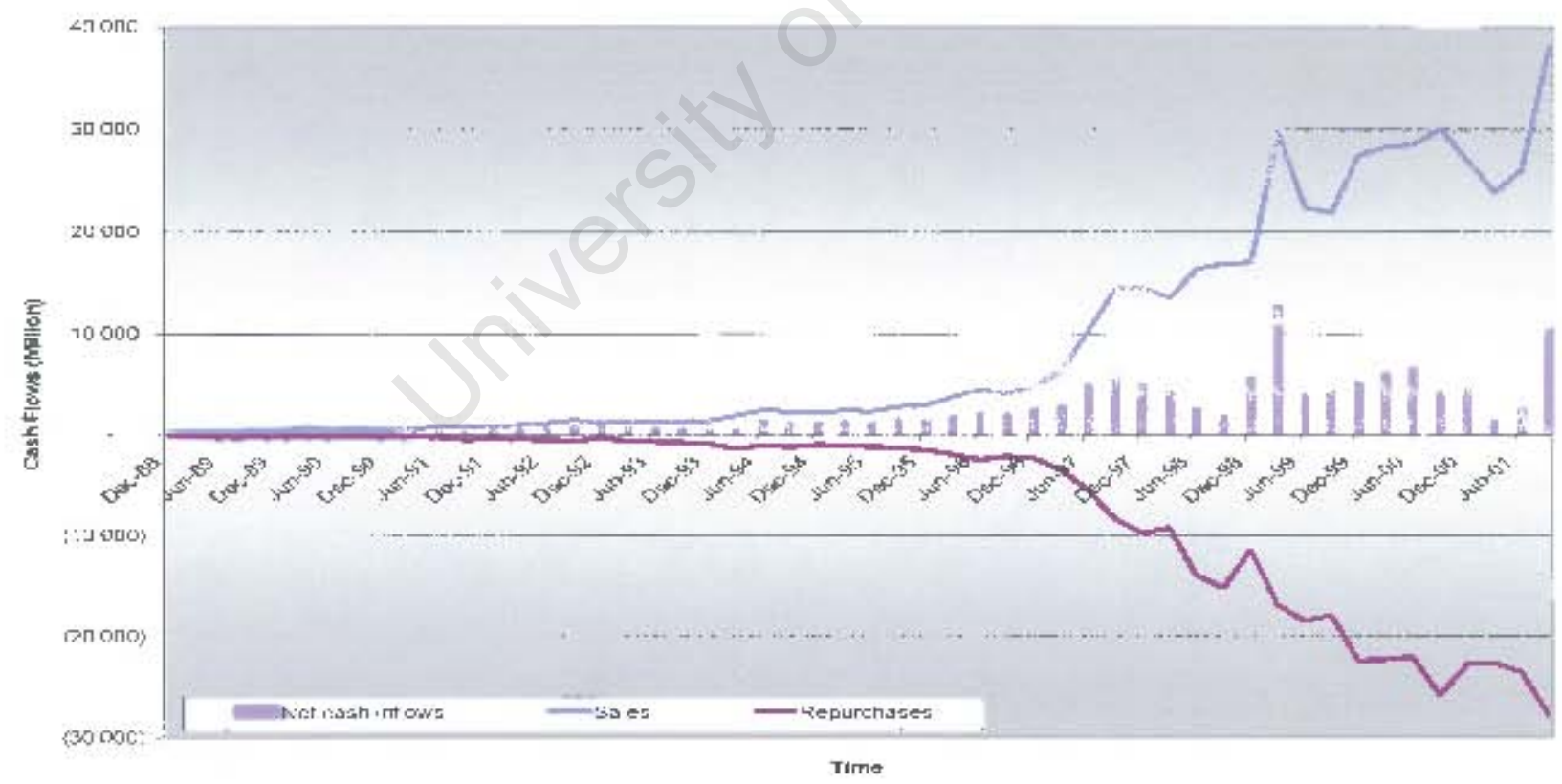

(SOURCE: AUT, 2002)

Figure 2 highlights the increase in investors activities since 1995, as indicated by the sales (investing) and repurchases (divesting) line charts. The solid line-chart represents cash in- and butfliows whereas the bar chart presents the net intiow position. 
Historically, the industry experienced net quarterly inflows, with the diversion between cash in- and outflows widening after 1996, due to greater demand. The size of this diversion could indicate that investors became more active in managing their investments, with cash inflows following a similar pattern as outflows. The change in investors' behaviour after 1996 originated from a wider distribution of wealth in South Africa and an increased demand for cheaper, more accessible investment vehicles (Coronation, 2002). A closer inspection of net cash flows reveals that these appeared to follow an annual cyclical pattern with periods of increased investments followed by periods of decline. Thus, investments reached a peak during September 1997 and June 2000 but declined consistently until a trough was reached in September 1998 and March 2001. The annual cyclical pattern coincided with major market movements and performances. March 1999 and September 2001 also stood out, arising from a combination of increased investments and divestiture respectively during the same quarter. Before both these dates, investments showed a moderate increase. After these dates, the net cash flows returned to a position slightly higher than the original inflow levels. These changes coincided with periods of volatile market conditions.

\subsubsection{Differences in environmental factors locally and internationally}

This dissertation compares findings in South Africa against international research from more established and larger markets. The following environmental factors might impact on the results:

- The South African market is much smaller, younger and less developed than, for example, the American market, with approximately 8400 mutual funds in 2001; consequently, the South African market is less liquid.

- South African investors do not have the resources that their international counterparts have, thus making search and information costs much higher.

- South African investors are over-weighted in Domestic Equity investments due to restrictions placed on unit trusts prior to 1995 and foreign exchange control restrictions. Furthermore, South Africa had 35 management companies in 2001 . Five firms managed more than $55 \%$ of the assets in the industry (Appendix $G$ ) and had immense power to move cash around and manipulate or control financial agreements.

- The South African regulations ${ }^{4}$ differ significantly from international markets with limitations to: (i) the exposure that unit trusts are allowed in a specific type of investment, (ii) the hedge instruments in which it is permissible for unit trusts to invest (Financial Services Board [FSB], 2001) and (iii) the foreign investment restrictions.

- Several unit trusts have closed or are capped; consequently, these may generate performance, but may be unable to accept new investments.

- The South African tax system differs substantially from other international systems. This will influence investors and their investing decisions differently. By implication, this might affect the comparability of returns.

- Guidelines exist for setting fee structures, but unit trusts' own fee structures may differ significantly between funds and countries.

\footnotetext{
${ }^{4}$ A positive development is the introduction of the new Collective Investment Schemes Control Act (CISCA), replacing the Unit Trust Control Act. This provides modern legislative framework to control, regulate and supervise the collective investment industry based on internationally accepted principles.
} 


\subsection{Concept statement and research objective}

This section outlines the concept statement and the main research objectives, followed by a discussion of the potential benefit that will be derived from this research.

\subsubsection{Brief background}

It has always been assumed that investors, by their very nature, are on a quest to maximise their own future economic benefits (Ross, Westerford, Jordan and Firer, 1996). This profit-driven behaviour places increased pressure on fund managers to attract investors and to generate significant positive results, on a consistent basis, so as to accumulate management fees (Chevalier and Ellison, 1997). Recently, with the advent of the internet, mass marketing et cetera, information has become more freely available with investors becoming more vigilant and informed. Investors consider a variely of factors besides performance when making investment selections (Alexander ef al. 1998), regardless of how financially "unsophisticated" (Gruber, 1996, p.807) they might be. This might make the quest for performance by fund managers non-optimal.

Prior empirical studies have focused mainly on factors helping to explain or predict future returns, ignoring unit trust investors' behaviour, whereas, theoretical or survey based studies have focused on reasons why investors invest and how they choose their investments (Sandler and Firer, 1994). Appendix A presents the timing interval, research period and measures used by these researchers and other studies referred to throughout this dissertation.

Researchers in the United States initially looked empirically at the relationship between cash flows and different performance measures to assess the factors influencing investors. Ippolito (1992), Hendricks, Patel and Zeckhauser (1993), Warther (1995), Gruber (1996), Chevalier and Ellison (1997), Sirri and Tufano (1998), Fant (1999) inter alia, documented that past non-risk-adjusted and risk-adjusted performances are important determinants of cash flows to mutual funds. This precipitated further research to ascertain the impact of investors' and fund characteristics on the cash flow-performance relationship. James and Karceski (2002) compared the cash flow-performance relationship between retail and institutional mutual funds, whereas Del Guercio and Tkac (2002) compared this relationship between mutual and pension funds. Then the investigation shifted towards market factors and the fund's characteristics, which influence the variation in cash flows (Chordia, 1996; Chevalier and Ellison, 1999; Sirri and Tufano, 1998; Berkowitz and Kotowitz, 2000; Jain and Wu, 2000). Rockinger (1995), Santini and Aber $(1996 ; 1998)$ and Zheng (1999) were amongst the first to consider a multivariate approach, which integrated and considered the interaction between these determinants. This improved the understanding of the dynamics behind the determinants driving cash flows.

These studies were conducted in well-established markets and economies, with arguably more informed investors than those in South Africa (Froot, O'Connell and Seasholes, 2001). It should be noted that it would still be expected that the same principle conclusions identified by international research would be applicable in a South African context. The differences in the environmental and economic factors give rise to the research questions outlined in section 1.2.2. 


\subsubsection{Concept statement}

An important behavioural requirement of the Arbitrage Pricing Theory is that investors perceive and care about a sel of factors driving returns (Ross, 1976). However, in practice this may not be the case because investors consider other factors, not related to relurns (Robertson, 2000). This research study investigates and determines the factors (market factors and the characteristics of the fund) which best explain net investment cash flows into and from Domestic General Equity unit trusts. The findings provide insight into investors' behaviour in the small, relatively undeveloped South African financial market compared to more established markets such as the United States.

The research aims to determine empirically the nature of the relationship between net investment flows and the following determinants:

1) Market factors - short- and long-term interest rates, local stock market returns on the Johannesburg Securities Exchange (JSE) and international stock market returns (as proxied by an international equity market index).

2) Unit trust characteristics - transaction costs and fee structures, past investors' contributions or investments, fund category cash flows, risk classification, age, fund size and different performance measures.

If there is a relationship, the research would endeavour to determine the extent to which these variables explain cash flows and how the relationship between these variables could change. The empirical research can be summarised to answer the following questions:

- To which extent are investors' decisions ${ }^{5}$ driven by unit trusts' performances?

- Which market factors provide the most explanatory power in explaining investors' behaviour? ${ }^{6}$

- Which unit trust characteristics provide the most explanatory power in explaining investors' behaviour?

These factors are investigated, since there are plausible economic theories justifying the inclusion thereof in a South African context. Moreover, data and quantifiable independent variables are available for these determinants. This dissertation uses the term 'determinant' as a collective term referring to the items listed above.

\footnotetext{
${ }^{5}$ Where net investment cash flows are acting as a proxy for investors' decisions.

This refers to a collective group of buyers and sellers as a homogeneous group.
} 


\subsubsection{Hypothesis}

The objective of the dissertation is to determine which factors best explain the variation in cash flows, in an attempt to establish whether a relationship exists between cash flows and the determinants or factors under review. This objective consists of a primary hypothesis, which can be divided into secondary components.

\subsubsection{Primary Hypothesis}

Ho: There is NO relationship between net investment cash flows and the potential determinants ${ }^{7}$ H1: There is a relationship between net investment cash flows and the potential determinants.

The primary hypothesis is to investigate which determinants best explain the variation in cash flows. These determinants can be divided into two components: market variables and fund characteristics. Two hypotheses, pertaining to the determinanis of cash flows, are tested: the first considering performance separately and the remainder relating to market variables and fund characteristics.

\subsubsection{Secondary Hypothesis}

Ho: There is NO relationship between net investment cash flows and the market factors.

H1: There is a relationship between net investment cash flows and the market factors.

Ho: There is NO relationship between net investment cash flows and the unit trust characteristics.

H1: There is a relationship between net investment cash flows and the unit trust characteristics.

The first component investigates whether returns on domestic and international equities (or markets) and/or shortand long-term domestic interest rates explain the variation of cash flows of Domestic General Equity unit trusts. The final testable component determines which fund characteristics, such as, risk profile, transaction costs et cetera help to explain investors' decisions to invest (or divest) in unit trusts. The analysis considers each determinant separately and in different combinations, to evaluate the related impact each has on the other.

\subsubsection{Expected benefit of the research}

This research is undertaken to better understand the common components underlying the behaviour of unit trust buyers. The knowledge gained, is expected to have potential value for fund managers. By documenting the different factors influencing investors' behaviour, the research might be contributing to the body of knowledge linking fund managers' behaviour to the implicit "incentive to take actions that increase the inflow of investments" (Chevalier and Ellison, 1997, p.1167). If naive investors consider and evaluate returns but not risks when making investment decisions, fund managers might have an incentive to increase the funds' risk profile in an attempt to boost or increase returns ${ }^{B}$, with no negative side effects on invested cash flows arising from the increased risk, which is presumably ignored by such investors.

\footnotetext{
${ }^{7}$ The determinants are outlined in section 1.2.2.

Assuming that, as financial theory suggests, risk and expecled retum are directly related.
} 
Although there is a trend towards performance-based remunerations, most fund managers are still remunerated based on the amount of assets they administer (Deloitte \& Touche, 2002). Understanding the determinants of cash flows would assist to establish whether this is the most appropriate compensation method. This research could help fund managers to structure products based on the factors driving investors' decisions. In addition, it could offer assistance to management companies, firstly, by providing guidance, with reference to marketing activities, as to the most significant determinants to incorporate into products and campaigns and secondly, by providing a tool with which to predict future variations in liquidity, thus enhancing cash flow management. It is, therefore, important to understand the dynamics driving cash flows for the following reasons:

- The unit trust industry is a significant source of market liquidity ${ }^{9}$, providing a valuable service to equity and bond market investors (Table 1).

- Most of the funds' own unit holders receive professional advice and it is a relatively cheap and effective method of switching between or out of funds, thereby providing valuable cash liquidity, by creating a pool of buyers and sellers.

- Unit trusts have limited access to cash in the form of borrowings. The only avenue available to fund managers to obtain new cash is either to attract cash flows from investors, or by limited borrowings in terms of the Unit Trust Control Act (FSB, 2001). Cash holdings are important indicators of investments and investment opportunities.

- Cash flows could be an important indicator of investors' sentiment (Smith, 1997) and might contain different types of information depending on the nature of cash flows.

- Cash flows could have an impact on funds' performances during a liquidity crisis. Fund managers could use cash holdings as a tool to buffer funds against the impact of a liquidity crisis, thus mitigating the potential negative effect a liquidity shock could have on funds' performances (Elton, Gruber and Busse, 2002) ${ }^{10}$. On the other hand, in a bull market, holding too much cash could decrease returns on investments.

- In an environment where the winners take all the cash, "fund managers have an implicit incentive to alter the risk of their portfolios" (Del Guercio and Tkac, 2002, p.525) to increase the probability of being amongst the "top performers" (Chevalier and Ellison, 1997, p.1170).

Notwithstanding the potential benefit this research might have regarding explaining investors' behaviour, cash flows to and from unit trusts are important from a fund's perspective.

\footnotetext{
- 'Market liquidity' refers to the level of trading taking place between willing capital market participants.

${ }^{10}$ For example, if a fund manager expects the decline, he loads his portiolio with cash, thus dampening the negative effect of investors withdrawing funds. It may also allow him to acquire "some bargains out there" (Willamson, 1998, p.2), which will be undervalued, with the potential to recover at a later stage.
} 


\subsection{Assumptions of the research}

\subsubsection{Return measures utilised}

Investors base their investment decisions on expectations of future returns, using past returns as a basis to make predictions. Therefore, this dissertation uses realised historic returns and measures of expected returns, because the available data do not reflect how investors determine their forecasts. In attempting to model the forecasting process, errors might be introduced into these estimates of excess returns and Jensen's single factor alphas.

\subsubsection{Cash flows occur at the end of the period}

The formula, used to calculate implied net investment cash flows (appendix B), assumes that cash flows occurred at the end of the period and that returns were earned only on assets invested at the beginning of the period, even though cash flows occurred continuously during the period. With the exception of Gruber $(1996)^{14}$, the results in research papers by Ippolito (1992) and Warther (1995) inter alia, were not affected when cash flows were calculated as having occurred at the beginning, halfway through, or continuously throughout the year. This dissertation utilises the same cash flow measure, used in other research papers, for comparative purposes.

\subsection{Biases and limitations of the research}

\subsubsection{Reverse causality between cash flows and performances}

Arguments are presented that cash flows follow the prior periods' returns, since investors might hold the belief that returns would persist in future periods. Furthermore, there is a component in net inflow which is positively related to future returns since new cash flows are utilised to generate fund returns (Warther, 1995; Gruber, 1996). If this is true, this reverse causality (or "two-way causation" [Remolona of al. 1997, p.34]) is a source of bias in this dissertation. The high correlation between cash flows and returns does not necessarily mean that there is a strong reverse causality. The correlation could arise in the absence of this process. An optimistic sentiment might encourage investment in unit trusts, whilst at the same time increase the underiying asset prices. Alternatively, the correlation might arise from a relationship in one direction only. If investors, observing the cash flows, believe that the cash flows convey useful information about future prospects of the unit trust, then the cash flows might result in future returns due to price pressures. On the other hand, a strong argument could be made that investors follow returns and do not cause these. Either way, this correlation arises from a one-way causation. It is important to note that this dissertation investigates correlation and not causation.

\footnotetext{
${ }^{11}$ Gruber $(1996, p .804)$ showed that cash flows occurring at the beginning of the period (which he called an "impossibility") overstate the results, while cash flows at the end of the period, understate the results. He commented that investors should receive compensation for the returns earned on cash introduced at the beginning of the period but posed no solution to correct for this misstatement.
} 


\subsubsection{Cash flow calculation}

An absolute (or rand) and a relative cash flow measure could be used in the dissertation. Both measures are defined as the change in total Net Asset Value (NAV) minus the appreciation in assets and reinvested distributions. The absolute amount of cash flows tends to have large absolute cash flows regardless of performance. Therefore, cash flows were standardised by dividing the absolute cash flow by the NAV of the fund at the beginning of the period, represented by an implied growth rate (referred to as cash flow henceforth). The formula, used to calculate cash flows, is based on fund size, which is sensitive to inflation.

There are various components to cash flows, consisting of exchanges (or switching) between funds, sales and redemptions. Fant (1999) surmised that little reason exists to expect that these cash flow components behave in the same manner. A similar point could be raised regarding the decomposition of cash flows into expected and unexpected components. This argument could be compounded by the fact that no separation was made between institutional and retail investors, each with different needs and investment requirements. As a result, certain features of the cash flows might be distorted when only examining aggregated net investment cash flows. Nonetheless, a generalised conclusion can be reached about the relationship.

\subsubsection{Survivorship biases}

If poor performing funds dropped out of the database during the sample period or if funds merged, it might induce survivorship bias into the dissertation. The impact is minimal, since only five General Equity funds merged or delisted during the sample period. The international debate surrounding survivorship bias could not reach consensus. Brown and Goetzmann (1995) and Grinblatt and Titman (1992) confirmed the economic significance of survivorship bias in equity fund performances. Neither cash flow studies by Goetzmann and Peles (1997), Chevalier and Ellison (1997), Sirri and Tufano (1998), Santini and Aber (1998), Del Guercio and Tkac (2002), Elton et al. (2002), nor Goriaev, Nijman and Werker (2002) reported any change in their findings when repeating their analyses, using samples free of survivorship bias.

Edelen (1999, p.447) stated that "survival bias is not likely to affect the results". He reasoned that it did not affect the central proposition of his paper, as the tests related performance measures to cash flows and did not focus on the level of performance per se. However, he conceded that, if survival bias existed in the sample, it would probably be the greatest for funds having high cash flow volumes.

From a practical point of view, calculating cash flows is dependent on obtaining reliable fund sizes on a monthly frequency. Only Standard \& Poors (S\&P) Micropal has a complete set of monthly fund sizes. I-Net Bridge and Profile Media only have fund sizes available on a quarterly basis, thus making it difficult to obtain cash flow information for discontinued and merged funds. The individual actual cash flows are available from the AUT and can be obtained, if authorised by management companies. Whether survivorship bias is an issue in the South African market has yet to be determined by an empirical study and falls outside the scope of this dissertation. 


\subsection{Summary of the introduction and research concept}

Unit trusts have existed in South Africa for almost 40 years but a noticeable amount of cash only started to flow into the industry after mid-1995, indicating that investors became more active in managing their own investments. This change in the cash flow dynamic gives rise to the research objectives. Researchers in the United States investigated the question that investors propose to maximise their own future economic benefits, by looking at how different investor and fund characteristics impact on the cash flow-performance relationship. This dissertation investigates and determines the factors which best explain net investment cash flows (as a proxy for investors' decisions) into and from Domestic General Equity unit trusts. The research was undertaken to better understand the common components underlying the behaviour of unit trust buyers. The research knowledge gained is expected to have potential value for fund managers.

\subsection{Organisation of the dissertation}

Chapter 1 provides an overview of the South African unit trust industry and outlines the concept statement and research objectives. It presents a background, as well as some assumptions, biases and limitations expected to be encountered during the research. Chapter 2, the literature review, presents the theories which explain the factors contributing to cash flow variability and behaviour. This includes an historical review of the major research studies conducted internationally, due to the limited South African research literature available.

Chapter 3 describes the data utilised and the methodology applied by this dissertation. The methodology was adopted from local and international research studies. Chapter 4 discloses and critically analyses the findings. The findings are based on South African data and are compared and analysed in terms of international research. Chapter 5 contains a summary of the findings, concludes the research and makes recommendations for further research opportunities. 


\section{ChAPTER 2}

\section{LITERATURE REVIEW}

\subsection{Introduction}

Chapter 2 presents an overview of local and international literature which served as a reference in undertaking the empirical work reported on in the subsequent chapters. Section 2.2 commences with a review of the historical development of the research conducted on the determinants of cash flows. Section 2.3 documents the different types of investors' behaviour. Sections 2.4 and 2.5 discuss the market factors and fund characteristics which act as determinants of cash flows. Finally, section 2.6 summarises and comments on the determinants in a South African context.

\subsection{Review of cash flow research literature}

Unit trust research in South Africa lags far behind the rest of the world (Sandler and Firer, 1999). Information and research regarding return predictability and risk assessment of unit trusts are available, however, only limited analyses regarding other aspects of unit trusts have been published in South Africa. Consequently, welldocumented research conducted in the United States, Australia, New Zealand and Spain are considered. The findings, presented by these studies, differ in terms of significance and strength. Several reasons could be presented for the inconsistencies and differences. These mainly arise from the structure of the data utilised and the different environmental factors which impact on the funds.

At first researchers investigated exclusively the relationship between cash flows and different performance measures. Gruber (1996) focused on using cash flows to predict returns and presented evidence that performances are significantly related to concurrent cash flows, using a multivariate and cross-sectional regression approach. Remolana et al. (1997) utilised an instrumental variable approach to indicate that, on average, the effects of short-term returns on mutual fund flows are weak. They found that net cash flows are highly correlated with returns and attribute this almost entirely to the correlation between unexpected cash flows and returns, while commenting that expected cash flows are neither affected by contemporaneous, nor lagged returns. Edelen and Warner (2001) demonstrated that unexpected lagged flows are not related to prior returns, while expected lagged cash flows are related. They utilised high frequency daily data and documented a very strong daily correlation between returns and subsequent flows and thereby confirmed findings by Warther (1995).

Fant (1999) further decomposed cash flows to the Growth Equity and Income Equity mutual fund category into: new sales, redemptions, exchanges-in and -out. The only significant cash flow-return relationship is between returns and future exchanges. He concluded that there is no evidence to suggest that a relationship, other than a concurrent and a one-month lag period, exists. He stated that exchanges are the dominant components. 
Gruber (1996) and Remolana et al. (1997) inter alia, confirmed the expectations that, for certain investors or speculators, past returns are the driving factors when making investment decisions, leading to larger than expected cash flows and an increased volume of exchanges.

Thereafter researchers concentrated on the forces driving the cash flow-performance relationship. Sirri and Tufano (1998) reported that investors follow performance cross-sectionally across funds. Karceski (2002) confirmed these findings.

Warther (1995) examined funds in a macroeconomic context to investigate whether aggregated cash flows are associated with concurrent or subsequent market movements for equities, bonds and precious metals. He attempted to establish whether investors follow the market, when returns move. He documented that monthly cash flows into equity and bond funds are contemporaneously correlated with market returns and long-term corporate and government bonds, and short-term money market interest rates. Contrary to his expectation, he did not find that cash flows are negatively related to interest rates, thus establishing that cash flows are correlated with returns of the securities held by funds and the funds' returns, but not with other securities. Consequently, when funds make a new investment, the addition also has an impact on cash flows.

Santini and Aber (1998) used a time-series multivariate model (including market returns, interest and disposable income as explanatory variables) to investigate aggregate money flows into and from the Equity mutual fund industry. This approach substantially improved the explanatory power of the model beyond that obtained in the studies outlined above.

Froot et al. (2001) and Brown, Goetzmann, Hiraki, Shiraisha and Watanabe (2002) conducted research into the relationship between daily international cash flows and fund performances. Froot et al. (2001) reported that cash flows have a positive forecasting power for future equity returns in emerging or high-risk countries. However, a similar relationship is not evident in developed countries. Brown et al. (2002) reported evidence that cash flows to foreign funds display negative correlation to returns on American Domestic funds.

Del Guercio and TKac (2002) investigated a difference in the cash flow-return relationship for pension funds as opposed to mutual funds. They found that mutual fund cash flows are unrelated to tracking error (except for the funds in the best performing quartile), but have a strong relationship with normal returns and Jensen's alpha. James and Karceski (2002) confirmed these findings regarding retail mutual funds and highlighted the importance of considering the nature of the investors. These appear to be anomalies because Warther (1995) and Gruber (1996) inter alia, consider mutual fund investors to be the least informed investors.

At an individual fund level, specific factors such as performance (Spitz, 1970), transaction costs (Chordia, 1996), risk (Lettau, 1997), fund size and marketing effort (Sirri and Tufano, 1998; Jain and Wu, 2000), portfolio turnover (Edelen, 1999), security returns (Potter, 2000) and after tax returns (Bergstresser and Poterba, 2002) were investigated to explain investors' behaviour. These studies were conducted in the United States and are extensively discussed in sections 2.4 .1 to 2.5 .10 . 
Torre and Garcia (2002) concluded that investments into Spanish mutual funds are driven by past performance history, showing little concern for transaction costs and risk structures. Rockinger (1995) noted that the pre-1995 studies are not comparable, as the econometric models and variables chosen, differ. Rockinger (1995) and Zheng (1999) combined the two paradigms considering market factors, style variables and fund characteristics. Zheng (1999) utilised a cross-sectional and a time-series approach on American mutual funds (excluding international and balanced funds) from 1970 to 1993. Failing to find that market factors and style variables explain Gruber's "smart money effect" (Zheng, 1999, p.90), he concluded that investors use fund specific information to make investment decisions.

\subsection{Investors' behaviour}

Prior to discussing the factors which investors consider when making investment decisions, it is necessary to outline the common components underlying investors' behaviour and the various types of investors.

\subsubsection{Common components of investors' behaviour}

Studwick and Grant (1995, p.15) indicated that "optimism is the enemy of the rationale [sic] investor and fear is our friend". Empirical research on mutual funds could have potentially significant implications for investors. However, most of the research published in journals or by private institutions, never reaches the investors. With the exception of institutional investors, most investors will either rely on broad commentaries by journalists, "rulesof-thumb" (Woerheide, 1982, p.129), or guidelines from their brokers or peers. It is not easy to identify individual decisions to trade or to analyse the grounds on which these decisions are based, nor is it the purpose of this dissertation.

Investors will generally respond in a similar manner to news events that have the same implications for investors' portiolio choice. Studwick and Grant (1995), Goetzmann, Massa and Rouwenhorst (1999) and Edelen and Warner (2001) suggested that a common component of investors' behaviour exists, providing a measure of the degree to which investors herd across assets and asset classes and exhibit herd psychology. Wermers (1999) examined the extent of institutional herding in the American market. He observed buy-side (sell-side) herding only, when markets experience extreme past positive (negative) returns. Connolly (1997, p.8) suggested that if investors invest for the long-term, they do not care about fluctuations as much and stated that "it is herd money and it is hard to spook this herd," but "when the herd moves, it will be hard to get them back into the corral." Investors might respond to returns and be influenced by market perceptions and thus trade more frequently. According to Goetzmann et al. (1999) and Barberis and Shleifer (2003), cash flows act as instruments which reflect investors' sentiment about market and other factors preceding the expectation. Investors might be aware that other investors have an incentive to behave in a similar manner. This common behaviour is important, since one of the assumptions of this dissertation considers investors as a single homogeneous group exhibiting similar behaviour. 


\subsubsection{Differences between retail and institutional investors}

Although net aggregated cash flows might reflect common behaviour, this emanates from a collection of investors with potentially different requirements, needs and wants and thus it is necessary to discuss the types of investors. Gruber (1996, p.807) referred to retail (or private) investors as "disadvantaged investors". These investors would probably have information in respect of past performances reflecting risk, returns and rankings relative to other funds in the same category. They are restricted in terms of asset selection as they are less mobile due to lack of information and high transaction costs (Sirri and Tufano, 1998). They monitor diligently the little information they have on investment performances (James and Karecski, 2002). Institutional investors are arguably financially more sophisticated as they rely on professional advice. Therefore, they will have tools, with a high degree of quantitative analysis including risk-adjusted measures, at their disposal.

James and Karceski (2002) ${ }^{12}$ used an annual and (then recalculated) a monthly interval period in separate analyses and noted strong evidence of a concurrent relationship between retail fund cash flows and returns (normal and excess) with the strongest relationship amongst the top performing funds. No significant cash flowperformance relationship exists for institutional funds. James and Karecski (2002) referred to the 'capture' hypothesis and concluded that institutional investors do not invest aggressively in the same manner as retail investors. They attributed this behaviour to the long-term investment cycle, whereby institutional investors do not monitor the investment decisions made by their trustees and other institutional investors as closely as retail investors do. Life-cycle money also makes certain cash flows insensitive to short-term returns, making the majority of these cash flows, consisting of pension premiums, investment annuities et cetera, predictable (Remolona et al. 1997; Del Guercio and Tkac, 2002). Elton et al. (2002) tentatively confirmed these findings for a sample containing a small number of institutional funds and commented that the performances of these two types of funds do not vary much. If this hypothesis holds, then it could prove to be a hindrance as the explanatory power of the determinants on cash flows is weakened, since no distinction can be made between retail and institutional trading activities. Most of the South African Equity unit trusts are designed to cater for retail investors. Yet, most of the investing activities (in terms of capital transactions or movement) are initiated by institutional investors (Lambrechts, 2002).

\subsection{Market factors}

It is not only important to consider the intrinsic characteristics of each fund but also the environment in which the fund operates (Torre and Garcia, 2002) ${ }^{13}$. Investors might be influenced by brokers' reports, direct media et cetera, which focus on specific funds and attributes. Similarly, they might also receive cues from information, which is freely avallable, regarding the overall return on the market, market indicators, media commentaries and other market factors. These environmental or market factors, influencing cash flows, are discussed in the following sections.

\footnotetext{
12 They divided their sample into retail and institutional funds based on the initial investment required by investors.

13 Torre and Garcia (2002) concluded that Spanish mutual fund investments are driven by past performance history, showing little concern for transaction costs and risk structures. They raised the concern that most investments are conducted through large institutions with the ability to manipulate costs and risk.
} 


\subsubsection{Impact of domestic market returns on investors' behaviour}

Modern "economic models of portfolio choice assume that investors will consider the returns on all assets when they determine their optimal portfolios" (Fortune, 1998, p.12). Therefore, it is expected that relative returns on securities would have value in predicting cash flows into alternative assets and classes (Fortune, 1998). Bernstein (1998) stated that 'clients' love affairs' with benchmarking make large tracking errors extremely perilous for managers, unless these go in their favour. The most well-known and utilised benchmarks are either the average returns of the funds' peers, or alternatively, a general stock exchange index such as the S\&P 500 or the ALSI. Considered in the light of these premises, Lettau (1997) and Fortune (1998) concluded that mutual fund investors respond to short-term market conditions. Investors exhibit a positive risk taking behaviour bias depending on the type of market outcomes they observe. They trade thus more frequently and "might be more subject to swings in animal spirits" (Fortune, 1998, p.8) that encourage investors to overreact either directly, or indirectly, to new information.

\subsubsection{Direct relationship between market returns and cash flows}

The United States experienced a bull market in 1995; subsequently, equity funds attracted record cash flows ${ }^{14}$ (Remolona et al. 1997). Warther (1995), Fortune (1997; 1998), Edelen and Warner (2001) and James and Karceski (2002) determined a monthly concurrent relationship between stock market performance as proxied by the S\&P 500 and aggregated equity cash flows. Goetzmann and Massa (2002) also documented this shift in demand using daily flows. It is evident that market declines cause some 'panic': outflows are higher following down days as investors respond to measures of "the dispersion of belief" (Goetzmann and Massa, 2003, p.2) about the market. Using confidential individual account data from one large Index fund, Goetzmann and Massa (2002) documented that the relative salience in the demand affects the different types of investors, finding evidence suggesting that marginal investor types shift funds over time according to market conditions.

Warther (1995), utilising an auto-regressive time-series model, and Santini and Aber (1998), utilising a multivariate time-series model, presented evidence of a significant positive relationship between cash flows and concurrent market returns and a significant negative relationship between lagged cash flows. Warther (1995) identified the strongest relationship between unexpected cash flows and concurrent market returns with no lingering effect longer than the current period (on a weekly, monthly, quarterly or annual basis). He concluded that this is consistent with the short-term momentum trading and is not a positive feedback strategy that would be evident by a negative relationship between unexpected cash flows and one month past returns. He established that aggregated flows divest away from the previous month's market returns (cash flows are negatively related to lagged market returns). Potter (2000) commented on Warther's (1995) findings that 'investors might be contrarian in nature' and suggested that this might be because the market is mean-reverting on a monthly basis.

\footnotetext{
${ }^{14}$ A further example proposed: in a given year there might be significant growth in the economy and equity markets, together with a high level of dividend declarations, possibly leading to higher liquidity in the economy. Rockinger (1995) commented that the increased dividends would result in higher stock prices and returns and cash inflows into mutual funds, not only presently, but also in the future.
} 
Edelen and Warner (2001) examined the proposition that cash flows follow returns on a daily basis and a one-day lag. They suggested that either a common component to both market returns and cash flows, new information in the market, or positive feedback-trading is responsible for the relationship between market returns and cash flows. They stated that momentum trading also contributes to this behaviour.

Bennett and Young (2000), using a stepwise regression analysis process, suggested that the opposite is true in a less competitive and less informed New Zealand market, where a negative contemporaneous and positive lagged relationship exists between cash flows to equity funds and market return. They theorised that investors' near-time decisions might see a fall in the market as a buying opportunity. Naive investors might take longer to decide, suggesting that a more appropriate time to buy is after the market has started to recover.

\subsubsection{Implied relationship between market returns and cash flows}

Research by Fortune (1997) proved a positive cross category correlation between return in one category and cash flows in another. The most significant correlation was noted between equity and semi-equity funds. He concluded that this was due to good returns on equities (and the market), also attracting investors to semi-equity funds, presumably due to expectations of return at a lower risk.

Goetzmann et al. (1999) ${ }^{15}$ and later Brown et al. (2002) showed that cash flows into equity funds are negatively correlated with money market and precious metal unit trust flows. They attributed this to negative sentiment about the equity premium (or market returns). Goetzmann et al. (1999) suggested that it might also be due to liquidity concerns. Similarly, resource investments have been considered a hedge in time of uncertain and low expected equity returns in the United States thus reflecting negative sentiment about future equity returns. Karceski (2002) documented that investors evaluate funds' performances relative to past performances and the performances of other funds. This confirms the findings presented by Goetzmann and Massa (2003).

\subsubsection{Implications of the relationship between market returns and cash flows}

The degree to which prior market returns influence investors' demand and the extent to which demand drives returns have important implications for the stability of the economy. For example, in a bear market a sharp drop in unit trust prices, resulting from a loss of value of the underlying assets, could lead to redemption by investors owing to a loss of confidence. This might then cause fund managers to liquidate in a bear market and thereby place further downward pressure on assets and prices (Remolana et al. 1997; Fortune, 1998). Remolona et al. (1997, p.34) showed that the short-term effect of market returns on cash flows typically has been "too weak to sustain a downward spiral" as suggested previously. Fortune (1998), investigating the 1987 market crash, concluded that the crash had a long-lived effect on cash flows. Yet, it did not have a long-term impact on returns. The immediate effect of the market decline was to induce net outflows from equity funds to bond and money market funds. This is "a sign of a flight to quality" (Fortune, 1998, p. 19). Both returns and cash flows returned subsequently to normal levels, with returns doing so faster than cash flows. Based on the research presented in this section, there is reasonable evidence to conclude that cash flows might be driven by market returns.

\footnotetext{
${ }^{15}$ Looking at cash in- and outflows separately, Goetzmann ot al. (1999) reported a strong relationship to positive and negative returns on the S\&P 500. Karceski (2002) indicaled this might be due to psychological bias. He noted that systematic (or market) risk is aseful variable in explaining time-series patterns in cash flows, concluding that the relationship is significantly negative.
} 


\subsubsection{Impact of international market returns on investors' behaviour}

South Africa is an emerging market. Given the size, openness and exposure, it tends to be strongly influenced by international developments and international patterns ${ }^{16}$, because South Africa is considered a more stable, more readily accessible market than other emerging markets (Ross ot al. 1996). Bennet and Young (2000) noted very weak evidence of a lagged relationship between cash flows and international equity market performance, contradicting their expectations that the New Zealand stock market is significantly influenced by international markets.

Froot et al. (2001), exploring the daily international cash flows, observed in a time-series study that market returns help to predict future cash flows over and above that predicted by past cash flows. More importantly, they reported that cash flows have a better positive forecasting power for future equity returns in emerging or high-risk countries than in developed countries. They concluded that this is consistent with feedback-trading, where sentiment in emerging markets ${ }^{17}$ is more sensitive to volatile market conditions.

In a similar vein Brown et al. (2002), while investigating investors' sentiment in Japan and the United States, documented that cash flows to (from) foreign mutual funds are negatively related to cash flows out of (into) Domestic Equity funds, occurring during bear (bull) equity markets compared to returns on international markets. They confirmed earlier findings by Goetzmann et al. (1999), surmising that American investors appear to regard domestic and foreign funds as economic substitutes and reported that daily flows to Japanese mutual trusts are strongly negatively correlated with American equity returns. This is consistent with a 'strong common sentiment factor amongst Japanese investors' (Brown et al. 2002) (section 2.3.1).

\subsubsection{Impact of interest rates on investors' behaviour}

Several arguments have been raised to explain the influence that long- and short-term interest rates could have on investors' decisions. However, empirically mixed evidence has been presented. Warther (1995) and Goetzmann et al. (1999) presented evidence of a negative monthly and daily correlation (respectively) between cash flows to equity funds and long- and short-term interest rates, with investors divesting from equity funds to money market and bond funds when the interest rises. Goetzmann et al. (1999) proposed that this behaviour could be attributable to investors using money market funds as short-term investments or cheque accounts. They commented that, if this is true, cash flows should then reflect a seasonal pattern. Contrary to their expectations, they did not report that cash flows are negatively related to interest rates ${ }^{18}$.

\footnotetext{
${ }^{15}$ The Argentinean crisis in 2001 and the earlier Asian crisis could be an example. International investors, (nervous about possible losses in emerging markets) in an attempt to limit their exposure, would divest from South Africa first.

${ }_{17}$ Froot at al. (2001) established that cross-border cash flows reflect shifting investors' sentiment regarding American Domestic Equity markets. International cas $h$ flows merely reflect the underlying state of fundamentals of the economy. They documented that cash inflows into emerging markets are an indication of future positive market retums over the next month or two. However, in developed countries these expectations of future retums are negative. They confimed the existence of smart money, suggesting investors should divest after a large inflow into US Equity funds as they could expect negative future returns.

${ }^{12}$ The intuitive hypothesis is that cash flows should be positively related to interest rates i.e. the higher the rate, the greater the investment in cash.
} 
Investors could regard different asset classes as economic substitutes, where the negative relationship reflects investors' perception about equity markets and interest driven markets. This is an interesting interaction, because it would be expected that the market value of bonds would decline when interest rates rise. Consequently, funds, trading in these types of securities, could make losses. This would, however, adversely affect the returns, irrespective of an increase in interest. It would be expected that investors would not invest in or divest from these funds. This is, however, not the case. A survey by Alexander of al. (1998, p.309) reasoned that many American respondents do not "believe that one can lose money" on bond funds. This could be attributable to investors equating money market with bond funds (similar instruments with different terms). Van Rensburg (1994) stated that the term structure of interest rates reflects investors' outlook for the economic future.

\subsubsection{Short-term interest rates}

Ferson and Warther (1996), Santini and Aber (1998) and Potter and Schneeweis (1998) provided no evidence of the relationship between cash flows and short-term interest rates ${ }^{19}$. Santini and Aber (1998) explained that, although stock prices might react immediately to changes in short-term interest rates, investors might not respond as swiftly because short-term interest rates are volatile and cannot be locked-in over the long-term. This explains their insignificant findings. Remolona et al. (1997) concluded that, on average, the effect of short-term interest rates on cash flows had been weak for the period 1986 - 1996. The most significant impact on cash flows occurred during periods such as February 1994 when the Federal Reserve Bank raised the interest rates considerably. Mc Donald (2002) argued that in the United States, when short-term interest rates change, financial institutions invest (divest) cash in (from) bond or money market funds because the interest rates lag by 30 to 60 days. In other words, institutions might not take a position on the market and invest because they are not too confident in the stock market stability, but rather prefer to seek the relative safety of bond or money market funds.

Bennett and Young (2000) indicated that short-term interest rates and exchange rates are negatively related to New Zealand Domestic Equity cash flows because the monetary policy, implemented by the Reserve Bank, utilises short-term interest rates to control inflation. Consequently, short-term interest rate is one of the main drivers of an investment decision. The South African Reserve Bank follows a similar policy of inflation targeting.

\subsubsection{Long-term interest rates}

Santini and Aber (1998) and Fortune (1998) showed that long-term treasury bond interest rates are negatively related to cash flows. Bennett and Young (2000) attributed a reasonable to weak negative relationship to the shape of the yield curve although they did not provide evidence of this. Santini and Aber (1998) argued that investors typically hold not only equity investments, but also fixed income securities and unit trusts which hold these investments. Consequently, it is expected that as yields increase, investors would shift funds between these two types of securities. They could earn higher yields on interest bearing securities at a low risk. As expected, equity returns decreased, due to firms' cost of capital increasing. This resulted in firms having to pay higher financing costs on existing projects and eliminating previously acceptable projects; consequently, depleting the firms' or underlying investments' profitability.

\footnotetext{
${ }^{12}$ Ferson and Warther (1996) utilised 6-month treasury yields, while other researchers used the certificate of deposit rate.
} 
Santini and Aber (1998) argued that long-term interest rates would have a more significant negative impact on firms' debt-to-equity consideration than short-term interest rates and concluded that the more important factor is long-term interest rates. Another argument is that when interest rates increase, inflation decreases, which should decrease production costs. However, the impact should be negligible since the benefit of increased interest rates would only be felt later. Similarly, investors are not able to determine the cost-benefit relationship between increased financing charges compared to cost savings. The research findings presented, provide inconclusive evidence on the reliability of short- and long-term interest rates to predict the variations in cash flows.

\subsection{Fund characteristics and policy variables}

The criteria for fund selection implied by the Efficient Market Theory include factors which directly affect funds' risk and return, such as, loads, management fees, portfolio turnover, brokerage expenses and the number of securities in the portfolios (Woerheide, 1982). Unit trusts are significantly influenced by these factors (AUT, 2002). The following sub-sections discuss the literature regarding the influence of the fund's characteristics and the policy variables of unit trusts on cash flows.

\subsubsection{Different performance measures}

Modern economic models of portfolio choice assume that investors would consider the returns on all assets when they determine their optimal portfolios (Fortune, 1998). Gruber (1996) theorised that the framework used to estimate returns, would be the same as that used by rational investors when making investment decisions. By implication, it would be expected that returns on securities have value in predicting cash flows. Gruber (1996) concentrated on using cash flows to predict returns and presented evidence that both normal returns and fourfactor Jensen's alpha are significantly related to concurrent cash flows. He indicated that investors follow returns particularly to the best performing funds and commented that investors pay attention to both the simpler and more sophisticated performance measures. He concluded that investors, who supply new cash flows to top performing funds, earn abnormal returns on their newly invested cash.

Capon, Fitzsimons and Prince (1996), Alexander et al. (1998), Najand and Prather (1999) and Chacho and Das (1999) inter alia, conducting behavioural research using mathematical derivations and survey techniques, found that funds with superior past performances experienced increased investments. Most empirical studies suggest that past performances (regardless of the level of sophistication of the measure used) are the most significant explanatory variables in the purchase decision-making process of many investors. The motive for this behaviour is not clear. 


\subsubsection{Types of performance information}

The following types of performance measures are available to investors:

- Ranking and normal returns - consist of returns earned by means of dividends and capital growth. Rockinger (1995) suggested that investors are not able to dissociate return numbers, presenting the example that naive investors might not be able to distinguish between a $5.8 \%$ and a $5.9 \%$ return, but could distinguish between rankings. He attributed the cash flow-performance relationship, reported by other studies, to rankings.

- Excess returns - consist of returns in excess of a benchmark. Santini and Aber (1998) concluded that there is a positive relationship between cash flows, excess returns and Sharpe measures. Edelen (1999) documented a statistically significant indirect cost in the form of a negative relation between cash flows and abnormal returns, when consideration is given to the liquidity service provided by fund managers. He criticised other researchers, who established a positive relationship, but did not consider transaction costs. Three possible reasons are suggested for the negative regression coefficient for excess returns. Firstly, Munro (2002) suggested that this could be attributed to investment mandates requiring that asset managers must invest in certain proportions (relative to the benchmark). When funds out- (under-) perform the ALSI, their holdings in the out- (under-) performing funds increase (decrease). This results in the managers divesting to reallocate the holdings back to the required holdings, resulting in a negative relationship. Secondly, Gruber (1996) argued that the majority of funds under-perform the benchmark. Most investors might not have all the information available to make an informed decision. When funds out-perform the benchmark, then investors might want to lock-in the gains before the returns retract. Lastly, investment strategies might contribute towards this negative coefficient. Institutional investors might have the strategy that, when the monthly returns out-perform the benchmark by a certain amount, then they would divest and vice versa (i.e. stop loss order). This argument is more likely to hold for shares than for unit trusts in a South African context. Furthermore, it is unlikely that a large portion of the investing community employs such techniques.

- Abnormal returns - calculated by Jensen's abnormal performance model. Various research studies state that the abnormal returns appear to show the best predictions of future returns and a significant association with cash flows. Gruber (1996) and Jain and Wu (2000) confirmed the findings using single- and four-factor alphas, reporting results that yield a significant similar conclusion. Del Guercio and Tkac (2002) surmised that ratings, such as published by Morningstar Incorporated ${ }^{20}$ and Lipper, provide users with similar information to Jensen's abnormal returns ${ }^{21}$.

\footnotetext{
${ }^{20}$ The Morningstar Inc., the Chicago-based investment advisory service, has been hailed as one of the most influential rating systems in the American mutual fund industry.

${ }_{21}$ South Africa does not have these rating facilities, neither is there reason to believe that the average investors would be able to calculate these measures, nor whether they have access to historic data-series to calculate such measures. However, as alluded to previously, this may not be the case with the large institutional investments in South African unit trusts.
} 


\subsubsection{Persistence of performance}

Investors must believe that good returns will persist in the future, (assuming that fund managers' skills and experience are not priced in unit trusts and that performance is predictable) before they invest in past performers. In the United States, Grinblatt and Titman (1992) concluded that a positive persistence exists in mutual fund performances.

Brown and Goetzmann (1995) used methods designed to control for survivorship bias and revealed evidence that relative performance persists, implying that investors could use historical information to out-perform their peers. According to Gruber (1996), if performance is persistent and wealth-maximising investors are aware of this predictability of return, it could reasonably be expected that rational investors would learn from observing the outcomes in the past and then adjust their portfolio composition for the next period, as investors try to capitalise on the predictability" ${ }^{22}$. Karceski $(2002$, p.585) explained that investors appear to suffer from the "influence of prior outcomes ${ }^{\mathrm{n} 23}$.

\subsubsection{Influence of prior performance outcomes and information assimilation}

Prior research has presented various theories and suggested reasons for and against this delay in the reaction of cash flows to past performances. The Efficient Market Hypothesis argues that the market would adjust rapidly to new information, thus reaching equilibrium, within the same period (Fortune, 1998). However, in reality, "different information performance signals get reflected in value at different points in time" (Holden and Subrahmanyam, 1996, p.691). In a survey of Money and Baron's magazines and The Wall Street Journal, Del Guercio and Tkac (2001) found that $54 \%$ of adverts contained 3-month-old information, resulting in investors reacting to old information. They made a further contribution in this regard, when they conducted an event-study on the release of Morningstar rating changes. They found that most of the observed cash flow responses were detectable in the same period, observing an immediate significant flow response to a rating change in funds' status (dissipating over time), particularly with four and five star funds.

It is worthwhile to discuss the speed of integration of the information. Even if investors use current information, orders to change a portfolio holding might be carried out over a long lag. If flows respond to returns, the response of sales/redemptions would be more lagged than for those of exchanges (Fant, 1999, p.393). Consequently, investors might react to performance with a delay over different time-periods.

\footnotetext{
22 The probability of good performing funds yielding future good relurns is higher than for other funds (Kliger and Sonsino, 1999).

${ }^{33}$ Goetzmann and Peles (1997) discussed 'cognitive dissonance', where investors adjust their portiolios and beliefs to justify previous decisions. They explained that in taking decisions, investors give too much weight to the most recent infomation.
} 
Edelen and Warner (2001) used high-frequency daily data to demonstrate a very strong daily correlation between returns and subsequent flows. They attributed this to a response to new information releases (which might have been overstated due to late reporting the next day) or return-chasing behaviour. Further research separated the interval periods into interday transaction periods and also semi-weekly periods. They established that returns do respond to concurrent cash flows, concluding that the interval periods do not influence the significance of the findings. They commented that a limitation of high frequency data is that it does not capture the cumulative effect of persistent cash flows. Warther (1995), utilising weekly and monthly time-series data, found that weekly data did not improve his monthly model's explanatory power. Remolona et al. (1997) suggested that the one-month time horizon and interval seem more consistent with the market dynamics. James and Karceski (2002) suggested that investors base their investment decisions on performances over a shorter time horizon than one year, suggesting that monthly intervals would produce the best results. Goriaev et al. (2002) confirmed the findings.

Elton et al. (2002), using a cross-sectional approach, showed that, when moving from three to one-year holding periods, the results changed slightly. They attributed the change to short-term returns containing a larger random noise component. Goriaev et al. (2002) suggested that the sensitivity of cash flows to past performances fades away after three years and concluded that this over-reliance on recent past information could be attributed to investors facing significant search and information costs. Warther (1995) and Sirri and Tufano (1998) shifted the focus to longer time-periods, using annual time-intervals and concluded that investors consider recent performances, placing more reliance on the latest information. Hendricks et al. (1993) provided evidence of higher levels of abnormal performances earned from strategies that bought mutual funds based on their performances measured over the past 2 to 8 quarters. Brown and Goetzmann (1995) corroborated these findings. From the studies presented above, it appears that monthly data provide the most significant findings.

Rockinger (1995), Gruber (1996) and Edelen (1999) inter alia, included between 1 to 12 lags when evaluating their findings, owing to the mixed evidence presented therein. Warther (1995) and Fant (1999) used a threemonth lag structure for returns. Fant (1999) re-performed his findings, using a four-month lag structure, and established no significant change in his findings. These researchers noted that, regardless of the number of lags included in the model, only concurrent and single period lagged performance variables add significant explanatory power to the model.

\subsubsection{Feedback-traders hypothesis}

According to Mc Donald $(2002$, p.1) "flows will follow performance and they always have." Agents are rational in the sense that, although they cannot compute the calculation required for expected utility maximization, they learn from observing the outcomes in the past and then adjust their portfolio composition for the next period (i.e. feedback-trading) (Lettau, 1997). Positive feedback-trading (i.e. trend or return-chasing) could be interpreted to mean that an increase in today's return leads to an increase in future flows, without holding current and past flows constant. Karceski $(2002$, p.561) presented evidence that investors tend to invest a large portion of money after the market has been "experiencing a significant move upwards", regardless of the fact that this performance might not persist. 
Sias and Starks (1997) attributed this feedback-trading to the use of 'stop loss orders' and portfolio insurance. Fant (1999) suggested that the possibility of return affecting cash flows is more complex than outlined by the positive feedback-traders hypothesis. He indicated that market timing might also be consistent with returns affecting future cash flows.

Two tests by Warther $\{1995\}$ showed a negative relationship between the prior period's returns (monthly and weekly) and the current period's cash flows. Warther (1995) interpreted this as evidence against returns affecting flows. He suggested that this might be due to the speed of investors' reaction, pointing out that high returns in the current month: should act as a signal to nvestors to divest the following month, before returns move downward from their peak. He also stated that the basis for rejection of the feedback-traders hypothesis arises since it seems improbable that all investors who use a feedback strategy, do so quickly. He concluded that the concurrent relationship should then be attributable to either price pressure, or the information effect, but failed to distinguish between these explanations, or to provide definite evidence of these theories. Santini and Aber $\{1998\}$ suggested that these findings support the Efficient Market Hypothesis; where, if the market is efficient, the past performances do not explain future performances and investors react to current information. ignoring past information. Santini and Aber $\{1998$ ) based their conclusion on four different lagged performance measures. As none of the results was significant, this adds robustness to Warther's $\{1995\}$ hypothesis.

Another form of the feedback-traders hypothesis suggests that investors chase returns cross-sectionally across different funds, categories and markets (Fortune, 1998; Edelen and Warner, 2001; Goetzmann et al. 1999; Barberis and Shleifer, 2003\}. Several of the research studies surveyed, concluded that investors are not only biased towards past returns, but also towards good performances (Kliger and Sonsino, 1999).

\subsubsection{Investors asymmetric response to performance information}

Findings by Chacho and Das (1999) deduced that the better the relative performances, the larger the portion of disposable cash flows delegated to such unit trusts. This is in spite of the fact that the relative performances neither provide, nor guarantee useful information about selected managers chances for good future performances. They detected a willingness to invest in response to good absolute performances. This could be because the chances that managers (who are perceived to be informed) would repeat their performances are more probable, compared to uninformed managers achieving the same results in the second period. Table 2 presents two types of past performance measures which might affect investors behaviour.

\section{Table 2. Investors' reliance on performance measures}

\begin{tabular}{|c|c|c|}
\hline $\begin{array}{l}\text { Performance } \\
\text { measure }\end{array}$ & Description & Influence on investors' behaviour \\
\hline $\begin{array}{l}\text { Absolute } \\
\text { performance } \\
\text { effect }\end{array}$ & Reflectiry the absolute percentage retum on the furd. & $\begin{array}{c}\text { Invesiors terd to delegaie morey to the furc with the } \\
\text { highest perfommance, when perforinance ievels are } \\
\text { uninfomative. }\end{array}$ \\
\hline $\begin{array}{l}\text { Reiative } \\
\text { performance } \\
\text { effect }\end{array}$ & $\begin{array}{c}\text { Reflecting ihe number ur parcentile ranking of the funds } \\
\text { relative to their peers. }\end{array}$ & $\begin{array}{l}\text { Investors iend to delegaie morey to the unif trusts with } \\
\text { the higher pertormance ralative to other furds. } \\
\text { regardless of :he source or consistency of the increased } \\
\text { performance. }\end{array}$ \\
\hline
\end{tabular}

(SOURCE: Kliger and Sonsino, 1999) 
Sirri and Tufano (1998) applied the cross-sectional regression process developed by Fama and MacBeth (1973) and were amongst the first researchers to report on investors chasing performances cross-sectionally across funds, i.e. investing the largest portion of cash flows to top performing funds (based on normal and risk-adjusted performance measures), whilst failing to divest from poor performing funds. They also argued that investors invest more cash in periods of good performances than poor periods. Applying the same piecewise non-linear relationship methodology ${ }^{24}$, Chevalier and Ellison (1997) and Karceski (2002) inter alia, confirmed these findings. Gruber (1996) suggested that there are two types of investors, who contribute towards this behaviour: sophisticated clientele directing their money towards the top performers and disadvantaged clientele. The disadvantaged clientele consist of the following:

- Institutional disadvantaged investors - This group is represented by pension funds and fiduciaries (as in South Africa's case) that are restricted by the plan or mandate.

- Unsophisticated investors - This group directs money to funds based at least in part on other influences such as advertising and advice from brokers.

In Australia, Sawicki (2001) documented the existence of a statistically and economically significant relationship between cash flows and performances and also noted a bias in the relationship because the top performing funds attracted the most cash flows.

\subsubsection{Contribution of the media and marketing to this return-chasing behaviour}

Once the cost of processing information was considered, Sirri and Tufano (1998) predicted that consumers would purchase those funds that are easier and less costly for them to identify. Three sources of information are presented: (i) broker information, (ii) media articles or marketing and (iii) rating information. Alexander et al. (1998) conducted a survey amongst American mutual fund investors to find the characteristics, level of knowledge and sources of information investors use. They concluded that investors mostly use information provided by brokers to determine their recent acquisitions, followed by newspapers/magazines. They surmised that reliance on brokers' information gives managers the ability to overstate their own performances and actively sell their own products to investors. Open Equity mutual funds are available at NAV, thus management ability is not incorporated in the price. However, managers can communicate their superior skill via advertising ${ }^{25}$.

According to Sirri and Tufano (1998) and Pritamani and Singal (2001), investors have a tendency to make decisions, in spite of a lack of specialist advice, under the influence of the marketing and financial press. Past performances form a satellite feature of funds' media campaigns. Funds are "more likely to heavily advertize superior performance and avoid advertizing poor performance" (Berkowitz and Kotowitz, 2000, p. 375). The media also tend to highlight extreme performers at either end of the spectrum (Sirri and Tufano, 1998). Lastly, rating company information such as the Morningstar ratings could be used as a source of marketing information ${ }^{26}$.

\footnotetext{
${ }^{24}$ Bergstresser and Poterba (2002) searched for a linear and a non-linear relationship. In these cases, the different models presented similar results. Findings by Berkowitz and Kotowitz $(2000$, p.365) suggested that the relationship is "mostly finear with significant non-linearities at the upper (and possibly the lower) end of the performance spectrum".

${ }_{2}^{2}$ Quality or service is a non-observable variable, yet, is very important for funds' success (Rockinger. 1995). Advertising could reflect this.

${ }^{26}$ South African investors could subscribe to Standard \& Poors, Moneymax, Alexander Forbes and Profile Media.
} 
Elton ef al. (2002) stated that marketing and spill-over measures account for some of the cash flows, not accounted for by past performances. Jain and Wu (2000) confirmed that advertised funds attract significantly more cash flows in comparison to unadvertised funds in the same investment objective.

\subsubsection{Transaction costs and fee structures}

Three different types of fee structures could affect the short-term returns received by unit holders. and by implication, also the sensitivity of the cash flows of investors annual management fees, front- and back-ended costs (reierred to as loads in the United States). These fees might consist of a compulsory service charge or performance portion. Annual management fees seem low compared to the initial front-ended fees but these charges accumulate over the medium to long-term. Management companies usually allocate a partion of the entry fee to the brokers ar advisors \{Lambrechts, 2000). These fees are negotiable for institutional investars (but not necessarily for the 'man-in-the-street') and create a potential bias in the findings of this dissertation. Since institutional investors make the majority of unit trust investments: this gives them significant power to negotiate lower costs either by virtue of the amount they invest or by waiving the advisors' portion of the fees.

\section{Table 3. General cost structure (incl. VAT)}

\begin{tabular}{|c|c|c|c|c|c|}
\hline & Unit Trusts & Fund of Funds & WRAP Funds & $\begin{array}{l}\text { Multi-Manager } \\
\text { Funds }\end{array}$ & $\begin{array}{l}\text { Link Investrient } \\
\text { Service Providers }\end{array}$ \\
\hline $\begin{array}{l}\text { Upfront } \\
\text { costs }\end{array}$ & Up to $5,7 \%$ & Up $107 \%$ & $U_{p}$ to $8 \%$ & Up to $6^{\circ} \%$ & Up to $9 \%$ \\
\hline $\begin{array}{l}\text { Annual } \\
\text { costs }\end{array}$ & $0.57-3.4 \%$ & $\begin{array}{l}2-4.5 \% / \mathrm{pa}+\text { cost of } \\
\text { underlying funds }\end{array}$ & $\begin{array}{l}1.8-4.3 \% p a+\operatorname{cost} \\
\text { of underlying funds }\end{array}$ & $\begin{array}{l}1.14-2.3 \% \rho a+c 0 s t \\
\text { of undertying funds }\end{array}$ & $\begin{array}{l}171-4.3 \% \mathrm{\%}+\cos t \\
\text { of underlying funds }\end{array}$ \\
\hline
\end{tabular}

(SOURCE: AUT, 2002)

Table 3 provides a generalised cost structure for various types of investment vehicles. Fund of Funds, Wrap Funds and Linked Investment Service Providers were created to facilitate regular switching amangst uni: trusts. These funds could acquire bulk investments at 'wholesale' prices for the retail market. Retail traders would transact at the bid and ask prices, whereas institutional traders typically would regotiate prices and costs directly with brokers (Keim and Madhavan, 1997). This is afforded to them due to their stature and large cash holdings. For example, certain Fund of Funds will not invest if the fund insists on charging front-ended fees; in ather words, a business decision supersedes the performance criteria

Rockinger (1995) theorized that investars are cost minimizers, selecting funds with low expenses but concluded that annual fees and initial investment requirements are not a determinant of cash flows. Empirically. Spitz (1970) separated the funds into two sub-samples, containing no- and load funds, showing that a significant cash flowperformance relationship only exists for no-load funds. Ippolito \{1992) and Berkowitz and Kotowitz (2900) employed a similar methodology and presented evidence that poor performances lead to half as many withdraws from load funds as from no-load funds The fact that no-load funds have more sensitive cash flows than load funds is interesting particularly because "the overalt perfomance of no-foad and foad funds is virtually indistinguishable (Gruber, 1996, p.789). However, when considering load costs, load funds intuitively underperform the no-load funds. 
Berkowitz and Kotowitz (2000) documented, although not explicitly calculated as such, that investors do consider the notional implications of load fees. They found that investors are significantly fee-sensitive because lower fee funds attract more cash flows. Sirri and Tufano (1998) and Bergstresser and Poterba (2002) confirmed these findings in the United States and Torre and Garcia (2002) in Spain. This negative relationship reflects investors' elasticity of demand with respect to the price asked by management companies for their services ${ }^{27}$.

James and Karceski (2002) suggested differently, finding no significant relationship between cash flows and transaction costs. They attributed this lack of sensitivity of cash flows to the fact that investors need to be compensated for the higher transaction costs by means of higher expected returns. In other words, the investors would invest, provided they believe that the benefit, in the form of higher returns, would exceed expected costs. Investors divest from a fund with a back-ended load charge if they expect poor returns or expect future returns on another fund to exceed the switching costs (Ippolito, 1992; Zheng, 1999). Alexander et al. $(1998, p .309)$ indicated that the "level of expenses did not seem to be an important factor in the purchasing decision" because many respondents expect that an inverse relationship between expenses and returns exists.

Managers "choose a fund's structure to maximize the rents they can capture from their ability, taking into account the effect their decisions have on investor flows" (Nanda, Narayanan and Warther, 2000, p.441) and to manage a fund's liquidity.

\subsubsection{The influence of revenue maximisation behaviour by fund managers}

Gruber (1996) hypothesised that high past expenses could be used by investors to infer higher expected performances in the future because managers might price excellent performances by charging higher fees, thus performing a similar function to performance related fees. However, he found that this is not the case. He conceded that the costs of top performing funds are neither higher than that of the poor performing funds, nor do managers raise expenses as performances increase in an attempt to accumulate more revenue.

Alternatively, it could be argued that managers generate their revenue by attracting larger volumes of investors, whereas poor performing funds are unable to increase their market share and thus must extract the maximum amount of revenue from their existing clientele. This motivates managers to adjust the fee structure.

Elton et al. (2002) stated that expense ratios are highly predictable. Higher expense ratios should motivate managers to greater effort that would lead to better performances to counter the negative effect of fees on cash flows. They provided evidence to the contrary that investing in funds with low expense ratios, earn better non- and risk-adjusted returns for a one- and three-month holding period than funds with a high expense ratio.

\footnotetext{
${ }^{27}$ Sirri and Tufano (1998) and James and Karceski (2002) defined Iransaction costs as the total annual adrninistration costs plus the load charges spread over an assumed seven-year holding period. Bergstresser and Poterba (2002) used an indicator variable for funds with frontor back-ended loads and expense ratio as a percentage. The indicator variable approach yield more significant findings than utilising actual transaction cost percentages.
} 
2) Financial planners and brokers - refers to compensation paid to brokers and investment advisors for recommending funds. Elton ef al. (2002) suggested that transaction costs would be a good proxy, since most front-ended fees in the United States are paid as rewards to salesmen. Their research conceded that the analysis did not include all the relevant effects of dedicated marketing variables. They proposed that changes in fees need not necessarily relate to increased marketing. Furthermore, there are various other counter arguments that these variables in fact do not reflect the information proposed. They recommended that this is an area for further research. It could be argued that funds with higher fees might have larger overheads to settle or excellent research and development departments. The funds might be costly to run, yet, at the same time are generating quality research, which could be used to create future economic benefit for their investors. Despite the higher fees, these funds (regardless of performances) might still attract cash flows, because investors consider the service provided by brokers as valuable. According to Berkowitz and Kotowitz (2000), load fund investors are more likely to rely on the advice of financial advisors and brokers, who tend to benefit from directing investors to load funds. These investors are likely to be less informed and possibly more risk averse and, as a consequence, less responsive to past performances, relying as they do on brokers' recommendations.

Elton et al. (2002) surmised that if the coefficients of loads are significantly positive, then brokers and financial planners would be a major determinant of cash flows, as they are rewarded for new business. This overshadows the negative effect that would be expected since these load costs erode the returns earned on the investments. Irrespective of the reasons or nature of the transaction costs, prior researchers have presented mixed evidence regarding the viability of transaction costs in explaining the variation in cash flows.

\subsubsection{The influence of risk on the return-chasing behaviour}

Unit trusts involve both investment and market risk. The risk profile depends on the combination of underlying investments and fund mandate. The decision to invest in the highest performing fund might be sub-optimal if it also carries high risk (Najand and Prather, 1999) ${ }^{30}$. Chordia (1996) and later Sirri and Tufano (1998) and James and Karceski (2002) inter alia, suggested that investors are intuitively averse to risk, as investors want a sure bet or prefer less risk, however, investors' behaviour might not reflect this.

\subsubsection{Fund managers' manipulation of risk}

Normal returns affect fund managers either in that high returns allow the funds' assets under management ${ }^{31}$ to grow, or by attracting new investors. Karceski $(2002$, p.562) commented that mutual fund managers "compete in toumaments ${ }^{n 32}$ where the highest performing funds capture the largest portion of cash flows (or increased assets under management) and, by implication, management fees. Assuming investors fail to consider risk, the performance tournaments give managers an incentive to manipulate the risk composition of the portfolio (Najand and Prather, 1999; Nanda et al. 2000; Berkowitz and Kotowitz, 2000; Fant and O'Neal, 2000).

\footnotetext{
${ }^{30}$ Najand and Prather (1999) documented that for higher risk funds, returns are better explanatory variable of cash flows.

${ }^{31}$ The effect of improved performances could also have a long-term impact on funds' asset size since investors are less likely to divest from a good performer.

South African managers are under pressure to perform, with information more freely available and cash flows more mobile (AUT, 2002).
} 
Del Guercio and Tkac (2002) and Karceski (2002) suggested that funds could tilt the portfolio towards high beta stock (during a bull market); consequently, out-performing their peers. Due to the increase in cash flows, funds collect more fees during a bull market, while it is accepted that during a bear market, fund managers would underperform their peers/the benchmark. Karceski $(2002$, p.562) concluded that this behaviour is rational, since "cash inflows dry up after down markets". Fund managers might be willing to accept the under-performance in return (during bear markets) for an increased probability of out-performing their peers during a bull market, where the rewards tend to last for a long time. In other words, the rewards for good performances in a bull market outweigh the rewards for good performances during a bear market. In addition, this behaviour coincides with the persistence of cash flows, as managers know that, with higher performances, they are able to secure a fixed income stream. This steady stream of cash flows would provide fund managers with a cushion, thus "reducing the incentive to undertake return boosting strategies in the future" (Del Guercio and Tkac, 2002, p.550).

An unpublished study conducted by Cadiz Holdings from 1994 to 1999 showed that, in most cases, the poor performers had the lower betas (and vice versa). They concluded that this is understandable, as unit trusts experienced a bull market over this period. This concurred with research done earlier by McGlashan (1995) that in bull markets the best performers over-invest in equity (high risk), thus underpinning fund managers' incentive to manipulate risk in a South African context.

On the other hand, Deli and Varma (2002, p.80) presented a view that poor performing fund managers have an incentive to increase fund risk in order to "go for broke". Fund managers might also attract new cash flows by using less admirable methods, to "misrepresent or boost performance figures" (Bhana, 1994, p.63). Chevalier and Ellison (1997) used a semi-parametric model to estimate the performance-cash flow relationship and claimed that fund managers alter the risk levels of funds towards the end of the year, close to reporting times.

\subsubsection{Investors' evaluation of risk ${ }^{33}$}

Several researchers analysed investors' behaviour with respect to their demand for mutual funds and showed that investors do not always respond with economic rationality, since they do not necessarily always pay attention to risk, but rather only to returns. Other researchers presented evidence of investors considering risk either explicitly, or implicitly, where sophisticated investors would consider risk adjusted figures, whereas naĩve investors would not. Najand and Prather (1999) and Berkowitz and Kotowitz (2000) concluded that investors appear to use publicly available information, giving equal weighting in their investment decisions to return and market risk components while ignoring the diversifiable or unique risk components of an investment.

\footnotetext{
${ }^{33}$ "Investors tend to beat up managers if they hold too much cash in a bull market, but look away when the markat is in a melt down" (Milliamson, 1998, p.4). For example, if $50 \%$ of the porttolio is kept in cash and the balance in equity, with the returns being $10 \%$ and $30 \%$ respectively, then the performance figures represent $20 \%$, whereas the category relurn might be in excess of $20 \%$ if the other funds are proportionately weighted towards equity hoiding.
} 
Lettau (1997, p.1118) stated that investors (not fund managers) become more bullish after positive market realisations, taking "too much risk $k^{34}$, in comparison to the optimal portfolio. Adaptive agents exhibit an asymmetric response after positive/negative returns, where the adjustment is more significant (sensitive) after negative returns, not due solely to expected future performances, but also due to changes in risk aversion. This contradicts other studies (section 2.5.1), which find that investors fail to divest after negative return events. Lettau (1997) added that cash flows are highly positively related to returns on a contemporaneous correlation, using an ordinary least-squares regression analysis. He identified that the strongest cash flow-performance relationship exists for high-risk profile funds. These findings confirmed those made by Thaler and Johnson (1990).

Goetzmann and Massa (2003) indicated that, unlike Karceski (2002) suggested, people react more to negative than positive returns, concluding that investors are strongly driven by risk aversion. To substantiate this prediction regarding the relationship between risk perception and cash flows, risk variables were included in their analysis. They theorized that volatility is likely to measure the arrival of information (possibly random), thereby shedding some light on the relation between information flows and cash flows.

Remolona et al. (1997) believed that funds with more conservative investment objectives are the most vulnerable to outflows as investors are less willing to allow for risk adjustments. These funds tend to have less volatile, predictable cash flows due to investors with high liquidity needs. Lettau (1997) suggested that 'portfolio insurance' might be another explanation for the positive relationship. If the risk tolerance of investors is decreasing with wealth, it might be optimal to sell stock when prices go down and to increase their holdings in risky assets when prices increase. He conceded that it is unlikely that all or most investors would follow this type of strategy. Although studies regarding the impact of the risk on cash flows have presented mixed evidence, researchers reached consensus that this relationship indeed exists.

\subsubsection{Past investors' capital contributions or net investment cash flows}

"Fund flows are the ultimate contrarian indicator" (Lashinsky, 2002, p.180). The view that cash flows are a predictor of future returns has been expressed in the financial media. If investors believe this, then it could be expected that they would follow past cash flows (Fortune, 1998). Lee and Swaminathan (2000) confirmed that the strategy of buying past high cash flow winners and selling past high cash flow losers, out-performs the traditional momentum strategy, thereby confirming findings by Warther (1995), Gruber (1996) and Edelen and Warner (2001). The media frequently discusses recent cash flows informally with headlines such as "Skip Growth or Value and Go for Cash Flows" or "Follow the Cash" ${ }^{\text {"35 }}$, as a predictor for future good returns. Two factors drive these headines. (i) Economists believe that trading (or large cash injections) is merely the process by which private information or misinformation is incorporated into asset prices. Therefore, cash flow movements act as a precursor to an expectation on the underlying state of the fundamentals of such fund, category or market (Froot ot al. 2001) reflecting fluctuations in the opinions, expectations or beliefs of traders and investors.

\footnotetext{
34 The investors" portfolios are biased towards high-risk investments containing a larger portion of high-risk unit trus ts thus eliminating any diversification benefit.

${ }^{35}$ Studwick and Grant, Business Press, Vol. 8(18): p.15, 9 January 1995 and Clash, Forbes, Vol. 161(4): p.130, 23 February 1998, respectively.
} 
Therefore, Lee, Shleifer and Thaler (1991), Warther (1995), Brown et al. (2002) and Goetzmann and Massa (2003) inter alia, suggested that cash flows act as a good proxy for the common sentiment factors. (ii) Investors might believe "record cash flows are typically great news for the stock market because rising inflows indicate bullishness/optimisms among investors and often foretell a rise in stock buying and prices" (Mc Donald, 2002, p.1).

\subsubsection{Cash flows reflecting private information}

Gruber (1996) argued that there is information in past flows relevant to future flows. Warther (1995) reported a significant auto-correlation in cash flows. His study directly incorporated lagged flows as an explanatory variable in order to measure and control for the consistency of cash flows from lifecycle and institutional monies. He argued that past cash flows do matter it investors have information about the true value of the fund or because large institutional funds might "wish to minimize the price impact of their trades" (Froot et al. 2001, p.188) or investments. Del Guercio and TKac (2002) later confirmed these findings.

Increased demand for a fund might cause a price increase. Warther (1995) and Gruber (1996) argued that when the trade is reported, it constitutes a public signal. Each agent has a different piece of private information, which, if aggregated, communicates and reflects a common signal. Investors only realise that, while the increased demand might have originated from an uninformed liquidity provider, it could also have originated from an informed trader in search of profit. In pursuit of gains, investors might follow these traders or cash flows, although they might not be able to establish the quality of the private information. If investors act on this information or simply follow the traders ${ }^{36}$ or cash flows, then their cumulative trades would be associated with further new information, possibly affirming expectations by investors. If other investors, observing the cash flows, are made to believe that the cash flows convey useful information about the future benefits of the fund receiving attention, then it might induce them to trade in the same direction. On the other hand, these cash inflows into unit trusts could instead reflect a signal for smart money to be removed from the market as a precursor to expected negative returns.

\subsubsection{Nature of transactions and the speed of investors' reaction to information contained in cash flows}

Before deciding to invest, investors should consider the sources of this increased demand, the destination of investment cash flows and the reason for the shift. Generally, cash flows could arise from: (i) new individuals' savings from disposable income, (ii) a shift in composition of saving via pension premiums, (iii) a shift from money market to equity unit trusts, (iv) switching to another unit trust or (v) sale of equity holdings (Smith, 1997; Fortune, 1997). Each source reflects a different investment objective, with investors preferring exchanges, while long-term investors use new investments or redemptions. Investors can move cash flows more easily and timeously via exchanges, thus reflecting more recent, relevant information than new sales and redemptions, which are assimilated into the market more slowly due to transaction friction.

\footnotetext{
36ise Iraders (or 'less than rational investors') are significant contributors to this behaviour, acting in response to this 'flocking' as opposed to basing their investment decisions on factual information about investment fundamentals.
} 
Investors also appear to use exchanges for market timing or asset allocation, trading on short-term conditional risk premia. These perceived gains from the exchange trading are too small to be captured by new sales or redemptions (Fant, 1999) ${ }^{37}$.

Edelen and Warner (2001) concluded that cash flows respond to returns or to information driving returns, mainly at a one-day lag, whereas within- or interday cash flows appear mainly to follow other cash flows or trades on the same day. James and Karceski (2002) disagreed, being able to predict cash flows, based on three months lagged cash flows for retail funds, but not for institutional funds.

\subsubsection{Total category cash flows}

Modern investment theory suggests a top-down and a bottom-up approach to investment selection (Bodie, Kane and Marcus, 1996), making sectorial flows important. Differences in category information might provide a useful piece of the cash flow puzzle, acting as indicators of both the incentives to reallocate portfolios between two categories and consequently, of portfolio shifts (Fortune, 1997). Investors are unlikely to make their decision to invest solely on fund characteristics. Sector or style-information plays an important role. Also, cash flows into a category are not necessarily driven exclusively by a belief about the market. It is by its very nature nondiversifiable, for example, flows into speciality funds might represent investors taking sector-focused bets in communication, financials, technology et cetera (Brown and Goetzmann, 1995; Goetzmann et al. 1999). Fant and O'Neal (2000) included the mean category cash flows into their micro-study, since they theorised that investors consider risk only in the context of investment objectives ${ }^{38}$, but found no significant relationship. Section 2.3.1 indicates that different categories might be regarded as substitutes. Sirri and Tufano (1998) and Sawicki (2001) attempted to explain individual fund flows and reported that individual fund flows are strongly related to sectorial flows and presented evidence that smaller funds enjoy a larger percentage of these sectorial cash flows.

\subsubsection{Age of the unit trust}

Most research conducted in the United States excludes funds younger than one-year from the sample period except for the studies presented below. Chevalier and Ellison (1997), Bergstresser and Poterba (2002) and Goriaev et al. (2002), using an indicator variable approach, concluded that young and small fund cash flows are more sensitive to recent past performances than older and larger funds. Berkowitz and Kotowitz (2000), including the log of the funds' age as a variable into their regressions, concluded that no additional explanatory power exists.

In Australia, Sawicki (2001) duplicated his analysis for two samples excluding all funds younger than 24 months, thereafter using all funds in the data set. He stated that investors react more significantly to recent performances for younger funds, attributing the asymmetric response reported by other studies, to a stronger relationship between cash flows and performance for younger funds.

\footnotetext{
${ }^{37}$ This is backed by the market microstructure theory, which predicts that traders with private information reach their desired position slowly, in order to mitigate market impact and costs, thus resulting in auto-correlated cash flows (Froot et al. 2001).

${ }^{3}$ Instrumental-variabie estimates by Remolona ot al. (1997) suggested that the funds with more conservative investment objectives are most vulnerable to outflows, but exhibit the least volatile cash flows. Since this research only looks at a single category, it is not possible to validate this statement in the South African market.
} 
It would be expected that investors in younger funds might be more sensitive to recent performances, since these funds lack the reputation and long-established track record of their oider counterparts. Furthermore, investors investing in these funds tend to be venture capitalists seeking high returns and are willing to take risks and accept losses.

\subsubsection{Fund size}

Arguments explaining the impact of fund size on cash flows are as follows: (i) fund size reflects investors' sentiment or beliefs, (ii) fund size represents investors' awareness and marketing exposure and (iii) large funds have economies of scale. Published studies have reached mixed conclusions regarding the explanatory power of fund size.

\subsubsection{Investors' sentiment}

Rockinger (1995) suggested that investors might perceive a signal of reliability in fund size, thus resulting in a positive relationship between cash flows and fund size. Warther (1995) investigated the link between cash flows and investors' sentiment by exarnining this relationship for small and large funds. He argued that the small fund investors are more attuned to changes in investors' confidence and sentiment. His model presents evidence that the regression coefficient for large funds is lower than for the small funds. Nevertheless, the findings are not statistically significant, thus not supporting the investors' sentiment hypothesis. Zheng (1999) asked whether (i) fund size affects investors' selections, (ii) investors are more cautious when investing in small funds, and (iii) management skill is more pronounced for small funds. He concluded that, if these arguments are true, he would expect 'smart money' to display some size-effect. Chevalier and Ellison (1997) and Zheng (1999) observed that only small funds do display a very strong 'smart money' effect and concluded that this asymmetry is consistent with the hypothesis that investors are more cautious when buying small funds. This confirmed findings by Lee et al. (1991) and Hendricks et al. (1993) who argued that the sentiment of individual investors affects smaller funds more than larger funds and that cash flows are directly related to fund size.

\subsubsection{Bellefs: Rules of thumb}

In terms of Woerheide's (1982, p.129) "rules of thumb" (prevalent amongst uninformed investors), fund size should be negatively related to fund performances. Intuitively, most investors might want to avoid large funds, if they believe that the funds are unable to deliver returns (Berkowitz and Kotowitz, 2000). Pension funds, on the other hand, might want the stability and security of large funds and thus invest in these funds on a consistent basis. While records are inconclusive, there is good reason to believe that the larger funds become, the harder it will be for managers to deliver market-beating returns ${ }^{39}$. Fitzpatrick (1997) documented that fund size has a significant impact on fund managers' selection and market timing ability. He posed the argument that accelerated large funds might achieve inferior returns compared to smaller funds following an identical strategy. This is because it would take longer to realign the funds in the same proportions (or to translate strategic decisions into actual positioning). Berkowitz and Kotowitz (2000, p.379) used a time-series regression approach and presented findings that "large funds grow more slowly" than their smaller counterparts.

\footnotetext{
${ }^{39}$ Funds become over weighted by under-performing blue chip stock or it might be too costly to identify undervalued stock. This inflexibility is referred to as being "muscle bound" (Nanda of al. 2000, 0.418 ). The funds have a high market capilalisation, leading to constrained performances.
} 
Del Guercio and Tkac's (2002) demand-side interpretation of the negative relationship between cash flows and size recognised that investors might consciously avoid large funds since these funds do not provide the desired level of performance (as per the 'rules of thumb' referred to above) and/or the personal service required. A year later, while evaluating the effect of the Morningstar rating releases on cash flows, Del Guercio and Tkac (2001) commented differently, finding that large funds have higher normal cash flows. The coefficient on fund size is negative, when they looked at the influence of fund size on abnormal cash flows using an updated sample over a different period. This indicates that larger funds have lower average abnormal flows. The 2001 study concentrated on an event-study methodology, supplemented by time-series regression analyses. Large funds are more flexible when selecting investments, being able to acquire the premium stock while at the same time, this allows them to invest in a wide range of companies and industries and thus to diversify risk, but also, possibly, to adversely affect returns. In either case, fund size should affect cash flows and generate returns. Smaller funds have fewer securities and a wider distribution of returns. Gruber (1996) commented that smaller funds tend to have higher risk due to the inability to diversify and the competitive pressure is probably more intense, as they might be faced with a 'do or die' situation. Woerheide (1982, p.133) proposed the view that "a more likely explanation lies in the skewed distribution in terms of total assets" in the industry, as in the case of South Africa. According to the Efficient Market Hypothesis, funds have an equal probability of being top-performing funds, but since there are more small funds, they are more likely to be top performers, thus attracting more cash flows.

\subsubsection{Investors' awareness and marketing exposure}

Investors' awareness of funds could also be considered to be a function of frequency of inclusion in publications and direct marketing, which researchers agree could be proxied by fund size. Sirri and Tufano (1998, p.1597) included funds' sizes as a control, "reflecting the fact that an equal dollar flow will have a larger percentage impact on smaller funds". They concluded that media coverage is biased towards the large funds, funds forming part of large management companies and high-risk funds. Yet, the coverage of performance focused on best or worst performing funds. This presented evidence that individual fund flows are strongly related to section cash flows with smaller funds enjoying a larger percentage of cash flows than their larger counterparts. Sawicki (2001) confirmed these findings in Australia although this contradicted his expectations, as he had theorised similarly to Sirri and Tufano (1998) that larger funds would be better known, receive a larger part of the marketing overheads and exhibit economies of scale.

\subsubsection{Economies of scale}

The importance of the volume of assets managed and the consequent appearance of economies of scale motivated the search for a positive relationship between larger funds and investors' interest. Large funds should exhibit the benefits of economies of scale. This would influence cash flows and return sensitivity (Chordia, 1996; Torre and Garcia, 2002; James and Karceski, 2002). Based on the intuition that large cash flows might induce market wide movements, Mutual Fund Guides suggest that smaller funds might be better investments than large funds since it is easier for them to find potential positive Net Present Value investments. This argument has been weighed against the understanding that large funds, in raising more cash, could also have larger research departments and multiple fund managers, each specialising in a niche market. 


\subsubsection{Fund size restrictions}

Cash flows to small and young funds appear to be more sensitive to past performance than their larger and older counterparts (Goriaev et al. 2002) since equal rand flows would have a larger impact on smaller funds. This is due to investors investing approximately equal dollar amounts in the best performing funds, irrespective of their current size. Unit trusts might be capped when they get too big and this might impact negatively on the sensitivity of the findings. These funds might perform well and would like to attract more cash flows, but might be unable to do so.

\subsubsection{Management company}

It is not only important to consider the characteristics of each fund, but also to consider the fund complex from which the funds are developed and operate. Torre and Garcia (2002) suggested that management companies' sizes communicate the funds' position in the market, reflecting the increased knowledge of investors about them and their funds ${ }^{40}$. Management companies are able to attract significant attention and cash and move large quantities of cash round, because of the size of the assets (i.e. capitalisation) and market exposure (i.e. identity). On the down side, funds' units might be subject to institutional selling, for reasons unrelated to the companies' management, identity or earning prospects ${ }^{41}$.

\subsubsection{Investor brand awareness and marketing}

Sirri and Tufano (1998) presented evidence that cash flows are directly related to the size of the assets managed by management companies, and fund complex or family of funds, as well as, current media attention. They concluded that this is a result of lowered consumers' search costs ${ }^{42}$. They argued that in most cases consumers must choose from a large number of alternative 'brands', these being a combination of management companies and the specific products, using a top-down approach. Sirri and Tufano (1998) equated this with buying durable assets such as cars and further proposed that large management companies spend more on advertising campaigns, receive greater media attention and are more visible to the average investors. However, using higher fees and self-constructed media variables as a proxy, their findings are inconclusive. Torre and Garcia (2002) studied the period from $1992-1997^{43}$ and surmised that the dynamic in the Spanish market changed to such an extent, that investors' knowledge about the market and its participants increased greatly. This resulted in a significant relationship between cash flows and management companies' size. Investors, hoping to take advantage of the appearance of economies of scale and believing that these large management companies are more secure and have lower costs, induce themselves to invest more in large funds or family complexes; this is partially attributed to the spill-over effect.

\footnotetext{
to Torre and Garcia (2002) suggested that good proxy is the total assets under management. The University of Pretoria presents a Unit Trust Survey of total assets managed by management companies and comments on certain companies on quarterly basis. Alternatively. Alexander Forbes publishes information on the ratings of management companies' performances.

${ }_{41}$ The ten (five) biggest management companies managed $77 \%(55 \%)$ of the assets in the industry as at 30 September 2001 (Lambrechts, 2001). Fund of Funds, Wrap Funds and Link Investment Service Providers are particularly facilitated to regular switching amongst unit trusts. The Association of Unit Trusts states that these investment vehicles have a negative impact on the unit trust industry as a whole. The constant chasing of performance is expensive for the investors and generally does not add value (AUT, 2002).

${ }_{42}$ Sirri and Tufano (1998) suggested three measures that act as proxies for search and information costs: fund complex and fund size (log of total assets under management and fund size respectively), marketing and distribution expenditure (change in level of fees, excluding load fees) and media coverage (self-constructed database).

45 Over this period, the Spanish environment and the South African market experienced similar changes.
} 


\subsubsection{Spill-over effect}

The spill-over effect has two benefits: (i) affiliation with other lines of business and (ii) having a star or good performer within a management portfolio.

1) Affiliations - Spill-over refers to the notion that being part of large management companies increases cash flows because investors may prefer to concentrate their investments with a single administrator. However, with the ease of switching between funds at a relatively low cost, this argument should become insignificant in a South African context ${ }^{44}$. Consequently, the structure and position of management companies should be evaluated (Torre and Garcia, 2002). An important consideration before investing is to determine whether the asset managers (such as Rand Merchant Bank) are part of a financial group providing various financial services such as banks, insurance et cetera or whether they are specialist asset managers (such as Oasis Crescent). Fund managers, forming part of a commercial group, might give investors greater visibility, access, security and distribution channels ${ }^{45}$ to reach customers. These channels are not necessarily available to specialist asset managers, thus limiting market exposure. Moreover, a common research department helps to create synergy while keeping costs low. Furthermore, if investors place their money with a brokerage house, these houses are likely to promote their own funds and products, rather than competitors' funds (section 2.5.2.3).

2) Star Performers - The presence of a top-performing fund as part of a portfolio of products managed by a management company might benefit other funds (via increased awareness) in the same portfolio, since investors might be unable to invest directly in this top-performing fund. They might then select another fund, managed by the same management company (as the next best alternative with lower capital requirements) in the hope that there will be a spill-over effect from the top-performing fund ${ }^{46}$. Investors might assume that the respective fund managers are backed by the same quantitative research or management team. These arguments lead researchers to examine the proposition that funds might benefit from strong performances by other funds within the same fund family. Elton et al. (2002) used total assets under management and total cash flows into particular management companies in an attempt to approximate this dynamic. They found that it provides marginal explanatory power. Goriaev et al. (2002) presented evidence that cash flows are directly related to funds' visibility as large management companies' funds and advertising tend to attract large cash flows. Furthermore, they found that cash flows are positively related to the performances of the management companies (as measured by the average performances of the funds managed) and the relationships are strengthened when star performers form part of the portfolios.

Investors' knowledge, experience and awareness are the main drivers of these decisions. The size of the management company contributes towards providing information for making investment decisions.

\footnotetext{
4. Finswitch, launched on 8 February 2002, a common automated platform, processes transactions and facilitates the trading and switching of unit trust products electronically between bulked investors. This system removes the transactional risk and contributes to more effective cash movement between funds (Lambrecht, 2002).

${ }_{45}$ For example, Woolworths Unit Trusts distribute application forms through all their retail outlets.

*or Fomple, if investors do not have the minimum required capital available, they might be induced to invest in a similar 'branded' lund of the same management company (Allan Gray Asset Management), in the hope that the high performances of the top perfoming runds (Allan Gray Equity) would be carried over to a fund (Allan Gray Balanced), in the same fund family.
} 


\subsubsection{After tax consequences}

Prior research papers have focused on before tax returns. Bergstresser and Poterba (2002) used a vector autoregression analysis to determine if there is a relationship between after tax returns (excess and abnormal returns) and cash flows. They presented evidence that after tax returns add more explanatory power of cash flows than pre-tax returns, concluding that tax-aware investors consider tax burdens when allocating their funds and investors are concerned about minimizing the tax burdens associated with mutual funds.

\subsubsection{Personal disposable income}

Investment is a conscious choice by investors. Therefore, investors' income could be a determinant of cash flows when additional disposable cash is available. For example, the contributions to pension plans could be defined as a function of income and would reflect a change in real per capita disposable income. It would be expected that an increase in disposable income would increase the portion invested. However, the timeliness of this dynamic is uncertain (Santini and Aber, 1998). Spitz (1970) initially introduced disposable income into his study but found no significant explanatory power, neither did Santini and Aber (1998), using the change in disposable income.

South Africa still has inequality between the high and low income groups, therefore, including real per capita income in any model will misrepresent the findings. These figures will consist of the high income group (which may or may not invest in unit trusts or have a retirement plan) and then the low income group (with a significantly lower per capita income and which probably neither invests in unit trusts, nor has a retirement plan). This will negatively influence these figures; therefore, this is not deemed a good indicator of prospective investors.

\subsection{Summary of the literature review}

Sections 2.2 to 2.5 .10 discuss studies mainly undertaken in an American context and present arguments for and against certain factors that contribute towards explaining the variation in future cash flows. The major determinants discussed in these studies, are summarised below ${ }^{47}$, first discussing market factors, followed by fund specific factors. Only the fund specific factors, which international studies found significant, are discussed. Various factors such as fund managers' tenure, age, qualification, fund turnover et cetera utilised in other studies, are omitted due to a lack of: (i) data, (ii) quantifiable independent variables, or (iii) plausible economic theories justifying the inclusion.

The local and international market returns and interest rates seem to be the market factors with the most explanatory power, but, the degree of significance is yet to be determined. These factors act as indicators, reflecting an expectation on the future prospects of the economy and investments. South Africa experienced declining interest rates and an inverted yield curve, which is negatively related to returns on equity markets. Furthermore, South Africa is considered as one of the more stable emerging markets.

\footnotetext{
47 There is no prior research to support the notion that the same factors could influence South African investors. There are differences between the South African and the international unit trust industry, however, their fundamental characteristics underlying the markets are similar.
} 
Therefore, it is conceivable that South African investors' expectations and consequently, unit trust cash flows would be affected by these market factors ${ }^{48}$.

Economic theory suggests that return, risk and transaction costs should be in the forefront of any investment decision. The influence of these factors on investors' behaviour is universal. Considering only these variables would not include the whole dynamic since there are life-cycle investors who would invest regardless of these factors. Therefore, consideration is given to past cash flows, category cash flows and historic track records. Including these variables into the model would imply that investors are return-maximising individuals. They are considered to be well-informed and have a wide variety of information at their disposal. However, in the South African context, this is not expected to occur due to the restrictions which are imposed by the limited access investors have to information regarding specific details about fund activities ${ }^{49}$. There is mixed evidence supporting the notion that fund size, management companies' size and unit trusts' age help to explain variation in cash flows.

Only studies conducted in the United States have presented empirical evidence to suggest that cash flows are predictable by the above-mentioned determinants. Considering some of these aspects, it is improbable that all these indicators will add any value in a South African context. Therefore, this research investigates which of these determinants have the greatest influence on cash flows in a South African context.

\footnotetext{
${ }^{48}$ The sample selected, consists of all General Equity unit trusts, with a mandate to invest in selected shares across all industry sectors of the JSE as well as across a range of large, medium and smaller capitalised shares.

49 An example would extend to knowledge about the respective fund fee structures. These structures are only available on request, while still being negotiable. Fees might even be deducted directly from the clients' portfolios, limiting the "out of pocket' impact.
} 


\section{Chapter 3}

\section{METHODOLOGY}

\subsection{Introduction}

This chapter presents the research methodology used to gather and analyse the data in order to answer the research questions outlined in chapter 1. Each section focuses on a particular aspect. The various types of data utilised, are discussed in section 3.2, while section 3.3 outlines the approach used to determine the number of independent variable lags to be included in the analysis. Section 3.4 presents a high-level overview of the approach and contrasts the approach to other studies. Section 3.5 outlines the exploratory analysis. Sections 3.6 to 3.8 discuss the approaches employed to investigate investors' asymmetric response to performance and the determinants of cash flows. Finally, section 3.9 presents the regression techniques utilised, the assumptions and weaknesses.

\subsection{Data collection}

The research used both monthly and annual data selected from the General Equity unit trust category over the five-year period from 1 September 1996 to 30 September 2001 and is limited to the General Equity category for the following reasons:

- R 37.6 billion (or $27 \%$ ) of assets invested in the unit trust industry was invested in Domestic General Equity unit trusts. Only the assets invested in the money market funds surpassed these investments. Furthermore, the General Equity category also attracted the second largest amount of cash flows.

- Selecting the General Equity category allowed funds of a similar mandate or risk and retum profile and funds which were exposed to similar environmental factors, to be compared. This avoided the biases, which resulted from the interaction between cash flow size and sectorial influences (Gruber, 1996).

- Hybrid funds were excluded since these hold a spread of non-and interest bearing securities that might react differently to market conditions. Specialist funds were excluded since the returns might be driven by different factors. For example, flows into specialist funds might represent investors making sector-focused bets, not related to the funds or the markets. Therefore, by implication, investors may have different, not necessarily quantifiable factors which affect their behaviour. This, however, should not be the case for General Equity investments. Furthermore, for certain specialist funds, it would not be possible to determine an appropriate market indicator. 
The number of unit trusts increased by $177 \%$ from 30 September 1996, resulting in consumers having a wider investment choice. There were 57 General Equity unit trusts in existence by September 2002. Only 18 were in existence for the full five-year period. To avoid CGT implications ${ }^{50}$, the study period ended 30 September 2001, which reduced the sample to 47 . Only funds with at least one year's historic data available were used which resulted in a further reduction of the sample to 41 . When performing the time-series analysis at a fund level, the sample consisted of 34 funds because only funds older than two years were considered. When abnormal returns were used as the performance measure, the sample size was further reduced to consider only 31 unit trusts, because a primary requirement for the calculation of betas is that funds must have at least a three-year return history. To eliminate any problems with a sample selection, the analysis was performed on a time-series and cross-sectional basis.

The five-year sample period was utilised because periods prior to September 1996 would have reduced the sample size significantly, making reliable conclusions difficult. Investors' interest in the unit trust market was stable before 1996, thereafter investors' activities increased, with the funds experiencing both monthly inflows and outflows. This is important because it permitted the investigation over different market conditions, as the study is not biased towards periods of net inflows and good times (and visa versa). It potentially adds strength and generality to the findings (Santini and Aber, 1998).

For the analysis, two sampling interval periods were utilised. Monthly data was utilised for the time-series analysis, while annual observations were utilised for the cross-sectional analysis. The two sampling intervals allowed the speed at which investors react to investment decisions to be considered. This is also consistent with previous studies. Warther (1995), Gruber (1996), Remolona et al. (1997), Zheng (1999), Edelen and Warner (2001) and James and Karceski (2002) were not conclusive on which timing interval is the most appropriate; utilising a range of data from inter-day to annual data (appendix A). Furthermore, fund size data, which formed the basis of the cash flow calculation, is not available on a daily and weekly frequency while selecting quarterly data would have resulted in too few data points being available to conduct reliable time-series analysis. Although it is preferable to use quarterly intervals for cross-sectional studies, from the point of view of statistical rigour, using annual observations would neither invalidate any trends in the findings, nor detract from the strength thereof.

Table 5 (page 42) presents a brief description of the data, its nature and source. Appendices B, D and E contain the formulae used to calculate the variables together with a comprehensive description of these variables. Various qualitative characteristics, discussed in sections 2.4 and 2.5 , were excluded from this dissertation due to difficulties in (i) obtaining data or (ii) finding a suitable measure. The data was reviewed for consistency and completeness and compared with data obtained from alternative sources. Data obtained from alternative sources such as the AUT, Profile Media, I-Net Bridge and the University of Pretoria Unit Trust Survey, replaced all missing or duplicated points. Where the data point was not available for the required date, the data point was replaced with data from the next trading day. This occurred when the month end was on a public holiday or a weekend. Outliers were identified by visual inspection of the scatter plots. Statistica V6 was used to adjust for any outliers.

\footnotetext{
${ }^{50}$ CGT was effective from 1 October 2001, therefore, the sampling period ended before its implementation. CGT could be seen as a barrier to future cash flows from tax-sensitwe investors (Bergstresser and Poterba, 2002). Restricting the analysis in this manner, also removed the problems associated wh having a different tax environment over the sampling period.
} 


\section{Table 5. Variables used in the analysis ${ }^{51}$}

\section{Dependent variable}

1. Net investment cash flows: These estimates were calculated from fund size and monthly unit trust returns based on repurchased prices, after reinvesting dividends.

Independent variables

2. South African market returns: The market returns were calculated from JSE All Share index and dividend yields.

3. International equity market returns: The Morgan Stanley International Stock market index (MSCl) for the foreign equity market was used.

4. Short-term interest rate: This was calculated from the yields of the 90-day Negotiable Certificates of Deposit.

5. Long-term interest rate: This was calculated from the yields on the long-term 30-year Government Bonds.

6. Transaction costs and fee structure: Three types of fee structures were used: Annual management fees, front- and back-ended costs. (The latter is not extensively used in South Africa)

7. Past investors' contributions: These were net investment cash flows lagged by one month.

8. Risk classification: The return standard deviation was used.

9. The unit trusts' age: Unit trusts can be classified by using indicator variables when conducting cross-sectional analysis and using control groups when conducting time-series analysis.

10. Fund size: The natural log of fund size was used to control for the non-normality of fund size.

11. Different performance measures: Different performance figures were utilised, based on different holding periods. These ranged from normal, excess and abnormal returns.

12. Category cash flows: The sum of the cash flows to individual funds in the General Equity category was utilised. It was only included when conducting the individual fund level analysis.

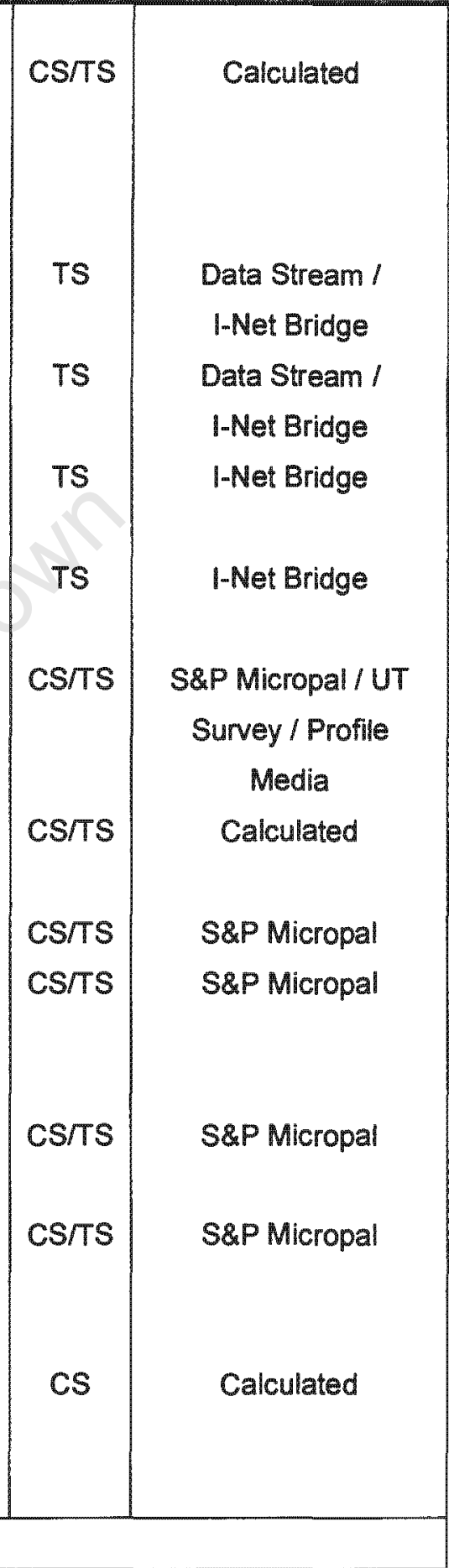

\footnotetext{
${ }^{51}$ It should be noted that if the methodology and the findings refer to 'independent variables', these refer to all the market factors and fund characteristics included in that part of the analysis, whereas the 'dependent variable' refers to cash flows.
} 


\subsection{Establishing the number of lags}

It was necessary to establish the number of variable lags to be included in this analysis, since prior studies have failed to find that cash flows are influenced by other factors for periods longer than the period under review (lie. concurrent relationship), other than the one-month lagged performance (section 2.5.1.3). The individual aggregated independent variables were regressed on cash flows using a repetitive process, each time including further lagged independent variables into the regression equation. This process was repeated for all aggregated independent variables until the explanatory power of the equation, as a whole, did not improve.

The results show that only the contemporaneous relationship between aggregated cash flows and the independent variables was significant (if significant at all), except when the performance variable was lagged ${ }^{52}$. Including further additional lagged performance variables into the equation, improved the regression equation's ability to explain cash flows marginally, although the second lagged performance variable was not significant. Only the concurrent and one month prior months' performance regression coefficients were significant, regardless of the number of lags included ${ }^{53}$. Therefore, only the concurrent relationship between cash flows and the other independent variables was tested (in the remainder of the dissertation), except for the inclusion of a one-month lagged performance.

\subsection{Overview of the research approach}

The behaviour of the data over the sample period was reviewed via visual inspection and event analysis. Regression analyses were performed to establish the asymmetric relationship between cash flows and different performance measures. Further multivariate regression analyses were conducted to determine which market factors and fund characteristics explain the most variation in cash flows, at an aggregated and an individual fund level on a time-series and cross-sectional basis.

Rockinger (1995) first evaluated the asymmetric investors' response and thereafter followed with an evaluation of the determinants of cash flows. Zheng (1999) performed time-series analysis on macro-economic market factors, followed by a series of cross-sectional analysis using fund specific information. This dissertation integrated and utilised these approaches. This has the advantage that it allows the analysis to consider the interaction between market factors and fund specific characteristics in combination, rather than considering these determinants in isolation. Throughout the following sections, the advantages and disadvantages of these approaches are discussed and, where applicable, any mitigatory approaches to these weaknesses are highlighted.

\footnotetext{
${ }^{52}$ The coefficient of detemination $\left(R^{2}\right)$ for the regression equation improved by 0.36 from a $R^{2}$ of $0.427(0$-value $<0.5)$ to $0.783(0$-value $<$ 0.5 ), when cash flows were regressed against the current and the prior months' returns as opposed to only considering contemporaneous relurns.

${ }^{3}$ In order to corroborate the results above, forward-stepwise linear regression analysis was performed using a three-month lag structure for the independent variables. The results from this stepwise process confirm the findings above.
} 


\subsection{Initial data review and analysis}

The analysis began by reviewing the data, by means of summary statistics and inspection of the behaviour of the variables utilised over the sample period, around exceptional events and market crashes. The time-series behaviour of variables in the first 24 months after the launch of a fund was investigated. Thereafter a correlation matrix was constructed between all variables.

Utilising the methodology employed by Bradfield (2000) ${ }^{54}$ and Fant and O'Neal (2000), General Equity unit trusts were ranked in terms of the size of each fund's annual cash flows. Based on these cash flow rankings, the fund characteristics were also grouped into four corresponding quartiles to facilitate observing any discernable pattern that may exist in the data quartiles.

\subsection{Asymmetric investors' response}

Investors' asymmetrical reaction to performances was classified into two behavioural components relating to: (i) the size (or significance) of performance and (ii) the direction of performance. The analysis was performed to establish the importance of performance in explaining the variation in cash flows. The techniques employed to test the behavioural components are presented in sections 3.6 .1 and 3.6 .2 respectively.

\subsubsection{Investors' bias towards top performing funds}

A piecewise linear regression was used to measure the sensitivity of cash flows to performance in different performance regions on monthly and annual time intervals. The coefficient measuring the relationship between performance and cash flows was estimated separately for funds in the bottom $20 \%$, middle $60 \%$ and top $20 \%$ performance regions in the current periods. These regions correspond with those used by Sirri and Tufano (1998), Fant and O'Neal (2000) and Sawicki (2001) and were set arbitrarily. The procedure designates three performance variables as follows:

$$
\begin{array}{ll}
\text { Low }_{t} & =\min \left(\operatorname{rank} k_{t}, 0.2\right) \\
\text { Medium }_{t} & =\min \left(0.6, \operatorname{rank}_{t}-\operatorname{Low}_{t}\right) \\
\text { High }_{t} & =\operatorname{rank}_{t}-\left(\operatorname{Low}_{t}+\text { Medium }_{t}\right)
\end{array}
$$

\begin{tabular}{|c|c|c|}
\hline Where: & $\begin{array}{l}\text { Low: } \\
\text { Medium, } \\
\text { High, } \\
\text { rank: }\end{array}$ & $\begin{array}{l}\text { is the low performance region } \\
\text { is the medium performance region } \\
\text { is the high performance region } \\
\text { is the fund's fractional rank }\end{array}$ \\
\hline
\end{tabular}

\footnotetext{
${ }^{54}$ Bradfield (2000) implemented the methodology described above in a study lo detemine the relationship between funds' size and unit trusts' perfomances. This methodology provides an overview of the data, highlighting any potential relationship.
} 
Rankings were based on normal, excess and abnormal performances as calculated in appendix D. Each fund's relative performance or rank was calculated by comparing the performances of the fund against those in the same investment objective. The fractional rank ranged from 0 to 1 and represented its percentage performance relative to other funds. This approach is consistent with that of investors considering risks only in the context of investment objectives (Fant and O'Neal, 2000). The rankings were transformed by equation (1). Based on these performance regions, two regression techniques were used: (i) a time-series approach using an indicator variable and (ii) a cross-sectional approach.

\subsubsection{Time-series approach}

A binary indicator variable defines the three performance regions presented in section 3.6.1. Cash flows take the form of a bivariate regression equation, which includes an interactive indicator variable. This allows the fund performance measure to interact with the binary indicator variable. This approach utilised by Sawicki (2001) and Fant and $\mathrm{O}$ Neal (2000) is represented by:

$$
C \boldsymbol{F}_{t}=\beta_{0}+\beta_{1} * \boldsymbol{I R}_{t} * \boldsymbol{R}_{t}+\varepsilon_{t}
$$

\begin{tabular}{|c|c|c|}
\hline \multirow[t]{6}{*}{ Where: } & $C F_{t}$ & is the realised cash flows in period $t$ \\
\hline & $\boldsymbol{I R}$ & is the indicator variable, which identifies the performance regions \\
\hline & $\mathbb{R}_{t}$ & is the current periods' performance measure \\
\hline & $\beta_{0}$ & is the regression intercept \\
\hline & $\beta_{1}$ & is the regression coefficient \\
\hline & $\varepsilon_{t}$ & is the residual \\
\hline
\end{tabular}

The time-series analysis was performed by aggregating the performance and cash flow measures. Thereafter the analysis above was reperformed on an individual fund basis for all the funds older than two years.

\subsubsection{Cross-sectional approach}

A series of cross-sectional regression analyses were used to address the potential weaknesses of the time-series method. A structured piecewise linear regression analysis was used, to test the investors' asymmetric response to high-to-low performance funds. This allowed for the sensitivity of cash flows to performance to be calculated separately. This dissertation adopted a piecewise linear regression model developed by Sirri and Tufano (1998) and Del Guercio and Tkac (2002) to designate three linear segments applied to each year in the sample period.

$$
\left.C F=\beta_{0}+\sum_{j=1}^{3} \mid \beta_{j} * \operatorname{Reg}_{j}\right\rceil+\varepsilon
$$

$\begin{array}{ll}\text { Where: } & \begin{array}{ll}C F & \text { is the realised cash flows } \\ R e g, & \text { is the variable, which defines the performance regions: High, Medium and Low } \\ \beta_{0} & \text { is the regression intercept } \\ \beta_{J} & \text { is the regression coefficients } \\ \varepsilon & \text { is the residual }\end{array}\end{array}$


The coefficient on fractional ranks was estimated using a piecewise linear regression framework over the three performance quintiles (which included three quintile variables depending on the performance level as outlined in section 3.6.1). The coefficient on each of these variables represents the marginal cash flow response to performance within the investment objective. The research analysed each year's observation separately, reporting the means and $t$-statistics on the mean of the time-series of coefficient estimates and standard errors as in Fama and MacBeth (1973). With less than five observations, Fama-Macbeth's methodology provided a conservative estimate (James and Karceski, 2002). Consequently, these results were used as a summary measure, considering each annual observation in context over the five-year period.

\subsubsection{Investors' bias in respect of directional changes of performance}

In order to establish the effect that directional changes of performance have on cash flows ${ }^{55}$, indicator variables for positive/negative return events were included in the time-series regression analysis. For each period, the indicator variables were used to represent either positive, or negative return events respectively. These were then interacted with the performance measure. The multivariate equation takes the following form:

$$
C F_{t}=\beta_{0}+\beta_{1} * R_{t}^{*} \boldsymbol{I P}+\beta_{2} * \boldsymbol{R}_{t} * I N_{t}+\varepsilon_{t}
$$

$\begin{array}{ll}\text { Where: } & \begin{array}{ll}\boldsymbol{R}_{t} & \text { is the realised cash flows in period } t \\ \boldsymbol{P}_{t} \& I N_{t} & \text { is the current periods' performance measure } \\ \beta_{0} & \text { are the indicator variables for positive and negative return events } \\ \beta_{t . \ldots 2} & \text { is the regression intercept } \\ \varepsilon_{t} & \text { is the regression coefficients }\end{array}\end{array}$

The time-series analysis was performed by aggregating the performance and cash flow measures. Thereafter the analysis above was reperformed on an individual fund basis for all the funds older than two years.

Del Guercio and Tkac (2002) suggested that the introduction of indicator variables into the regression analysis gives the same result as running two separate regressions for each indicator variable condition. Rockinger (1995) employed a different methodology, constructing a change in rankings and performance variables respectively, investigating investors' behaviour as the rating changed. South Africa has no equivalent to the Morningstar rating, therefore, this dissertation did not consider this approach. However, the concept behind Rockinger's (1995) approach remains applicable to the methodology employed.

\footnotetext{
55 Investors invest disproportionately to positive relurn events, yet seem to look away (or do not dives) from short-term negative return events. By implication, it couid be argued that investors seem unwilling to limit their losses (Rockinger, 1995).
} 


\subsection{The determinants of the cash flow model}

The principle objective was the estimation of a behavioural model of demand for unit trusts for the entire period under consideration. The analysis began by conducting bivariate regression analysis between cash flows and all the independent variables. These analyses were followed by a stepwise linear regression process, to determine the most significant independent variables for explaining cash flow behaviour. Thereafter the multivariate timeseries regression analysis was performed, utilising the following equation:

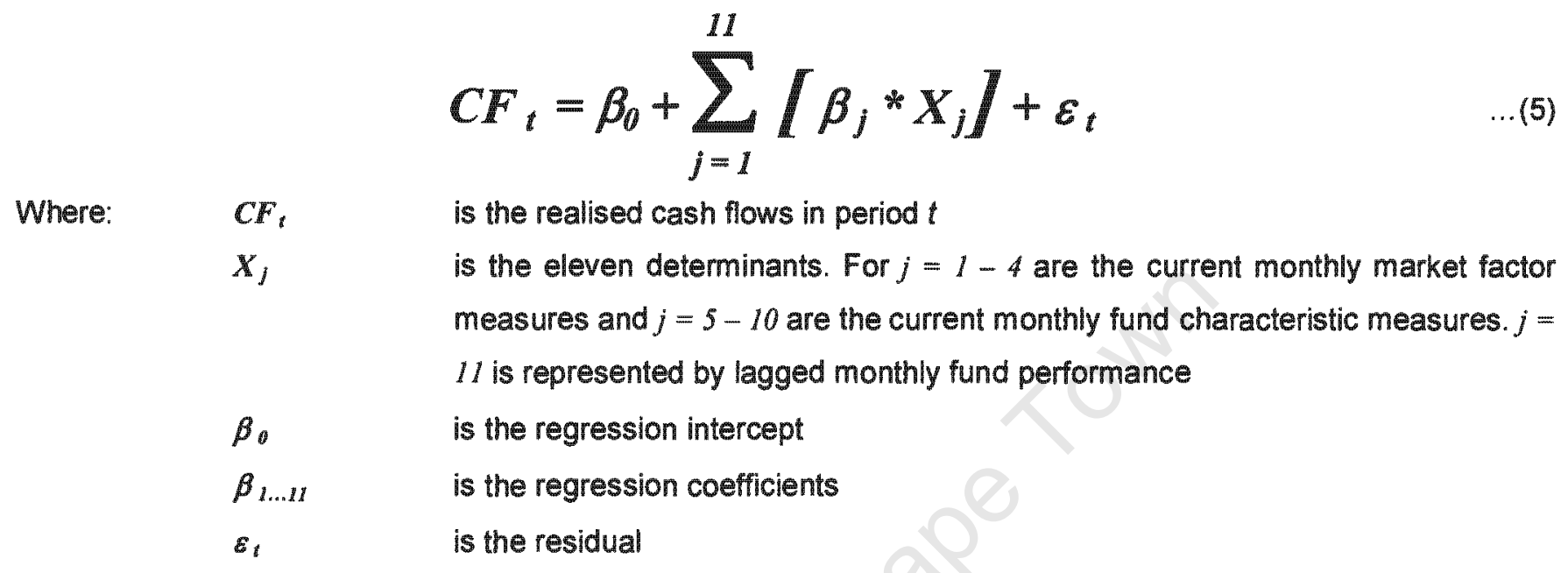

Firstly, a time-series analysis was conducted on the market factors and aggregated fund characteristics. The determinants of all the unit trusts in the General Equity category were aggregated together into a single dataseries to perform the above-mentioned time-series regression analysis. The advantage of looking at the aggregated level was that the information about fund managers and individual funds would cancel out, enabling concentration on the factors affecting the whole sector. Thereafter time-series analyses on an individual fund basis for all funds older than two years were performed. This eliminated any biases introduced into the findings through the aggregation process. It also considered market factors and each fund's characteristics against the fund's own cash flows, thereby considering the interaction between the variables explicitly.

This time-series analysis was followed by a cross-sectional study on fund characteristics. The multivariate crosssectional regression equation utilised by the research, takes the following form:

$$
\left.C F=\beta_{0}+\sum_{j=1}^{7} \mid \beta_{j} * X_{j}\right\rceil+\varepsilon
$$

Where: $\quad C F \quad$ is the realised cash flows

$X_{j} \quad$ is the seven fund characteristics. For $j=1-7$ are the annual fund characteristic measures

$\beta_{0} \quad$ is the regression intercept

$\beta_{1 \ldots,} \quad$ is the regression coefficients

$\varepsilon \quad$ is the residual 
The analysis was conducted on cross-sectional data for each year under review, to determine if these independent variables changed over the period. The analysis concentrated on how funds compete against each other for attention to attract investors' money, compared to the large-scale shifts in cash flows. Furthermore, the usage of annual data removed potential volatility in the monthly data. Unfortunately, cross-sectional analysis does not allow for the inclusion of any lagged variables, as this would have reduced the sample further. Another drawback to performing cross-sectional analysis is that it tests for a relationship between variables at a point in time. As a result, it was only used when considering funds' specific characteristics, since the market factors did not differ between funds at a single point in time. In order to mitigate these weaknesses of cross-sectional analysis, a time-series analysis was performed on a fund-to-fund basis as outlined above:

\subsection{Unit trusts' age}

Fund age was incorporated by classifying the unit trusts by means of indicator variables, for funds younger and older than two years, in order to directly investigate the findings by Sawicki (2001) while conducting the crosssectional analysis. This posed problems because, as the sample period moved towards 1996, the number of eligible funds reduced significantly, comprising mainly of older funds. Furthermore, the sample of funds used in the analysis was not separated into an equal number of funds, making the comparability of the results problematic. Time-series analysis was performed, to mitigate the effect of these limitations discussed above. The performance and cash flow data-series were aggregated into control groups according to age and regression analysis was performed on the control groups.

\subsection{Regression techniques}

The analysis was conducted using correlation to measure the strength of the association between the variables, discussed in section 3.2 , at a $5 \%$ significance level.

\subsubsection{Regression analysis}

A bivariate linear regression model was used to determine the relationship between cash flows (dependent variable) and the independent variables. Due to the limitations of bivariate linear regression, forward-stepwise linear and multivariate regression analyses were conducted to identify whether statistically significant relationships exist between cash flows and the independent variables tested on a time-series and cross-sectional basis. Time-series and cross-sectional analyses were used, matching the type of data with the technique best suited for the nature of the data (Table 5 [page 42]). The methodologies used by Warther (1995), Rockinger (1995), Gruber (1996), Fant (1999) and Zheng (1999) inter alia, were adopted in this dissertation. Both timeseries and cross-sectional regression analysis approaches were used because the methodologies used by the above-mentioned authors considered only a single aspect of the relationship in isolation, either: (i) the asymmetric investors' response to relurns; (ii) the influence of market factors; or (iii) the influence of fund characteristics on cash flows. The chosen methodology integrated these factors and provided a better insight into the interaction between the determinants. 
A benefit of the regression analysis is that the results could be used to build a model to make predictions, considering the influence of individual variables and the interaction between these variables. Furthermore, regression analysis is versatile enough to facilitate the usage of both time-series and cross-sectional data, thereby minimising the timing issue noted in sections 3.2 and 3.3 .

Although three alternative approaches were considered, namely: an event-study, a survey and a factor analysis approach $^{56}$, these approaches have inherent weaknesses, which are not applicable to regression analysis. An event-study approach could not be used, since no 'alternative event definition' approach could be identified. Surveys might not be answered truthfully and usually have poor response rates. Furthermore, using these approaches would have made it difficult to compare the findings to other studies that used regression techniques.

Due to the change in investment patterns and the growth experienced in South Africa, it was appropriate to conduct stepwise linear regression since it considered only significant variables, allowing for the identification and elimination of the multi-collinearity problem ${ }^{57}$ which could be experienced. The multi-collinearity would not invalidate the equation as a whole, but could complicate determining the extent to which the variables contribute to the explanatory power of the relationship.

\subsubsection{Normality of distribution}

The use of parametric regression techniques carries an inherent assumption of normality. The validity of this assumption does not affect the regression estimates, however, a violation affects the validity of the hypothesis ${ }^{58}$ about the relationship being tested. A chi-squared test of normality was performed to validate this assumption, using an excel-macro on a per fund and an annual basis. The indicator variables and rankings used, were not tested to determine whether the data fitted a normal distribution, since they were, by their nature, distribution free (Cooke, 1998).

Fund size with a chi-squared stat of $5.697(p$-value $=1.7 \%)$ appears to be the only time-series data that was not normally distributed. The fund size data was therefore transformed, by using a natural log fransformation. Most of the cross-sectional data used, except for risk and administration fees ${ }^{53}$, was not normally distributed. Consequently, the data was transformed by ranking the data points from smallest to largest and allocating absolute rank to each data point. This transformation would correct the non-normality of the data since the rankings were distribution free. Furthermore, rank transformation was relatively insensitive to outliers and useful for non-linear related data (Cooke, 1998). The transformed data was used throughout the dissertation. On several occasions, the results of the parametric regression techniques were tested by using the non-parametric regression alternative.

\footnotetext{
${ }_{5}^{5}$ Due to the high level of multi-collinearity between the independent variables, it was possible to expand the research using factor analysis.

${ }^{57}$ Multi-collinearity is a condition wherein the independent variables are highly correlated, thus distorting the istatistics, making it difficult to interpret the relationship between the independent and dependent variables (Potier, 2000).

st Miburn-Pyle (1984) stated that the lack of nomality of one variable only becomes significant in attempting to arrive at the parameters governing the population and that it is not objectionable if the technique is merely applied to determine the relationship between variables.

${ }^{5}$ While lesting the cross-sectional data for nomality, the risk data had a chi-squared stat of $1.103(p$-value $=29.4 \%)$ and administration fees data had a chi-squared stat of 4.104 ( $p$-value $=7.8 \%)$.
} 


\subsubsection{Regression analysis assumptions}

Linear regression analysis is based on several restrictive assumptions. If these assumptions are violated, it will restrict the usefulness of the equation produced. The first assumption relates to the linearity of the relationship between the dependent and independent variables ${ }^{60}$. Two other assumptions concerning the error term of the relationship are relevant to the findings and are discussed below.

\subsubsection{Hoteroscedasticity of the cross-Sectional data}

Regression analysis requires that the variance of the error term is constant. The problem of heteroscedasticity is relevant to cross-sectional studies ${ }^{61}$. Since most of the cross-sectional data was not normally distributed, thus requiring transformation, it negated the need to test for heteroscedasticity. Furthermore, an advantage of using normalised cash flows facilitated the elimination of heteroscedasticity from the data, which might be present in rand denominated cash flows (Fant and O'Neal, 2000).

\subsubsection{Non-independence of the error term}

While the existence of strong auto-correlation tends to destroy the validity of the regression analysis, it provides an opportunity to produce accurate forecasts (Keller and Warrack, 2000). Auto-correlation implies that a large component of a particular variable is predictable based on lagged values of themselves, resulting in the error term being correlated over time. Therefore, only the times-series data was tested. First-order auto-correlation was detected by viewing an alternating movement or trend in the plot of the residuals. However, since these patterns were not always apparent, it was necessary to produce a correlation matrix to determine the correlation coefficient of variables against lagged values of themselves (i.e. the same variable).

The correlation matrix highlights a significant $(p$-value $<0.05)$ element of auto-correlation amongst short-term and long-term interest, fees, fund risk and size ${ }^{62}$. The cash flow and return variables appear to show no significant level of auto-correlation $\left(R^{2}=6 \%, 0.15 \%\right.$ respectively). The non-persistence of cash flows $(p$-value $=0.059)$ at a $5 \%$ significance level might be evidence that investors adjust their portfolio over the short-term. The findings were tested, by considering Spearman rank order non-parametric correlation coefficients, but remained unchanged.

The analysis discussed in sections 3.6 to 3.8 was first conducted using data not adjusted for auto-correlation, but with the inclusion of a time dependent variable, as shown by the regression equations presented in earlier sections. These results, using unadjusted data, are presented in appendix I. Due to the significance of the autocorrelation results mentioned earlier, it was necessary to apply the first-differencing approach by Rockinger (1995) to the data which showed an auto-correlative nature used in later analyses (regression equations are omitted). The first-differencing resulted in the relative difference tending to show a uniform dispersion over time, thereby reducing auto-correlation, where the variables represent the difference between the value at time interval $t$ and $t-1$.

\footnotetext{
The regression observations were plotted and visually inspected for a significant departure from linearity.

"In the presence of heteroscedasticity, the regression estimates are still unbiased but are inefficient, not having the least variance of all unblased estimators. As a result, the reliability of the standard errors is reduced and a reduction in the accuracy of the t-statistics employed.

${ }^{62}$ The correlation matrix highights that short-term interest has a $R^{2}=95.3 \%$; long-term interest has a $R^{2}=78.3 \%$; fees reflect a $R^{2}=31.4 \%$, while fund risk shows a $R^{2}=63.9 \%$ and size reflects a $R^{2}=68,7 \%$.
} 
Using the first-differencing approach also assisted in reducing any non-stationarity in the data. Consequently, only the results of the transformed data are presented in subsequent sections. The findings based on transformed data were tested by means of Durbin-Watson statistics to determine whether the auto-correlative nature of the data had been mitigated ${ }^{63}$.

The findings, adjusted for auto-correlation, presented in chapter 4 , do not differ significantly from those presented in the appendices. The differences which did arise in the findings when using unadjusted data, are as follows:

- After adjusting the data for auto-correlation, the correlation of lagged cash flows improved from a $R^{2}$ of 0.036 $(p$-value $=0.144)$ to $0.322(p$-value $<0.05)$. The inclusion of lagged cash flows, as a variable into the models, improved the coefficient of determination $\left(R^{2}\right)$ of the models significantly.

- The importance of including short- and long-term interest rates into the models to explain the variation of cash flows became insignificant after adjusting the data for auto-correlation. This is understandable, since interest rates are highly auto-correlated. The other auto-correlated variables, which exhibited auto-correlated features, added no explanatory power to the analysis either before, or after the data was adjusted for auto-correlation.

\subsection{Summary of the methodology}

The analysis began with a review of the behaviour of the data over the sample period. Some exploratory analyses were performed. Selected data were transformed to correct for the non-normality and auto-correlation identified. Thereafter, the regression tests were conducted to establish whether there is an asymmetric relationship between cash flows and different performance measures. This was followed by time-series and cross-sectional regression analysis to determine which market factors and fund characteristics explain most variation in cash flows, at an aggregated and an individual fund level.

\footnotetext{
* The critical values were calculated at a $5 \%$ significance level, where $k=1$ and $n=60$, for the aggregated bivariate testing. This gave rise to $1.55\left(d_{1}\right)$ and 1.62 (du). For the aggregated multivariate regression analysis, the critical values were calculated where $k>5$ and $n=60$ with corresponding critical values of $1.41\left(d_{\mathrm{L}}\right)$ and 1.77 (du). The critical values for the individual fund regression results were determined based on the parameters of the data for the fund.
} 


\section{CHAPTER 4}

\section{ANALYSIS AND DISCUSSION OF FINDINGS}

\subsection{Introduction}

The empirical results test the hypothesis that there exists a statistical relationship between cash flows and the independent variables, using a multi-stage approach. The results are analysed in the context of the literature review presented in chapter 2 . The statistical results indicate the extent to which a relationship exists at a $5 \%$ significance level. Section 4.2 presents the initial review findings, describing the interaction between the market factors and fund characteristics. Section 4.3 investigates whether investors invest disproportionately in top performing unit trusts when observing positive return events, but tend to neglect poor performing funds. Section 4.4 presents evidence, testing the premise that the market factors and fund characteristics contribute to cash flow variability and behaviour. Thereafter, section 4.5 discusses the findings of individual factors, which might influence cash flows at a fund level. Finally, section 4.6 briefly provides a summary of the findings. Only the results, which provide significant findings, are discussed in the following chapters. If the results are not discussed, these are presented in the appendices.

\subsection{Initial review and analysis ${ }^{64}$}

The interaction between the market factors and fund characteristics is graphically analysed. Section 4.2 .1 briefly discusses the findings. Section 4.2 .2 outlines the interaction between the market factors and fund characteristics over the first 24 months of the funds' existence. Section 4.2 .3 presents the correlation coefficients obtained from a correlation matrix and section 4.2 .4 concludes and summarises the initial review.

\subsubsection{Features of the General Equity unit trusts}

This section provides an overview of the features of the General Equity category and the market factors over the study period. Further detailed analyses are presented in appendix $F$. Appendix $G$ highlights the most salient summary statistics of a few individual funds as a useful method of gaining a broad overview of the data set.

All the independent variables were stable until the 1998 market crash, except for local and international equity market returns. All the return variables (including market returns) and interest rates lost large amounts of value during the $1998 \mathrm{crash}$. These were matched by comparable large cash flows, however, the effect on cash flows and the market was short-lived. After the crash, equity markets stabilised quickly, which contributed towards the recovery of General Equity unit trust performances. Remolona et al. (1997) noted a similar expedient US market recovery after the 1997 Asian emerging market crash, but contradicted US findings by Fortune (1998) after the 1998 Russian debt crisis.

\footnotetext{
${ }^{64}$ Data, not adjusted for auto-correlation, was used to pertorm the analysis in sections 4.2 .1 to 4.2 .4 .
} 
Notwithstanding the crash, cash flows appeared to move in the same direction as normal returns, but in a different direction to excess and abnormal returns. Return on the ALSI moved in unison with returns of the General Equity category. However, the returns on the ALSI were slightly higher and more volatile.

It appeared that international markets influenced local markets, as these equity market returns followed the same patterns. These changes in returns were met by corresponding cash flows. Although the General Equity category went through periods of inflows and outflows, it experienced a total net inflow.

Long-term interest rates, lagged by two months by short-term interest rates, showed a steady downward trend over the past five-years. Transaction costs also reflected a decline, due to increased market competition. The standard deviation of returns almost doubled, while surprisingly the total assets under management increased by $10.5 \%$ over the five-year period. This small increase in fund size was mainly attributable to the 1998 market crash, where the General Equity category lost half its value, after which the funds made a steady recovery. It is worth noting that none of the variables exhibited any particular pattern, or seasonality.

\subsubsection{First 24 months of the funds' existence}

The summary statistics (appendix G) highlight the minimum and maximum data points of the fund characteristics under investigation and the date of occurrence. Fifteen cash flow events, exceeding a normalised cash flow measure of $100 \%$, were identified. Thirteen of these events occurred within the first year of existence. The funds also earned the highest returns around the same period. These large capital contributions might skew the results of the review. This necessitated the need to discuss briefly how the dynamic between the fund characteristics changed over the first 24 months of the funds' existence. This is relevant because these funds had no historic track record, which would aid in making investment decisions.

Over the period covered by the dissertation, 29 funds were launched; six within the 42 months ending 30 September 2001. Although it might weaken the analysis, these six funds were analysed separately in order to allow for a reasonable analysis. These six funds exhibited similar patterns in the first few months of the funds' existence, as the results presented on page 54 indicate. In analysing the behaviour of the normal returns, frontended fees and funds' risk profile through time, all data points from the 23 funds were collected and adjusted to a common starting point, with month 1 being all the funds' first, fully completed month, month 2 representing the second month since the launch and so forth. These common data points were then averaged into a single dataseries reflecting the behaviour of most funds used in this part of the study. To test whether these findings, using the averaged data, applied to individual funds, the individual fund data-series were also analysed. With a few exceptions, the individual fund level results confirm the findings reported in Figure 3 (page 54) and are described thereafter. 


\section{Figure 3. Behaviour of selected variables over the first 24 months of the unit trusts' existence based on averaged data of all funds launched during the study period}

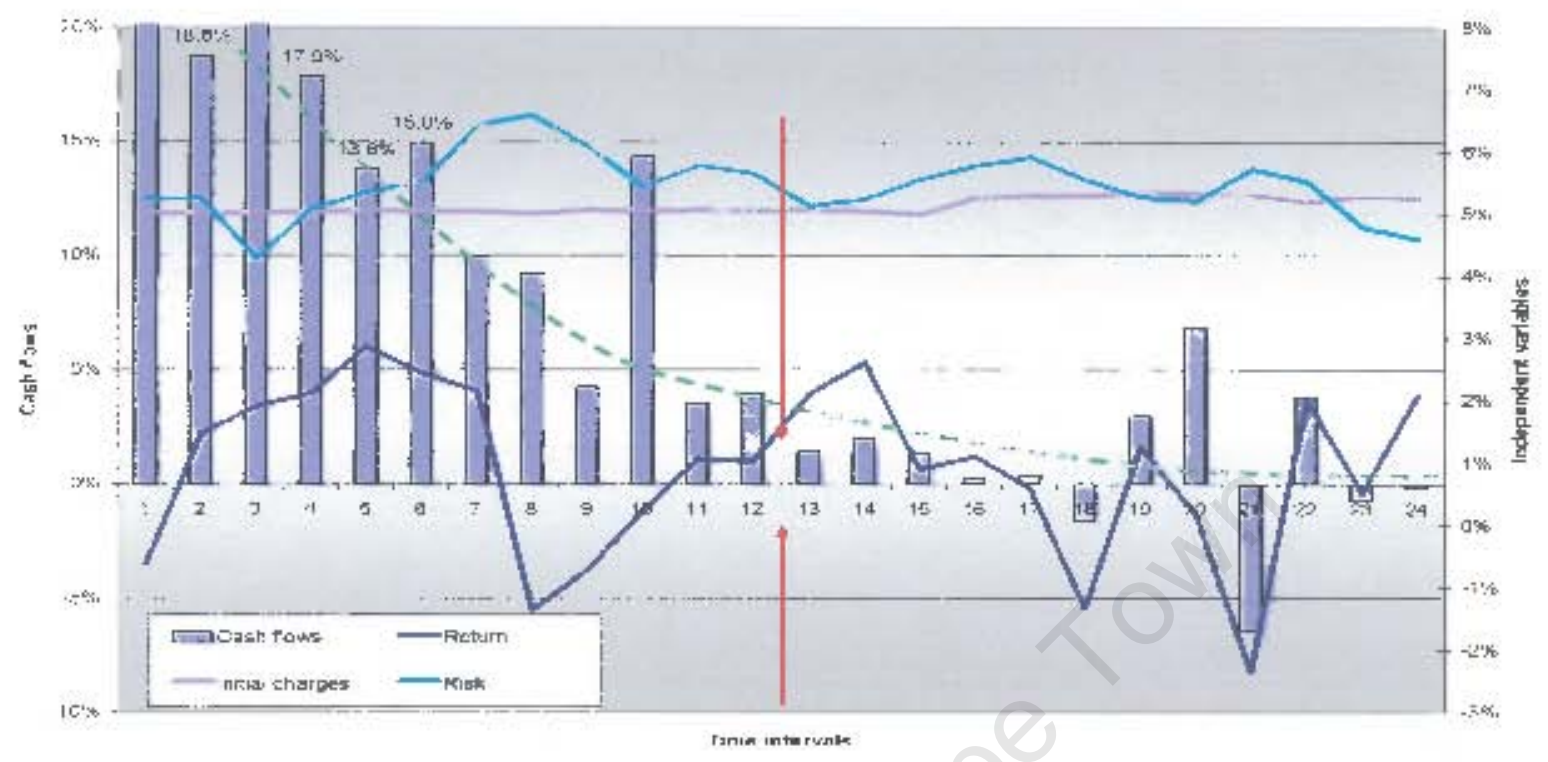

One of the most striking features in Figure 3 is the large decline in cash flows wittin the first eight to sixteen mionths of the funds' existence as shown by the dashed line. Furtherritore, most funds experienced cast inflows in the first year since their launch, irrespective of the funds sisk and retum profile. The large initial inflows arose in most cases due to large once-oft capital injections" into the funds, either within the first month after inception or shortly thereafter. During the first year of the funds' launch, the cash flows were very volatile. stabilising as time went on. The standard deviations of the monthly cash flows are 0.272 for the first 12 months, as opposed to 0.032 for the next 12 months. It could be argued that funds initially attracted institutional investors and investrinents driven by fund manager promises. As the funds developed track records, other investors contributed lo the funds consistently over time, placing more reliance on the funds history as indicated by a closer comovement between cash flows and returns from month 12 onwards. No relationstip is apparent with cast flows, over the first 12 months, after which a visual co-movement appears $\left\{R^{2}=36 \%\right)$. It is assonoted that not a single fund selected for this part of the analysis. experienced more than three months worth of cast outflows within the first six months of existence, regardless of performance. Returis appear to be stable over the 24 months with a standard deviation on average monttily returns of $1.5 \%$. Funds, initially experienced negalive retusns in the first month, followed by a couple of months of strong positive performances. During periods of increasing returns, the average monlhly fund sisk declined slightly, but it increased when the funds experienced downward returns. Transaction costs appear stable as expected. Cash inflows greater than $100 \%$ were removed from the data-series to test whether these laraje cast flows influenced the findings above. The pattem in the constructed cash flow data-series remained unchanged, wittı the high initial castı flows reducing over time. This resulted in the standard deviation in average monthly cass flows to declining from $10.53 \%$ to $2.65 \%$ for both consecutive 12 -month periods, also aligning cash flows and returns more closely.

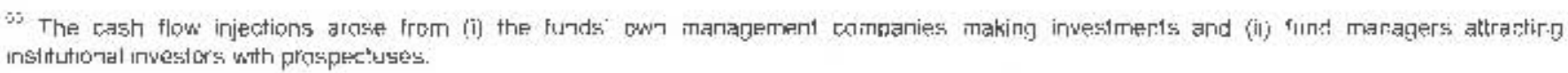




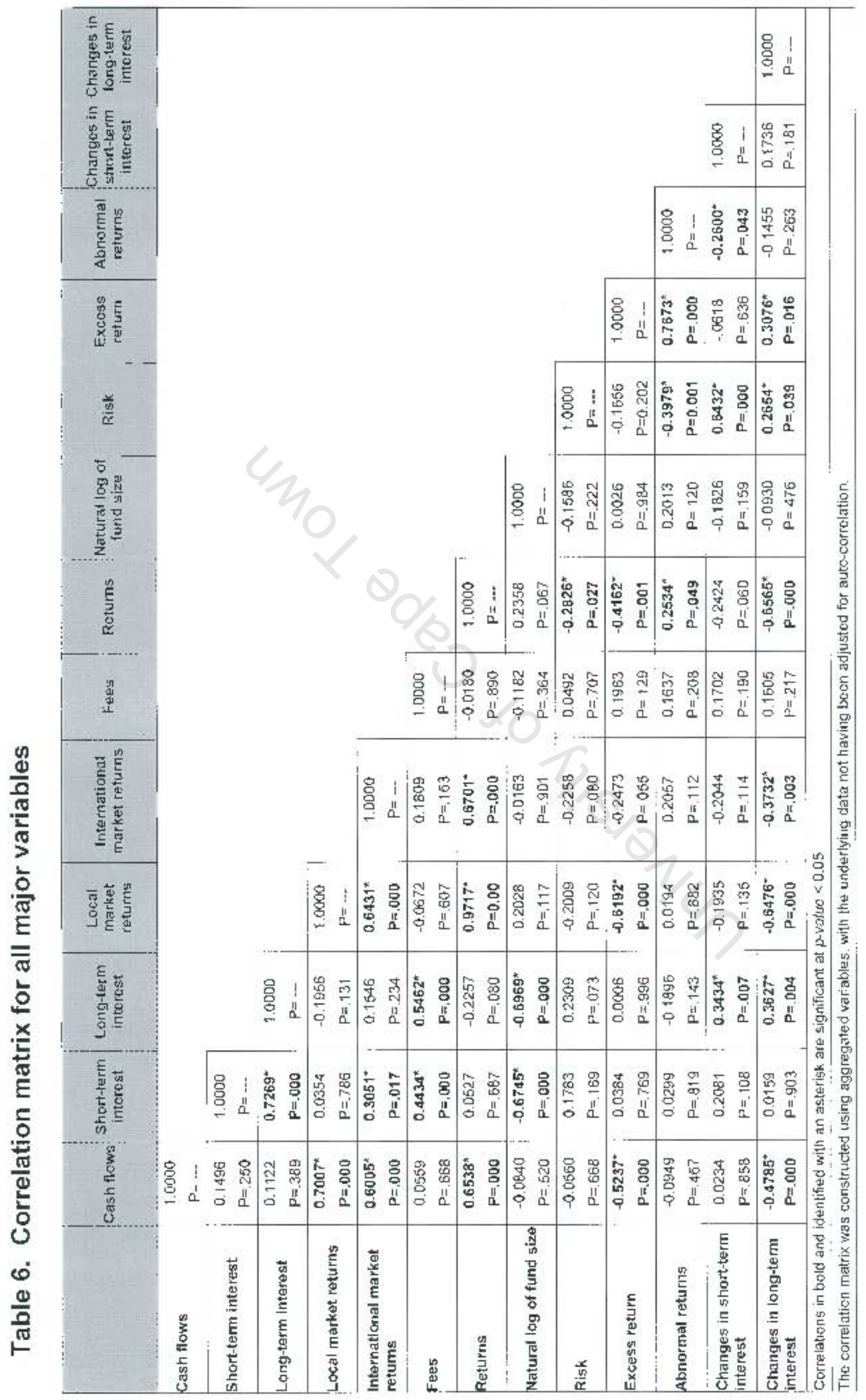

i势

| 


\subsubsection{Interaction between the independent variables}

The cross-correlations between the aggregated determinants are reported in Table 6 (page 55) with the significant correlations and related p-vatue, highlighted in bold and identified with an asterisk. Appendix $\mathrm{H}$ contains a nonparametric Spearman rank order correlation matrix, used to test the versatility of these results. Although the correlation coefficients in appendix $H$ changed slightly, the same determinants found to be significantly crosscorrelated, using the parametric matrix, were also correlated when using the non-parametric alternative. When evaluating the correlation between the various variables in Table 6 , it is apparent that there is a strong crosscorrelation between the various independent variables. This highlights the importance of using a stepwise linear regression approach.

\subsubsection{Market and fund performance indicators}

It is evident that market and fund returns are important determinants of aggregated cash flows. By virtue of the close influence international equity markets exert on local equity market returns $(r=0.64, p$-vatue $<0.05)$, returns on international equity markets impact on General Equity cash flows $(r=0,6, p$-value $<0.05)$. The correlation ( $r$ ) between aggregated cash flows and local market returns $(r=0.7, p$-value $<0.05)$ is higher than the aggregated cash flows' correlation with aggregated normal returns $(r=0.65, p$-value $<0.05$ ). This arises since aggregated returns on the General Equity unit trusts are closely correlated ( $r=0.97, p$-value $<0.05$ ) with domestic market returns. Thus, it appears that the returns on the ALSI have a greater explanatory power of cash flows compared to General Equity returns, even though this is, in fact, not the case. This arises since the average returns on the ALSI are higher and more volatile than the returns of the General Equity category ${ }^{66}$. Cash flows; on the other hand, as shown in Table 7 below also reflect high average cash flows and standard deviation. This results in a better correlation of market returns with cash flows, suggesting an over-estimation of the relationship. This is expected since General Equity funds have the mandate to invest in a wide spread of equities, forming a well-diversified portfolio, thus reducing the standard deviation of returns. Moreover, several of the funds attempt to replicate the ALSI. These results confirm local findings by Gilbertson and Vermaak (1982) and Knight and Firer (1989). This might also arise due to the aggregation process used.

\section{Table 7. Summary statistics of the monthly market variables}

\begin{tabular}{|c|c|c|c|c|c|c|c|}
\hline & Obs. & Average & Stc dev. & Min. & Min data & $\max$ & Max date \\
\hline Return on ALSI & 60 & $0.90 \%$ & $7.35 \%$ & $-29.48^{1 \%}$ & Aug-98 & $14.39 \%$ & Dct-98 \\
\hline Return on MCSI & 60 & $0.38 \%$ & $4.68 \%$ & $-13.45 \%$ & Aug -98 & $8.90 \%$ & Dct-98 \\
\hline Aguregated cash flows & 60 & $2,69 \%$ & $10.54 \%$ & $-30.70 \%$ & Alug-99 & $33.01 \%$ & Sep-98 \\
\hline GE category returns & 60 & $0.80 \%$ & $6.34 \%$ & $-27.75 \%$ & Aug-98 & $12.84 \%$ & Oct-98 \\
\hline GE category excess returns & 60 & $-0.10 \%$ & $1.91 \%$ & $-6.27 \%$ & Apr-99 & $3.96 \%$ & May- 98 \\
\hline GE category abnomal returns & 60 & $-0.12 \%$ & $1.48 \%$ & $-4.39 \%$ & Apr-99 & $3.35 \%$ & Fép-ges \\
\hline
\end{tabular}

\footnotetext{
thi The General Equity category consisis of fureds holding well-diversified portfolios it would be expected that it would have a lower risk and return than the ALSI. General Equity unit trus1s have a comparable composition with the ALSI, making it ar: appropriate benchmark. For example, unit trusts historically have beer: over-weighted towards resoutce stocks (Van Rensburg, 2002). whereas the JSE is influenced significantly by the mining and industrial sector (Bowie and Bradfield. 1993).
} 
Aggregated cash flows appear to be significantly negatively associated with excess aggregated returns on all General Equity unit trusts $(r=-0.52$, p-value $<0.05)$, although it does not present a significant correlation with abnormal returns. Abnormal returns have an insignificant negative relationship with cash flows and a significant negative correlation with risk. mainiy because both are stable indicators. Fees and fund size also show a correlation with the other stable variables.

\subsubsection{Short- and long-term interest rates}

There appears to be no apparent relationship between cash flows and the level of long-term interest rates. Considering changes in interest rates, rather than the level of interest, a concurrent negative relationship between cash flows and changes in long-term interest rates is evident. as shown by the calculated correlation coefficient of -0.48 ( $p$-value $<0.05$ ) indicating that when interest rates rise, market returns decline $(r=-0.64, p$-value $<0.05$ ). This is accompanied by cash outflows.

Short-term interest rates follow a similar pattern to that of long-term interest rates $(r=0.72, p$-value $<0.05)$, thereby reducing the possibility of a relationship between cash flows and short-term interest rates. A relationship does not exist between changes in short-term interest rates $(r=0.02, p$-value $=0.858)$. This could arise since longterm interest rates are used by financial analysts and the media as economic indicators, being freely available to and monitored by investors. Cash flows might also react to changes in long-term interest rates rather than shortterm interest rates, because long-term interest rates could be locked-in in the long-term, but not the short-term.

\subsubsection{Summary overview of fund characteristics}

The aim of the ranking analysis is to determine the extent to which a range could be identified in which the funds: characteristics are at their greatest, thus revealing the points where the funds' characteristics are consistently high in relation to cash flows across all funds. The cash flows from individual funds and related independent variables are summarised into equal quartiles. Quartile one (Q1) contains funds attracting the largest annual cash flows and quartile four (Q4) contains funds attracting the least annual cash flows. This is done for each year under investigation. to examine whether any trend is evident over time amongst the independent variables. Table 8 (page 58 ) presents the results. The normal return and risk measures represent the annulal performance and risk measures for the funds in the various quatiles as obtained from S\&P Micropal, whereas the fund size and fees measures contain the average fund size and fees over the year under consideration. The number of funds in the various quartiles is classified according to age. 


\section{Table 8. Summary overview of fund characteristics relative to cash flows}

\begin{tabular}{|c|c|c|c|c|c|c|c|c|}
\hline & & Cash filow & Northal return & Foes & $\begin{array}{l}\text { Age <24 } \\
\text { months }\end{array}$ & $\begin{array}{l}\text { Age }>24 \\
\text { months }\end{array}$ & Fund size & Rlsk \\
\hline \multirow{4}{*}{$\bar{్}$} & Q1 (Highesfi & $374 \%$ & $5.6 \div$ & $6.7 \%$ & 4 & 5 & 237 & $5.4 \%$ \\
\hline & Q2 & $-14.5 \%$ & $4.8 \times 1$ & $6.5 \%$ & $i$ & 9 & a2s & $5.7 \%$ \\
\hline & Q3 & $-2 i \cdot y^{4}$ & $-5 . \bar{x} x_{11}$ & E. 5 hi & $i$ & 9 & 275 & $5.9 \%$ \\
\hline & Q4 (1 cousti) & $.74 .5 \%$ & $-7.6 \%$ & $8.7 \%$ & 1 & 0 & 275 & $6.5 \%$ \\
\hline \multirow{4}{*}{ 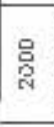 } & Q1 (t- ighes1! & $i^{2} 1.5^{\prime}$ & $21.3 \%$ & $8.2 \%$ & 8 & 3 & $22 ?$ & j.j\%: \\
\hline & 32 & $8.3 \%$ & $24.2 \%$ & $7.2 \%$ & 1 & 8 & 771 & $5.5 \%$ \\
\hline & 23 & $.111 \%$ & $22.0 \%$ & $6.7 \%$ & - & a & $10 \leq 7$ & B. 14 \\
\hline & Q4 Law'es: & $-32.9 v_{i}$ & $1<.3 \%$ & $7.5 \%$ & 2 & \$ & $39 \%$ & gro \\
\hline \multirow{4}{*}{$\begin{array}{l}\text { Wn } \\
\text { 总 }\end{array}$} & E1 IHıçhex:' & $125.5 \%$ & $502 \%$ & $6.6 \%$ & 5 & 2 & 135 & B) 3 't \\
\hline & Q2 & $15.5 \%$ & $15 B^{2} \%$ & $3.2 \%$ & 2 & 5 & $84 i$ & 544 \\
\hline & 23 & $-14.0 \%$ & $25.3 \%$ & $7.0 \% 0$ & - & 7 & 857 & $6.2 \%$ \\
\hline & Q4 (: oresen! & $.25 .3 \%$ & $10.4 \%$ & $i .2 \%$ & 1 & 5 & BJ5 & $35 \%$ \\
\hline \multirow{4}{*}{$\stackrel{\mathscr{9}}{\stackrel{9}{\mathscr{s}}}$} & $\mathrm{Q} \div$ iHigheat? & 21.24 & $.120^{11}$ & $3.1 \%$ & 1 & 4 & 616 & $120 \%$ \\
\hline & $\mathrm{Q2}$ & $-10.2 \%$ & $-24.8 \%$ & B. $\gamma \%$ & - & 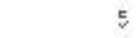 & $\$ 36$ & $11.1 \%$ \\
\hline & Q3 & $-13.4 \%$ & $-211 \%$ & $7.0 \%$ & - & 5 & 1230 & $107 \%$ \\
\hline & Q4 rlonvesti & $-23.1 \%$ & $-274^{\prime} K=$ & $7.0 \%$ & 1 & 1 & $5 \%$ & $: 04 \%$ \\
\hline \multirow{4}{*}{$\stackrel{\stackrel{g}{g}}{\stackrel{g}{\sigma}}$} & Q1 (Highest) & $7^{\circ} .6 \%$ & $24.2 \%$ & 6.78 & - & 4 & 1372 & $2.6 \%$ \\
\hline & $\mathrm{Q} 2$ & $127 \%$ & $44 \%$ & $6 \mathrm{G}^{\prime \prime} \mathrm{k}$ & - & 4 & 529 & 2.s \\
\hline & $\mathrm{Q}^{2}$ & $-1 \epsilon .5 \%$ & $7.4^{\prime \prime} \times$ & $\bar{c} 9 \%$ & . & 4 & 1504 & 2.35 \\
\hline & Q4 i: awesil) & $-41.6 \%$ & G.5\% & $7.0 \%$ & - & 4 & $2: 32$ & $\hat{2}, 9: 0$ \\
\hline \multicolumn{9}{|c|}{ 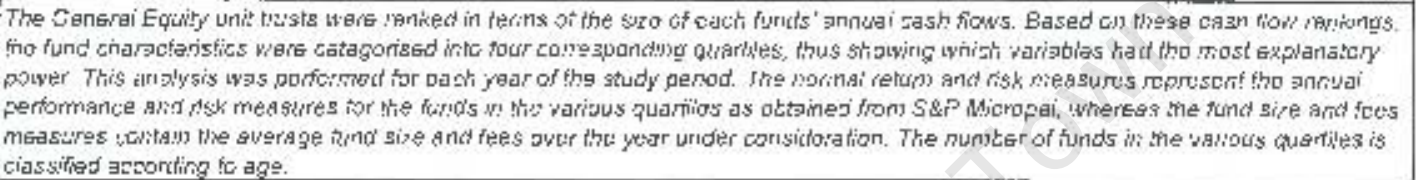 } \\
\hline
\end{tabular}

The relationship depicted in Table 8 is reflected graphically in Figure 4 (page 59), which summarises the information of each quartile into a five-year summary ${ }^{67}$. The figure shows the average annual measures over the five-year period. The bar graph shows the average fees, returns and risk over the five-year period for each quartile on the $x$-axis. The dashed line shows the five-year average cash flows per quartile. The primary $y$-axis shows the fees, returns and risk of the quartiles, while the secondary $y$-axis shows the measurements of the average cash flows.

It is evident that Q1 over the five-year period, repressenting the funds that attracted the largest cash flows, also generated the highest returns. The reverse holds for $Q 4$, it is noteworthy that throughout the analysis period: Q4 experienced caș oufflows, yet, only earned negative returns during 1998, when all the funds experienced negative returns, and during 2001, corresponding with two well-known market crashes. A further feature relates to the volatility in cash flows over the five years. The funds in $Q 1$ experienced the higheșt volatility in caș flows, matched by high volatility in returns. $Q 2$ and $Q 3$ funds attracted more stable cash flows and returns as previously noted. This iarge volatility could be partially attributed to volatile market returns.

The largest funds tended to attract medium level cash flows as represented by $Q 2$ and $Q 3$. With the exception of 2001 , it appears that funds within $Q 1$ had slightly lower transaction costs than funds in $Q 4$. When the five years are consolidated in Figure 4, this trend becomes clearer. Funds in $Q 1$ had an average tee of $6.4 \%$ compared to $Q 4$ with an average fee of $7.1 \%$. No noticeable dynamic, exists between cash flows and the funds: age or between risk $^{68}$ and cash flows. An exception is during 2DD1, 2000 and 1999 when the funds younger than two years old, are concentrated around $\mathrm{Q} 1$.

\footnotetext{
bi The findings correspond to a similar figure constructed by researchers such as Sirri and Tuiano (1998) and Del Guercio and Tkac (2002) showing the convex relationship between cas h flows and performances. This is discussed in section 4.3.

Garri and Tufano (1998) found a similar, yet more persuasive pa!tern, when they plotted the same information, including more funds in their analysis. Their findings revaled that parformance showed an upward sloping curve, while fees showed no trend. Risk on the other hand
} 


\section{Figure 4. Five-year summary of the annual fund characteristics relative to annual cash flows ${ }^{69}$}

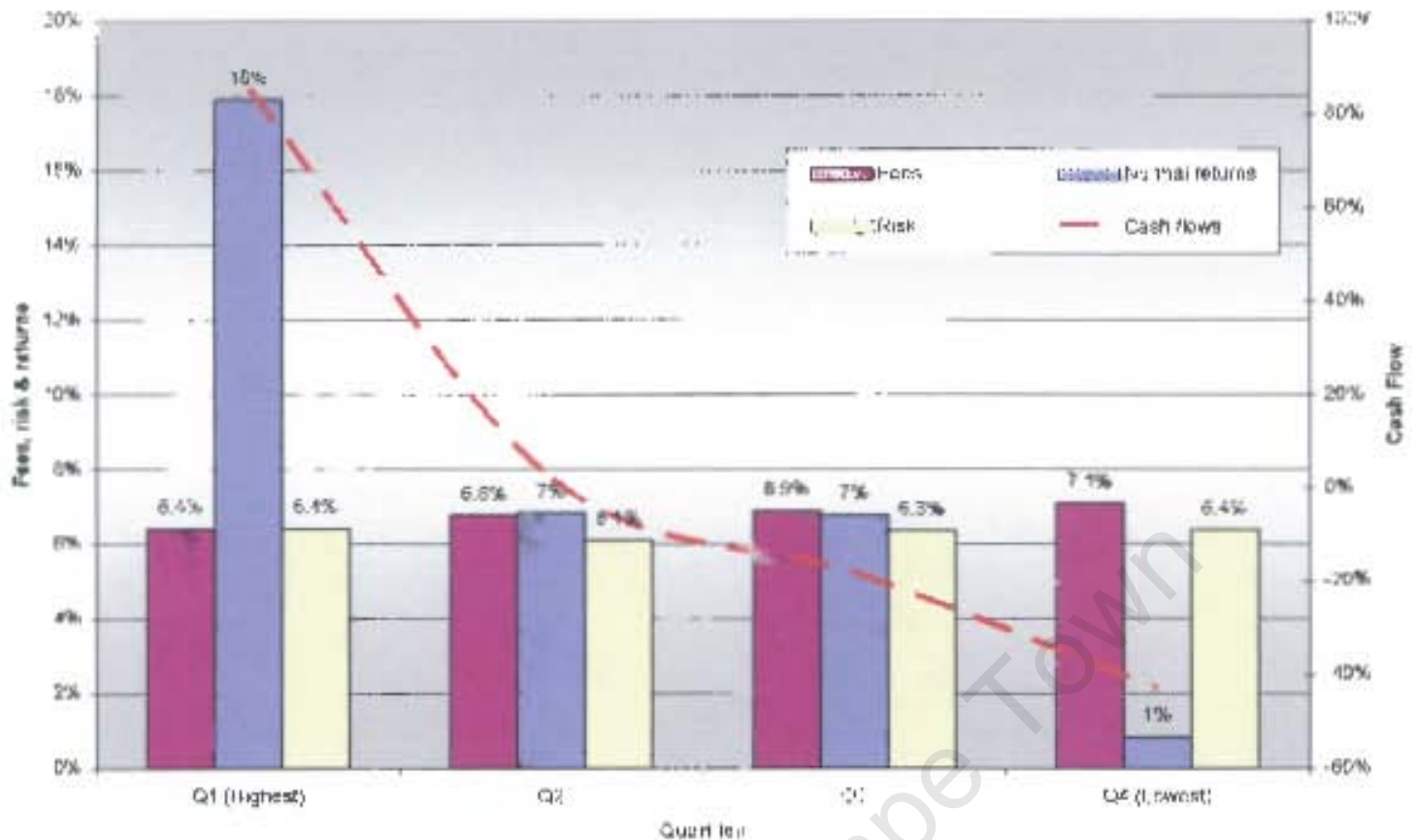

\subsection{Asymmetric investors' behaviour}

The analysis investigates the asymmetric bias investors exhibit towards top performing funds (section 4.3.1) and towards positive, rather than negative return events (section 4.3.2). The overall research anaiysis concentrates on normal retums, suppiemented by excess and abnormal pertormance measures.

\subsubsection{Disproportionate investment in the top performing funds}

A time-series and a cross-sectional approach were used to investigate whether investors invest disproportionately in the best performing funds.

\subsubsection{Time-series asymmetric analysis}

Table 9 (page 60 ) indicates that investors might not necessarily be attracted exclusively to the best performing funds. The funds were grouped into three performance regions in terms of the methodology discussed in section 3.6 and regressed against their corresponding cash flows.

orected a U-shepe with Q1 and Q4 being higher thar Q2 and Q3. The analysis presen:cu above vas weaket since lewer funds were included B) Ihe slidy

9M Fi:e normal retum ard risk measurcs repxcsent the anrial performance und risk measures for the furds in the various quartiles as obteinet trom S\&P Micropsl, whereas the fJnd size and fecs measures ocntain the avcrige furd size erat lees over the yeat under consideration. Fhe nuriber at funds in the varlous auartiles is classified arcordirg to agc. 


\section{Table 9. Regression results highlighting investors' asymmetric response through time for the three performance regions}

\begin{tabular}{|c|c|c|c|c|c|c|c|c|c|}
\hline \multirow[b]{2}{*}{ Perfommance reglons } & \multicolumn{3}{|c|}{ Panal A: Nommal return } & \multicolumn{3}{|c|}{ Panel é Excess roturil } & \multicolumn{3}{|c|}{ 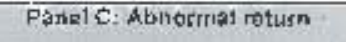 } \\
\hline & $\begin{array}{l}\text { High } \\
\text { (1) }\end{array}$ & $\begin{array}{l}\text { Medium } \\
\text { (2) }\end{array}$ & $\begin{array}{l}\text { Law } \\
\text { \{3\} }\end{array}$ & $\begin{array}{c}\text { High } \\
\text { t1t }\end{array}$ & $\begin{array}{l}\text { Medium } \\
\text { (2) }\end{array}$ & $\begin{array}{l}\text { Low } \\
\text { (1) }\end{array}$ & $\begin{array}{l}\text { High } \\
\text { (1) }\end{array}$ & $\begin{array}{c}\text { Medium } \\
\{2\}\end{array}$ & $\begin{array}{l}\text { Low } \\
\text { (3) }\end{array}$ \\
\hline \multicolumn{10}{|l|}{ Eeta soetticients } \\
\hline Cons:ant & $\begin{array}{r}0033 \\
(0.52 \%)\end{array}$ & $\begin{array}{r}0042 \\
(1000)\end{array}$ & $\begin{array}{r}0.200 \\
(1452)\end{array}$ & $\begin{array}{c}0.226 \\
(2.911 ;\end{array} \quad \cdots$ & $\begin{array}{r}0.207 \\
(0.806)\end{array}$ & $\begin{array}{r}0.244 \\
(0.445)\end{array}$ & $\frac{0.205}{(2.331)}$. & $\begin{array}{r}0.075 \\
(0.324)\end{array}$ & $\begin{array}{c}0665 \\
\text { (a.sot) }\end{array}$ \\
\hline Periermiance pgion & $\frac{1.254}{(7.663)}$ & $\begin{array}{r}1.009 \\
\text { (5.160) }\end{array}$ & $\begin{array}{r}1.068 \\
(2.886)\end{array}$ & $\begin{array}{r}-2.648 \\
(-4.640)\end{array}$ & $\begin{array}{c}-2.932 \\
(-4.713)\end{array}$ & $\begin{array}{r}0.4 .56 \\
80.457\end{array}$ & $\begin{array}{r}1.341 \\
(1.419)\end{array}$ & $\begin{array}{r}0652 \\
(0.682)\end{array}$ & $\begin{array}{r}-0.24 \\
i-0.52 \%\end{array}$ \\
\hline $\begin{array}{l}R^{2} \\
\text { Mdi Q2 } \\
\text { p-vaho }\end{array}$ & $\begin{array}{l}0.512 \\
0.503 \\
0.000\end{array}$ & $\begin{array}{l}0.352 \\
0.361 \\
0.000\end{array}$ & $\begin{array}{l}0165 \\
0.146 \\
0.006\end{array}$ & $\begin{array}{l}0.271 \\
0.255 \\
0.000\end{array}$ & $\begin{array}{l}0475 \\
0228 \\
0.000\end{array}$ & $\begin{array}{l}0.075 \\
0.005 \\
0650\end{array}$ & $\begin{array}{l}0.934 \\
0.917 \\
0151\end{array}$ & $\begin{array}{r}0.009 \\
-0.909 \\
0.499\end{array}$ & $\begin{array}{r}0.012 \\
-\square 005 \\
0.412\end{array}$ \\
\hline $\begin{array}{l}\text { Durbir-Wetson } \\
\text { Obs. }\end{array}$ & $\begin{array}{r}1.555 \\
60 \\
\end{array}$ & $\begin{array}{r}1.836 \\
50 \\
\end{array}$ & $\begin{array}{r}2.0 \% 9 \\
50 \\
\end{array}$ & $\begin{array}{r}2.2 \mathrm{Eg} \\
60 \\
\end{array}$ & $\begin{array}{r}2.257 \\
60\end{array}$ & $\begin{array}{r}2045 \\
60 \\
\end{array}$ & $\begin{array}{r}1721 \\
50 \\
\end{array}$ & $\begin{array}{c}2.275 \\
80\end{array}$ & $\begin{array}{r}2.39^{\circ} \\
60 \\
\end{array}$ \\
\hline \multicolumn{10}{|c|}{ 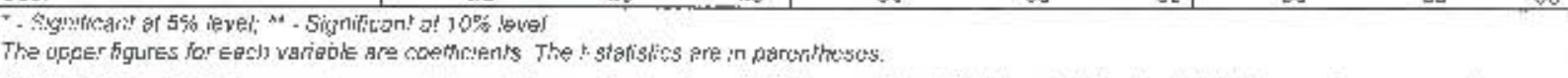 } \\
\hline \multicolumn{10}{|c|}{ 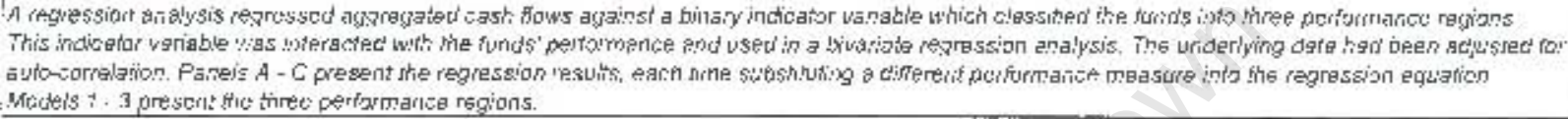 } \\
\hline
\end{tabular}

Regardless of the normal return performance region (panel A), each region's cash flows are significantly correlated with the respective performances at a $5 \%$ significance level. The coefficient of determination presented in panel $A_{1}$ indicates that the relationship is the strongest for funds within the high normal return performance region (A. 1) with a $R^{2}$ of 0.51 , compared to the lowest performance region (A.3) with a $R^{2}$ of 0.16 . This shows that, although all the relationships are significant: the relationship is the strongest for the funds with the highest return. These coefficients of determination are reduced slightly, although still high, when they were adjusted for degrees of freedom. This $\mathrm{R}^{2}$ suggests that the higher the performance, the more cash flows are attracted to the funds, while low return funds still attract investors' monies.

When considering the regression coefficient, regardless of the performance measure, the asymmetric responses, documented in earlier studies, are apparent from the fact that the regression coefficient (1.25) for the high performance region (A.1) is larger than the other regions. Interestingly: the difference in size between the three models' regression coefficients is not as large as those found by Fant and O'Neal (2000).

A similas, yet less significant dynamic exists when the test was re-performed using the funds' excess and abnormal returns (panels $B$ and $C$ ). A significant relationship exists for funds that earned medium to high excess returns $\left(R^{2}\right.$ $=0.47$ [B.2]; 0.27 [B.1] respectively, $p$-value < 0.05 ) with the cash flows they attract. This, however, coes not appear to be the case when considering abnormal returns (panel C). A decline in the coefficient of determination is evident when evaluating the high to low performance regions regardless of the performance measures used. Fant and O'Neal (2000) documented differently and found that the medium and low abnormal performance regions are significant. The analysis was reperformed on an individual fund basis. The findings confirmed those above and consequently are omitted. 


\subsubsection{Cross-sectional asymmetric analysis}

The findings, reported in section 4.3.1.1, suggest that the investors are biased towards top performing funds. This section endeavours to provide evidence that investors do indeed invest proportionately more in the top performing funds, while at the same time tend to ignore poor performing funds. The coefficient on each of these variables, shown in Table 10 (page 62), represents the marginal cash flow response to performance within the investment objective. Each year's observation is discussed separately in context over the five-year period covered by the research. The five-year average column reports the mean of the coefficients and $t$-statistics.

Table 10 is separated into two sections. Panel A presents the explanatory power of each of the three performance regions independently, using a cross-sectional bivariate regression approach. Panel B considers the performance regions explanatory power collectively, using a cross-sectional multivariate approach. This separation is necessary, since investors evaluate funds performances in context with the performances relative to all the other funds collectively and to the funds earning a similar level of performance (Kliger and Sonsino. 1999). 
Table 10. Regression results showing investors' asymmetric response across funds on annual cross-sectional regression analysis

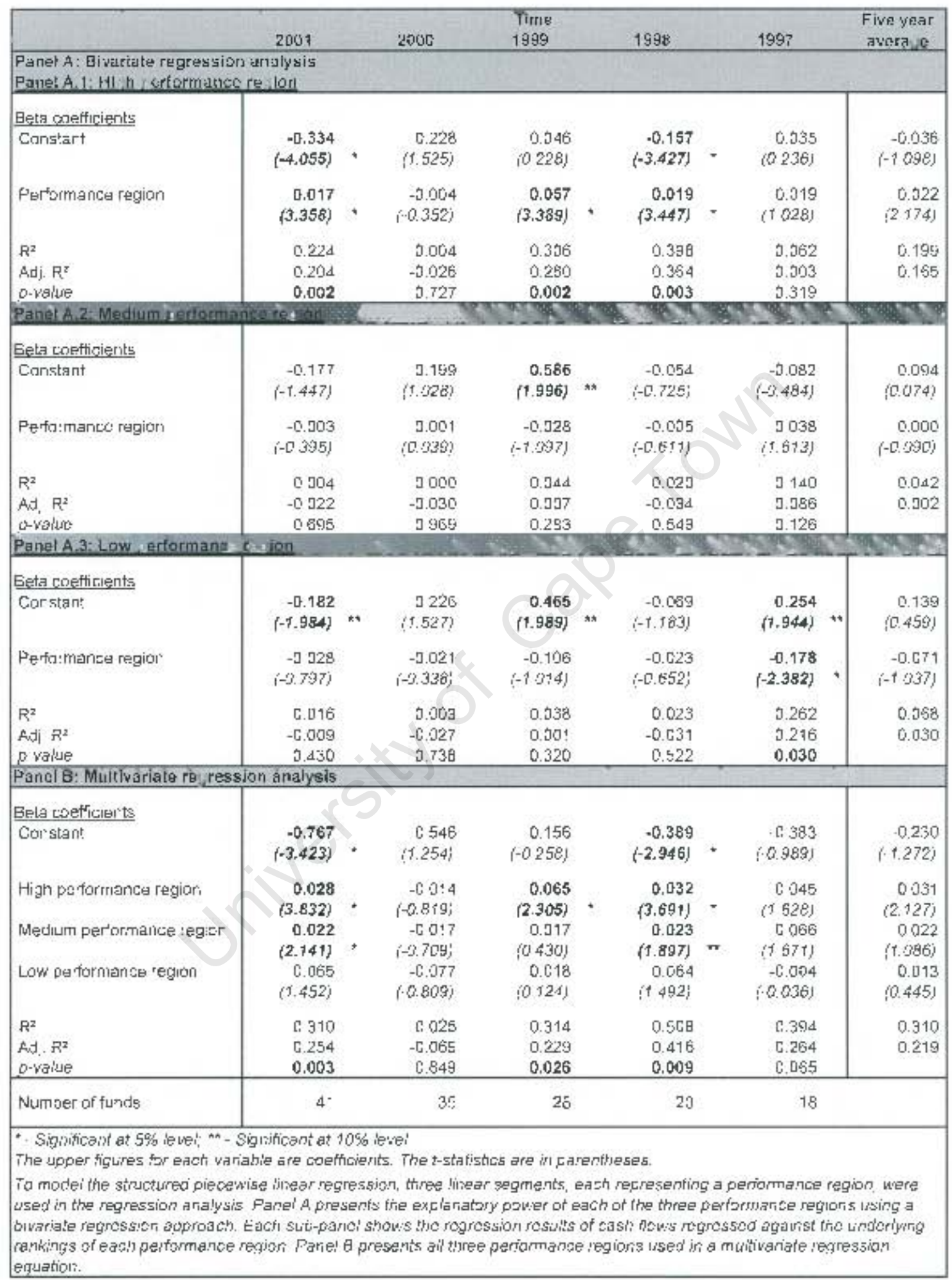


As expected, this analysis provides weak results when the bivariate (panel A) and multivariate (panel B) regression equations are used. Only 2001, 1999 and 1998 provide any significant explanation for the high performance funds, with neither 2001. nor 1997 being significant with a p-value of 0.8488 and 0.0646 respectively, when a bivariate regression equation is used. There is no significant trend in the coefficient of determination for the regression performed on the top performing funds, except that they appear to be higher than the other regions. No crosssectional relationship exists between cash flows and performance of the medium and low performing funds: regions, when using a multivariate regression technique.

The regression and correlation coefficients of the high performance region do appear to be larger than those of the low performance region, but are not significant. The multivariate results confim the bivariate regression results: with the same key features. The regression coefficients of the medium to low performance regions are in fact negative in most instances as estimated by Sirri and Tufano (1998). These results indicate that the marginal cash flow response to performance is greater for the average fund included with the top performing funds although the results are not significant. The analysis was re-performed, using excess and abnormal performance measures. No significant relationships are reported; consequently, the findings are omitted.

The overall conclusions of these time-series and cross-sectional analyses (although not being significant) highlight the same non-linear relationship between cash flows and returns similar to those documented by Sirri and Tufano (1998) and Fant and ONeal (2000). This suggests that investors might invest the largest portion of cash flows in top performing funds. but fail to divest from the poor performing funds.

\subsubsection{Directional changes in performance}

The previous sections established that cash flows are more correlated with returns from the best performing funds than the poorer funds. The analysis shifted towards the asymmetric response by investors when funds exhibit positive and negative returns during a particular month. A significant relationship at the $5 \%$ level exists between cash flows and normal (panel 1) and excess return events (panel 2) but no relationship exists with abnormal return events (panel 3) as displayed in Table 11 (page 64). 
A similar phenomenon of negative coefficients exists for abnormal return events (panel 3) and cash flows, although it is not significant and is similar to findings by Edelen (1999). This may be due to the impact of transaction costs on abnormal returns or the fact that South African investors do not have access to sophisticated performance information on a real-time basis.

\subsection{Determinants of aggregated cash flows}

Table 12 and Table 13 (page 66) present the results for the regression models constructed, using cash flows and other independent variables adjusted for auto-correlation, where applicable. All the independent variables are contemporaneous, except for performances, which are also lagged by one month. Each independent variable was tested using a bivariate regression technique, followed by a multivariate regression approach. The muitivariate analysis findings were tested for resilience, by means of a stepwise linear regression analysis. The same independent variables identified by the multivariate analysis, are also significant: when conducting the stepwise regression analysis: thus adding rigour to these findings. The stepwise regression analysis results are consequently presented in appendix I.

\section{Table 12. Regression results between cash flows and independent variables}

\section{using a bivariate regression technique}

\begin{tabular}{|c|c|c|c|c|c|c|c|c|}
\hline 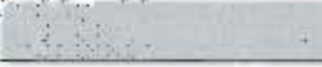 & Constant & $\begin{array}{l}\text { Botaco- } \\
\text { efflclents }\end{array}$ & $\mathbf{R}^{\mathbf{x}}$ & Ad], $R^{2}$ & p-value & & $\begin{array}{l}\text { Durbin- } \\
\text { Watson }\end{array}$ & Obs. \\
\hline \multicolumn{9}{|l|}{ Independent variables } \\
\hline Short-term interest & $\begin{array}{r}-0.006 \\
(-0.295)\end{array}$ & $\begin{array}{l}42.871 \\
(1.155)\end{array}$ & 0.022 & 0.006 & 0.253 & & 2.347 & 80 \\
\hline Long-term interest & $\begin{array}{r}-0.017 \\
(-0799)\end{array}$ & $\begin{array}{l}-92.909 \\
(-2.891)\end{array}$ & 0.124 & c. 109 & 0.054 & *n & 2.229 & 80 \\
\hline Losal market retums & $(-0.543)$ & $\begin{array}{r}1.222 \\
(8.852)\end{array}$ & 0.570 & 0.563 & 0.000 & . & 2.040 & $6 \mathrm{C}$ \\
\hline Intemational marke: returns & $(-0.029)$ & $\begin{array}{l}1.44 \mathrm{~B} \\
(5.204)\end{array}$ & 0.315 & 0.303 & 0.000 & * & 2.322 & 60 \\
\hline Normal re:tm & $\begin{array}{c}-0000 \\
(.0 .533)\end{array}$ & $\begin{array}{r}1.416 \\
(6,027)\end{array}$ & 0.522 & 0.514 & 0.000 & $\cdot$ & 2.002 & BO \\
\hline Lagged nermal return & $\begin{array}{c}-0.050 \\
(-0.600)\end{array}$ & $\begin{array}{r}-1.531 \\
(-9.274)\end{array}$ & 0.593 & 0.586 & 0.000 & - & 1.943 & BD \\
\hline Excess retuin & $\begin{array}{l}-0.009 \\
(-0485)\end{array}$ & $\begin{array}{r}-3.656 \\
-5.744)\end{array}$ & 0.369 & 0.348 & 0.000 & . & 2.208 & 60 \\
\hline Lagged exceas return & $\begin{array}{r}-0.009 \\
(-0.497)\end{array}$ & $\begin{array}{r}3.381 \\
(5.046)\end{array}$ & 0.301 & 0.290 & 0.000 & - & 2.221 & 60 \\
\hline Abnormal return & $\begin{array}{l}-5235 \\
(-0371)\end{array}$ & $\begin{array}{r}-0.473 \\
(-0.455)\end{array}$ & 0.003 & -0013 & $065^{\circ}$ & & 2.297 & 65 \\
\hline Laggec abnormal return & $\begin{aligned} &-0.205 \\
&(-0.371)\end{aligned}$ & $\begin{array}{r}0.734 \\
(0707)\end{array}$ & $0.00 \mathrm{~B}$ & -0.008 & 0482 & & 2.281 & 60 \\
\hline Lagged cash flow & $\begin{array}{r}-9.009 \\
(-0519)\end{array}$ & $\begin{array}{r}-0.541 \\
(-5.305)\end{array}$ & 0.323 & 0.311 & 0.000 & . & 2.031 & 60 \\
\hline Fees & $\begin{array}{l}-0.011 \\
(-0.489)\end{array}$ & $\begin{array}{r}-8.816 \\
(-0.626)\end{array}$ & 0.307 & 3.010 & ధ.534 & & 2.352 & 60 \\
\hline Risk & $\begin{array}{r}-0.011 \\
(-0.491)\end{array}$ & $\begin{array}{r}1.114 \\
(1.157)\end{array}$ & 0.022 & $0 \mathrm{c56}$ & 0252 & & 2.346 & $B D$ \\
\hline Fund size & $\begin{array}{r}-0.012 \\
0.563)\end{array}$ & $\begin{array}{r}-0.624 \\
-2.080) \\
\end{array}$ & 0.068 & 0.053 & 0.084 & $\leftrightarrow$ & 2.155 & 60 \\
\hline $\begin{array}{l}\text { * Significant at } 5 \% \text { level; } \\
\text { The upper figures for each ve }\end{array}$ & lificant at s & $\begin{array}{l}\text { Ox fevel } \\
\text { cients The }\end{array}$ & itisticas & in pare & eses. & & & \\
\hline
\end{tabular}


Local and international market returns, the three fund characteristics including contemporaneous and lagged returns and lagged cash flows, are found to be highly correlated with aggregated cash flows. Table 12 presents the regression coefficients derived by using the bivariate regression model, with all significant regression coefficients marked in bold. Market returns and General Equity category returns both have a coefficient of determination $\left(\mathbf{R}^{2}\right)$ in excess of $50 \%$, with local market returns having a higher coefficient of determination than aggregated General Equity returns. This disparity noted initially in section 4.2.3.1, resulted in the multivariate regression analysis being conducted in three stages as detailed in Table 13. An analysis was performed using only the market indicators (panel A), then a multivariate analysis was performed based on only the fund characteristics, each time using a different performance measure (panel B) and finaily all the independent variables were used in a multivariate regression model, using each performance measure (panel $C$ ).

The results of Table 12 and Table 13 are discussed in the following sections, starting with the relationship between local market returns and aggregated cash flows.

\section{Table 13. Regression results between cash flows and independent variables} using a multivariate regression technique

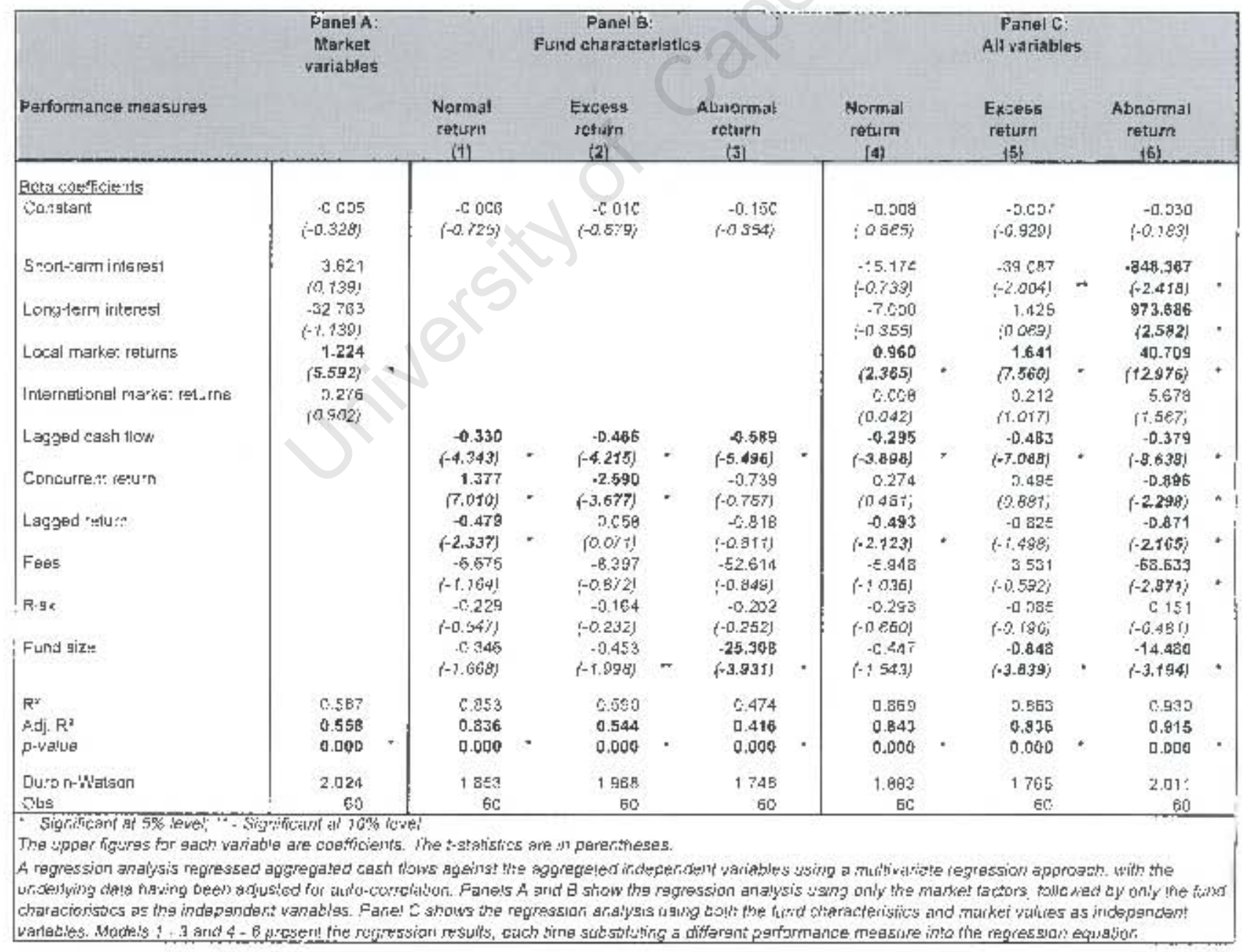




\subsubsection{Interaction between market returns and General Equity returns}

The high coefficient of determination for market returns and General Equity category returns arises from the fact that the General Equity category tracks market returns. Furthermore, General Equity unit trusts are sensitive to the same factors as the ALSI. Although these arguments might have a valid basis, the significant correlation with cash flows appears to be anomalous. Where the investigation concentrates on the relationship for individual funds, it is expected that the explanatory power of market returns would decline significantly. The conflicting findings between market returns and General Equity returns require the analysis to split market returns and fund characteristics, evaluating them in separate multivariate regression models in panels $A$ and $B$ respectively. When this is done, it becomes apparent that the market factors only explain $55 \%$ of the variation in cash flows, compared to $83 \%$, if normal returns are used in conjunction with the other fund characteristics. It is intuitively apparent that the contribution of local market returns, in explaining the variation in cash flows, becomes insignificant. When these variables are combined in panel $C$, an adjusted coefficient of determination (Adj. $R^{2}$ ) of 0.84 is achieved, with local market returns taking prominence again. As previously indicated, this occurs due to the correlation between local market returns and the General Equity category returns.

Another co-movement between international market returns and aggregated cash flows is expected due to South Africa's exposure to the influence of international developments and international patterns. International market returns, which initially, as part of the bivariate analysis, showed an Adj. $R^{2}$ between cash flows and international market returns of 0.30 , add no additional explanatory power, once local market returns and international market returns are considered as part of the multivariate model (panel A). This confirms reasoning presented earlier that, although international returns represented a significant correlation at a $5 \%$ significance level, there is relatively little co-movement between these cash flows and international market returns, with most of the variation in cash flows being explained by local market returns. The results support the conclusion that international market returns would not explain a significant proportion of cash flows.

\subsubsection{Excess returns}

Table 12 shows the significant negative regression coefficient, which is associated with the excess returns' independent variable (Adj. $R^{2}=0.35, p$-value $<0.05$ ) while being positive when considering lagged excess returns. The second regression results in Table 13 , panels $B .2$ and $C .5$ contain the multivariate regression results, substituting excess returns for normal returns. This corroborates the bivariate findings presented earlier (Table 12), however, it presents a less significant relationship. Lagged excess returns are now not significant when considered in context with the other independent variables. Excess returns become insignificant, with local market returns, acting as a proxy for normal returns, influencing regression results. When only fund characteristics are evaluated (panel B), lagged cash flows and concurrent excess returns contribute $54 \%$ (panel B.2), highlighting the importance of normal returns and the investors' reliance on returns as opposed to a single predetermined benchmark. 


\subsubsection{Abnormal returns}

The substitution of abnormal returns into the model (panels B.3 and C.6) adds no additional explanatory power as part of a bivariate or a multivariate analysis, potentially introducing bias into the findings since only funds older than three years were considered during this part of the analysis. As discussed in section 4.2 .1 , cash flows to these old funds were stable. Moreover, the older funds tended to earn negative risk adjusted returns with a low standard deviation. This gives rise to the higher correlation.

The results in Table 12 and Table 13 show an insignificant negative abnormal return regression coefficient and contradict the findings by Rockinger (1995) and Edelen (1999). Gruber (1996), Sirri and Tufano (1998), Jain and Wu (2000) and Del Guercio and Tkac (2002) showed that investors use simple and more complex performance measures subject to constraints, when making investment decisions. The results in Table 13 indicate that when investors are paying attention to the sophisticated models, they also consider various other information - relating to the independent variables. Interestingly, the results provide the same explanatory power as if investors were only considering normal returns and cash flows, when deciding to allocate their cash. It must also be pointed out that lagged cash flows might not be available, thus making the large quantity of information important. In South Africa, it would be expected that abnormal performances would drive investment decisions, given the high institutional investor concentration. The results seem to suggest that the opposite might be true.

\subsubsection{Lagged performance and cash flows}

Contemporaneous and lagged returns and lagged cash flows add significant explanatory power towards the variation in cash flows. These two lagged variables have negative regression coefficients of -1.53 for lagged normal returns and -0.54 for lagged cash flows as shown in Table 12 . These features remained when multivariate regression analysis was performed.

The negative coefficient of lagged returns ${ }^{71}$ is in contrast with the positive relationship predicted by the feedbacktraders hypothesis, but is consistent with findings by Gruber (1996), Santini and Aber (1998), Fant (1999) and Potter (2000) who reported a significant positive concurrent performance relationship and a significant negative relationship between lagged performances using bivariate and multivariate regression models. Sections 2.5 .1 and 2.5.4 present possible reasons for the negative lagged relationship.

South Africa is a developing country, therefore, a positive lagged cash flow relationship is expected, yet, the findings above show otherwise. Warther (1995) and Edelen and Warner (2001) presented negative regression coefficients.

\footnotetext{
${ }^{71}$ Intuitively, the negative coefficient arises from investors buying units during periods of increasing returns. This is followed by attempts to lockin higher performances in the previous month by shifting money to other investments and vice versa.
} 


\subsubsection{Interest rates, fee structures, risk and fund size}

Neither short- ${ }^{72}$, nor long-term interest rates show any significant relationship. Long-term interest rates add more explanatory power towards explaining cash flows than short-term interest rates, improving the Adj. $R^{2}$ by approximately $10 \%$ (Table 12). Cash flows are negatively related to long-term interest rates at a $10 \%$ significance level. The results conform to expectations because the South African Reserve Bank follows an inflation targeting policy. This negative relationship could be attributed to the shape of the inverted yield curve. These results do not reflect the expectation by Santini and Aber (1998) that investors substitute equity investment for long-term fixed income investments when long-term interest rates change. Similarly, as expected, this substitution effect does not occur for short-term interest rates.

Fees in Table 12 and Table 13 show an insignificant negative regression coefficient at a $5 \%$ significance level. This negative relationship reflects investors' elasticity of demand with respect to the price asked by management companies for their services when fees increase and cash flows decline. Intuitively, these findings corroborate the results discussed in section 4.2.4. In these results it appears that funds in Q1 attracting the largest cash flows, have lower fees and vice versa.

Risk appears to add neither additional explanatory power to the cash flow models when considering them individually (Adj. $R^{2}=0.005$ [Table 12]), nor as part of a multivariate model (Table 13). The negative regression coefficient suggests that smaller funds enjoy the larger percentage of cash flows.

However, no conclusive deduction could be made from the significant relationship noted. This corroborates findings by Rockinger (1995), Berkowitz and Kotowitz (2000), Torre and Garcia (2002) and James and Karceski (2002) that show little concern for transaction costs and risk structures as indicated by the insignificant regression coefficients.

\subsubsection{Conflicting findings}

Several studies discussed in chapter 2 provide mixed evidence in respect of a positive or negative relationship and the explanatory power of each independent variable. This could arise from (i) the method used for variable specification and (ii) the combination with other variables in the context in which they were used and (iii) the methodology employed. The coefficient of determination in this dissertation is higher than those reflected in other studies conducted in developed markets. This confirms findings by Froot et al. (2001) that the results are more significant in emerging markets as opposed to developed markets. Warther (1995) employed a single performance measure to reach $R^{2}$ of 0.55 . Santini and Aber (1998) employed several performance measures and market information and improved the explanatory power to $0.66\left(R^{2}\right)$. Potter $(2000)$ employed a similar time-series methodology to that referred to in section 4.4 and noted an Adj-R $R^{2}$ of 0.904 in the US.

\footnotetext{
${ }^{72}$ Warther (1995), Ferson and Warther (1996), Santinl and Aber (1998) and Potter and Schneeweis (1998) provided no evidence of the relationship between cash flows and short-lem interest rates.
} 


\subsubsection{Age control group}

A control group approach and an indicator variable approach were used in analysing the influence of funds' age on cash flows. The results from the latter approach are discussed in section 4.5.1. The control group approach entails aggregating the funds under investigation into two separate groups: funds older than 36 months and younger funds. Time-series cash flows and normal and excess returns were regressed against each other ${ }^{73}$ for these grouped funds. Abnormal returns were not considered: as 36 months' worth of data is required to calculate reliable betas A comparison of the data-series revealed a different number of data points, thus it was necessary to consider Adj. $R^{7}$, which considered the differences in degree of freedom. The Adj. $R^{2}$ is only slightly weaker than the conventional coefficient of determination.

\section{Table 14. Age control group regression analysis results}

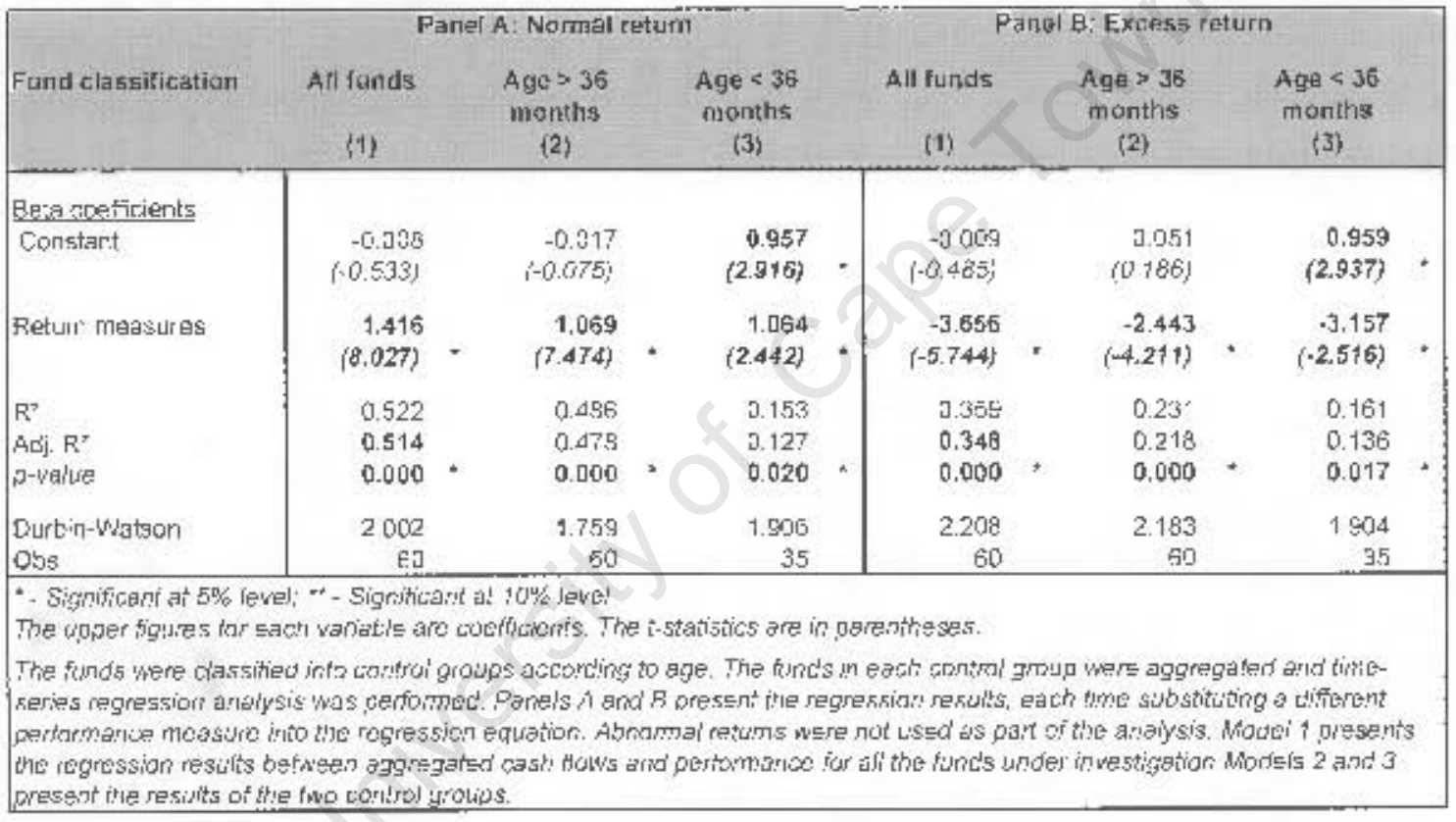

Table 14 shows that the cash flow-performance relationship improves slightly when the younger funds are removed from the sample. Both normal and excess returns (panels $\mathrm{A}$ and $\mathrm{B}$ ) are significantly correlated with cash flows for the funds older and younger than 36-months. The Adj. $R^{2}$ improves significantly for older funds (panels $A .2$ and B.2). For normal returns (panel A). the Adj. $R^{2}$ improves by 0.35 when considering older funds as opposed to younger funds. The conclusion is that fund performance history is important in attracting future cash flows. This improvement in correlation might possibly be due to the different number of data points utilised for the two series being compared ${ }^{74}$. A further reason might be due to the significant cash injections younger funds received during their first year of operation as reported earlier in section 4.2.2. These outliers might distort the relationship between cash flows and performances. The regression coefficients are similar (slightly higher) for the two normal return series (panels A.2 and A.3), whereas the opposite is true for excess returns.

\footnotetext{
ia This aggregated control group analysis was supplemented by a further analysis at the individual fund lavel, whera the ragrassion coefficients were aggregated, rather than the data-series. This presented similar results, adding rigour to the findings.

${ }^{79}$ Bolh data-saries were tested for normality by means of a ibi-squaled test and found to be normally distributed at it $5 \%$ signifacance level.
} 
These findings contradict Sawicki (2001) who engineered this approach in the Australian market. The stronger correlation for older funds also contradicts findings by Chevalier and Ellison (1997), Bergstresser and Foterba (2002) and Goriaev ef at. (2002). The different findings might be due to a different indicator variable approach used in a more established US market.

\subsection{Determinants of fund level cash flows}

In section 4.3, the analysis presents evidence that cast flows to the various unit trusts are not necessarily affected uniformly by the same determinant, particularly when considering the asymmetric response cash flows exhibit. From the aggregated time-series analysis in section 4.4 , it is apparent that concurrent General Equity and market returns, lagged cash flows and returns explain most of the aggregated cash flows when considering the large-scale shifts of cash flows. This gives rise to the need to investigate the determinants at individual fund level and eliminate the weaknesses in the aggregated tests ${ }^{75}$. The objective behind analysing each fund is to give more rigorous insight into the potential relationship between the data for each fund. In addition, these findings are compared to the aggregated results of the General Equity category. The results from the cross-sectional analysis are presented in section 4.5 .1 , followed by the results from the time-series analysis on an individual fund basis in section 4.5 .2

\subsubsection{Cross-sectional regression analysis results}

The principle objective is the estimation of a behavioural model to explain cash flows for the whole period under consideration. The profound changes in the unit trust industry over the sample period give rise to the expectation that the findings would change from year to year. Table 15 (page 72) presents the cross-sectional regression results of the annual cash flows to individual unit trusts against each fund's characteristics. The performance independent variable is the only significant variable at a $5 \%$ level for each year when the stepwise regression analysis was perfomed. In some instances, using only the performance independent variable increased the coefficient of determination, thereby confirming the multivariate regression results, presented on page 72 . The stepwise regression results are consequently omitted.

\footnotetext{
" The aggregated testing had the weakness of aggregating variables into a single series, thereby reducing these variables' unique explanatory power. At the same fime, the analysis might have helped to make certain variables such as local market returns, more important than they really 


\section{Table 15. Cross-sectional regression results using normal returns as the performance measure}

\begin{tabular}{|c|c|c|c|c|c|c|}
\hline & 2009 & 2000 & $\begin{array}{l}\text { Time } \\
1999 \\
\end{array}$ & 1998 & 1997 & \\
\hline \multicolumn{7}{|l|}{ Beta cosfficents } \\
\hline Constant & $\begin{array}{r}-83203 \\
(65535.000)\end{array}$ & $\begin{array}{r}01,061 \\
(0,000)\end{array}$ & $\begin{array}{r}-9.478 \\
(65535.000)\end{array}$ & $\begin{array}{r}-5.479 \\
(55,335000)\end{array}$ & $\begin{array}{r}0.853 \\
(0.000)\end{array}$ & \\
\hline Concurrent re:Lin & $\begin{array}{r}\text { C } 348 \\
\{2.014\}\end{array}$ & $\begin{array}{r}0.268 \\
\langle 1.476\rangle\end{array}$ & $\begin{array}{r}0.308 \\
(1.975) \\
4 \wedge\end{array}$ & $\begin{array}{r}0.660 \\
(3.007)\end{array}$ & $\begin{array}{r}0.727 \\
(3.996)\end{array}$ & ง \\
\hline In tal chargets & $\begin{array}{r}0.924 \\
\{0702\}\end{array}$ & $\begin{array}{r}5.111 \\
(0,300)\end{array}$ & $\begin{array}{r}-0.2 f 9 \\
(-1.722)\end{array}$ & $\begin{array}{r}0.198 \\
(0.394)\end{array}$ & $\begin{array}{r}-0.083 \\
(-0.300)\end{array}$ & \\
\hline Maragement fees & $\begin{array}{r}0406 \\
(1.412)\end{array}$ & $\begin{array}{r}0.127 \\
(0.307)\end{array}$ & $\begin{array}{c}-0.487 \\
(-1.932)\end{array}$ & $\begin{array}{r}0.323 \\
(3.041)\end{array}$ & $\begin{array}{r}-6249 \\
(-0,881)\end{array}$ & \\
\hline Total foes & $\begin{array}{r}-0.328 \\
(-0.954)\end{array}$ & $\begin{array}{r}-0.410 \\
(-0.844)\end{array}$ & $\begin{array}{r}-019 \mathrm{f} \\
(-0.697)\end{array}$ & $\begin{array}{r}-0<20 \\
(-0.609)\end{array}$ & $\begin{array}{r}-C .1<1 \\
(-2.35-4)\end{array}$ & \\
\hline Aje $<24$ mont 9 & $\begin{array}{r}93.78 \mathrm{C} \\
(85535.000)\end{array}$ & $\begin{array}{l}-79.289 \\
(-0.020)\end{array}$ & $\begin{array}{r}21.316 \\
(25536,000)\end{array}$ & $\begin{array}{r}787 \mathrm{r} \\
\text { if5535.000) }\end{array}$ & $\begin{array}{r}-1.455 \\
(-0.000)\end{array}$ & \\
\hline Age > 24 monlns & $\begin{array}{r}150,500 \\
(65535000)\end{array}$ & $\begin{array}{l}-68.020 \\
(-0.000)\end{array}$ & $\begin{array}{r}32.000 \\
(05535.900)\end{array}$ & $\begin{array}{r}4.690 \\
(555.35 .007)\end{array}$ & $\begin{array}{r}4444 \\
(0,000)\end{array}$ & \\
\hline $\begin{array}{l}\text { Risk } \\
\text { Fund size }\end{array}$ & $\begin{array}{r}-0.219 \\
(1.567) \\
0.901 \\
(0.005)\end{array}$ & $\begin{array}{r}-0.158 \\
(-0.879) \\
-0.072 \\
(-0.375)\end{array}$ & $\begin{array}{r}0.058 \\
(-0.354) \\
0.168 \\
(0.302)\end{array}$ & $\begin{array}{c}-2.098 \\
(-0.383) \\
0425 \\
i 2.020)\end{array}$ & $\begin{array}{r}-0.127 \\
(-0.759) \\
-0.096 \\
(-0.456)\end{array}$ & \\
\hline $\mathrm{R}^{2}$ & $0 . \angle 36$ & 2.321 & 0.581 & 5598 & C 787 & \\
\hline Adj. $R^{\prime}$ & 0.295 & 5.112 & 0.404 & 0.305 & 0.597 & \\
\hline povalus & 0.011 & 0.192 & $0,015<$ & 3135 & 0.024 & * \\
\hline Numoer of finds & 41 & $\begin{array}{r}35 \\
\end{array}$ & 28 & 20 & 18 & \\
\hline $\begin{array}{l}\text { - Signibicant at 5\% } \\
\text { The upper figures fo } \\
\text { A cross sectiansi in }\end{array}$ & $\begin{array}{l}\text { - Significant al } \\
\text { variable are coet } \\
\text { re regnession an }\end{array}$ & tevel & $\begin{array}{l}\text { fick are in pares } \\
\text { cash 0ows ag } \\
\text { grperiad }\end{array}$ & 6ses. & Biating ta & \\
\hline
\end{tabular}

Only the return regression coefficients for 1997 and 1998 are significant at a $5 \%$ level. No apparent pattern emerges over the five-year period. The summary adjusted coefficient of determination for the period is $0.34(p$ value $>0.05$ ), whereas when considering return only, it drops to 0.24 ( $p$-vatue $>0.05)$. Although not reliable or significant, the results show that there might be a possible influence of returns on cash flows. Except for returns. none of the other independent variables is statistically significant. The fees are separated into their two components. Not surprisingly, these variables are insignificant. The regression coefficients for the front-ended load fee variables are smaller than the regression coefficients for administration fees. It could be inferred that an increase in administration fees would possibly have a larger impact on cash flows, than a similar increase in frontended fees. These findings are in contrast to the observations by Rockinger (1995). It would be expected that the regression coefficient signs would be consistently negative indicating at least a notion of cost minimization. In the case of the risk variable, the regression coefficient's sign is insignificantly negative, similar to studies by Sirri and Tufano (1998) and James and Karceski (2002).

It must be noted that no concrete assertion could be derived from these coefficients due to the weak crosssectional results arising potentially from the number of funds utilised. The results are similar, yet slightly weaker for the analysis performed when substituting excess and abnormal returns for normal returns and are accordingly omitted. 


\subsubsection{Time-series regression analysis results}

A time-series regression analysis was pertormed on all the funds obder than two years. The time-5eries cash flows were regressed for each unit trust against the markel variables: short- and long-term interest rates, focal and international market returns and each fund's individual characteristics: fee structure, fund size: contemporaneous and lagged fund returns. lagged fund cash flows and risk. A multivariate regression analysis was performed using all the variables for each fund. This was followed by a stepwise regression approach to eliminate unnecossary independent variabies. Aggregated General Equity cash flows were included as part of a mulivariate regression model, thereby including eleven independent variabies into each equation.

The summary results for the mullivariate regression analysis presented in Figure 5 and Table to (page 74) are consistent with and are corroborated by the findings provided by the stepwise-regression analysis pertormed on a fund-to-fund basis (appendix J). Appenofix $\mathrm{J}$ also contains the full results using the multivariate and stepwise regression analysis approach, outlining the $R^{2}$, Adj. $R^{2}, \rho$-value per unit trust for the models as a whole and each independent variable included in these modets. In discussing the results, section 4.5.2. 1 outlines the significant independent variables and section 4.5.2.2 outtines the overall success of the models and explains a significant amount of the variation in the individual fund's cash flows.

\subsubsection{Independent variabies contributing the most explanatory power}

Figure 5 shows the proportionate number or times which the respective independent variables are significant at the $5 \%$ significance level and contributes towards explaining the variation in the individual fund's cash flows. Each ring represents these findings: substituting different performance measures into the multivariate regression analysis.

\section{Figure 5. Significant regression coefficients based on a multivariate regression analysis approach}
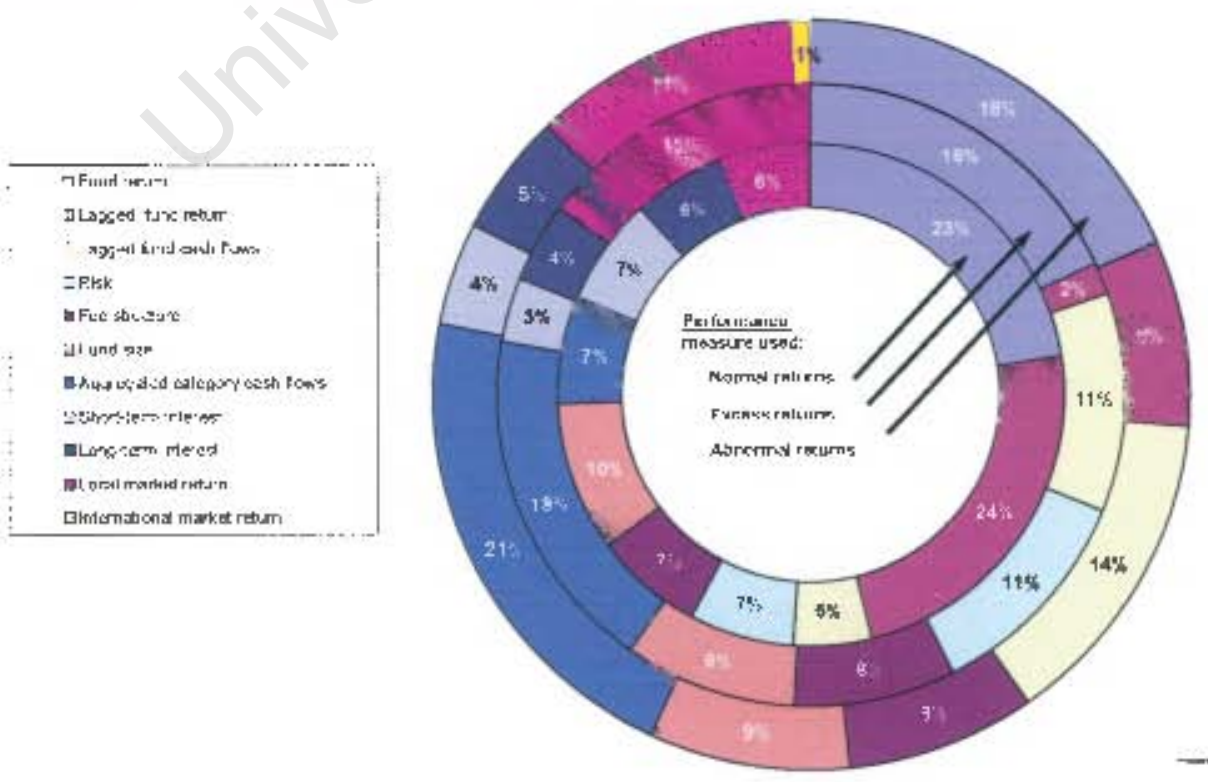
Table 16. Multivariate regression analysis results showing the significant independent variables that explain a variation in cash flows

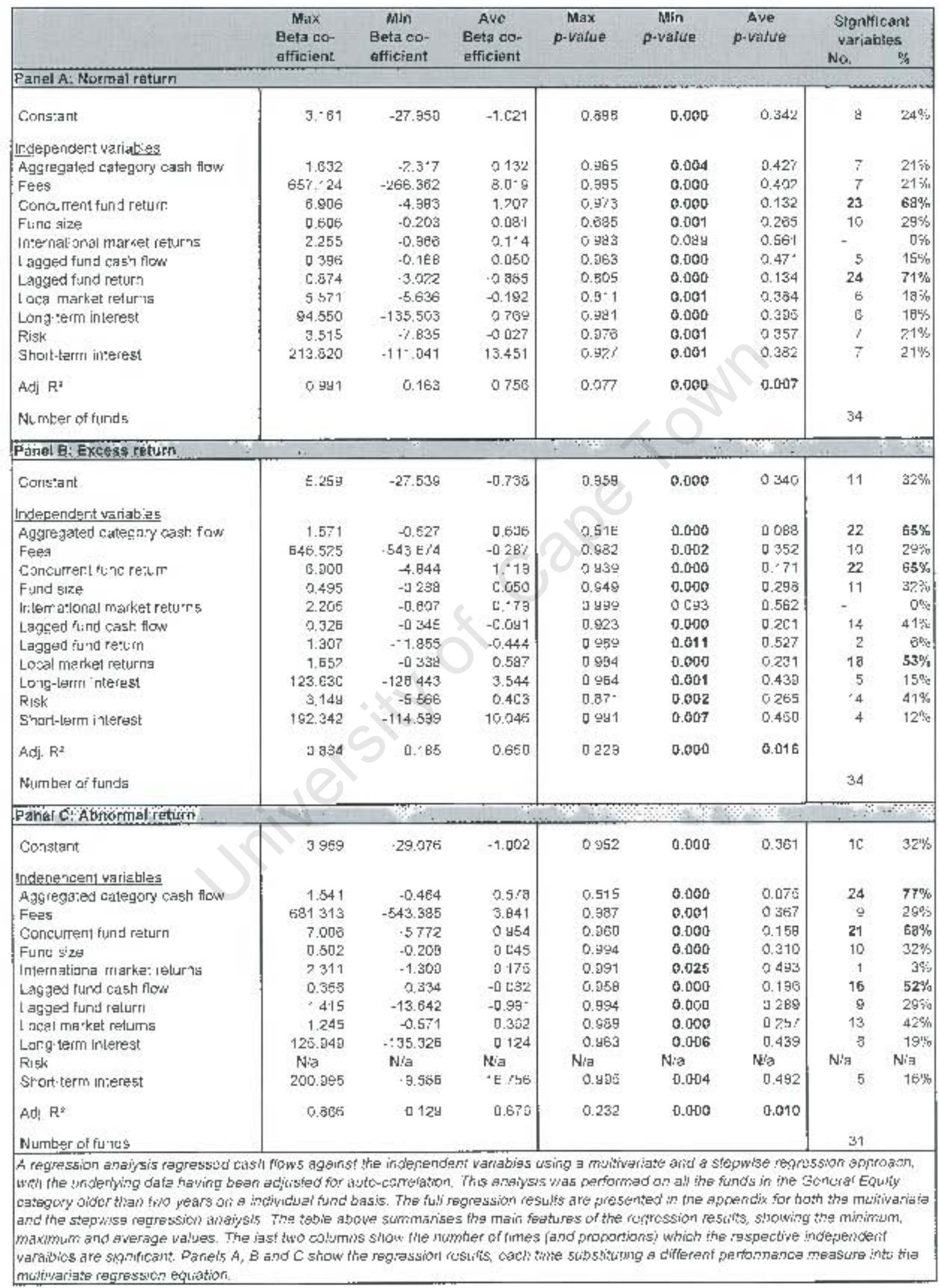


Similar to Figure 5, Table 16 (last two columns in the respective performance panels) shows the number of times which the respective independent variables are significant in explaining the variation in cash flows for the individual funds. It also indicates the number of funds for which each variable is significant as a percentage of the number of funds investigated. The maximum, minimum and average betas (or sensitivity of cash flows to the independent variables) and the related $p$-values for each variable are included in Table 16, which summarises the individual fund results in appendix J. The main features of Figure 5 and Table 16 are discussed below:

- Performance: The most striking feature of Figure 5 is the importance placed on contemporaneous and lagged normal returns. The concurrent and lagged normal returns' regression coefficients are significant for 23 and 24 of the 34 funds respectively. Regardless of the measure used, the funds' performances remain the primary consideration driving fund cash flows because the performance regression coefficients are significant for at least 20 funds. This is reflected by the low average $p$-values for the three performance measures in panels $A$, $B$ and $C$ of $0.132,0.171$ and 0.158 respectively. The average sensitivity of cash flows to the performance variable declines from 1.2 to 0.95 (panels $A$ and $C$ respectively) as more sophisticated performance measures are used and the effect of normal returns is distorted. In contrast to the negative relationship found for excess returns when performing the aggregated testing, all the funds (using excess returns) have significant positive regression coefficients.

- Lagged normal returns: All the funds have significant negative lagged normal returns' regression coefficients, yet, when considering other performance measures (i.e. excess and abnormal returns), lagged relurns become insignificant. These results add rigour to the aggregated testing.

- Lagged cash flows: The lagged cash flows regression coefficients, in combination with normal returns, are only significant for 5 of the 34 funds. This is less than expected, given the significant correlation when performing the aggregated analysis. Yet, intuitively it is correct, since cash flows to General Equity category might be known, whereas fund specific information will probably not be publicly available. The findings do improve when excess and abnormal returns are used. Lagged cash flows have the least impact on future cash flows as shown by the Gryphen Imperial regression coefficient of 0.395 (panel A).

- Aggregated cash flows: Interestingly, when normal returns (panel A) are removed from the regression equation and replaced with excess returns (panel B), aggregated cash flows become more important relative to the other independent variables, with an overall importance of $18 \%$, contributing towards explaining cash flows for 22 of the 34 funds. When abnormal returns (panel C) are considered, the importance of the aggregated cash flows increases by $3 \%$ to $21 \%$. This confirms findings by Sirri and Tufano (1998).

- Local market returns: Local market returns appear to exhibit the same tendencies and features as aggregated cash flows. The local market return regression coefficients are only significant for 5 funds, when considering normal returns as the performance measure. This provides clarification on the distortions in the findings (presented earlier) created by the similarities between the returns on the General Equity category and the returns on the ALSI, as correlation becomes insignificant. The number of times which the local market return coefficient is significant, increases to 18 of the 34 funds and 13 of the 31 funds, considering excess and abnormal returns respectively as the performance measure (panels $\mathrm{B}$ and $\mathrm{C}$ ). This is understandable. The excess and abnormal regression coefficients are significant $(p$-value $<0.05)$ for these funds and are part of the multivariate regression equation including the local market variables, which work in combination to explain the same variation in the funds' cash flows as normal returns. 
- International market returns: The international market returns' regression coefficient is only significant for Coronation High Growth, in conjunction with other variables such as abnormal returns, fees, fund size and long-term interest rates. Assuming investors know the fund's holding structure, this would mainly arise because the fund has a $7.1 \%$ holding in foreign investments. The influence of interest might come from Coronation High Growth's significant investment in financial institutions. These holdings might affect returns and by implication affect cash flows. Except for international market returns, all the other variables contribute towards explaining cash flows, regardless of the performance measure used as indicated by the minimum $p$-values.

- Interest, fee structures, fund size and risk: The regression coefficients for short- and long-term interest rates, fee structures and fund size do contribute towards explaining the variation in cash flows to some degree for certain funds. However, these variables do not appear to be as consistently significant between the funds as cash flows and returns, thereby corroborating the findings obtained from the aggregated testing. Allan Gray Equity has the largest regression coefficient ranging from 657.12 to 681.31 considering normal and abnormal returns (panels $\mathrm{A}$ and $\mathrm{C}$ ). It is one of the few funds, for which the fee regression coefficient is significant. Interest rates have the second largest regression coefficient, indicating a high level of sensitivity. Although the results are insignificant, interest rates might impact indirectly on cash flows by influencing the other independent variables in the models, such as market returns, fund performances et cetera. The poor relationship between fee structures, fund size, risk and cash flows corroborates the aggregated test results which show that fee structures, fund size and risk are insignificant at a $5 \%$ significance level.

\subsubsection{Significant cash flow models}

Regardless of the independent variables or combinations thereof used in the regression equations to predict individual level cash flows for the unit trusts, most of the equations/models contribute towards explaining the variation in the respective unit trusts' cash flows, with the lowest Adj- $R^{2}$ of 0.328 .

Table 17 (page 77) ranks the funds in descending order of size of adjusted coefficient of determination. These funds are then allocated to quartiles. Q1 contains the fund with a multivariate regression which explains the most variability of cash flows given its combination of independent variables and so forth. The related number of times which the independent variables are significant for the funds included in these quartiles, is reported on page 77. 


\section{Table 17. Interaction between the independent variables at different levels of correlation}

\begin{tabular}{|c|c|c|c|c|c|c|c|c|c|c|c|c|}
\hline & Ade. $R^{2}$ & $\begin{array}{l}\text { Shori-term } \\
\text { lntereat }\end{array}$ & $\begin{array}{l}\text { Long-term } \\
\text { intercst }\end{array}$ & $\begin{array}{l}\text { Lncal } \\
\text { market } \\
\text { pejums }\end{array}$ & $\begin{array}{l}\text { Intemafional } \\
\text { masket raturns }\end{array}$ & $\begin{array}{l}\text { Lagged } \\
\text { fund } c \text { ash } \\
\text { flowe }\end{array}$ & $\begin{array}{c}\text { Aggregalad } \\
\text { catugory eash } \\
\text { floir }\end{array}$ & $\begin{array}{l}\text { Concurrerit } \\
\text { fund rewim }\end{array}$ & $\begin{array}{l}\text { Lagged } \\
\text { Fund return }\end{array}$ & Fets & Risak & Fund size \\
\hline \multicolumn{13}{|c|}{ Ponet A: Normal rebura } \\
\hline $\mathrm{D}^{+}$(Hlgreslj) & $5 i \%$ & 3 & e & $\bar{y}$ & ก & 1 & 3 & 9 & E & 2 & 1 & 2 \\
\hline$a 2$ & $52 \%$ & 1 & 2 & $i$ & 0 & 2 & $\overline{2}$ & 7 & 3 & 1 & 1 & 3 \\
\hline 53 & $14 *$ & 1 & 3 & 2 & 0 & 2 & 3 & 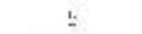 & 5 & $\ddot{3}$ & $i$ & 4 \\
\hline as it_owcsti & $41 \%$ & 2 & 1 & $z$ & 0 & 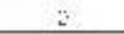 & $\ddot{z}$ & 2 & 2 & $\hat{v}$ & 1 & 1 \\
\hline \multicolumn{13}{|c|}{ Panel $B$ : Excoss numsib } \\
\hline al i Highesti & กิระ & 0 & 1 & 은 & 3 & 7 & B & $\bar{\theta}$ & 1 & E & 9 & 4 \\
\hline 102 & $7 y+$ & 0 & E & $\mathrm{s}$ & (1) & 4 & B & 8 & $\therefore$ & 1 & 2 & 2 \\
\hline 2.7. & $68 \%$ & 2 & . & 2 & $\hat{i}$ & 2 & 4 & 7 & 3 & $\therefore$ & 1 & 1 \\
\hline 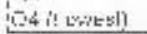 & $32 \%$ & $z$ & i & 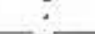 & $\hat{x}$ & $i$ & 7 & 1 & $\therefore$ & $\ddot{z}$ & 1 & 1 \\
\hline \multicolumn{13}{|c|}{ Panel G: Abmorthal coturn } \\
\hline GI (Highesti & $\mathrm{d3} / \mathrm{s}$ & 0 & $\div$ & 7 & $=$ & $\overline{7}$ & 百 & 7 & 4 & 4 & $\pi$ & 3 \\
\hline jaz & $79 \%$ & 0 & z & 5 & 1 & 5 & 7 & 5 & 2 & 2 & 11 & $x$ \\
\hline 63 & $72 \%$ & $z$ & 1 & 1 & $\ddot{z}$ & 3 & $\theta$ & 6 & 1 & i & 0 & 1 \\
\hline [os [! istukal] & $38 \%$ & 3 & z & D & 0 & 1 & 1 & 3 & 2 & 2 & 0 & 3 \\
\hline
\end{tabular}

A key feature of Table 17 relates to quartiles $Q 1$ and $Q 2$, where the independent variables identified in section 4.4 : are concentrated around the top quartiles. Contemporaneous and lagged normal returns exhibit the highest explanatory power, in conjunction with a few other independent variables. Moving down the quarkiles, these variables become less important while other independent variables take prominence. This highlights the importance of performance. aggregated cash flows and local market returns. It is also worth pointing out how, on a fund-to-fund basis, other independent variables, not significant at an aggregated level analysis, start carrying more importance. In particular, when considering other performance measures (panels $\mathrm{B}$ and $\mathrm{C}$ ). lagged and aggregated cash flows and local market returns interact to provide the same explanatory power as cancurrent and lagged normal returns. A further point to note relates to the number of times the fee and risk regression coefficients are significant, while using excess returns as a performance measure, forming part of Q1 in panel $B$. The analysis was re-preformed using a stepwise regression approach (appendix $\mathrm{J}$ ) and the results are similar to those obtained above.

\subsection{Summary of the findings}

This research is a South African attempt to explain the variability in cash flows to the General Equity unit trust category and individual unit trusts. Before summarising the main findings. it should be pointed out that the results presented, are generalised. It is, however, worth noting that several funds are the exception to the rule.

Performance influences cash flows in several ways. A significant relationship is noted between cash flows and contemporaneous and lagged returns, where all the lags longer than one month add no significant explanatory power to the analysis. The reward for a 'wimingitop performing' fund is greater than the reward for a fund earning medium performances. The 'loseripoar performing' fund continues to benefit by attracting and retaining investors cash flows as shown by the absence of a detectable disinvestment activity. Contrary to expectation, investors react more proactively when observing regative return events which is intuitively irrational, cantradicting previous researchers. Performance, normal or otherwise, remains an important driving factor behind cash flows. 
Excess and abnormal returns provide interesting findings. Excess returns are negatively related to cash flows. This intuitively does not make economic sense. Similarly, abnormal returns are insignificant, regardless of the large contingency of institutional investors in South Africa. It initially appears that market return is one of the most significant independent variables. However, after further evaluating market factors and fund characteristics separately, it is apparent that this is not the case. In fact, normal returns take prominence with an Adj. $R^{2}$ of 0.83 as opposed to an Adj. $R^{2}$ of 0.5 when considering the market factors.

Several variables, which had theoretical justification for inclusion into the model as contributing towards explaining cash flows, proved to be insignificant at an aggregated level. These included: fee structures, fund size and risk. Contrary to expectation, the research notes that the cash flow relationship is stronger for older funds, possibly arising from the large capital injections most of the younger funds received in their first year of existence.

The aggregated findings are refined, when individual funds are analysed on a one-on-one basis. The findings present models consisting of a wide variety or combinations of independent variables, all of which explain a significant portion of cash flows, regardless of the combination. The top performing funds provide the strongest relationship, utilising variables such as normal returns. As the relationship becomes weaker, more variables are included in the model to provide the same level of explanatory power towards the variability of cash flows. Once again, normal returns and lagged cash flows take prominence, with market returns becoming insignificant. This provides reassurance that the interaction between market returns and General Equity category returns, giving rise to the high aggregated cash flow-market return relationship, is anomalous. However, when considering other return measures, lagged cash flows become insignificant, whereas aggregated cash flows become a significant contributor towards the relationship. Furthermore, at a fund level, interest rates, fee structures, size and risk remain insignificant.

The findings of this chapter are consistent with prior research, except where otherwise indicated and provide a reasonable basis for the conclusions. 


\section{ChAPTER 5}

\section{CONCLUSIONS AND RECOMMENDATIONS FOR FURTHER RESEARCH}

The primary objective of this research is to investigate and determine the market factors and the fund characteristics which best explain net investment flows into and from Domestic General Equity unit trusts and to provide insight into the dynamics behind cash flows. International studies document the relationships between cash flows, market variables and fund characteristics. The contribution of this research lies primarily in the documentation of the interaction of these factors explaining the variation in South African cash flows, rather than providing the reasons for the relationship.

This research provides insight into the quantifiable factors, which might contribute towards influencing investors' behaviour with respect to their demand for unit trusts. The analysis of the demand for unit trusts takes the form of a function where, although financial factors are the most significant, these are not the only consideration of investors' behaviour. It is also necessary to consider the nature and structure of unit trusts and their position in the market.

The findings suggest that the attitudes adopted by investors do not always respond to economic rationality, since investors appear to over-emphasize certain determinants such as normal return while they ignore other determinants such as risk. The findings suggest that a positive relationship exists between monthly cash flows and contemporaneous returns of (i) the General Equity unit trusts and (ii) the equity market. Monthly cash flows are negatively related to (i) one-month lagged returns and (ii) one-month lagged cash flows at a $5 \%$ significance level. No other determinants show a significant relationship with cash flows.

It can be concluded that investors make their investment choices based on a narrow view, focussing on current winners (based on publicly available information such as normal returns and performance rankings rather than considering long-term risk-adjusted performance measures). Although unit trust investors might be considered cost minimizers, preferring small funds and funds with a good track record, the findings (at a $5 \%$ level) suggest this is not the case. It can further be surmised that a common component to investors' behaviour appears to exist. This common behaviour is influenced mainly by concurrent and lagged returns and lagged cash flows, being reflected in the market expediently.

By documenting the investors' asymmetric response, this research might contribute towards the growing body of literature linking fund management behaviour to the implicit incentive of the fund to increase assets under management. The findings, in conjunction with the prevailing compensation structure, give managers a payoff, which resembles a call option. When returns are high, assets gain in value and fees' revenues increase. But, when returns decline, revenue declines slightly. This response suggests that funds can exploit the option-like nature of their payoff by increasing the funds' risk exposure. 
The knowledge gained, could have potential value for fund managers. They could increase the funds' risk profile to increase returns, with no negative side effects on the invested cash flows. The findings could assist them with the structuring of new products. Managers could also amend their marketing activities by incorporating the most significant determinants such as returns et cetera into their products or campaigns. Unit holders, on the other hand, could utilise the findings to establish an appropriate compensation method for fund managers.

The results of this dissertation provide insight into the unit trust industry, but more work needs to be done to understand the South African money management industry. This opens further avenues for future research opportunities.

- Risk profiles: In an environment where the winners take all the cash, the fund managers have an "implicit incentive to alter the risk of their portfolios to increase the chances that they are among the winners" (Del Guercio and Tkac, 2002, p.525). The research notes that funds' risk profiles appear not to add value towards explaining cash flows. This gives fund managers an incentive to boost the funds' returns by investing in higher risk underlying investments. It is worthwhile to investigate the dynamics surrounding risk.

- Temporal changes in the cash flow-performance relationship: The results indicate that the strongest relationship exists between cash flows and contemporaneous and lagged performances. The sample size could be increased to include more funds with longer historic information available, to investigate this relationship pre-1996 compared to the post-1996 era. A study could investigate the factors which contribute to the increased investors' attention that unit trusts received post-1996 and the effect this would have on the cash flow-performance dynamic.

- Weaknesses in the methodology: The contribution of this research lies primarily in the documentation of the relationship between cash flows and determinants, rather than providing evidence of causation. Weaknesses arising from having too few numbers of data points available to complete conclusive regression analyses, were identified in the methodology. The analyses could be re-performed including longer periods of historic information. More sophisticated regression techniques could be used such as vector auto-regression and Granger's causality test et cetera.

- Unit trust types: This research explored the General Equity category to limit the influence which nonquantifiable factors have on investors' decision-making. The relationship for a sample selection of asset allocation funds, bond funds or other specialist funds could be investigated. For this research, the coefficient of determination was high. It would be expected that the significance of these findings would decline significantly, should non-General Equity unit trusts be selected. Money market funds would also be a particularly interesting category to investigate, because returns are presented in the form of an interest rate at low risk. More importantly, money market funds are more accessible than other unit trusts since several financial institutions allow clients to link these funds to savings, cheque and credit accounts (Goetzmann et al. 1999). 
- Investors' types and behaviour: This research grouped all investors into a single group when considering net cash flows. The South African investment community is over-weighted with institutional investors. The analyses could be extended to separate the cash flows into investors' types: retail and institutional investors. As argued in section 2.3, investors have different needs and wants. The analysis could be extended to separate the cash flows into their components, each reflecting different information regarding the funds' prospects. An attempt was made in section 4.3.2 to separate the cash flows into their components, yet, the analysis still considered net in- and outflows. This dynamic could also be explored in further research to provide valuable information in explaining investors' behaviour. 


\section{BIBLIOGRAPHY}

Affleck-Graves, 3. B Money, A. 1975, "A note an the rondom walk madel and SA share prices." The South African Journal of Economics, Vol 43(3), PP.382- 398

Ahern, D. 1997, "Examination of Unit Trust fond size verse relative quarteny performance" University of 5tellenbosch, Unpublished MBa dissertation

Alexander, G., Jones, J. \& Nigro, P. 1998, "Mutubl fund sharehuiders: chararteribtics, invebtor knowtedge and sourres af infomation." Financial Services Review, Vol 7, pp. $301-716$

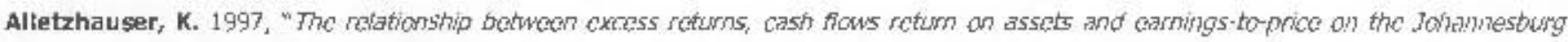
Stock Exchange. "University of Cape Town, Graduate School of Business, MBA dilssertation

Association of Unit Trusts (AUT), 2002, "The farts on bnit Trosts. * Available at: www. aut.co.za

Atanasov, M. 1998, "W/y funds s/zould swear off nsset growth." Fortune, Wol $137(6)$, p.182

***Barberis, N. \& Shielfer, A. 2001, "Style Investing." Working paper serles. Uriversity of chicago, Graduate School of Business and Harvard University, Available at: http:/paper5.55rn.com/sol3/results.tfm

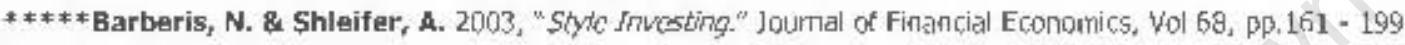

Bennett, A, \& Young, M. 2000, "Datominanis of Mutual Fund Flows: Evdence from New Zeadand" Massey University, Unpubleshed working páper, Jul-p0, Available at: hetg://accfinnt3,ecorm.unimelb, edhu.au;finance/research/pacap/papers/47.pdf

Bergstresser, D. \& Poterba, J. 2002, "Do after-tax ratturns affect mutual fund inflows?" Journal of Financial Econornics, vol 63, pp.381 414

Berk, 3. Ba Green, R. 2002, "Mutual fund flows and perfomance in rationaf markets." University of Califormla \& Carnegie Mellon University, Unpublished working paper, Oct-02

Berkowiz, M. \& Kotowiz, X. 2000, "Investor nisk evaluation in the detomination of management incentives in the muthat fund industry." Joumal of Financial Markets, Vol $3, \mathrm{pp} .365 \cdot 387$

Bemstein, P. 1998, "Where, of where are the. 400 hittess af yesteryear?" Financial Analysts Journal, vol 54(6), pp.6 - 15

Bhana, N. 1994, "Window dressing by institutional investors on the JSE." Finlancial Analysts Journal, Vol 39(Winter), pp.61 - 71

Blrinyi Jr, L. 1996, "Foolishncss about funds." Forbes, Vol 158(6), p. 226

Bodie, Kane \& Marcus 1996, "Investments." 3rd edition, Inwin Inc. and Times Mirror International Publishers Limited, London

Bowie, D. \& Bradfield, D. 1993, "A review of systematic risk estimation on the J5E." De Ratione, vol 7(1), pp.6-22

Bradfield, D. 2000, "Docs size count? What insights are theme for fund management?" Cadiz 5tockbroking, Quantitative Research, Internal research, Pp. 1 - 11

Brennan, M. \& Subrahmanyam, A. 1998, "The determinants of avcrage trade size" The Journal of Business, Vol $71\{1\}$, pp.1 - 25

Brent, A. 2001, "Flows set record, despite performance." Mutilal Fund Market News, Vol 9(6), p.1

Brown, K., Harlow, W. \& Starks, L. 1996, "Of towmanents and tomptitions: An analysis of managerat incontives in the mutual fund industry." The Journal of Finance, vol 51(1), pp.85-110

Brown, \$. \& Goetzmann, W. 1995 , "Performance Persistonce" Journal of Finance, Vol Lᄂ2), pp.679 - 698

Brown, S., Goetzmann, W., Hiraki, T., Shiraishi, N. \& Watanabe, M. 2002, Invebter Sentiment in japanese and U.5. datly mutual hund fiows." YaLE International Centre for Finance, ICF D2-09, Már-02, Avallable at: www.paperș.ssin.com/altzatract id -302829

Brown, 5., Goetzmann, W., Ibbotson, R. \& Ross, S. 1992, "Survivorship bits in performance sthdies, "Review of Financial Studies, Vol 5 , pp. $553-500$

Busse, J. \& Irvine, P. 2002, "Bayesian Alphas and Muhlat Fund Persisterce" Golzueta Business School, Emory Џniversity, Unpublished working paper, Feb-02

Capon, N., Fitzsimons, G. B Prince, R. 1996, "An individual tevel andysis of the mutud fund muestment decosion." Journal of Financial Services Research, vol 10, pp. 59 - B2

Cha, н. 2001, "The Dynamit ralationstip between security returris and mutual fund flows." University of St. Thormas, Unpublished working paper, ]ип-01

Chacko, G. \& Das, S.R. 1999, "A theary of aptimal timing ard selectivity." Joumal of Economic Dynarnics and Control, Vol 23, pp.929 - 965

Chakravarty, S. 2001, "Steath-trading. Which traders' trodes move 5tock pricest" Journal of Financial Economlcs, Vol $61, \mathrm{pp} .289$ - 307 
Chang, W., Hamberg, D. Mirata, J. 1983, "Liquidity preference as behaviour towards risk is demand for short-term securities - Not money." The American Economic Review, Vol 73(3), pp.420 - 427

Chevaller, J. Ellison, G. 1997, "Risk taking by mutual funds as a response to incentives." Joumal of Political Economy, Vol105(6), pp.1167 $-1200$

Chevalier, J. Ellison, G. 1999, "Are some Mutual Fund Managers better than others? Cross-sectional Pattems in behaviour and performance." The Journal of Finance, Vol LV(3), pp.875 - 899

Chordia, T. 1996, "The structure of mutual fund charges." Joumal of Financial Economics, Vol 41, pp.3 - 39

Chordia, T., Sarkar, A. Subrahmanyam, A. 2001, "Common determinants of bond and stock market liquidity: The impact of Financial Crises, Monetary Policy and Mutual fund flows." Federal Reserve Bank of New York, Nov-01, Available at: www.papers.ssrn.com

Clash, J. 1998, "Follow the cash." Forbes, Vol 161(4), p.130

Collins, D. 2001, "The relationship between business confidence surveys and stock manket performance." Financial Analysts Journal, vol 54(1), Available at: umm.moneymax.co.2a

Connolly, 3. 1997, "Sky high values have execs on watch. "National Underwriter / Life \& Health Financial Services, Vol 101(11), pp.7 - 9

Cooke, T. 1998, "Regression analysis in Accounting disclosure studies." Accounting and Business Research, Vol 28(3), pp.209 - 224

Coronation, 2002, "Issues/concerns facing the SA Asset Management Industry" June 2002.

Correla, C. \&ormaid, M. 1988, "The Association between stock market retums and rates of inflation." De Ratione, Vol 2(1), pp.11 - 18

Daniel, K. Titman, S. 1997, "Evidence on the characteristics of cross-sectional variation in stock retums." The Journal of Finance, Vol LII(1), pp.1 - 33

Danlel, W. Terrell, J. 1995, "Business Statistics for Management and Economics." 7th Ed., Boston: Houghton-Mifflin Co.

** Del Guercio, D. Akac, P. 2000, "The determinants of the Flow of funds of managed Portfolios: Mutual funds vs. Pension funds." Federal Reserve Bank of Atlanta, 2000 - 21, Nov-00, Available at: www.frbatlanta.org/oublica/work-papers/index.html

*** Del Guerclo, D. 2. Tkac, P. 2002, "The determinants of the Flow of funds of managed Portfollos: Mutual funds vs. Pension funds." Journal of Financial \& Quantitative Analysis, Vol 37(4), pp.523 - 558

***Del Guercio, D. \& Tkac, P. 2001, "Star power: The effect of Momingstar rating on mutual fund fiows." Federal Reserve Bank of Atanta, 2001 - 15, Aug-01, Available at: umw.fibatlanta.org/publica/work-papers/index.html

Deli, D. Varma, R. 2002, "Contracting in the investment management industry: evidence from mutual funds." Journal of Financial Economics, Vol 63(1), pp.79- 98

Deloltte \&ouche, 2002, "Financial Senvices Team: ILDP Training manual." Deloitte \& Touche: FIST Woodlands

Dimson, E. Jackson, A. 2001, "High frequency performance monitoring." Journal of Portfolio Management, Vol 28(1), pp.33 - 52

Droms, W. Walker, D. 1994, "Investment Performance of Intemational Mutual Funds." Journal of Financial Research, Vol 1, pp.1 -14

Droms, W. Walker, D. 1995, "Determinants of variation of in mutual fund returns." Applied Financial Economics, Vol 5, pp.383 - 389

Du Plessis, H.I. 1974, "Notes on the characteristics and performance of some South African mutual funds." The Investment Analyst Joumal, Vol 5(4), pp.29- 37

Du Plooy, A. 2003, Personal communications

Duvenhage, H. 2003, "SA spaar minder, regering inkluis." Rapport, Aug-03

Edelen, R. 1999, "Investor fows and the assessed performance of open-end mutual funds." Journal of Financial Economics, Vol 53, pp.439 466

****Edelen, R. Wamer, J. 1999, "Aggregate price effects of institutional trading: A study of mutual fund flows and market retums." The Wharton School, University of Pennsylvania, Unpublished working paper, Oct-99, Available at: htto: //finance. wharton. upenn.edu/ urfwctr

***** Edelen, R. Wamer, J. 2001, "Aggregate price effects of institutional trading: A study of mutual fund flows and market retums." Journal of Financial Economics, Vol 59, pp. 195 - 220

Elton, $\mathrm{E}_{\mathrm{ag}}$ Gruber, M. Blake, $\mathrm{C}_{\mathrm{s}}$ 1995, "Fundamental Economic Variables, Expected returns, and Bond fund performance." The Journal of Finance, Vol $L(4)$, pp.1229-1256

***Eton, E, Gruber, M. Blake, C. 2001, "Incentive fees and Mutual Funds." University of New York, Unpublished working paper, Jun01, Available at: umw.papers.ssrn.com

***** Elton, $\mathbf{E}_{\text {af }}$ Gruber, M. Blake, C. 2003, "Incentive fees and Mutual Funds." Journal of Finance, Vol 58(2), pp.779-806

Elton, E., Gruber, M. \& Busse, J. 1998, "Do investors care about sentiment?" Journal of Business, Vol 71(4), pp.477 - 500 
Elton, Es, Gruber, M. Busse, 3. 2002, "Are investors rational? Choices among Index Funds." University of New York, Unpublished working paper, Jun-02, Available at: htto://finance.wharton.upenn.edu/ rufiwct

Fama, E. Maçeth, J. 1973, "Risk retum and equilibrium: Empirical tests" Joumal of Political Economy, pp.607 - 636

Fant, F. O'Neal, E. 2000, "Temporal changes in the determinants of mutual fund flows." The Journal of Financial Research, Vol XXIII(3), pp.353 - 371

Fant, F. 1999, "Investment behaviour of mutual fund shareholders: The evidence from aggregated fund flows." Journal of Financial Markets, Vol 2, pp.391 - 402

Ferson, W. Schadt, R. 1996, "Measuring fund strategy and performance in changing economic conditions." Journal of Finance, Vol 51, pp. $425-462$

Ferson, W. Warther, V. 1996, "Evaluating fund performance in a dynamic market." Financial Analysts Journal, Vol 52, pp.20-28

Financial Services Board (FSB), 2001, "Registrar of Financial Markets." Available at: www.fsb.co.za

Firer, C. 2003, Personal communications

Fitapatrick, M. 1997, "An analysis of South African unit trust managers' market timing and security selection skills." University of Cape Town, Unpublished MBA dissertation

Fortune, P. 1997, "Mutual Funds, Part I: Reshaping the American Financial System." New England Economic Review, Jul / Aug 1997: pp.45 72

Fortune, P. 1998, "Mutual funds, Part II: Fund flows and security retums." New England Economic Review, Jan / Feb 1998: pp.3 - 22

Francis, J. 1975, "Skewness and Investor decisions." The Journal of Financial and Quantitative Analysis, Vol 10(1), pp.163-172

Friedman, . Roley, V. 1979, "Investors' portfolio behaviour under altemative models of long-term interest rate expectations. Unitary, rational or auto-regressive." Econometrica, Vol 47(6), pp.1475 - 1498

Froot, K., O'Connell, P. a Seasholes, M. 2001, "The portfolio flows of intemational investors." Journal of Financial Economics, Vol 59, pp.151- 193

Garmhausen, S. 1999, "Redemptions are offsetting money flowing into funds." American Banker, vol 164(126), p.8

Garvin, T. 1995, "A Study of the relative performance of South African Unit Trust Fund Managers utilizing the portfolio change measure technique." University of Cape Town, Unpublished dissertation

Garvin, T. 2000, Unpublished lecture notes: BUS464/5H "Active Portfollo management." University of Cape Town

Geweke, I. 1982, "Measurement of linear dependence and feedback between time series." Journal of the American Statistical Association, Vol 77, pp. $302-324$

Gubertson, 8. 2. Vermaak, M. 1982, "The performance of South African Mutual funds: 1974 - 1981." The investment Analyst Journal, Vol $20, p p .35-45$

Giimour, S. Smit, E. 2002, "Institutional Herding: Evidence from the South African Unit Trust Industry." The Investment Analyst Journal, Vol 55(2), Available at: wuw.moneymax.co.za

*** Goetzmann, W. Massa, M. 1999, "Index Funds and Stock Market growth." NBER Working paper No. 7033, Mar-99, Available at: www.papers.5sm.com

***** Goetzmann, W. \& Massa, M. 2003, "Index Funds and Stock Market growth." Joumal of Business, Vol 76(1), pp.1 - 29

** * Goetzmann, W. Massa, M. 2000, "Daily momentum and contrarian behaviour of index fund investors." NBER Working paper No. 7567, February 2000, Available at: www.papers.ssm.com

***** *oetzmann, W. Massa, M. 2002, "Daily momentum and contrarian behaviour of index fund investors." Joumal of Financial \& Quantitative Analysis, vol 37(3), pp.375 - 390

Goetsmann, W. 2000, "Stock markets, behaviour and the limits of history." NBER Reporter, Summer 2002: p.7, Available at: search.epnet.com

Goetzmann, W. Peles, N. 1997, "Cognitive dissonance and mutual fund investors." Joumal of Financial Research Vol 20, pp.145 - 158

Goetzmann, W., Massa, M. Rouwenhorst, K. 1999, "Behavioural factors in mutual fund flows." YALE, International Centre for Finance, Unpublished working paper no. 00-14, Avallable at: wuw.papers.ssm.com

Gompers, P. Lemer, 3. 2000, "Money chasing deals? The impact of fund inflows on private equity valuations." Journal of Financial Economics, vol 55, pp. $281-325$

Goriaev, An Nijman, T. Werker, B. 2002, "The dynamics of the impact of past performance on mutual fund cash flows." CentER, Discussion Paper No. 2002-02, Jan-02: pp.1 -25 
Grinblatt, M. Keloharju, M. 2000, "The investor behaviour and performance of various investor types: a study of Finland's unique data set." Journal of Financial Economics, Vol 55, pp.43-67

Grinblatt, M. "Ttman, S. 1989, "Mutual fund performance: An analysis of Quarterly holding." Journal of Business, Vol 62, pp393 - 416

Grimblatt, M. Titman, S. 1992, "The persistence of Mutual Fund Performance." Journal of Finance, Vol XLVII(5), pp.1977 - 1984

Grinblatt, M. Titman, S. Wermers, R. 1995, "Momentum Investment Strategies, Portfolio performance and Herding: A study of mutual fund behaviour." The American Economic Review, Vol 85(5), pp. 1088 - 1105

Gruber, M. 1996, "Another puzzle: The growth in actively, managed mutual funds." Journal of Finance, Vol LI(3), pp.782 - 810

Gujarati, D. 1992, "Essentials of Econometrics." McGraw-Hill International ed., Singapore

Madady, R. E. 1997, "Mutual funds flow sinks bear market." Futures: News, Analysis \& Strategies for Future, Options \& Derivatives Traders, Vol 26(7), p.30

Marris, S. 1998, "Can the blue chips fight back?" Personal Finance, Finance week, Vol 76(14), p.14

Hendricks, D. Patel, J. Zeckhauser, R. 1993, "Hot hands in Mutual Funds: Short-run persistence of relative performance, 1974 - 88." Journal of Finance, Vol XLVII(1), pp.93 - 130

Hess, A. 1991, "The effects of transaction costs on households" financial asset demand." Joumal of Money, Credit \& Banking, Vol 23(3)(1), pp.383- 409

Meun-Joo C. Bong-Soo L. 2001, "The market demand curve for common stocks: Evidence from equity mutual fund fiows." Joumal of Financial and Quantitative Analysis, Vol 36(2): pp.195 - 220

Holden, C. Subrahmanyam, A. 1996, "Risk aversion, Liquidity and Endogenous short horizons." Review of Financial Studies, Vol 9(2), pp.691 -722

Ippolito, R. 1992, "Consumer reaction to measures of poor quality." Joumal of Law and Economics, Vol 35, pp.45 - 70

Jain, P. Wu, J. 2000, "Truth in Mutual Fund advertising: Evidence on future performance and fund flows." Journal of Finance, Vol LV(2), pp.937- 958

James, C. Karceskd, J. 2002, "Captured Money? Differences in the performance characteristics of Retail and Institutional Mutual Funds." Warrington College of Business, University of Florida, Current draft, Feb-02, Available at: mww.papers.ssm.com

Kadapakkam, P., Kumar, P. Riddick, L. 1998, "The impact of cash fows and firm size on investment. The intemational evidence." Joumal of Banking and Finance, Vol 22, pp.293 - 320

***arceski, 1. 2000, "Returns-Chasing behaviour, Mutual funds and Betas Death." Warrington College of Business, University of Florida, Unpublished working paper, Feb-00, Avallable at: www.papers.ssm.com

*****Karceski, J. 2002, "Retums-Chasing behaviour, Mutual funds and Betas Death." Journal of Financial \& Quantitative Analysis, Vol 37(4), pp.559- 596

Keim, D. Madhavan, A. 1997, "Transactions costs and investment style: an inter-exchange analysis of institutional equity trades." Journal of Financial Economics, Vol 46, pp. $265-292$

Keller, G. Warrack, B. 2000, "Statistics for Management and Economics." 5th edition Duxbury (Thomson Learning), Pacific Grove, USA

Kilger, D. Sonsino, D. 1999, "On absolute and relative performance and the demand for mutual funds - experimental evidence" Unpublished working paper, Dec-99, Available at: www.papers. $55 m . c o m$

Knight, E. Firer, C. 1989, "The performance of South African Unit Trusts 1977 - 1986." Journal of Economics, Vol 57(1), pp.52 - 69

Knight, E. 1991, "The performance of Mutual runds." Unpublished MBA dissertation, Graduate School of Business of the University of Witwatersrand

Knight, R. 1983, "The association between published accounting data and the behaviour of share prices." Unpublished thesis, University of Cape Town

Kovaleski, D. 2001, "Heavy turnover, cash flows help "hot hands" managers keep edge." Pensions \& Investment, Vol 29(13), p.28

Lambrechts, M. 2000, "Unit Trust Survey:" University of Pretoria, Department of Financial Management

Lambrechts, H. 2001, "Unit Trust Survey." University of Pretoria, Department of Financial Management

Lambrechts, H. 2002, "Unit Trust Survey." University of Pretorla, Department of Financial Management

Lambrechts, H. 2003, "Unit Trust Survey" University of Pretoria, Department of Financial Management

Landskroner, Y. 1977, "Non marketable assets and the determinants of the market price of risk." The Review of Economics and Statistics, Vol 59(4), pp.482- 492

Lashinsky, A. 2002, "Sweet surrender." Fortune, Vol 146(4), pp.180-183 
***ee, C. Swaminathan, B. 1998, "Price momentum and trading volume" Cornell University, December 1998, Available at: www.papers.ssin.com

**** Lee, C. Swaminathan, 20. 2000, "Price momentum and trading volume" Journal of Finance, Vol 55(5), pp.2017 - 2070

Lee, $C_{\text {.y }}$ Shielfer, A. Thaler, R. 1991, "Investor Sentiment and the closed-end fund puzzle." The Journal of Finance, Vol 46(1), pp.75 109

Lettau, M. 1997, "Explaining the facts with adaptive agents: The case of mutual fund flows." Journal of Economic Dyramics and Control, Vol $21, \mathrm{pp} .1117-1147$

Markowitz, H. 1952, "Portfolio selection." Joumal of Finance, Vol 7(1), pp.77-91

Markowitz, M. 1959, "Portfolio selection: Efficient diversification of investments." Yale University Press, New Haven

Mc Donald, I. 2002, "New cash into funds broke records in January! But... ." Feb-01, Available at: www.thestreet.com/funds/fundjunkie/ 1316367.htm

McGiashan, G. 1995, "An investigation into the management of unit trust portfolios during different stages of the business cycle." University of Stellenbosch, Unpublished MCom dissertation

Milbourne, R. 1986, "Financial Innovation and the demand for liquid assets." Journal of Money, Credit \& Banking, Vol 18(4), pp.506 - 511

Millburm-Pyle, P. 1984, "Is a pension fund's investment yield influenced by the size of the fund's assets?" Financial Analysts Journal, Vol 23(1), Avallable at: www.moneymax.co.za

Munro, 2002, Personal communications

Murrell, 3. 1994, "An application of index models to Unit Trusts on the Johannesburg stock exchange." Unpublished Masters thesis, University of Natal

Myers, D. 2001, "Asset Flow and performance in pension funds." Lehigh University, College of Business and Economics, Preliminary Draft, Jan-01

Nalk, N. 1997, "On aggregation of information in competitive markets: The dynamic case." Journal of Economic Dynamics and Control, Vol 21, pp. $1199-1227$

Najand, M. \& Prather, L. 1999, "The risk level discriminatory power of mutual fund investment objectives: Additional evidence." Journal of Financial Markets, Vol 2, pp.307 - 328

Nanda, V. 2 Singh, R. 1998, "Mutual fund structures and the pricing of liquidity." University of Michigan Business School, First draft, Sep-98, Available at: www.papers.ssrn.com

****Nanda, V., Narayanan, M. Warther, V. 1997, "Liquidity, investment ability and mutual fund structure." University of Michigan Business School, First draft, Jul-97, Available at: www.papers.ssm.com

* ** * Nanda, V., Narayanan, M. Warther, V. 2000, "Liquidity, investment ability and mutual fund structure." Journal of Financial Economics, Vol 57, pp.417 - 433

Nesbitt, S. 1995, "Buy High, Sell Low: Timing Errors in Mutual Fund Allocations." The Journal of Portfolio Management, Fall-95: pp.57 - 60

Noceta, J. 1997. "Who's got the answers? The mutual fund industry teaches that buy and hold is the wisest strategy. So why don't fund managers practice what they preach?" Fortune, Nov-97

Optivest Plexus Asset Management, 2000, "Cash flow index" Sept-00, Available at: www.plexus.c0.za

Peterson, J., Pietranico, P. Riepe, M. 2001, "Explaining the performance of domestic equity mutual funds." Journal of Investing, Vol $10(3), \mathrm{pp} .81-92$

Potter, M. Schneewels, T. 1998, "The relationship between aggregate mutual fund flows and security returns." Working paper, Babsan College

Potter, M. 1996, "The dynamic relationship between secunity retums and mutual fund flows." University of Massachusetts - Amherst, Unpublished Ph.D. dissertation, Oct-96, Available at: www.papers.ssm.com

Potter, M. 2000, "Determinants of aggregate mutual fund flows." Journal of Business \& Economic Studies, Vol 6(2), pp.55-72

Pratt, R. Martin, P. 1968, "Structural Changes in Mortgage fund flows: Discussion." The Journal of Finance, Vol 23(2), pp.378 - 387

Pritamani, M. Singal, V. 2001, "Return predictability following large price changes and information releases" Journal of Banking and Finance, Vol 25, pp.631- 656

Remolona, E.M., Kieiman, P. Gruenstein, D. 1997, "Market retums and Mutual fund flows." Federal Reserve Bank of New York Economic Policy Review, Jul-97: pp.33 - 52

Revell, 3. 2001, "The hunt for yield." Fortune, Vol 144(8), p.180 
Robertson, M. 2000, Unpublished lecture notes: BUS464/5H "Active Portfolio management." University of Cape Town

Robertson, Ma, Firer, C. Bradfleld, D. 2000, "Identifying and correcting misclassified South African equity unit trusts using style analysis." Financial Analysts Journal, Vol 52(2)

Rockinger, M. 1995, "Determinants of capital flows to mutual funds." HEC - School of Management, Unpublished working paper, June 1995

Ross, 5. 1976, "The Arbitrage Theory of Capital Asset Pricing." Journal of Finance, Vol 35(5), pp.1073-1103

Ross, S., Westertield, R., Jordan, B. FIrer, C. 1996, "Fundamentals of Corporate Finance" 1st SA edition Irwin Inc. and Times Mirror International Publishers Limited, Londion

Sandier, M. Firer, C. 1994, "Finance research in South Africa." Investment Analysts Journal, Vol 39, pp.25 - 42

Sandler, M. Firer, C. 1999, "Finance research in South Africa: 1949 - 1997." Financial Analysts Joumal, Vol 48(4), Available at: www.moneymax,co.za

Sanlam, 2003, "Sanlam Unit Trust Annual Report." March 2003

Santini, D. Aber, J. 1996, "Investor response to mutual fund policy variables." The Financial Review, Vol 31(4), pp.765 - 781

Santini, D. Aber, J. 1998, "Determinants of Net New Money Flows to the equity mutual fund industry." Joumal of Economics and Business, Vol 50, pp.419- 429

Sauer, D. 1997, "Information content of prior period mutual fund performance rankings:" Joumal of Economics and Business, Vol 49(6), pp.549- 567

Sawicki, 1. 2001, "Investors' differential response to managed fund performance." The Journal of Financial Research, Vol XXIV(3), pp.367 384

Schwartz, N. 1997, "Which Fidelity Fund can still soar?" Fortune, Jun-97: p.70

Scott, A. Uhlig, H. 1999, "Fickle investors: An impediment to growth?" European Economic Review, Vol 43, pp.1345 - 1370

Slas, R. Starks, L. 1997, "Retum autocorrelation and institutional investors." Joumal of Financial Economics, Vol 46, pp.103-131

Simi, E. \&ufano, P. 1998, "Costly search and mutual fund flows." Joumal of Finance, Vol LIII(5), pp.1589 - 1622

Slaney, K. 1995, "An investigation into the indices that proxy the macroeconomic forces undertying equity retums on the JSE." University of Natal, M Com dissertation

Smith, G. 1997, "Surprisel Mutual funds aren't driving the market" Business Week, 3 March 1997, Available at: www.businessweek.com/ @k*nipglOAZanGdgAA1997/09/b3516126.htm

Spitz, A. 1970, "Mutual Fund Performance and Cash Inflows." Applied Economics, Vol 2, pp.141 - 145

Studwick, B. Grant, C. 1995, "Skip growth or value and go for cash fiow." Business Press, Vol 8(18), pp.15 - 17

Thaler, R. Johnson, E. 1990, "Gambling with the house money and tying to break-even: The effect of prior outcomes on risky choice." Management Science, Vol 36, pp.643-660

***Torre, B. Garcia, M. 2001, "Investment Companies as altemative institutions to Traditional Banks: An empirical Analysis of Spanish reaction to the mutual funds market." University of Caribbean, Unpublished working paper, Available in English at: www.papers.ssm.com

*** Torre, B. Garcia, M. 2002, "Factores determinantes del comportamiento inversor en el mercado espanol de fondos de inversion de renta variables." Informacion Comercial Espanola, Vol 800, pp.193 - 207

Underhill, L. Bradfield, D. 1996, "IntrostaT." 2nd edition Juta \& Co Ltd. Kenwyn, South Africa

Van Rensburg, P. 1994, "The application of a multifactor model to the Johannesburg Stock Exchange." University of Natal, M Econ dissertation

Van Rensburg, P. 2002, Personal communications

Warther, V. 1995, "Aggregated mutual fund flows and security retums." Journal of Financial Economics, Vol 39, pp.209 - 235

Warther, V. 1997, "Are Tax-minimizing mutual funds stabllity? Mutual fund flows and Capital Gains Overhangs." University of Michigan, Unpublished working paper, Available at: www.papers.ssm.com

Wegner, T. 1995, Unpublished lecture notes: "Analysis of vanances - Research and survey Statistics." University of Cape Town

Welsh, J. 1999, "Half Full or Half Empty?" On Wall Street, vol 9(7), p.26

Wermers, R. 1999, "Mutual fund herding and the impact on stock prices." Journal of Finance, Vol 54, pp.581 - 622

Williamson, C. 3acoblus, $\AA_{a}$ 1998, "Weekly net cash fows estimated at \$9 billion." Pensions \& Investment, Vol 26(23), pp.27 - 29

Williamson, C. 1998, "Mutual fund cash runs low." Pensions \& Investments, Vol 26(22), pp.2 - 4 
Woerheide, W. 1982, "Investor response to suggested criteria for the selection of mutual funds." Joumal of Financial and Quantitative Analysis, Vol XVII(1), pp.129-140

Zhang, X. Edwards, F. 1998, "Mutual funds and stock and bond market stability." Journal of Financial Services Research, Vol 13(3)

Zheng, L. 1999, "Is money smart? A study of mutual fund investors' fund selection ability." The Joumal of Finance, Vol LV(3), pp.901 - 933

Zheng, L. 1999, "Who moves the market? - A study of stock prices and investment Cash Flows." University of Michigan, Unpublished working paper, Available at: www.papers.ssm.com

Zweig, J. 1996, "Today's hottest funds are too big for their britches." Money, Vol 25(4), p.146 


\section{APPENDICES}

A.

SUMMARY OF PRIOR RESEARCH STUDIES A2

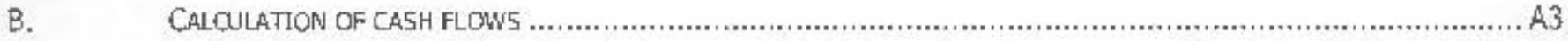

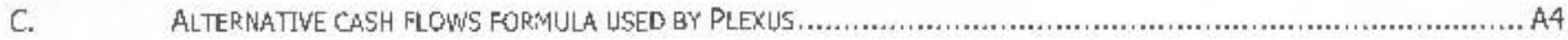

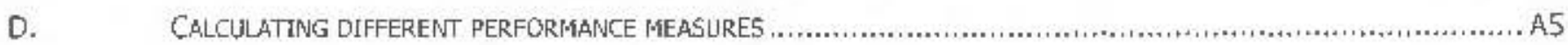

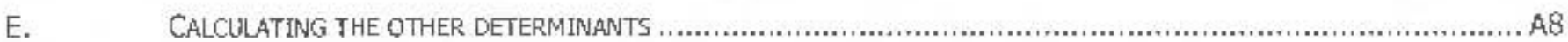

F. MOVEMENTS OF THE VARIOUS YARIAELES THROIJGH TIME UNDER INVESTGGATION .....................................A1O

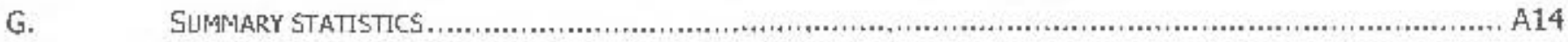

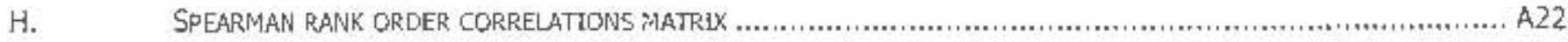

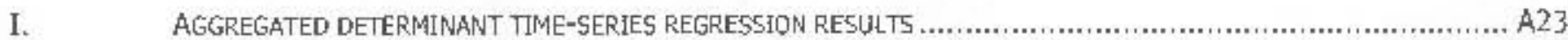

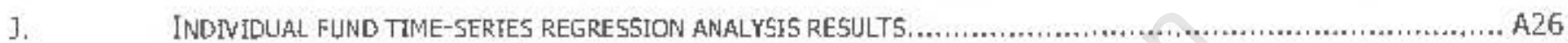




\section{A. Summary of prior research studies}

Appendix A presents a summary of 35 different research studies conducted in the United States: New Zealand. Australia and Spain from 1960 to 2003. Several reasons could be presented for the inconsistencies and differences in the findings of these studies. A change in the data definition could have a significant impact on the conclusions of a study. The most prominent reasons raised affecting the data definition. arise from the period covered by the studies. the sampling interval ${ }^{76}$ and the regression methods used" The different aggregation processes utilised in respect of fund categories; cash flows and return measures, et cetera, could also have influenced the findings. Different variables and combinations of variables were used by these studies and could explain the disparity between the findings.

\footnotetext{
${ }^{75}$ Most of the studies used monthly data, while others used daily, quarterly and annual data.

"The regression methods ranged from vector-auto-regression to bivariate regression.
} 


\begin{tabular}{|c|c|c|c|c|c|c|c|c|c|}
\hline Authar & $\begin{array}{l}\text { Yeat } \\
\text { of } \\
\text { souay }\end{array}$ & Country & $\begin{array}{l}\text { Sividy } \\
\text { perreal }\end{array}$ & requans, & Crouping ger & 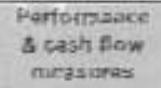 & Relateinalop & $\begin{array}{l}\text { Appreachi s } \\
\text { thetinquet }\end{array}$ & Findisys \\
\hline 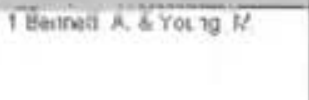 & 2060 & Vex=7aka & एक2 1897 & thor hy & $\begin{array}{l}\text { hivestiri int } \\
\text { objective }\end{array}$ & $\begin{array}{l}\text { Nat cesthicus } \\
\text { S miarker } \\
\text { relums }\end{array}$ & $\begin{array}{l}\text { Dorlemininar is } \\
\text { af eash nowis }\end{array}$ & $\begin{array}{l}\text { Stepwise } \\
\text { inuitivariata } \\
\text { ragrassion }\end{array}$ & 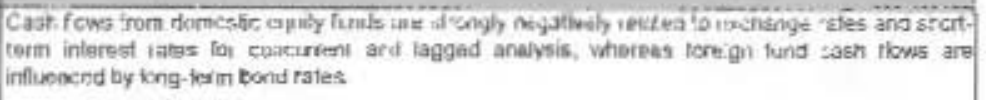 \\
\hline 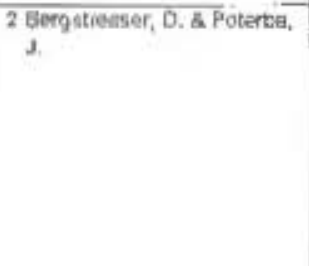 & 2002 & Unillad Stanss & $1093-1999$ & Nanitily & $\begin{array}{l}\text { Stuvesimert } \\
\text { objectrve }\end{array}$ & 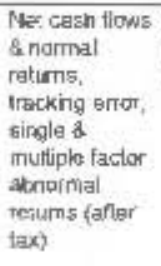 & $\begin{array}{l}\text { Cash lows \& } \\
\text { fund iotums } \\
\text { (aflar tax) }\end{array}$ & $\begin{array}{l}\text { Veclor auto } \\
\text { regrestion }\end{array}$ & 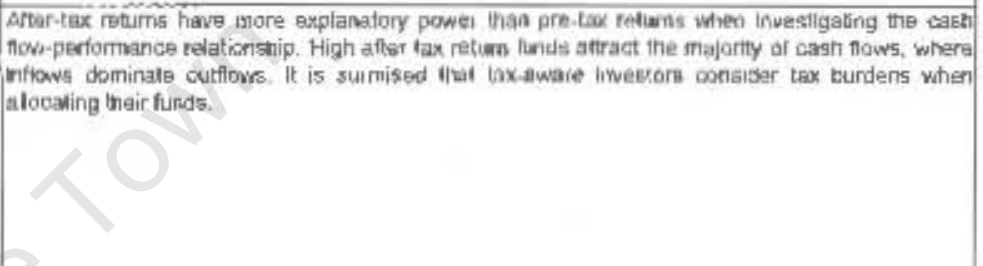 \\
\hline 3. Barkowitz, M. 8 Konswinz, V & 2000 & Unted Stales: & $1970-1000$ & Guartaly & Oen objective & 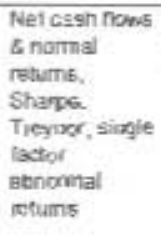 & $\begin{array}{l}\text { Casi flowe } 8 \\
\text { Nund returns }\end{array}$ & $\begin{array}{l}\text { lowitivarise } \\
\text { regention }\end{array}$ & 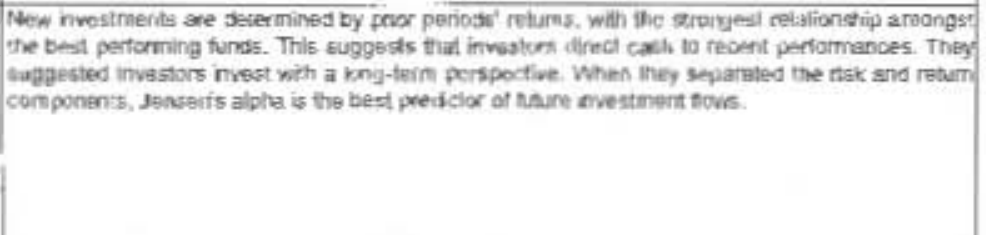 \\
\hline 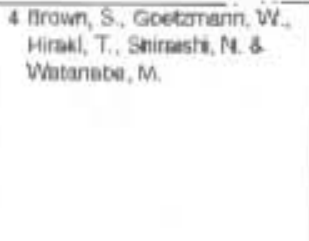 & 2002 & $\begin{array}{l}\text { Unitod Siates } \\
\text { 8 Japan }\end{array}$ & $1996 \cdot 2000$ & Dally & Con ojejictive & 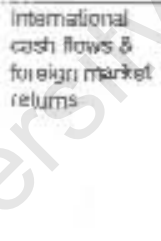 & $\begin{array}{l}\text { Cagit fluws } 8 \\
\text { aggregaie } \\
\text { retums }\end{array}$ & $\begin{array}{l}\text { Mtullivarale } \\
\text { iegreseion }\end{array}$ & 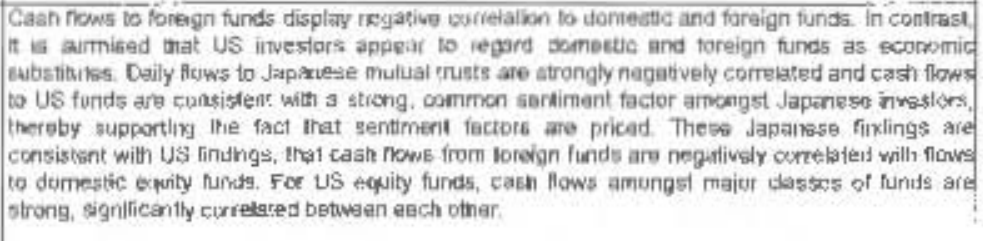 \\
\hline $\begin{array}{l}\text { SChordia } T \text {, Serkar, A \& } \\
\text { Sibrahmaryam, } A \text {. }\end{array}$ & 20011 & Uniled Slales & $1981-1895$ & Nonitity & $\begin{array}{l}\text { Bons A equaty } \\
\text { lunde }\end{array}$ & & 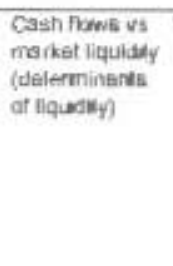 & $\begin{array}{l}\text { Veciar auto:- } \\
\text { iegrescion }\end{array}$ & 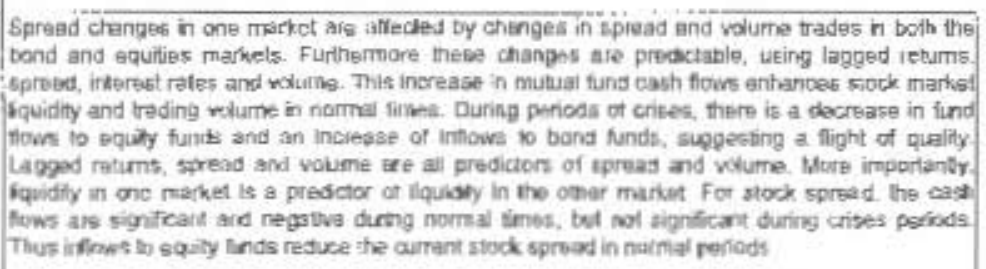 \\
\hline
\end{tabular}




\begin{tabular}{|c|c|c|c|c|c|c|c|c|c|}
\hline Auther & $\begin{array}{l}\text { Yeat } \\
\text { of } \\
\text { exudy }\end{array}$ & County & $\begin{array}{l}\text { Study } \\
\text { perioa }\end{array}$ & Hequency & Grouptina har & $\begin{array}{l}\text { Parformatice } \\
\text { \& nash fow } \\
\text { metsurea }\end{array}$ & Resaticenilip & $\begin{array}{l}\text { Aporeach of } \\
\text { then que }\end{array}$ & Finelagt \\
\hline 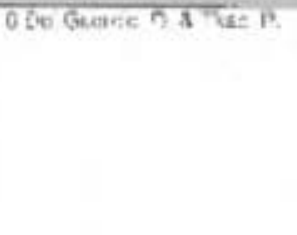 & 2005 & -ns stales & $287 \cdot-236$ & Armisily & $\begin{array}{l}\text { Sptron } \\
\text { bungenin-s }\end{array}$ & 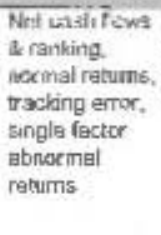 & 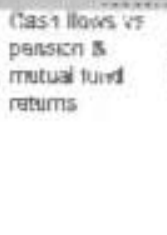 & $\begin{array}{l}\text { Crons- } \\
\text { sectional } \\
\text { negression }\end{array}$ & 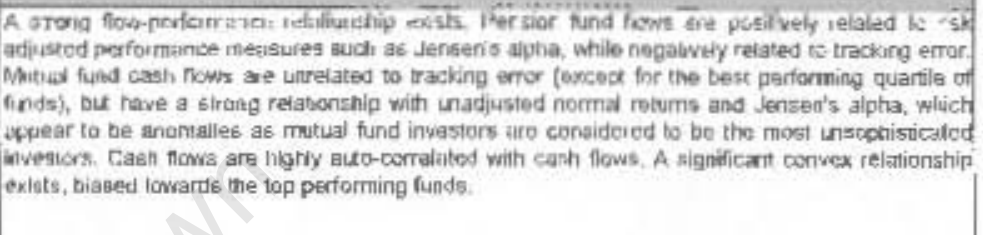 \\
\hline 7 Del Griordo, D \& TKas, P. & 2001 & United Scatas " & $1996-19091$ & Menthity & $\begin{array}{l}\text { Momingstat } \\
\text { raing obiective }\end{array}$ & 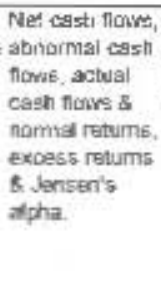 & $\begin{array}{l}\text { Cagh flowi } \\
\text { changes due to } \\
\text { Murmingeler } \\
\text { rating changes }\end{array}$ & $\begin{array}{l}\text { Event sudy } \\
\text { (insial rating. } \\
\text { changed } \\
\text { rating) \& } \\
\text { croso. } \\
\text { soctional } \\
\text { regroesion }\end{array}$ & 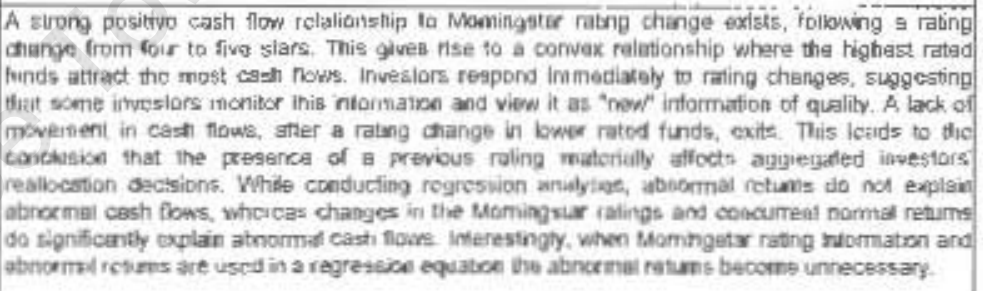 \\
\hline G Edicn, R. & 199 & Uniled Sisue: & $1865-1060$ & $\begin{array}{l}\text { Serti. } \\
\text { arnuaty }\end{array}$ & $\begin{array}{l}\text { Inowidual } \\
\text { hurvids }\end{array}$ & $\begin{array}{l}\text { In } 8 \text { out coch } \\
\text { mbers } 3 \text { nocinal } \\
\text { retums, gingle } \\
\text { tector alpha } \\
\text { ratums }\end{array}$ & $\begin{array}{l}\text { Cann nowes vis } \\
\text { luidd refurma s } \\
\text { trading octidity }\end{array}$ & $\begin{array}{l}\text { Mutivarabo } \\
\text { regressee }\end{array}$ & 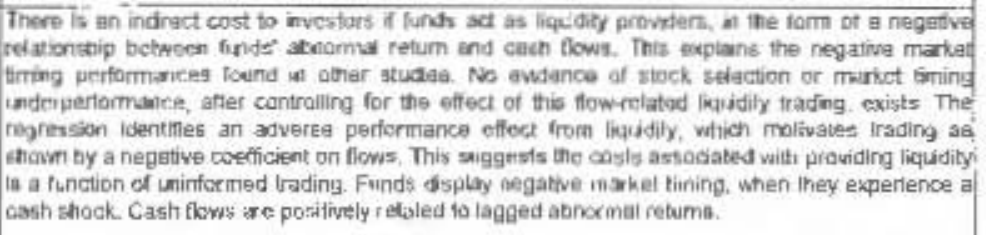 \\
\hline D Edeven R. \& Warmes I & 2001 & Lhited Statas & $\begin{array}{l}1896-1599 \\
\text { (Daily) a } \\
1994-1960 \\
\text { (Eemi. } \\
\text { woekly) }\end{array}$ & 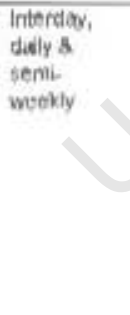 & Dum objective & $\begin{array}{l}\text { Expected \& } \\
\text { unexpecied } \\
\text { cash flows \& } \\
\text { normal nelurns }\end{array}$ & $\begin{array}{l}\text { Ággregated } \\
\text { creh flows vs } \\
\text { markel rotum }\end{array}$ & $\begin{array}{l}\text { Multtwarialo } \\
\text { ragression }\end{array}$ & 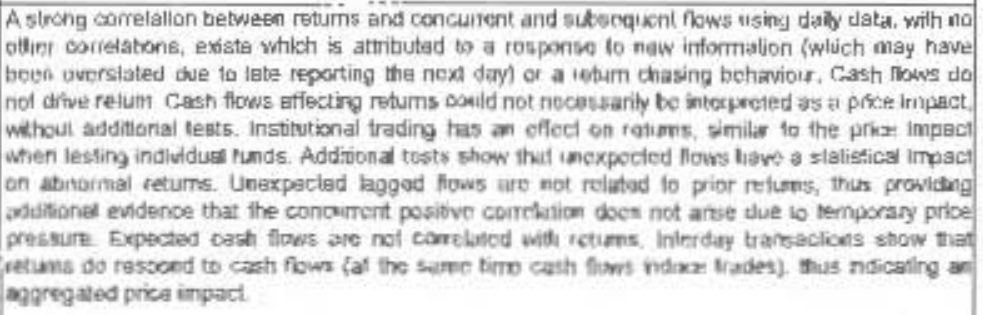 \\
\hline
\end{tabular}




\begin{tabular}{|c|c|c|c|c|c|c|c|c|c|}
\hline Atethor & $\begin{array}{l}\text { Your } \\
\text { of } \\
\text { stuidy }\end{array}$ & Country & $\begin{array}{l}\text { Sindy } \\
\text { paricat }\end{array}$ & Fnequensy & Grovpleo par & $\begin{array}{l}\text { Pedommanre } \\
5 \text { cash floor } \\
\text { measwites }\end{array}$ & Ratationahip & 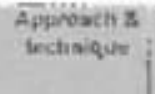 & Fivelings \\
\hline $\begin{array}{l}\text { ic illon, I, cuber, it b } \\
\text { Busen :- }\end{array}$ & हरण & Un: $x=5 x=5$ & 1ूa - mon & $\begin{array}{l}\text { Nonititiy a } \\
\text { matually }\end{array}$ & roestunas & $\begin{array}{l}\text { Leaxprcicod } \\
\text { cash flows \& } \\
\text { axcess returns, } \\
\text { Jenseris } \\
\text { alpria. }\end{array}$ & $\begin{array}{l}\text { Cash flows } 6 \\
\text { fund retums: }\end{array}$ & $\begin{array}{l}\text { Cevor } \\
\text { soctional } \\
\text { regrestaion }\end{array}$ & 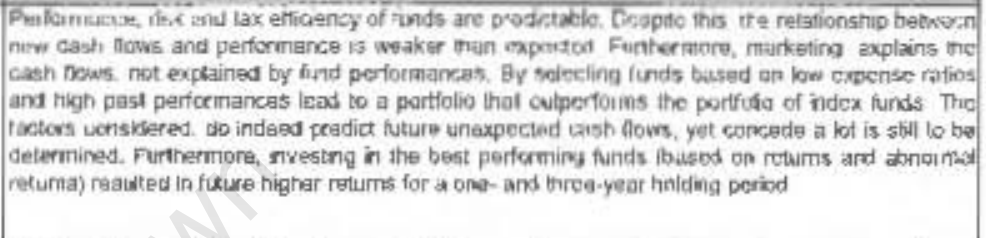 \\
\hline 11 Fant, $F$. & 1099 & United States & 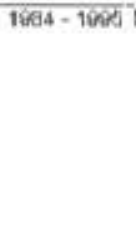 & Monktay & Oren okjective: & 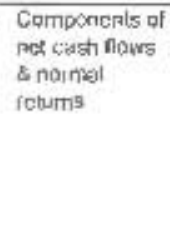 & $\begin{array}{l}\text { Casth fitive vI } \\
\text { niarkot ceture }\end{array}$ & vector anto: & 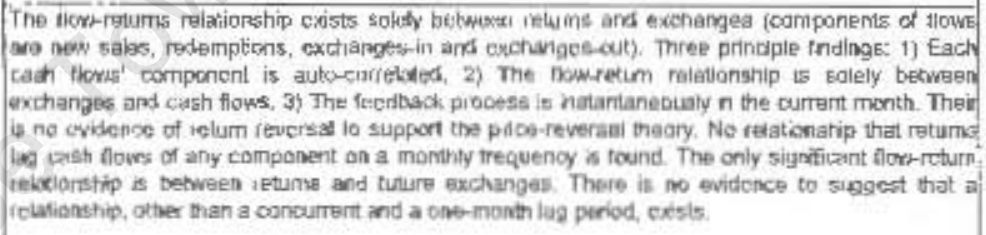 \\
\hline 12 Farm $\vec{F} . \triangle O N$ Neal $E$ & 2000 & Unites Shates & 1978 - 1927 & Nowany & $\begin{array}{l}\text { twestiment } \\
\text { objective }\end{array}$ & 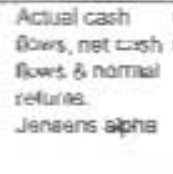 & $\begin{array}{l}\text { Coeh thoes \& } \\
\text { retima }\end{array}$ & 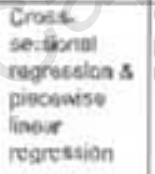 & 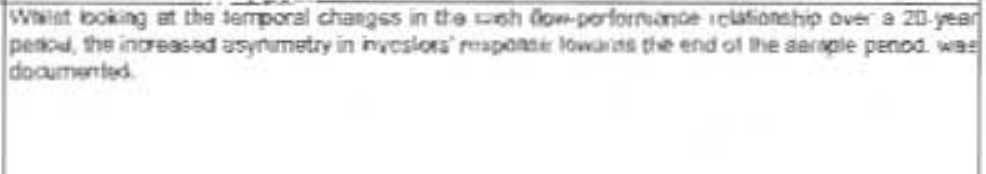 \\
\hline "sistrite. P. & 1967 & United Sithes & 1964 - 1968 & Monitivy & Own cejective & $\begin{array}{l}\text { Nat cash flars } \\
\text { \& change in } \\
\text { teppita }\end{array}$ & $\begin{array}{l}\text { Cash flows ve } \\
\text { shampe in } \\
\text { Gopilat value }\end{array}$ & Contation & 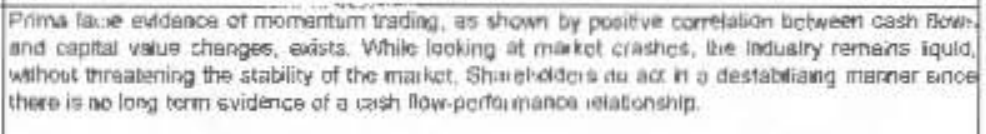 \\
\hline 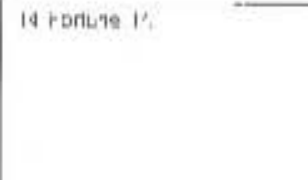 & 1900 & Uniterd States & 1927.7998 & Markiny & Own chjectivis & $\begin{array}{l}\text { Nei cash fions } \\
\text { s nommal } \\
\text { rebums }\end{array}$ & $\begin{array}{l}\text { Cash flows vs } \\
\text { market rcturns }\end{array}$ & $\begin{array}{l}\text { Vector vido- } \\
\text { ingrission }\end{array}$ & 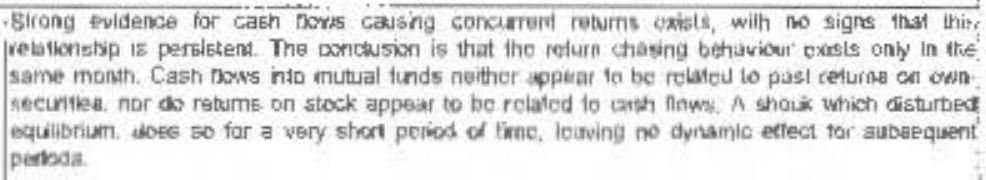 \\
\hline 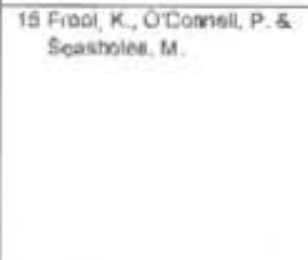 & 2001 & Indernational & $1024-1035$ & Daily & $\begin{array}{l}\text { Irtentrationat } \\
\text { fineds }\end{array}$ & $\begin{array}{l}\text { Intemastional } \\
\text { cash flows a } \\
\text { foreign market } \\
\text { returns }\end{array}$ & $\begin{array}{l}\text { Inderngilonal } \\
\text { cash wows vo } \\
\text { market retume }\end{array}$ & $\begin{array}{l}\text { Voctor audo } \\
\text { rogrwsicn s } \\
\text { Do-varince }\end{array}$ & 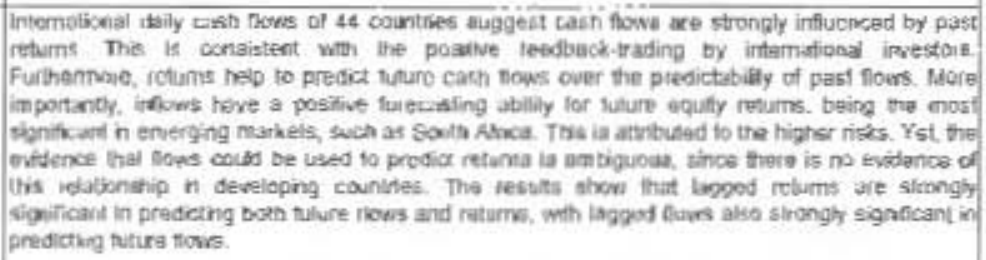 \\
\hline
\end{tabular}




\begin{tabular}{|c|c|c|c|c|c|c|c|c|c|}
\hline Anthar & $\begin{array}{c}\text { Yaar } \\
\text { nif } \\
\text { study }\end{array}$ & Crititry & $\begin{array}{l}\text { Sluity } \\
\text { perrout }\end{array}$ & Frequething & Gresuppirilig pes & $\begin{array}{l}\text { Petfariminite } \\
\text { t. Eash now } \\
\text { minstures }\end{array}$ & Relatio isjaip & $\begin{array}{l}\text { Apenosict \& } \\
\text { techilique }\end{array}$ & Flatlisgs \\
\hline 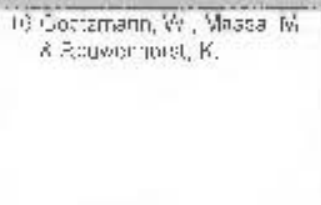 & 10000 & Unr: S1:165 & T.56-500 & Da:y & 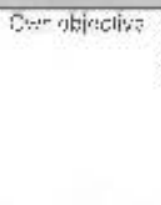 & $\begin{array}{l}\text { Nel caj: firs: } \\
\text { anxirial } \\
\text { returng }\end{array}$ & 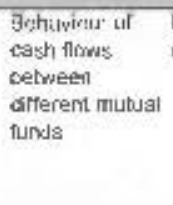 & $\begin{array}{l}\text { R.ollivitifialt: } \\
\text { regression }\end{array}$ & 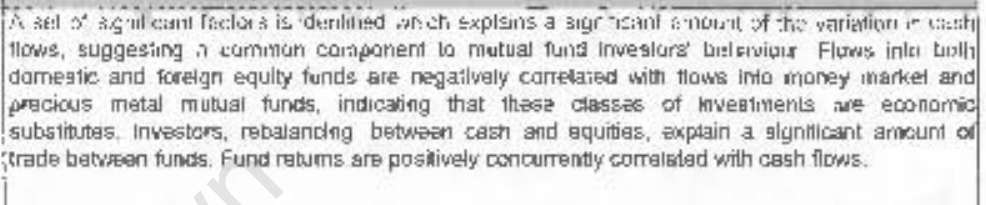 \\
\hline $\begin{array}{l}\text { I7 Goriagu, A, Nijman, T. \& } \\
\text { Werker, B. }\end{array}$ & 200021 & Uniked Slatas & $1976-1928$ & Mundthy & $\begin{array}{l}\text { Irvesiment } \\
\text { ntjos=tive }\end{array}$ & $\begin{array}{l}\text { Net rash flows } \\
\text { \& nuirnial } \\
\text { returnas. Eaur } \\
\text { factors Jensen's } \\
\text { alpha }\end{array}$ & 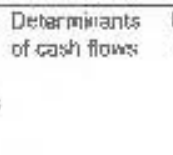 & 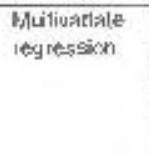 & 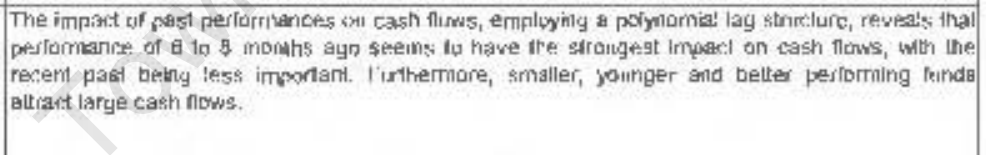 \\
\hline 18 Gruber, If & 1996 & Uniled Silale日 & $1865-1984$ & $\begin{array}{l}\text { Mesming \& } \\
\text { querlerty }\end{array}$ & $\begin{array}{l}\text { Grouped into } \\
\text { declleg }\end{array}$ & $\begin{array}{l}\text { Nel casit tlows } \\
\text { \& normal } \\
\text { returns, axcoss } \\
\text { retums, single } \\
\text { \& four lador } \\
\text { ters:er's } \\
\text { alpha }\end{array}$ & $\begin{array}{l}\text { Cash flows vs } \\
\text { fund ratums } \\
\text { (6) }\end{array}$ & $\begin{array}{l}\text { Multivariate } \\
\text { regression: } \\
\text { cross:- } \\
\text { spocticinal } \\
\text { regression. }\end{array}$ & 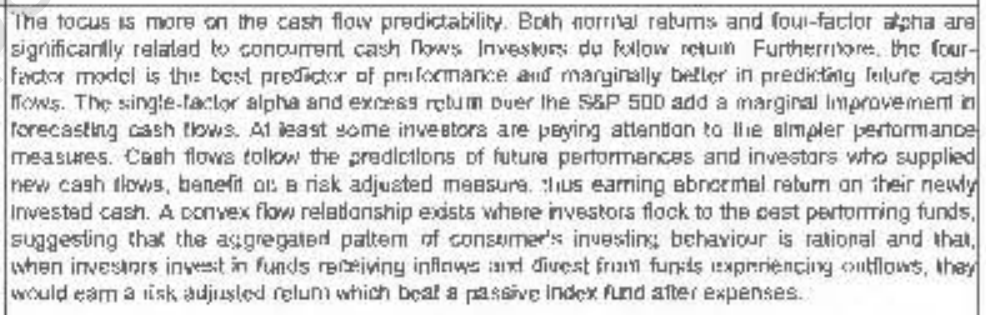 \\
\hline 18 Jan, P. \& Wu, J. & 2000 & Lnilied SLlfles & $1984-1986$ & Quarterty & Controd group & 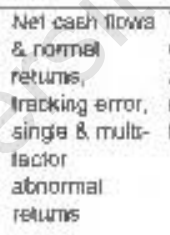 & $\begin{array}{l}\text { The irrluenice } \\
\text { of pro and port } \\
\text { advertising } \\
\text { ratums on cash } \\
\text { flaws }\end{array}$ & $\begin{array}{l}\text { Naltwariata } \\
\text { Nagression }\end{array}$ & 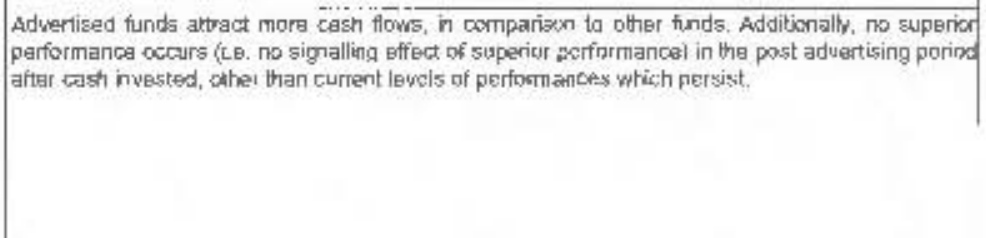 \\
\hline 20 Jamea, C. \& Kerceski, J. & 2002 & Unibed siales & $1995 \cdot 1089$ & $\begin{array}{l}\text { Annualiy } s^{\circ} \\
\text { momihly }\end{array}$ & $\begin{array}{l}\text { inivestiment } \\
\text { cojectiva }\end{array}$ & $\begin{array}{l}\text { Net cast flows } \\
\text { 8. normal } \\
\text { retums, excoss } \\
\text { retums }\end{array}$ & 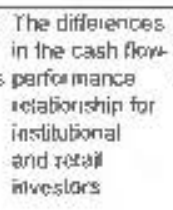 & $\begin{array}{l}\text { Piघcawiso } \\
\text { + lincad } \\
\text { regres:inn }\end{array}$ & 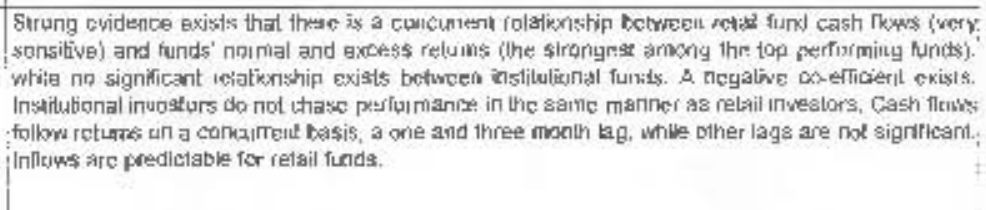 \\
\hline
\end{tabular}




\begin{tabular}{|c|c|c|c|c|c|c|c|c|}
\hline Anthar & $\begin{array}{l}\text { Year } \\
\text { uf } \\
\text { staily }\end{array}$ & Conustry & $\begin{array}{l}\text { Simdy- } \\
\text { periud }\end{array}$ & Gruaping per & $\begin{array}{l}\text { Perroniance } \\
\text { \& cash Row } \\
\text { measures }\end{array}$ & Rạlationshup & $\begin{array}{l}\text { Approar.h \&: } \\
\text { tarhuiquas }\end{array}$ & Findinge \\
\hline $21 \mathrm{~K} . \exists \subset \in \varepsilon \%, \mathrm{~J}$ & 250 & Unile:ed Slat:mi & 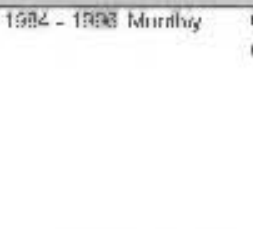 & 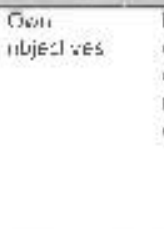 & 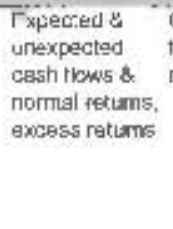 & $\begin{array}{l}\text { Cus? tlows is } \\
\text { tund \& market } \\
\text { ratums }\end{array}$ & $\begin{array}{l}\text { bilunirsiate } \\
\text { rearessiknt }\end{array}$ & 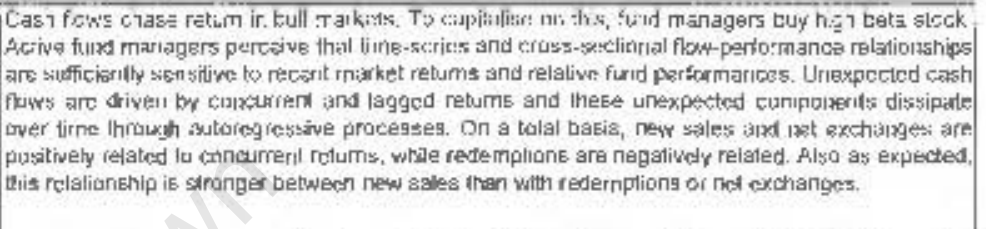 \\
\hline 22 _el:as M. & 1907 & $\begin{array}{l}\text { United States } \\
\text { \& Neilherlands }\end{array}$ & $1985-1982$ morithly & $\begin{array}{l}\text { Onmin } \\
\text { abjedtives }\end{array}$ & 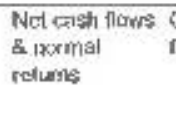 & $\begin{array}{l}\text { Cossh flowels vs } \\
\text { fisd inturts }\end{array}$ & $\begin{array}{l}\text { Multweribata } \\
\text { regression }\end{array}$ & 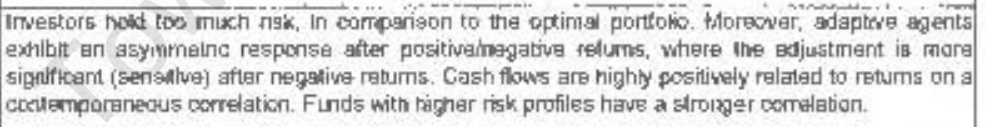 \\
\hline 23 Proter, $\mathrm{M}$. & 2000 & United Slatas & 1964 - 1990 shantily & $\begin{array}{l}\text { Irwastmert } \\
\text { stipectives: }\end{array}$ & $\begin{array}{l}\text { Expectled \& } \\
\text { inekpecled nel } \\
\text { casin nows \& } \\
\text { market retumg }\end{array}$ & $\begin{array}{l}\text { Deleminanls } \\
\text { of taen flows }\end{array}$ & $\begin{array}{l}\text { Midthariete } \\
\text { regregelon }\end{array}$ & 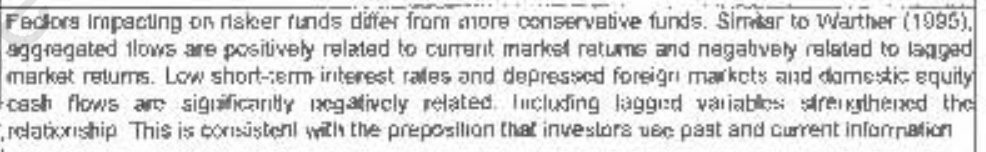 \\
\hline 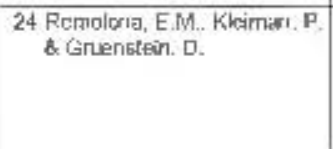 & 1997 & Uniled Slates: & 1986 - 1998 Mortity & $\begin{array}{l}\text { Oanh } \\
\text { objectives }\end{array}$ & 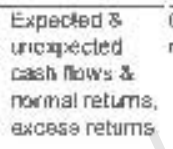 & $\begin{array}{l}\text { Cast thess ins } \\
\text { nuarket ictum }\end{array}$ & $\begin{array}{l}\text { Instrumental } \\
\text { variable \& } \\
\text { vactor auto- } \\
\text { regrassion }\end{array}$ & 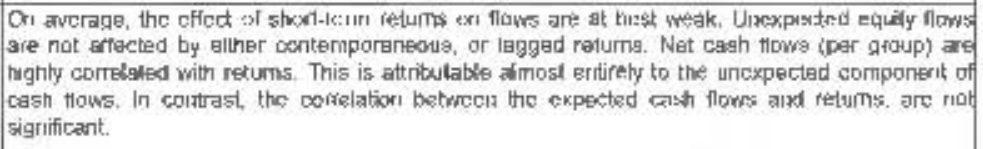 \\
\hline F Rodinger, M & 1995 & Unthed Strege- & 18:i - 1983 Amudy & $\begin{array}{l}\text { Orm } \\
\text { objotives }\end{array}$ & 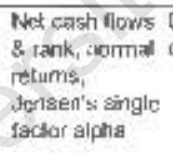 & $\begin{array}{l}\text { Costerminants: } \\
\text { af cosin now }\end{array}$ & $\begin{array}{l}\text { Cross- } \\
\text { Extional } \\
\text { regresgion }\end{array}$ & 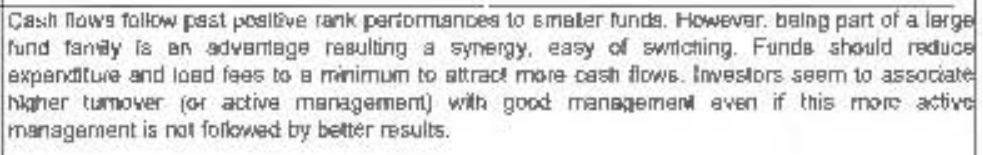 \\
\hline 20 S̈antini, D. \& Abcr, d. & 1976 & Unilad Stales & 1973 - 1945 Suarierty & $\begin{array}{l}\text { Own } \\
\text { objectives: }\end{array}$ & 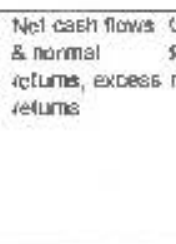 & $\begin{array}{l}\text { Cissh thowe } \\
\text { solbuing anter } \\
\text { measuree }\end{array}$ & $\begin{array}{l}\text { Ciross- } \\
\text { sedknal } \\
\text { regresilon a } \\
\text { time-serles } \\
\text { ragresion }\end{array}$ & 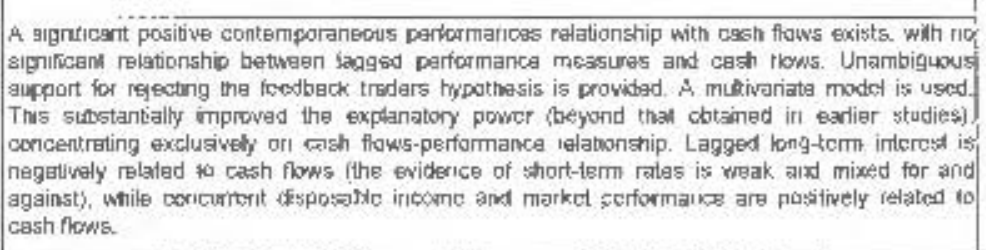 \\
\hline izj Sartin, D. \& Abar. $\mathrm{J}$. & $18 \%$ & United Sitas:- & 19774 - 1986 Quartarty & Equily fulxts & 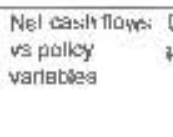 & $\begin{array}{l}\text { Cast rowis \& } \\
\text { palloy ventaltes }\end{array}$ & $\begin{array}{l}\text { Crovs } \\
\text { sectional } \\
\text { reglession }\end{array}$ & 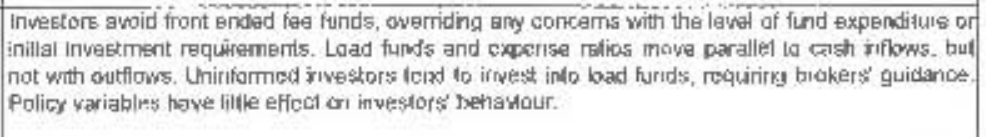 \\
\hline
\end{tabular}




\begin{tabular}{|c|c|c|c|c|c|c|c|c|c|}
\hline Austor & 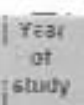 & Coevery & $\begin{array}{l}\text { Stuvidy } \\
\text { jenod }\end{array}$ & Frnactiky & Grouping per & $\begin{array}{l}\text { Pertoraisnce } \\
\text { A cash nowi } \\
\text { netsureas }\end{array}$ & Relationship & $\begin{array}{l}\text { Approsch s } \\
\text { tecthingus }\end{array}$ & Findiegs \\
\hline 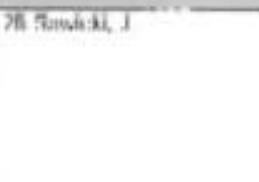 & 2001 & Austrafia & $1005-1906$ & Annecenth & 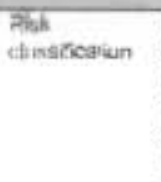 & 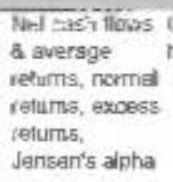 & $\begin{array}{l}\text { Cast rows vs } \\
\text { had returms }\end{array}$ & $\begin{array}{l}\text { De twariate } \\
\text { legrasvion }\end{array}$ & 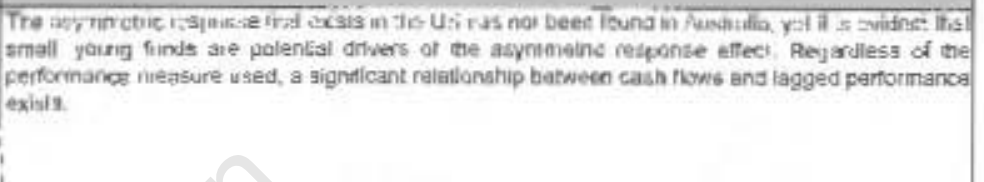 \\
\hline 20 Sim, E. \& Tufano.P. & 1998 & Undered States & $1971-1090$ & $\begin{array}{l}\text { Moirthy } \\
\text { inteod) }\end{array}$ & $\begin{array}{l}\text { Own } \\
\text { objectives }\end{array}$ & 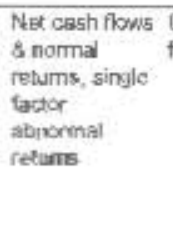 & $\begin{array}{l}\text { Cesh flows vs } \\
\text { furd roturns }\end{array}$ & $\begin{array}{l}\text { Croces. } \\
\text { eectional } \\
\text { regression }\end{array}$ & 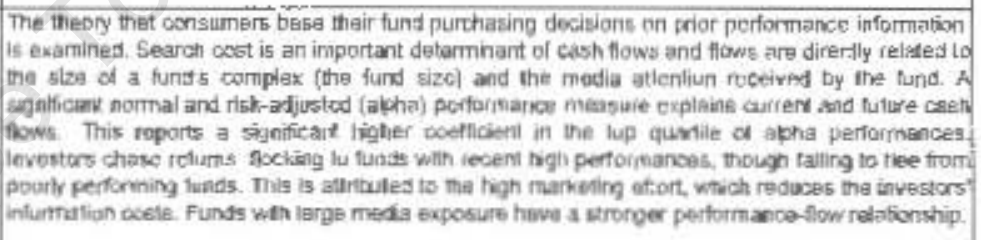 \\
\hline So spila. A & 1900 & Unitad Skakes - & $1960-1007$ & Moently & $\begin{array}{l}\text { Imbiviaval } \\
\text { furts }\end{array}$ & $\begin{array}{l}\text { Achual net cash } \\
\text { flaws o nombal } \\
\text { peturng }\end{array}$ & $\begin{array}{l}\text { Casn Bows vo } \\
\text { fund refoms }\end{array}$ & $\begin{array}{l}\text { Molvariote } \\
\text { regreason }\end{array}$ & 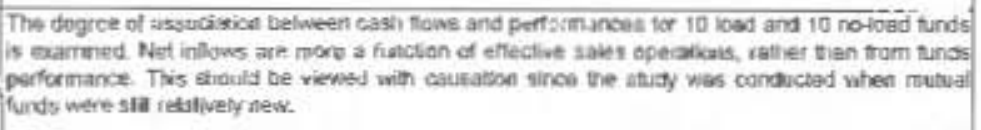 \\
\hline 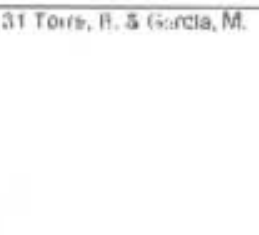 & 2008 & spar & $1592-1087$ & $\begin{array}{l}\text { Anniwly s } \\
\text { manthisy }\end{array}$ & Equity funds & 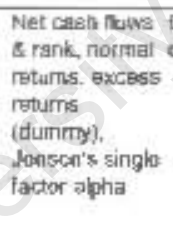 & $\begin{array}{l}\text { Delarmularis } \\
\text { of cash flows }\end{array}$ & $\begin{array}{l}\text { Stap-wiso } \\
\text { lingar } \\
\text { regressike \& } \\
\text { time-verins } \\
\text { mullwaiste } \\
\text { ingressical }\end{array}$ & 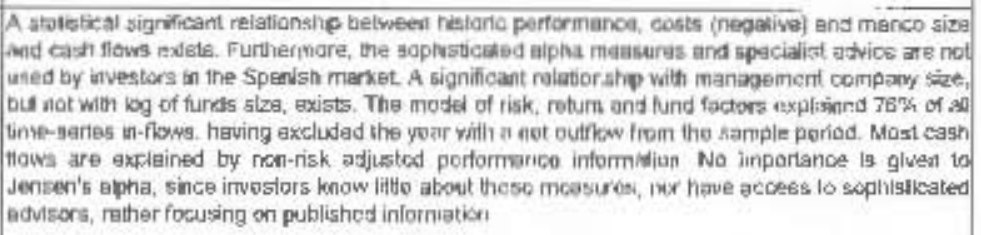 \\
\hline 32 Worthar, $V$ & 9995 & Unined Stakes & $1954-1$ FQS & $\begin{array}{l}\text { Woekily, } \\
\text { mantily, } \\
\text { querentys } \\
\text { anreally }\end{array}$ & abjecthes & $\begin{array}{l}\text { Expecled \& } \\
\text { unexpected } \\
\text { carti flows \& } \\
\text { nomal retums }\end{array}$ & $\begin{array}{l}\text { Casi flows: vs } \\
\text { manket return }\end{array}$ & $\begin{array}{l}\text { Vector auto } \\
\text { regrestion }\end{array}$ & 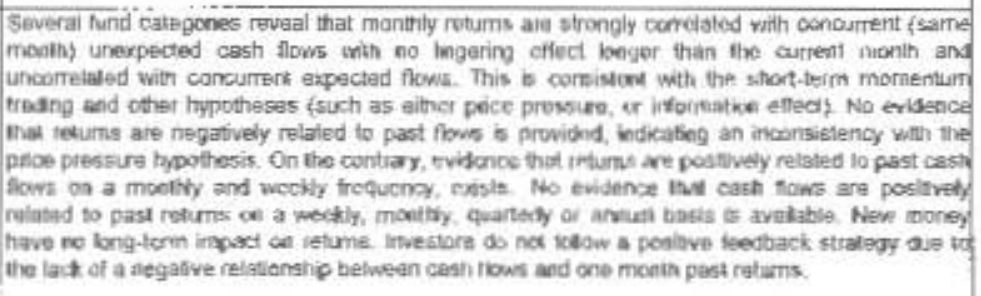 \\
\hline
\end{tabular}




\begin{tabular}{|c|c|c|c|c|c|c|c|c|c|}
\hline Author & $\begin{array}{l}\text { Yeat } \\
\text { if } \\
\text { stedy }\end{array}$ & coentery & $\begin{array}{l}\text { Stedy } \\
\text { period }\end{array}$ & riequescy & Grouping per & $\begin{array}{l}\text { Performance } \\
\text { S cash flow. } \\
\text { measuras }\end{array}$ & Pretationsthip & $\begin{array}{l}\text { Approsch s } \\
\text { iectinique }\end{array}$ & Findings: \\
\hline \multirow{2}{*}{$\begin{array}{l}\text { Ongec } \\
33 \text { Conten, P. } 8 \text { Lemer. } 1 \text {. }\end{array}$} & & & & & & & & & \\
\hline & 2000 & Unilad Stater & 1987.1005 & Guartenly & $\begin{array}{l}\text { tacirians } \\
\text { Mveaintenil } \\
\text { dejectiven }\end{array}$ & & $\begin{array}{l}\text { Cash flows vs } \\
\text { letum of } \\
\text { indertying } \\
\text { invesimentis }\end{array}$ & $\begin{array}{l}\text { Mutivariato } \\
\text { rogrustion }\end{array}$ & 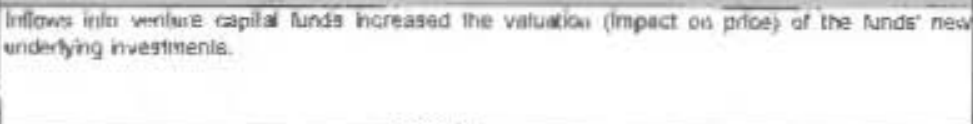 \\
\hline $\begin{array}{l}34 \text { Hendricks, D. Patol, J. \& } \\
\text { Zerkhausar, R. }\end{array}$ & 1093 & Unithed Stales & 1974.1568 & Quarterty & & & $\begin{array}{l}\text { Stort-tarm } \\
\text { persistence ol } \\
\text { performatices }\end{array}$ & $\begin{array}{l}\text { Serial } \\
\text { correlation }\end{array}$ & 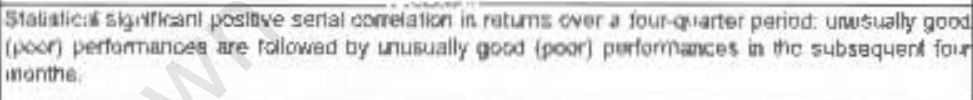 \\
\hline as zharig. $X .8$ Edwards, $F$. & 1989 & Uniled Statas. & $1061-1960$ & Monthly & $\begin{array}{l}\text { Own } \\
\text { objectives }\end{array}$ & & $\begin{array}{l}\text { Relalioniship } \\
\text { between rash } \\
\text { hows ve sioch } \\
\text { S thond markat } \\
\text { ietums }\end{array}$ & $\begin{array}{l}\text { Grangor } \\
\text { cosisaility teat } \\
\text { \& } \\
\text { instrumbnial } \\
\text { variable }\end{array}$ & 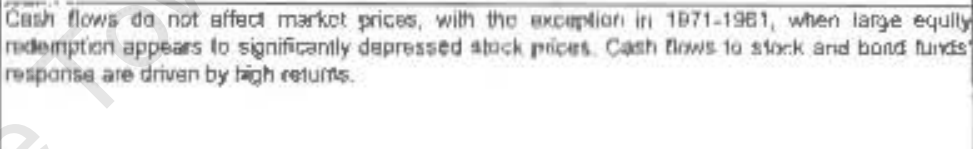 \\
\hline
\end{tabular}




\section{B. Calculation of cash flows}

"Net cash flows are defined as the proceeds in cash received by the mutual fund from investors less the cost of the capital shares, which investors redeem for cash." (Spitz, 1970, p.141)

The formulae, used to extract cash flows from the fund size data, are the same as those used in the research studies presented in appendix A. Net implied cash flows are defined as the net growth in fund assets beyond reinvested dividends and interest. Automatic reinvested dividends and interest are not considered part of cash flows, since most investors are likely to forgo conscious re-evaluation of their investments at the time of reinvestment. Implied cash flows (referred to as 'cash flows') were normalised, to control for any trend in cash flows during the period, thus minimising the possible effect of heteroscedasticity and auto-correlation in cash flows. This percentage flow was preferred above the rand cash flows, when cash flows are positively related to fund size, whereby large funds attract higher absolute cash flows regardless of performance (Del Guercio and Tkac, 2002). These normalised cash flows were calculated as follows:

$$
C F_{t}=\frac{T N A_{t}-T N A_{t-1} *\left(1+R_{t}\right)}{T N A_{t-1}}
$$

Where: $\quad$ TNA, is total fund size at time $t$

$T N A_{t-1} \quad$ is total fund size for fund at the beginning of the period $t$

$\boldsymbol{R}_{t} \quad$ is the fund's return over the period $t$

$C F_{\ell} \quad$ reflects the percentage growth of a fund in excess of the growth that would have occurred had no new funds flowed in and all dividends been reinvested

The annual cash flow measure was modified, using a formula developed by Zheng (1999) and Bergstresser and Poterba (2002), to account for the fact that cash flows occurred throughout the year:

$$
C F_{a d j_{t}}=\frac{C F_{t}}{\left(1+1 / 2 * R_{t}\right)}
$$

Where: $\quad \boldsymbol{R}_{t} \quad$ is the normal return over the entire year $t$

$C F_{\varepsilon} \quad$ is the annual cash flow for the fund

CFadj ${ }_{t} \quad$ is the adjusted annual cash flow for the fund

This adjustment was considered when testing the cross-sectional findings. This adjustment was not necessary for the time-series analysis since short time intervals were utilised. The findings remained unaffected; consequently, as the adjustment had an insignificant impact on the cash flow figures, the results are omitted. This is consistent with the findings by Ippolito (1992), Santini and Aber (1998) and Zheng (1999), when they used an adjusted cash flow measure. 


\section{Alternative cash flows formula used by Plexus}

The formulae, outlined in appendix B, assume that cash flows occurred at the end of a period. Previous research papers found that the results were unaffected when recalculating this measure for flows occurring at the beginning, halfway through or continuously throughout the periods. OptiVest Plexus Asset Management publishes a cash flow index, which assurnes that cash flows occur at the beginning of the period and investors earn a return on their invested money. The following information, presented below, is an extract obtained from the Plexus website available at: umw.plexus.co.za dated 10 September 2000 . This formula was used to test the accuracy of the cash flow measure in appendix $B$ on a sample basis of five funds. The cash flows, using the two measures, were similar.

Cash flows might be defined as the total market value at the end of the period, deflated by the change in the price over the period, minus the total market value at the beginning of the period. The net cash flows were calculated as follows:

$$
C F_{t}=\frac{\left[\frac{T N A_{t}}{\left(P_{t} / P_{t-1}\right)}\right]-T N A_{t-1}}{T N A_{t-1}}
$$

\begin{tabular}{|c|c|c|}
\hline \multirow{5}{*}{ Where: } & $\mathrm{CF}_{t}$ & reflects the implied cash flows \\
\hline & $T N A_{\imath}$ & is the total market value for fund at the end of period $t$ \\
\hline & $r N A_{t-1}$ & $\begin{array}{l}\text { is the total market value for fund at the beginning of the } \\
\text { period } t\end{array}$ \\
\hline & $P_{t}$ & is unit price for fund at the end of the period $t$ \\
\hline & $P_{t-1}$ & is unit price for fund at the beginning of the period $t$ \\
\hline
\end{tabular}

This formula is based on the following rational: the market value of a unit trust is a function of the unit price and the number of units in the fund. A change in the value of the underlying assets will result in a change in the price, while the flow of funds into or out of the unit trust will result in a change in the number of units. In order to estimate the flow of funds into or out of a unit trust from its NAV, it is necessary to eliminate the effect of any change in the value of the underlying assets from the change in the NAV. The net effect on the NAV will then be restricted to changes due to the flow of funds into or out of the unit trust. 


\section{Calculating different performance measures}

An investigation into the determinants of cash flows is far from perfect because the best performance measure utilised by investors, is still a matter of some uncertainty (Elton et al. 2002). It is unciear which performance or risk measures are most salient to investors or aver which period the measure should be used. However, it is not the purpose of the dissertation to prove which measures are the best predictors of the behaviour of investors but rather to reach a generat conclusion about performance. Therefore, alternative measures were used over different periods. Likewise, different performance figures had to be considered because institutional and relail investors were grouped together as outlined in section 2.3.2.

Four performance measures were considered: (i) normal returns, (ii) absolute performance rankings, which are freely available and most widely used, (iii) excess returns over the ALSI, being the official and best-known benchmark for General Equity unit trusts and lastly (iv) Jensen's abriormal returns, taking risk into account. Throughout this dissertation, reference is made to different performance figures used by other researchers. Table $\{8$ shows the number of times the different performance measures were used in the research studies presented in appendix $\mathrm{A}$.

\section{Table 18. The number of times the performance measures were used}

\begin{tabular}{|c|c|c|c|}
\hline Normal, returns & Excess returns & $\begin{array}{c}\text { Jengen's single factor abnormal } \\
\text { returns }\end{array}$ & $\begin{array}{c}\text { Jensen's multiple factor abnomal } \\
\text { returns }\end{array}$ \\
\hline 27 & 12 & 13 & 4 \\
\hline
\end{tabular}

\section{D.1: Normal returns and rankings}

The regression test utilised the original unadjusted normal fund returns (after (ransaction costs) from Standard \& Poors (S\&P) Micropal. Holding period returns were computed, using a change in wealth over the holding period, assuming reinvestment of all dividends and capital gains. The tax effect on investors could not be determined, therefore, pre-tax returns were used. Holding period returns were calculated as follows:

$$
R_{t}=\frac{\left(T N A_{t}+D_{t}\right)-T N A_{t-1}}{T N A_{t-1}}
$$

Where: $\quad T N A, \quad$ is total fund size for fund at time $t$

$D$, is distribution for fund at time t

$\boldsymbol{R}$, reflects the return on the fund

In this case, the research used realised past returns. rather than a measure of expected return, since it is likely that unil trust investors do not have the opportunity to interact with portfolio masagers to develop an expectation. It is likely that they would rely on past fund managers' track records and performances. The periodic absolute rankings of each fund for the period relative to its peers: were used, represented by " 1 " for the best performing fund and so forth (Rockinger, 1995) 


\section{D.2: Excess return over the ALSI}

The unit trust returns were also adjusted to relative performance terms which were determined by deducting the return on the ALSI from the normal fund returns. This enabled consideration to be given to the fund's ability to outperform its published benchmark. The return on the ALSI was used since it is freely available to all investors and is used frequently in advertising as a benchmark. The ALSI is also considered as the official benchmark of General Equity unit trusts (AUT, 2002). The following formula was used to calculate this excess return:

$$
\boldsymbol{R} e_{t}=\boldsymbol{R}_{t}-\boldsymbol{R} \boldsymbol{m}_{t}
$$

Where: $\quad \boldsymbol{R} e_{t} \quad$ is the excess return over the ALSI at period $t$

$\boldsymbol{R}_{t} \quad$ is the normal return on the individual unit trust at period $t$

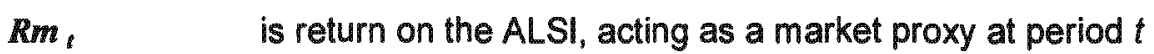

\section{D.3: Jensen's abnormal risk-adjusted return}

This dissertation used these simple measures for most of the tests, supplementing them with more formal portfolio performance measures, such as Jensen's alpha. Jensen's measure was calculated using the formula:

$$
\alpha_{t}=\boldsymbol{R}_{t}-\left[\boldsymbol{R} f_{t}+\beta_{1} *\left(\boldsymbol{R} m_{t}-\boldsymbol{R} f_{t}\right)\right]
$$

Where: $\quad \alpha$

is the abnormal return above that predicted by capital asset pricing model or the risk-adjusted return of the unit trust at period $t$

$\boldsymbol{R}_{t} \quad$ is the return on the unit trust at period $t$

$R m, \quad$ is the market proxy return at period $t$

$\beta_{1} \quad$ is the slope of the returns on the unit trust (the change in returns on the fund with respect to the change in market returns) at period $t$

$R f_{i}$ is the monthly 90 -day $N C D$, used as the risk-free rate, at period $t$

The Bankers Acceptance (BA), 90-day Negotiable Certificates of Deposit (NCD) and 3-month Treasury Bill (T-Bill) rates were considered as the risk-free rate. These three interest rates are significantly correlated $\left(R^{2}=+1.0 .995\right)$. The $B A$ and $T$-Bill rates are alike, with the NCD rates being higher, on average, by $0.5 \%$. Financial literature suggests that the T-Bill rate should be used for the risk-free rate since its default risk is zero. However, in South Africa, the NCD rates are considered to be more liquid, since T-Bills are previously prescribed liquid asset requirements for life office, pension funds and insurance companies. Furthermore, NCD rates have a short maturity and are free from default risk (Ross et al. 1996). As a result, the 90-day NCD was used. 
The betas used, were obtained from the University of Pretoria Unit Trust Survey for either a 36-, or 60-month period, depending on the age of the fund. Either the three- or the five-year betas could be used, since unit trust betas tend to remain stable ${ }^{78}$. When comparing the betas, it was found that they were not significantly different when calculated over a three- or five-year period. Funds younger than three years were excluded from the sample when calculating abnormal returns.

\section{D.4: Annualising returns}

To calculate rolling annual performances from monthly performance figures, a summation formula was utilised:

$$
\boldsymbol{R} a_{a}=\left[\left(1+R_{t}\right) *\left(1+R_{t+1}\right) * \ldots *\left(1+R_{t+12}\right)\right]-1
$$

Where: $\quad \boldsymbol{R} \boldsymbol{a}_{\boldsymbol{a}}$

is the annual return

$R_{t}$

is the interval percentage return forming the basis for the annual return

\footnotetext{
7s A study by Du Plessis (1974), outlining the characteristics of South African mutual funds, concluded that there is theoretical justification for using beta as a measure of risk. Furthermore, he confirmed that betas appear to be remarkably stable for unit trusts. This indicates that these coefficients would explain the historical movement in the value of funds' units and could be used to predict future movements.
} 


\section{E. Calculating the other determinants}

\section{E.1: Market returns}

The JSE ALSI was selected as a measure for local market performances. The market returns were calculated utilising the formula used by Firer (2003) for his historic database as follows:

$$
R m_{t}=\left[1+\frac{1 / 2400 *\left(A L S I_{t} * D Y_{t}+A L S I_{t-1} * D Y_{t-1}\right)}{1 / 2 *\left(A L S I_{t}+A L S I_{t-1}\right)}\right] *\left[\frac{A L S I_{t}}{A L S I_{t-1}}\right]-1
$$

Where: $\quad R m_{\imath} \quad$ is the nominal market return at period $t$

$A L S I_{t} \quad$ is the index value of the ALSI at period $t$

$D Y_{t} \quad$ is the dividend yield from securities included in the index at period $t$

These calculated market returns closely approximate the returns calculated from the Morgan Stanley South African market return index and the FT South African Actuaries index. The JSE ALSI was selected as a measure for local market performances. Remolana et al. (1997) suggested that, when selecting an index, it is not critical that a correct index is selected as various market indices tend to move together and indicate a change in the markets' performance.

In line with Bennett and Young (2000), for returns on the international stock markets, the Morgan Stanley International Stock market index (MSCI) was used:

$$
R I m_{t}=\frac{M S C I_{t}-M C S I_{t-1}}{M S C I_{t-1}}
$$

Where: $\quad \boldsymbol{R} I m_{t} \quad$ is the nominal international market return at period $t$

$M_{S C I} \quad$ is the index value of the MSCl at period $t$

The return on the $\mathrm{MSCl}$ was compared with the return calculated on the FT Actuaries World market index (including dividend yields). The returns on the two indices were virtually indistinguishable at a $1 \%$ significance level. 


\section{E.2: Interest rates}

The 90-day NCD rates and the 30-year Government Bond interest rates were used as measures for short- and long-term interest rates. In similar vein to Santini and Aber (1998), the level of interest rates rather than the changes in the interest rate, was used as the interest variable. A large change in the interest rate beginning from a low base rate might not lead to a level of interest high enough to induce investors to react. The different shortand long-term interest rates tended to move together ( 0.99 correlation) with other similar termed interest measures. All the short-term interest rates were very similar, with the exception of 90-day NCD that was about 0.5 $\%$ higher than the other short-term rates. As the 90-day NCD rates were considered more liquid, accordingly the dissertation utilized it as a short-term interest rate indicator. Bennett and Young (2000) utilised the 3-month Interbank rate as a short-term interest rate. Potter (2000) utilised the 6-month NCD whereas Santini and Aber (1998) used the 3-month T-Bill rate.

For long-term interest, Santini and Aber (1998) suggested that the longest government bond interest rate would be the best suited for evaluating cash movements. Bennett and Young (2000) used the 10-year Bond. In South Africa, the 30-year Government Bond has the longest term-structure. Since the 10- and 30-year Bond interest rates are similar ${ }^{79}$, this dissertation utilised the 30-year Government Bond rate. Choosing the correct interest rate is not paramount, since regression analysis looks at co-movement of variables which, as discussed earlier, is similar.

\section{E.3: Transaction costs and fee structures}

Transaction costs were calculated from the spread between the buy and sell prices, as a proxy for transaction costs on purchases of units (Du Plooy, 2003). Annual administration fees were manually captured from combined information obtained from Profile's Unit Trust Handbook, S\&P Micropal Workstation and the Unit Trust Survey.

\section{E.4: Risk classification}

Risk was incorporated into the study by: (i) including a risk variable into the regression equation as measured by the standard deviation of returns over the period obtained from S\&P Micropal and (ii) utilising risk-adjusted performance measures, which implicitly consider risk.

\section{E.5: Fund size}

The log of fund size (measured by total NAV) was included to control for equal dollar flows, having a larger impact on smaller funds, thereby controlling for the possibility of heteroscedasticity in the data (Sirri and Tufano, 1998; Berkowitz and Kotowitz, 2000; Elton et al. 2002). The average value of assets of each fund was also included for each year covered by the dissertation, to underline the positive relation between fund size and cash flows during the cross-sectional study.

\footnotetext{
${ }^{78}$ This co-movement of interest rates also holds for long-term interest rates, with the long-term debentures being on average one percentage point higher, presumably to compensate for higher risk.
} 


\section{F. Movements of the various variables through time under investigation}

Figures F.1 to F.3 show the independent variables, which had a significant relationship at $5 \%$ level with cash flows. The other insignificant determinants are graphically represented over time in Figures F.4 to F.7.

\section{F.1: Aggregated cash flows and General Equity returns}

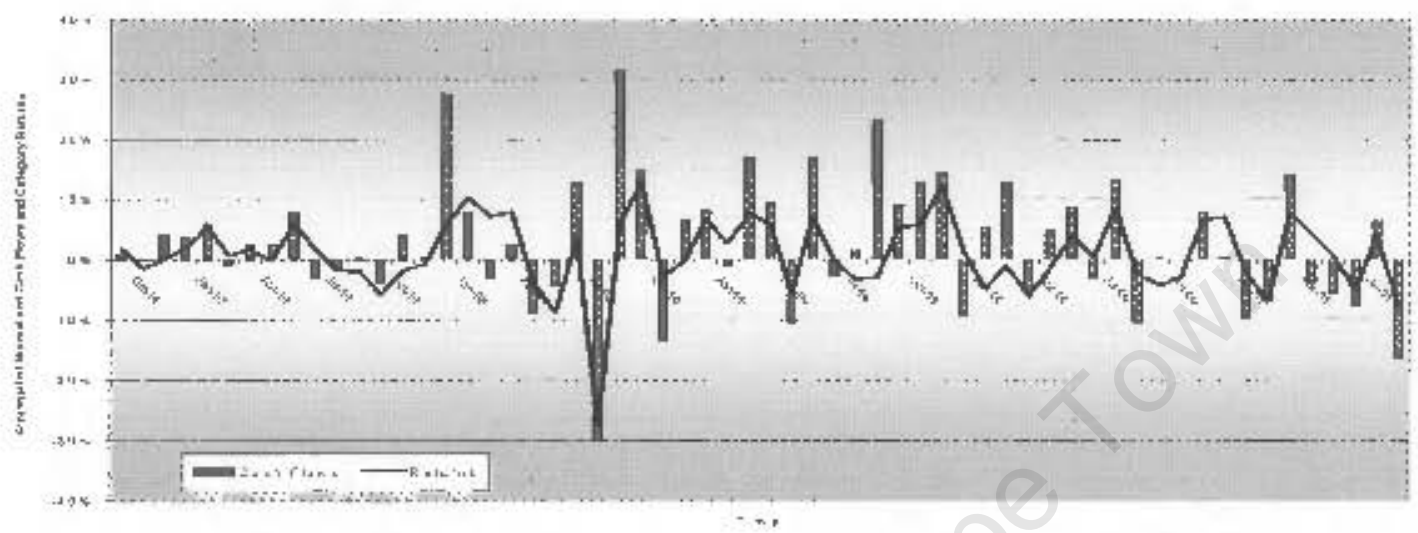

F.2: Aggregated cash flows and local and international market returns

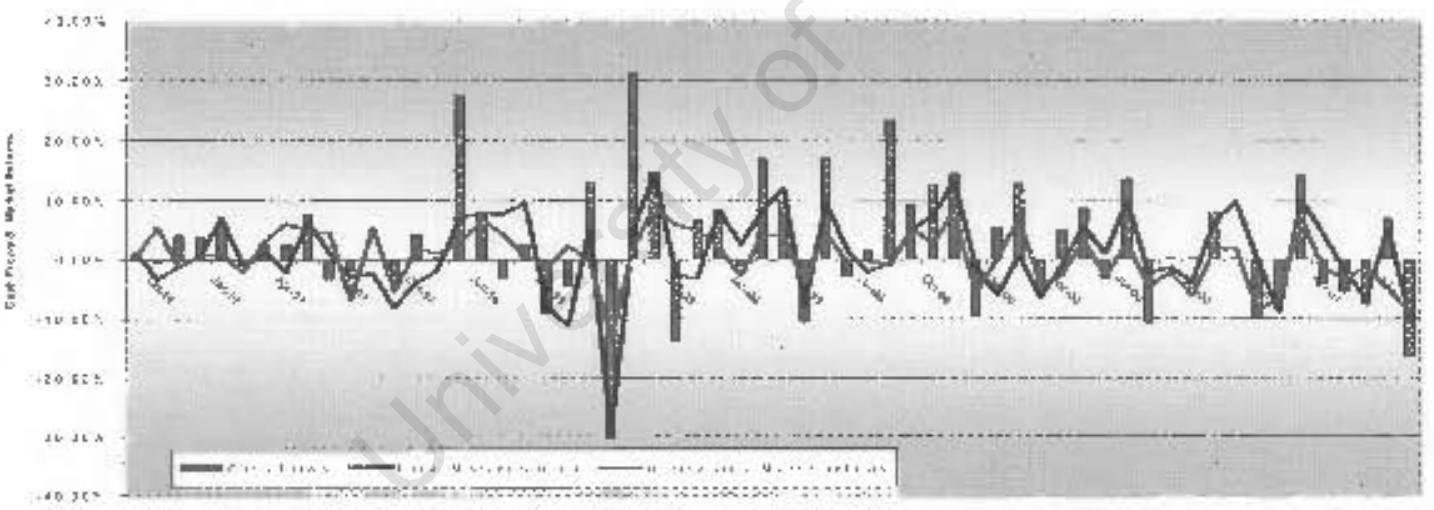

F.3: Aggregated cash flows and changes in long-term interest rates

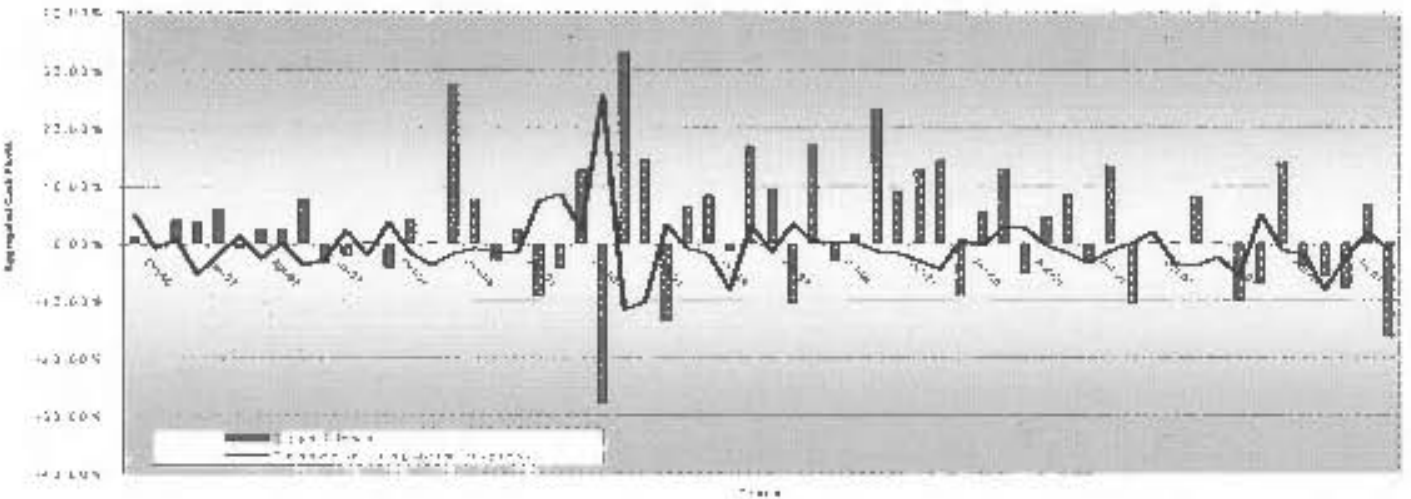



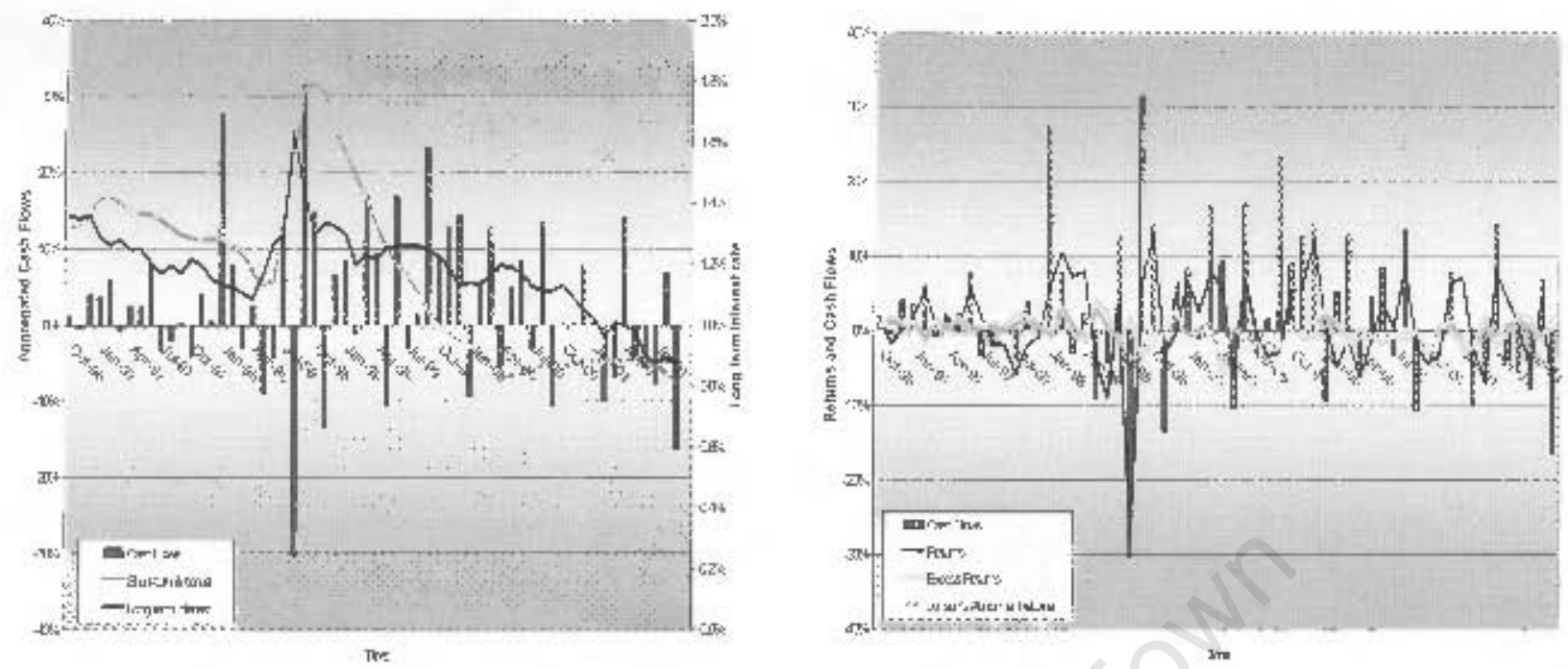

\section{F.6: Risk}

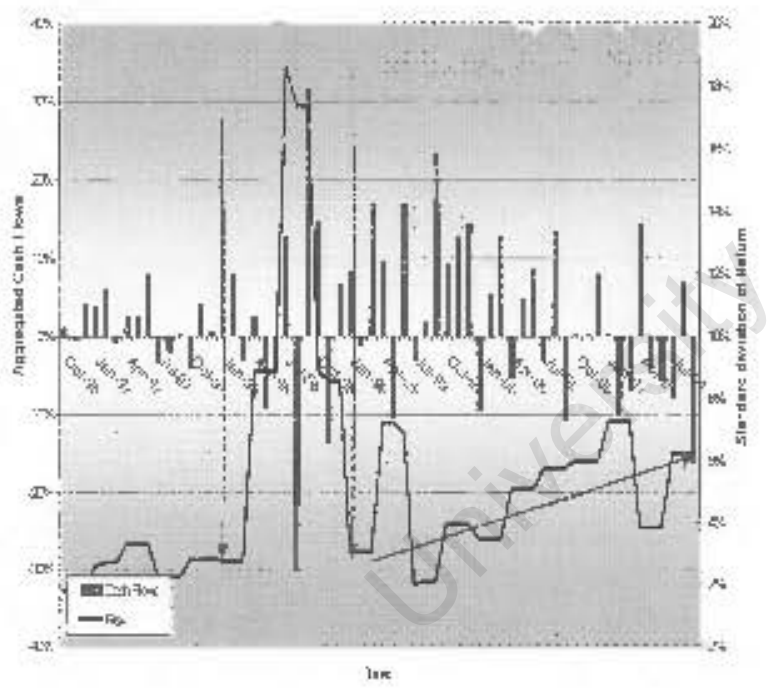

\section{F.7: Fund size}

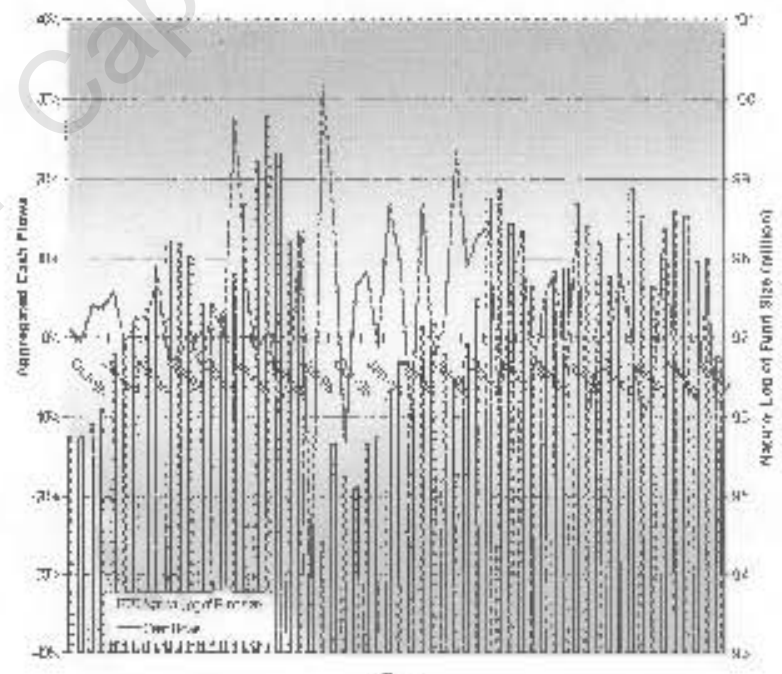

7x 
The following sub-sections present an overview of the determinants over the study period.

\section{F.8.1: Return indicators}

Cash flows appeared to move in the same direction as normal returns and in the opposite direction to excess and abnormal rekurns, with abnormal returns being relatively stable over the five-year periad (Figure $F .5$ ). Return on the A.SI moved in unison with returns on the General Equity category, although the returns on the ALSI were slightly higher and more volatile than that of General Equity category returns. This might have arisen because several General Equity unit trusts track the ALSI. International markets inflyenced local markets which moved in a similar direction, although not necessarily following the same patterns (Figure F.2). The standard deviation of returns increased over the study period from about $2.5 \%$ in 1996 to $5.5 \%$ for 2001 (Figure F.6).

\section{F.8.2: Cash flows}

Total cash inflows exceeded cash outflows over the five-year period. The three largest inflows occurred in January and September 1998 and September 1999. matched by comparable large positive return events around these dates. Positive return events experienced larger percentage cash flows than negative return events. Similarly, it is noteworthy that the net percentage cash inflows always exceeded the positive returns, yet never gave rise to net percentage outflows larger than negative returns. This indicates that investors react disproportionately to changes in returns.

\section{F.8.3: Long- and short-term interest rates}

bong-term interest rates showed a steady downward trend over the past five years, decreasing trom a levet of approximately $15 \%$ (1996) to $10.5 \%$ (2001). This downward trend was briefly interrupted during 1998 . During this period, the long-term interest rates showed significant movement, increasing twice by $6 \%$, reaching a high of $19.5 \%$ and dropping again to $15.5 \%$ by December 1998 . Interestingly, these increases were met by large corresponding outflows and declines in market and General Equity returns. Cash flow volatility increased over these periods, with unit trusts experiencing the largest inflow of $33 \%$ in September 1998 and outflow of $27 \%$ in August 1998 . There appeared to be no apparent co-movement between cash flows and the level of long-term interest rates over other periods.

It is evident from Figures F.2 and F.4 that changes in long-term interest rates and domestic market returns moved in oppasite directions. When interest rates increased: stock market performances declined. Short-term interest rates, on the other hand, were higher than long-term interest rates until March 1995. Thereafter short-term interest rates were significantly lower than long-term interest rates. Short-term interest rates appeared to follow a similar pattern as long-term interest rates, following long-term interest rates by two months as shown in Figure F.4.

\section{F.8.4: Fee structure}

Transaction costs declined slightly over the past five years from an average fee of $5.8 \%$ to $5.5 \%$ of total assets under management. This reduction was mainly due to increased competition in the unit trust industry, causing funds to employ fee reduction techniques to attract new clients (Coronation: 2002). 


\section{F.8.5: Fund Size}

Surprisingly the total assets under management only increased by a meagre $10.5 \%$ over the five-year period from 1996 as shown in Figuse F.7. This can be attributed mainly to the market crash during 1998, when the General Equity category lost $41.6 \%$ in value during the three-month period from its peak in April 1998 (R 26724 million to a low of R 15602 million). Two aspects contributed to this decrease in fund size: (i) investors divesting and (ii) capital depreciation of the underlying stock. The total assets under management made a steady recovery to January 2002 after which it tapered off, moving around the R 23 billion mark until mid 2002 . On the back of the weakening of the American markets and the strengthening of the Rand, total assets under management moved around the R 25 billion mark for a couple of months, resembling the levels it had reached before the 1998 market crash. The General Equity fund managers lost some value after September 11, 2001 due to the decline in the American market, which impacted on South African markets; but recovered their losses by the end of November 2001. 


\section{G. Summary statistics}

This appendix presents the summary statistics for the General Equity category. Appendix G.1 starts with an overview, followed by appendices G.2 to G.6 which contain the fund level summary statistics.

\section{G.1: Features of the General Equity unit trusts}

\section{G.1.1: Cash flows}

Funds younger than two years old ${ }^{\text {g. }}$ such as Fairheads Equity, FT NIB Quants Core Equity. African Harvest Rainmaker and Core Equity attracted the largest average cash flows, without having earned any noteworthy returns since their launch. The cash flows attracted to these four funds had a standard deviation between $40 \%$ and $80 \%$, arising from large ance-off capital injections within the first few months of the funds' existence. FT NIB Quants Core Equity used the additional capital injections to facilitate a partial recovery in returns by investing in higher yielding investments. This had been unaffordable previously. These large inflows could be attributable to initial investments made ${ }^{\theta 1}$ by the management companies themselves or from institutional investors. These cash injections were important, since these funds did not have track records.

The majority of funds older than five years experienced stable cash oufflows: generating stable average returns. About $25 \%$ of the funds under investigation attracted average monthly cash flows in excess of $10 \%$, including Prudential Optimiser, Fairheads Equity, FT N!B Quants Core Equity: Allan Gray Equity and African Harvest Core Equity. Many of these funds experienced average cash flows over the remainder of their lifespan. Furthermore, funds attracting large average monthly cash flows, attracted liquidity investors as indicated by the high volatility in cash flows. A possible consequence of these volatile cash flows could be that these funds might experience liquidity probtems or might need to hold excess cash as a provision against a liquidity crisis. The five funds which attracted the most stable cash flows, all earned positive average monthly returns. These included Liberty RSA Equity and FT NIB Prime Select. Interestingly: Liberty Wealthbuilder and NIB Altikude Equity Fund of Funds experienced the largest average manthly outflows, arising from consistent outflows rather than large once-off outfows. NIB Altitude Equity Fund of Funds experienced negative average monthly returns.

The minimum and maximum cash flows through time did not appear to move in a particular manner, or in relation to one another. This difference between the maximum and minimum cash flows was relatively wide, with minimum cash flows or withdrawals remaining stable. The maximum cash flows or capital contributions, on the other hand, were extremely volatile. This behaviour indicates that investors are more willing to invest during periods of upturns and react faster to positive return events, than they are unwilling to divest during poor performing periods.

Returns moved together alongside the average fund returns over the period, experiencing both significant increases and declines in minimum and maximum returns. This indicates that the maximum, by which an average fund is able to out-perform its peers, is about $4 \%$ and vice versa.

\footnotetext{
"All funds younger ihan one-year were excluded when calculating the sumunary statistics, since inclusion would distort any results, as it was difficult to calculate a realistic mean and standard deviation with few data points.

${ }_{\text {si }}$ The Unit Trust control Act requires inanagentent compan es to main'ain cenlain investments in unir trusts they manage. This accoun's for a portion of the laige once-off investments each of these funds receised.
} 


\section{G.1.2: Fund performance, risk and fund size}

The best performers showed medium to low-risk, attracting competitive cash flows, relative to their peers. High-risk funds tended to attract mixed cash flows. This can be partially attributed to the poor, yet positive returns. On the other hand, the low-risk funds appeared to be medium sized funds with mixed performances, attracting a large portion of the average monthly cash flows. Several of the largest funds experienced stabie average monthly cash outflows over the study period. These largest funds appeared to be oider funds, accumulating their assets over time, rather than from market appreciation and significant new investments. The majority of funds earned an average monthly excess return below zero, while abnormal returns were generally close to zero, as expected.

\section{G.1.3: Transaction cost and initial investment requirements}

A negatively significant relationship (correlation $(r)=-0.511, p$-value $=0.047$ ) exists between the initial required investment and upfront fees, while no reiationship exists between subsequent investment and the funds' fee. This suggests that the larger the initial required investment, the larger is the front-ended fee percentage charged by the management company. While various combinations of entrance and administration fee structures were utifised by management comparies, none of the funds charged exit fees (appendix G.7). Funds with high total front-ended loads tended to have high administration fees $(r=0.58, \rho$-vatue $<0.05)$. Coronation High Growth, Investment Solutions Pure Equity and Old Mutual Growth funds had the largest front-ended load charges. The two Galaxy funds, however: had the lowest load charges and the highest administration fees. When considering all funds; the minimum investment required, ranged from $R 100$ to the maximum of $R 50000$ (by the third party funds [Aggressive and Equity] managed by Galaxy\}), with most of the other funds requiring an initial investment below R 5000 . Most funds did not require a further investment. If they did, they tended to charge a minimum of $R 1000$.

\section{G.1.4: Total assets under management}

The ten (five) biggest management companies managed $77 \%(55 \%)$ of the assets in the industry as at 30 September 2001 (Lambrechts: 2001) as shown in Table 19.

\section{Table 19. Total assets managed by the ten largest management companies}

\begin{tabular}{|c|c|}
\hline Fund Name & $\begin{array}{l}\text { Total assets managed } \\
\text { (Rand Milioris) as at } \\
30 \text { September } 2001\end{array}$ \\
\hline $\begin{array}{l}\text { Sanlam } \\
\text { Old Mutual Asset Management } \\
\text { ABSA } \\
\text { Standard Bank } \\
\text { Inveslec } \\
\text { Libery Asset Managernent } \\
\text { Coranation } \\
\text { Rand Merchant Bank } \\
\text { Invest.ment Solutions } \\
\text { Fedsure }\end{array}$ & $\begin{array}{l}78,400 \\
i 6,073 \\
15,7: 0 \\
75,487 \\
14,385 \\
7.775 \\
6.411 \\
6,388 \\
5,738 \\
5.502 \\
\end{array}$ \\
\hline TOTAL ASSETS & 146,446 \\
\hline
\end{tabular}




\section{G.2: Normalised cash flows}

\begin{tabular}{|c|c|c|c|c|c|c|c|c|c|}
\hline & & & & Hor & thalk & sect casth & flows. & & \\
\hline & Obs. & Avarage & & Std.dey. & & Min. & Hin date & Max & Max date \\
\hline ABSA General R & 50 & $-\Gamma, 8 \%$ & 29 & $1.7 \%$ & 22 & $-46.7 \%$ & Áng- 95 & $410 \%$ & Ser 98 \\
\hline ABSA Growtin FoF & $3 \bar{s}$ & $42 \sigma_{i j}$ & 13 & $14.3 \%$ & 16 & $12.1 \%$ & Јат. & $59.3 \%$ & Aug 98 \\
\hline Afr'Harvesi Core Equity & 21 & $155 \%$ & 5 & $43.1 \%$ & 6 & $.39 .3 \%$ & Sep-01 & $1496 \%$ & Det-or \\
\hline Aff'Harves: Rainr aker & 14 & $13.0^{v}$ & 6 & $39.7 \%$ & 7 & $-11.2 \%$ & Sep- $\Gamma 1$ & $1480 \%$ & AUg $\cdot \mathrm{OD}$ ? \\
\hline Alan Gra;' Equity A & 35 & $160 \%$ & 4 & 34..$\%$ & 8 & $-22.0 \%$ & $M E \gamma-99$ & $137.9 \%$ & Mar-99 \\
\hline BoE Equit'j & 60 & $.1 .4 \%$ & 35 & $9.7 \%$ & 33 & $-41.6 \%$ & Rug -98 & $26.2 \%$ & Sep. 98 \\
\hline Comrruาi; Growth & 60 & г, $2 \%$ & 24 & $10.5 \%$ & 29 & $-39,8 \%$ & Aug-9B & $429 \%$ & Sep. 92 \\
\hline Coror:atior. High Growtin & 60 & $18 \%$ & 19 & $11.9 \%$ & 21 & $-24,3 \%$ & Aug-98 & $344 \%$ & Det-95 \\
\hline Fa theads Equity & 20 & $249 \%$ & 2 & $83.6 \%$ & 2 & $-12.9 \%$ & Sep- $\Gamma 1$ & $3781 \%$ & Feb or \\
\hline FNG Erowth & 34 & $8.7 \%$ & 11 & $30.4 \%$ & 10 & $-129 \%$ & Sep-Г1 & $166.8 \%$ & Kar.99 \\
\hline FT NIB LT Wealth Creator & 49 & $\Gamma \%$ & 23 & $29.5 \%$ & 11 & $-33.4 \%$ & NO2-Г, & $1743 \%$ & Apr 95 \\
\hline FT NiB Prirre Seled & 60 & C $1 \%$ & 26 & $8,3^{\prime \prime} \%$ & 39 & $-28.5 \%$ & Aug-98 & $2 \Gamma, 8 \%$ & Sep. 98 \\
\hline FT NIE Juarts Core Equity & 21 & $195 \%$ & 3 & $81.0 \%$ & 4 & $.598 \%$ & 5eu-91 & $3550 \%$ & $\mathrm{Xar}-\mathrm{OC}_{\mathrm{O}}$ \\
\hline Futhregrow'h Core Equity & 32 & $8.9 \%$ & 10 & $23.9 \%$ & 13 & $-15.0 \%$ & Seu-91 & $1125 \%$ & Aug. 89 \\
\hline Futuregrowth Pure Equit; & 60 & $09 \%$ & 31 & $9.5 \%$ & 34 & $-3 \Gamma .0 \%$ & Aug-9日 & $335 \%$ & Sep-98 \\
\hline Gryphon Imf General Equity & 20 & $010 \%$ & 25 & $10.1 \%$ & 3. & $-14.7 \%$ & รัย - 11 & $19.5 \%$ & $A \mathrm{FI}-01$ \\
\hline Gryphon !mp Sit Tracker & 55 & $2.5 \%$ & 16 & $17.1 \%$ & 15 & $-35.1 \%$ & Aug-98 & $59.4 \%$ & 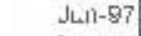 \\
\hline Investec Equ.ty R & 60 & $.0 .4 \%$ & 28 & $11.1 \%$ & 25 & $-433 \%$ & Aug- 98 & $33.6 \%$ & Sef-98 \\
\hline investac!ndex R & 60 & $1.4 \%$ & $3 \mathrm{~B}$ & $19.7 \%$ & 28 & $-319 \mathrm{gu}$ & Aug - 95 & $31.4 \%$ & Sef-so \\
\hline Iberty Prospe ity R & 60 & $-1.5 \%$ & 37 & $9 \Gamma \%$ & 36 & $-310 \%$ & Aug-a8 & $32.0 \%$ & Sep-9o \\
\hline Libe'ty RSA Equlty A & 34 & $1 \mathrm{c} \%$ & 22 & $9.0 \%$ & 36 & $-159 \%$ & $\operatorname{Jan} \cdot D_{0}$ & $19.8 \%$ & Aur-01 \\
\hline Libe'ty wealsbluulide? $R$ & 60 & $2.2 \%$ & 40 & $9.0 \%$ & 37 & $-300 \%$ & Aug- פō & $30.6 \%$ & Sep-98 \\
\hline ' $\pi$ CLbed Equl:y "of & 45 & $11.3 \%$ & 7 & $72.7 \%$ & 5 & $-366 \%$ & Aug-98 & $470.4 \%$ & Ja'l-98 \\
\hline Metrauclitar, General Equity & 60 & $2.2 \%$ & 17 & $11.5 \%$ & 24 & $-376 \%$ & Aug-98 & $38.4^{2}$ & Sef-98 \\
\hline Nerttengk Grawilit & 45 & $4.1 \%$ & 14 & $19.0 \%$ & 14 & $-334^{w 10}$ & Feh- $\Gamma, 1$ & $39.3 \%$ & Sef- $8 \mathrm{~g}$ \\
\hline Nerdhank Harlequln & 23 & $15.2 \%$ & 8 & $82.0 \%$ & 3 & $-378 \%$ & $X_{E \gamma-\Gamma 1}$ & $379.5 \%$ & Nov-89 \\
\hline NIB Alsitude Equ:ty FoF A & 27 & $.7 .8 \%$ & 41 & $11.5 \%$ & 23 & $-373 \%$ & Jun-J0 & $9.4 \%$ & Oct-sg \\
\hline NIE tiorizer Equily FoF $A$ & 27 & $0.1 \%$ & 27 & $123 \%$ & 19 & $-237^{\circ \%}$ & Sep-91 & $44.0 \%$ & Jun-DJ \\
\hline Oasis Crescent Equly & 37 & $10.1 \%$ & 9 & $14.0 \%$ & 17 & $.86 \%$ & Fet- $\Gamma 0$ & $49.6 \%$ & Mar-9g \\
\hline 0 .t Mutua: Inves:ors & 60 & $1.6^{0}$ & 38 & $-1.3 \%$ & 25 & $-43.5_{0}^{0}$ & Aug.98 & $4.0 \%$ & Sef-89 \\
\hline Top Comoanies & 60 & 1.3 & 33 & $10.5 \%$ & 30 & $4 \mathrm{C} 2 \%$ & Aug-98 & $35.1 \%$ & Sep-98 \\
\hline Prudential Ostim:iser & 25 & $32.2 \%$ & 1 & $142.7^{\mathrm{i}} \%$ & 1 & $-28.4 \%$ & Sep-11 & $712.5 \%$ & Sep-99 \\
\hline RME Lqui:y & 60 & $-0,9 \%^{\prime}$ & 30 & $13.8^{\mathrm{n} \%}$ & 27 & $-431 \%$ & hug -98 & $28.0 \%$ & Sep- 98 \\
\hline RMB Pefformance FoF & 38 & $1.8 \%$ & 20 & $12.2^{\mathrm{m}} \mathrm{h}$ & 23 & $-2.2^{\mathrm{m} i \mathrm{i}}$ & Sep-91 & $42.6 \%$ & $\sec 98$ \\
\hline Sage Furd & 60 & $-1.0 \%$ & 32 & $7.7 \%$ & 41 & $-25.2 \%$ & hug-98 & $23.2 \%$ & Sep-98 \\
\hline Saniam Future Trends & 35 & $4.4 \%$ & 12 & $23.9 \%$ & 12 & $-26.3 \%$ & Feb-91 & $198.7 \%$ & Jun 99 \\
\hline Senlem Genera! & 30 & $-1.5 x$ & 34 & $-9.9 \%$ & 32 & $-35.4 \%$ & Álg-98 & $307^{\circ} \mathrm{iu}$ & $\sec 98$ \\
\hline Standerd Ek Aggres sve FuF A & 37 & $3.7 \%$ & 15 & $12.7 \%$ & 18 & $-11.4 \%$ & Sen-91 & $541 \%$ & Sep-ag? \\
\hline Stendand Bk !ndex R & 50 & $1.4 \%$ & 21 & $31.8 \%$ & 9 & $-37.0^{\%} \%$ & Aug 98 & $212.3 \%$ & $2 \mathrm{ec}-99$ \\
\hline Stendend Bk Mutual R & 60 & $-2.0 \%$ & 39 & $9.3 \%$ & 35 & $273 \%$ & Álg 98 & $272 \%$ & Sep- $5 \mathrm{~g}$ \\
\hline Woo wo'ths Unl: I rust & 22 & $1.5 \%$ & 18 & $7.9 \%$ & 40 & $-11.1 \%$ & ડер-J1 & $152 \%$ & A:ul-01 \\
\hline
\end{tabular}




\section{G.3: Fund normal returns}

\begin{tabular}{|c|c|c|c|c|c|c|c|c|c|}
\hline & & & & Nor & irmat & returns & & & \\
\hline & Obs. & Average & & Std depr. & & Min & Min date & Max & Max date \\
\hline ABSA General R & 60 & $0.3 \%$ & 34 & $7.9 \%$ & 3 & $-38.0 \%$ & Aug-9A & $17.5 \%$ & reb-9h \\
\hline ABSA Growth FoF & $3 \mathrm{~B}$ & $0.4 \%$ & 31 & $5.4 \%$ & 36 & $-16.5 \%$ & Aug-98 & $13.4 \%$ & Dec-99 \\
\hline Afr'Harvest Core Equity & 21 & $0.6 \%$ & 23 & $5.3 \%$ & 38 & $-8.9 \%$ & Feb-00 & $11.0 \%$ & Aug-00 \\
\hline Afr'Harvest R日inmaker & 14 & $2.0 \%$ & 3 & $5.8 \%$ & 30 & $-5.3 \%$ & $\operatorname{sep}-01$ & $112 \%$ & Aug -00 \\
\hline Allan Gray Equity A & 35 & $34 \%$ & 1 & $5.9 \%$ & 25 & $-5.3 \%$ & $b-00$ & $17.8 \%$ & Apr-99 \\
\hline BoE Equity & 60 & $0.5 \%$ & 26 & $6.7 \%$ & 17 & $-34.5^{\circ}$ & Aug 98 & $13.4 \%$ & Ocl-98 \\
\hline Communety Growth & 60 & $1.0 \%$ & 9 & $7.0 \%$ & 11 & -34. & Aug-98 & $13.6 \%$ & Lee -99 \\
\hline Coronatior & 60 & $0.9 \%$ & 11 & $5.5 \%$ & 35 & -17. & Aug-98 & $13.3 \%$ & Feb-9B \\
\hline Fairhe: & 20 & $-0.9 \%$ & 40 & $5.7 \%$ & 31 & & & $8.8 \%$ & Aug-DD \\
\hline $\mathrm{FNBC}$ & 34 & $1.5 \%$ & 4 & $5.9 \%$ & $2 \theta$ & & & $14.8 \%$ & Mar-9g \\
\hline Vealth Creator & 49 & $0.5 \%$ & 27 & $7.7 \%$ & 5 & & & 16. & Oct-98 \\
\hline FT NIBP & 60 & $1.3 \%$ & 6 & $6.2 \%$ & 23 & & & & ec 99 \\
\hline FT NIB Gua & 21 & $-0.1 \%$ & 37 & $5.1 \%$ & 39 & & & A. $5 \%$ & Ausy -00 \\
\hline Futuregrow & 32 & $0.8 \%$ & 13 & $5.4 \%$ & 37 & & & $12.4 \%$ & Dec- $5 \mathrm{~A}$ \\
\hline Futuregrowt & 50 & $0.9 \%$ & 12 & $6.6 \%$ & 18 & -26. & & $15.8 \%$ & Apr 98 \\
\hline Cryphan I & 20 & $-0.5 \%$ & 38 & $6.1 \%$ & 24 & -10 . & & $9.3 \%$ & Apr-01 \\
\hline Gryphon & 55 & $0.7 \%$ & 17 & $7.5 \%$ & 7 & $-30.8 \%$ & & $15.7 \%$ & Oct-9日 \\
\hline & 50 & $1.0 \%$ & 10 & $7.1 \%$ & 10 & $-34.9 \%$ & Auy-98 & $14.0 \%$ & act-9日 \\
\hline Inves & 60 & $0.7 \%$ & 16 & $6.9 \%$ & 12 & $-274 \%$ & Aug-98 & $14.5 \%$ & Oct-9A \\
\hline Libert & 60 & $0.7 \%$ & 19 & $6.8 \%$ & 16 & $-30.3 \%$ & Aug-98 & $14.2^{\psi} \%$ & Dec-99 \\
\hline Libe: & 34 & $1.5 \%$ & 5 & $5.9 \%$ & 27 & & $r-01$ & 13 & Dec-99 \\
\hline ar $R$ & 60 & $0.6 \%$ & 22 & $6.3 \%$ & 21 & -26 & & & Dec-99 \\
\hline $\mathrm{mc}$ & 45 & $0.6 \%$ & 25 & $8.1 \%$ & 2 & & & & t. 98 \\
\hline peral Equily & 60 & $1.0 \%$ & 8 & $7.1 \%$ & 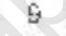 & -32 & & & $e b-9 \theta$ \\
\hline Ned & 45 & $6 \%$ & 24 & $8.5 \%$ & 1 & -28 & $-9 \mathrm{~A}$ & $16.5 \%$ & $c 9-98$ \\
\hline Nedb & 23 & $-1.4 \%$ & 41 & $77 \%$ & 4 & -13 & -00 & $11.5 \%$ & ec-99 \\
\hline N1B A & 27 & $-0.8 \%$ & 39 & $5.8 \%$ & 29 & $-84 \%$ & Sep-01 & $132 \%$ & ecc-99 \\
\hline NIB Horiz & 27 & $0.6 \%$ & 21 & $5.7 \%$ & 32 & $-8.8 \%$ & Sepp-01 & $13.0 \%$ & Dec-99 \\
\hline Dasis Cres & 37 & $2.9 \%$ & 2 & $3.8 \%$ & 41 & $-4.8 \%$ & Feb-00 & $11.3 \%$ & Mar-99 \\
\hline Old M & 60 & $0.8 \%$ & 14 & $7.6 \%$ & 6 & $-37.0 \%$ & Aug-98 & $18.4 \%$ & Oct -98 \\
\hline Old & 60 & $0.5 \%$ & 28 & $7.3 \%$ & $\theta$ & $-34.7^{\circ}$ & aug-98 & $17.2 \%$ & Oct-98 \\
\hline miser & 25 & $1.2 \%$ & 7 & $5.9 \%$ & 26 & $9.0^{\circ}$ & Feb-Do & $13.0 \%$ & Dec-99 \\
\hline & 60 & $0.7^{\pi} \%$ & $1 B$ & $6.9 \%$ & 13 & $335 \%$ & Aug-98 & $15.6 \%$ & Oct-98 \\
\hline RMB Hertormance FoF & 38 & $0.2 \%$ & 36 & $6.3 \%$ & 22 & $-24.9 \%$ & Aug-98 & $11.4 \%$ & Lec-99 \\
\hline Sage Fund & 60 & $0.7 \%$ & 20 & $5.7 \%$ & 33 & $24.7 \%$ & nug-98 & $12.4 \%$ & Oct-98 \\
\hline Sanlam Future Trends & 35 & Q.5\% & 29 & $6.6 \%$ & 19 & $.11 .3 \%$ & Mar-D1 & $11.1 \%$ & Dec-99 \\
\hline Sanlem Ceneral & 60 & $0.5 \%$ & 30 & $6.8 \%$ & 14 & $-29.5 \%$ & Aug-98 & $12.4 \%$ & Dec-99 \\
\hline Standard Bk Aggressive Fo & 37 & $0.3^{\mathrm{m}} \%$ & 35 & $4.5 \%$ & 40 & & Sep-01 & $9.2 \%$ & Lec-99 \\
\hline Standard $B \mathrm{k}$ Lindex $\mathrm{F}$ & 60 & $0.8 \%$ & 15 & $6.6 \%$ & 15 & $27.5 \%$ & Nug-98 & $13.8 \%$ & Oct-98 \\
\hline & 50 & $0.3 \%$ & 33 & $6.5 \%$ & 20 & $-25.3 \%$ & Aug-98 & $14.5 \%$ & Dec.99 \\
\hline & 22 & $0.4 \%$ & 32 & $5.6 \%$ & 34 & $.7 .9 \%$ & Sep 01 & $12.6 \%$ & Dec-99 \\
\hline
\end{tabular}




\section{G.4: Fund excess returns}

\begin{tabular}{|c|c|c|c|c|c|c|c|c|c|}
\hline \multirow[t]{2}{*}{$\mathrm{m}^{\mathrm{n}}$} & \multirow[b]{2}{*}{ Obs. } & \multicolumn{2}{|c|}{ 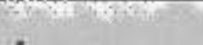 } & \multicolumn{4}{|c|}{ Excess retuens } & \multicolumn{2}{|c|}{ at } \\
\hline & & Average & & Std dev. & & Min & Min date & Max & Max date \\
\hline ABSA General R & 60 & $-0.6 \%$ & 30 & $3.7 \%$ & 9 & $-10.2 \%$ & Apr-99 & $12.5 \%$ & May-98 \\
\hline ABSA Growth FoF & 38 & $-0.8 \%$ & 31 & $4.2 \%$ & 2 & $-9.0 \%$ & Sep-98 & $13.0 \%$ & Aug- -88 \\
\hline Afr'Harves1 Core Equity & 21 & $0.4 \%$ & 5 & $2.2 \%$ & 28 & $-3.4 \%$ & May-01 & $4.5 \%$ & Sep-01 \\
\hline Afr'Harves1 Rainmaker & 14 & $1.3 \%$ & 2 & $2.4 \%$ & 25 & $-2.2 \%$ & Oct-00 & $5.1 \%$ & Jun-01 \\
\hline Allan Gray Equity A & 35 & $1.8 \%$ & 1 & $3.6 \%$ & 10 & $-5.2 \%$ & Mar-00 & $9.7 \%$ & Mar- 99 \\
\hline EoE Equity & 60 & $-04 \%$ & 23 & $3.1 \%$ & 13 & $-9.6 \%$ & Apr -99 & $6.1 \%$ & Nov-97 \\
\hline Community Growth & 60 & $0.1 \%$ & 8 & $3.2 \%$ & 12 & $-11.5 \%$ & Apr-99 & $10.6 \%$ & May-98- \\
\hline Cosonation High Growth & 60 & $0.0 \%$ & 10 & $3.4 \%$ & 11 & $-8.3 \%$ & $\operatorname{Sep} \cdot 98$ & $11.8 \%$ & Aug-98 \\
\hline Faisheads Equity & 20 & $-1,1 \%$ & 38 & $2.5 \%$ & 22 & $-5.4 \%$ & Oct.00 & $4.4 \%$ & Jun-01 \\
\hline FNB Growth & 34 & $-0.2 \%$ & 14 & $3.7 \%$ & 3 & $-8.4 \%$ & Apr.99 & $10.1 \%$ & Dec-98; \\
\hline FT NIB LT Wealth Creator & 49 & $-0.4 \%$ & 28 & $1.6 \%$ & 35 & $-4.3 \%$ & Apr-99 & $2.2 \%$ & Jเח-01 \\
\hline FT NIB Prime & 60 & $0.4 \%$ & 4 & $3.1 \%$ & 14 & $-7.7 \%$ & Sep-98 & $7.2 \%$ & May-98 \\
\hline FT NIB Qu & 21 & $-0.2 \%$ & 21 & $1.7 \%$ & 34 & $-3.1 \%$ & Jan-01 & $2.8 \%$ & Jun-01 \\
\hline Futuregro & 32 & $-0.8 \%$ & 33 & $2.2 \%$ & 27 & $-8.7 \%$ & 99 & $2.7 \%$ & Jun-01 \\
\hline Future & ह0 & $0.0 \%$ & 11 & $3.8 \%$ & 4 & $-11.5 \%$ & Oct-9s & 8. $3 \%$ & Mar-01 \\
\hline Equity & 20 & $-0.8 \%$ & 32 & $1.2 \%$ & 39 & $-2.8 \%$ & 00 & $1.5 \%$ & Dec-00 \\
\hline Gryphon ir & 55 & $-0.2 \%$ & 16 & $13 \%$ & 37 & $-3.2 \%$ & 01 & $3.3 \%$ & Feb-00 \\
\hline Investec & हण & $0.1 \%$ & 9 & $2.6 \%$ & 19 & $-8.5 \%$ & 99 & $5.6 \%$ & May-98 \\
\hline Investec In & है० & $-0.2 \%$ & 15 & $0.9 \%$ & 41 & $-5.3 \%$ & 00 & $2.1 \%$ & Aug -98 \\
\hline Liberty Pros & 60 & $-0.2 \%$ & 10 & $1.9 \%$ & 30 & $-6.5 \%$ & Jul-98 & $4.1 \%$ & Jun-Di \\
\hline Liberty RSA & 34 & $-0.2 \%$ & 19 & $1.2 \%$ & 38 & $-4.5 \%$ & Apr-99 & $1.7 \%$ & Nov-Do \\
\hline Liberty Wealt & 60 & $-0.3 \%$ & 22 & $1.9 \%$ & 31 & $-5.0 \%$ & Jul-98 & $3.5 \%$ & Nov-97 \\
\hline m Cubed $\mathrm{E}$ & 45 & $-0.8 \%$ & 35 & $2.9 \%$ & 17 & $-9.7 \%$ & Apr-99 & $0.0 \%$ & Feb-98 \\
\hline neral Equity & 60 & $0.1 \%$ & b & 3.1\% & 15 & $-10.1 \%$ & Apr-s9 & $5.7 \%$ & Feb-98 \\
\hline Nedbank & 45 & $-0.8 \%$ & 34 & $39 \%$ & 3 & $-10.5 \%$ & Oct-00 & $3.3 \%$ & Jun-98 \\
\hline Nedbank & 23 & $-2.5 \%$ & 41 & $4.3 \%$ & 1 & $-12,3 \%$ & Oct-00 & $9.7 \%$ & Jan-D0 \\
\hline NIB Altiturd & 27 & $-1.8 \%$ & 40 & $2.4 \%$ & 23 & $-6.2 \%$ & Sep-99 & $3.0 \%$ & Jan-DO \\
\hline NIB Horizon Equit & 27 & $-0.4 \%$ & 26 & $1.5 \%$ & 36 & $-3.1 \%$ & Jul-99 & $2.7 \%$ & Dec-00 \\
\hline Oasis Crescent & 37 & $0.9^{\prime \prime}$ & 3 & $3.7 \%$ & 8 & $-8.2 \%$ & Oct-98 & $6.6 \%$ & Mar-D1 \\
\hline Old Mutusal & 60 & $-0.1 \%$ & 12 & $2.3 \%$ & 26 & $-7.5 \%$ & A.ug-9B & $6.1 \%$ & May-98 \\
\hline Old Mutts: & 60 & $-0.4 \%$ & 25 & $2.6 \%$ & 20 & $-7.8 \%$ & Apr -99 & $4.0 \%$ & Feb-00 \\
\hline Prudential Optimiser & 25 & $0.1 \%$ & 7 & $1.9 \%$ & 32 & $-3.3 \%$ & 0 ot-00 & $3.1 \%$ & Jan-DO \\
\hline RME E & 60 & $-0.2 \%$ & 17 & $2.5 \%$ & 21 & $-8.2 \%$ & Apr -99 & $3.9 \%$ & Oct-97 \\
\hline imance FoF & 38 & $-1.0 \%$ & 36 & $3.8 \%$ & 5 & $-10.3 \%$ & Apr-99 & $6.0 \%$ & Feb-00 \\
\hline Sage Fur & 60 & $-0.2 \%$ & 20 & $2.7 \%$ & 18 & $-6.7 \%$ & Apr -98 & $5.5 \%$ & Jul-01 \\
\hline Sanlam F & 35 & $-1.0 \%$ & 37 & $2.9 \%$ & 16 & $-6.9 \%$ & Mar-00 & $4.8 \%$ & Dec-9g \\
\hline & 60 & $-0.4 \%$ & 27 & $2.0 \%$ & 29 & $-7.7 \%$ & Aps-99 & $6.0 \%$ & May.98 \\
\hline & 37 & $-17 \%$ & 39 & $3.9 \%$ & 6 & $-11.3 \%$ & & $48 \%$ & Now-00 \\
\hline & 60 & $-0.2 \%$ & 13 & $1.0 \%$ & 40 & $-2.5 \%$ & & $2.1 \%$ & Oct-96 \\
\hline & 60 & $-0.6 \%$ & 29 & $2.4 \%$ & 24 & $-7.4 \%$ & Apr-99 & $4.2 \%$ & Aug-98 \\
\hline Woolworths Unit Trust & 22 & $-04 \%$ & 24 & $1.7 \%$ & 33 & $-2.8 \%$ & $\operatorname{Jan}-01$ & $2.6 \%$ & गuח-01 \\
\hline
\end{tabular}




\section{G.5: Fund abnormal returns}

\begin{tabular}{|c|c|c|c|c|c|c|c|c|c|}
\hline & & & & Ábn & iorme & at retums & & & \\
\hline & Obs. & Average & & Std dev. & & Min & Min date & Max & Max date \\
\hline ABSA General R & 60 & $-0.7 \%$ & 23 & $3.7 \%$ & 2 & $-10.1 \%$ & Aug-98 & $12.1 \%$ & May-9B \\
\hline ABSA Growth FoF & 38 & $-0.7 \%$ & 26 & $25 \%$ & 16 & $-7.9 \%$ & Sep-98 & $5.2 \%$ & Fan-00 \\
\hline Allan Gray Equity A & 35 & $1.9 \%$ & 1 & $3.3 \%$ & 5 & $-5.2 \%$ & Mar-00 & $10.7 \%$ & Mar- 80 \\
\hline BoE Equity & 60 & $-0.4^{n} \%$ & 20 & $2,9 \%$ & 10 & $-10.3 \%$ & Aug-98 & $5.2 \%$ & Nov-97 \\
\hline Community Growth & 60 & $0.1 \%$ & 5 & $3.1 \%$ & 6 & $-100 \%$ & Apr-99 & $9.3 \%$ & May-98 \\
\hline Coronation High Growth & 60 & $-0.1 \%$ & 8 & $2.4 \%$ & 17 & $-7.3 \%$ & Sep-98 & $7.6 \%$ & Feb-98: \\
\hline FNB Growth & 34 & $0.0 \%$ & 7 & $3.4 \%$ & 4 & $-5.4 \%$ & Oct-Do & $8.8 \%$ & Mar-99 \\
\hline FT NIB LT Wealth Creator & 49 & $-0.4 \%$ & 21 & $1.6^{\circ} \%$ & 26 & $-3.6 \%$ & Feb-01 & $2.8 \%$ & ott-98 \\
\hline FT NIB Prime Select & 60 & $0.4 \%$ & 3 & $2.5 \%$ & 13 & $-7.0 \%$ & Sep-96 & $5.8 \%$ & Јал-00 \\
\hline Futuregrowth Core Eqully & 32 & $-0.7 \%$ & 25 & $1.8 \%$ & 24 & $-6.5 \%$ & Apr-99 & $2.2 \%$ & Jun-01 \\
\hline Futuregrow1h Pure Equity & BO & $-0.1 \%$ & 9 & $3.6 \%$ & 3 & $-9.0 \%$ & Aug-98 & $9.4 \%$ & Apr-98 \\
\hline Gryphon Imp SA Tracker & 55 & $-02 \%$ & 14 & $1.3 \%$ & 28 & $.3 .0 \%$ & Feb-01 & $3.0 \%$ & Feb-00 \\
\hline Investec Equity R & Bo & $00 \%$ & 6 & $2.5 \%$ & 15 & $.8 .6 \%$ & Aug.98 & $4.7 \%$ & May-98 \\
\hline Investec Index R & BO & $-02 \%$ & 13 & $0.8 \%$ & 30 & $-5.4 \%$ & May-D0 & $1.1 \%$ & Dec-00 \\
\hline Liberty Prosperity $R$ & 60 & $-02 \%$ & 15 & $1.8 \%$ & 26 & $-6.0 \%$ & Jul-9B & $3.8 \%$ & Jun-01 \\
\hline Lberty RSA Equity A & 34 & $-0.1 \%$ & 11 & $1.0 \%$ & 29 & $-3.5 \%$ & Apr-99 & $1.9 \%$ & Oct-99 \\
\hline Liberty Mrealthbuilder $R$ & 60 & $-0.3 \%$ & 18 & $1.5 \%$ & 27 & $-4.4 \%$ & Jul-98 & $2,7 \%$ & Nov-97 \\
\hline m Cubed Equity FoF & 45 & $-0.8 \%$ & 27 & $2.9 \%$ & $B$ & $-9.6 \%$ & Aug-98 & $7.0 \%$ & Feb-98 \\
\hline Melropolitan General Equity & 60 & $0.1 \%$ & 4 & $2.9 \%$ & 7 & $-8.9 \%$ & Apr-99 & $7.4^{4} \%$ & Fab-9â \\
\hline Nedbark Growth & 45 & $-0.8 \%$ & 28 & $3.9 \%$ & 1 & $-10.7 \%$ & Oct-0D & $8.2^{2 \%}$ & Jun- 98 \\
\hline Oasis Crescent Equity & 37 & $1.4 \%$ & 2 & $1.8 \%$ & 22 & $-2.1 \%$ & Feb-0o & $6.5 \%$ & Mar- $\$ 9$ \\
\hline OHF Mtulual Investors & 60 & $-0.1 \%$ & 10 & $2.3 \%$ & 19 & $-7.8 \%$ & Aug-98 & $6.1 \%$ & May- 98 \\
\hline OHe Mtutual Top Companies & 60 & $\cdot 0.4 \%$ & 19 & $2.5 \%$ & 14 & $-7.3 \%$ & Aug-98 & $3.6 \%$ & Oct- $9 \mathrm{~B}$ \\
\hline RMB Equlty & 60 & $-0.2 \%$ & 16 & $2.4 \%$ & 18 & $-7.6 \%$ & Aug-98 & $3.7 \%$ & Dec-00 \\
\hline RME ferformance FoF & 38 & $-1.0 \%$ & 29 & $2.9 \%$ & 11 & $-8.7 \%$ & 5ep-98 & $3.4 \%$ & Feb- 0 D \\
\hline Sage Fund & 60 & $-0.3 \%$ & 17 & $1.8 \%$ & 23 & $-4.4 \%$ & Apt-98 & $3.5 \%$ & Jut-01 \\
\hline Sanlam Future Trends & 35 & $-1.0 \%$ & 30 & $29 \%$ & 9 & $-6.9 \%$ & Mar-00 & $4.8 \%$ & Dec- 28 \\
\hline Sanlam General & 60 & $-0.4 \%$ & 22 & $1.9^{\%} \%$ & 21 & $-6.6 \%$ & Apt-99 & $5.0 \%$ & May-98 \\
\hline Standard ak Aggressive FoF A & 37 & $-1.4 \%$ & 31 & $2.6 \%$ & 12 & $-10.0 \%$ & Sep-96 & $2.8 \%$ & Now-00 \\
\hline Standard 8 k Index R & 60 & $-0.2 \%$ & 12 & $0.8 \%$ & 31 & $-2.0 \%$ & Oct-97 & $2.1 \%$ & Oct- $\$ 6$ \\
\hline Standard Bk Mulual R & 60 & $-0.7 \%$ & 24 & $2.1 \%$ & 20 & $-6.3 \%$ & 5ep-99 & $3.7 \%$ & Jut 97 \\
\hline
\end{tabular}




\section{G.6: Fund size}

\begin{tabular}{|c|c|c|c|c|c|c|c|c|c|}
\hline & & & & & & d siza & & & \\
\hline & Obs. & Average & & Std dev. & & Min & Min date & Max & Max date \\
\hline ABSA Gervial R & 60 & 647 & 13 & 168 & 13 & 410 & Mar-01 & 1085 & Jul-9B \\
\hline ABSA Growth FoF & 38 & 100 & 26 & 29 & 28 & 33 & Aug-98 & 133 & Aug 00 \\
\hline Afr Harvest Core Equily & 21 & 62 & 29 & 50 & 25 & $?$ & Fet-00 & 133 & May-01 \\
\hline Afr'Harvest Raismaker & 14 & 568 & 15 & 115 & 20 & 366 & Aug-00 & 748 & Jut-01 \\
\hline Allan Giay Equity A & 35 & 417 & 18 & 326 & 6 & $\theta$ & Mov 98 & 1188 & ALQ 01 \\
\hline BoE Equity & 60 & 1969 & 2 & - 000 & 1 & 771 & Sep-01 & 4445 & Apr-98 \\
\hline Community Growth & 60 & 732 & 9 & 139 & 16 & 406 & Nov -96 & 990 & May-98 \\
\hline Coronation High Growh & 60 & 1440 & 5 & 354 & 5 & 322 & 0c1-96 & 1990 & Јвূ-00 \\
\hline Falıheads Equity & 20 & 40 & 33 & 15 & 34 & 20 & Mar.00 & 62 & Aug -01 \\
\hline FPB Growth & 34 & 52 & 31 & 17 & 31 & 6 & Dec-9g & 66 & Jari-01 \\
\hline FI NIB LT Wealth Creato & 49 & 37 & 35 & 15 & 33 & 18 & Aug-98 & 66 & Dec-99 \\
\hline FT NIB Prime Seled & 60 & 1496 & 4 & 371 & 4 & 656 & Oct-96 & 2101 & Jani-00 \\
\hline FT NIB Quants Care Equity & 21 & 149 & 24 & 55 & 24 & 21 & Jan-00 & 202 & Jan-01 \\
\hline Futuregrowth Core Equity & 32 & 242 & 22 & 139 & 18 & 24 & Feb-99 & 409 & Jan-01 \\
\hline Futuregrowth Pure Equity & 60 & 67 & 28 & 12 & 36 & 49 & Now-Do & 91 & A.p1-98 \\
\hline Gryphort Imp General Equity & 20 & 7 & 41 & 0 & 41 & 6 & Now-00 & 8 & Mar-00 \\
\hline Gryphon Imp 5^ Tracker & 55 & 25 & 38 & 5 & 39 & 7 & Mar-97 & 35 & Apr-98 \\
\hline Investec Equity $R$ & 60 & 1254 & 7 & 316 & 7 & 749 & Det-96 & 1819 & Aulg-00 \\
\hline Investec Index R & 60 & 104 & 25 & 15 & 32 & 70 & Sep-01 & 131 & SULI-97 \\
\hline Liberty Prosperity R & 60 & 658 & 12 & 145 & 15 & 433 & A.ug- -48 & 572 & Oct-56 \\
\hline Liberty R5A Equity A & 34 & 369 & 19 & 100 & 22 & 221 & Dec-98 & 553 & Aug- D1 \\
\hline kiberty Weal1hbuilder R & 60 & 1960 & 3 & 755 & 3 & 1331 & Sep-01 & 3619 & Oct-5g \\
\hline m Culed Fquity FoF & 45 & 44 & 32 & 17 & 30 & 13 & $\operatorname{Jan} 98$ & 87 & Jul.9日 \\
\hline Metropolitan General Equity & 60 & 562 & 16 & 255 & 9 & 129 & $0 \mathrm{cil}-96$ & 938 & Feb-01 \\
\hline Nedtiarik Growth & 45 & 262 & 21 & 228 & 10 & 18 & $\operatorname{Jan} 98$ & 765 & Mar 0 OO \\
\hline Neobank Harlequān & 23 & 33 & 36 & 22 & 20 & 6 & Sep-01 & 68 & Fub-00 \\
\hline NiB Altitude Equiry FoF A & 27 & 158 & 23 & 139 & 17 & 34 & $\operatorname{sep} \cdot 01$ & 401 & $\operatorname{Jan}-00$ \\
\hline NIB Horizoni Equity FoF A & 27 & 329 & 20 & 58 & 23 & 233 & Sep-gg & 411 & Aug- 00 \\
\hline Oasis Crescent Equily & 37 & 62 & 30 & 46 & 26 & 3 & Sep-98 & $14 \theta$ & Aug-01 \\
\hline Ord Mutual Investors & 80 & 4081 & 1 & 885 & 2 & 2 日32 & Augg-98 & 5787 & Ort-96 \\
\hline Odd Mutual Top Companies & 60 & 595 & 14 & 154 & 14 & 360 & Sep-01 & $98 \mathrm{\theta}$ & Apr-gga \\
\hline Prudential Optimiser & 25 & 457 & 17 & 174 & 12 & 159 & Sep-99 & 688 & Nay-01 \\
\hline RiMB Equity & 60 & 710 & 10 & 136 & 19 & 489 & Sep-01 & 1015 & Apr-98 \\
\hline RMAB Performance FoF & 38 & 39 & 34 & 5 & 38 & 24 & Aug-9日 & 47 & Aug- -00 \\
\hline Sage Fund & 60 & 1404 & $\theta$ & 215 & 11 & 973 & Sep-98 & 1822 & Feb-97 \\
\hline Santam Future Trends & 35 & 92 & 27 & 40 & 27 & 19 & Nov -98 & 160 & Jan-oo \\
\hline Sanlam General & 60 & 683 & 11 & $10 ?$ & 21 & 508 & Sep-01 & 902 & Apr-58 \\
\hline Standaro Bk Aggressive FoF A & 37 & 27 & 37 & 9 & 37 & 14 & Sep 98 & 42 & Jan-01 \\
\hline Standaro Bk Index R & 60 & 23 & 39 & 14 & 35 & 8 & Aug-98 & 73 & Dec-99 \\
\hline Standard Bk Mutual R & BD & $B 8 G$ & 8 & 287 & $g$ & 490 & Sep-D1 & 1399 & Fet- 97 \\
\hline Woakworths Unit Trust & 22 & 19 & 40 & 4 & 40 & 13 & Apr-00 & 24 & Aug -01 \\
\hline
\end{tabular}




\section{G.7: Fee structures}

\begin{tabular}{|c|c|c|c|c|c|c|c|c|c|c|c|c|}
\hline & \multirow{2}{*}{$\begin{array}{l}\text { Miñ fnitial } \\
\text { investunent. }\end{array}$} & \multirow{2}{*}{$\begin{array}{l}\text { Win sub } \\
\text { investment }\end{array}$} & \multicolumn{5}{|c|}{ Administration fees } & \multicolumn{5}{|c|}{ Initial charges } \\
\hline & & & 1997 & 1898 & 1999 & 2000 & 2001 & 1997 & 1998 & 1999. & 2000 & 2001 \\
\hline ABSA General R & R500 & $\mathrm{R} 100$ & $10 \%$ & $1.04 \%$ & $1 \mathrm{FW}^{2}$ & $1 \mathrm{JT}^{\mathrm{m}}$ & :Cक्रा & $5.0 \%$ & $5.9 \%$ & $6 \mathrm{c \%}$ & $61 \%$ & 5.05 \\
\hline ABSA Growth FoF & R 2000 & & & & $1.5 \%$ & $1.5 \%$ & $1,6 \%$ & & & $4.4 \%$ & $4.5 \%$ & 4.455 \\
\hline Afr Harvest Core Equity & R2 200 a & & & & & & $1.4 \%$ & & & & & $4.9 \%$ \\
\hline Afr' Harvest Rainmaker & R2 000 & & & & & & $1.4 \%$ & & & & & $49 \%$ \\
\hline Allan Gray Equity A & R 10000 & R 10000 & & & $30 \%$ & $3.0 \%$ & 3. 056 & & & $4.2 \%$ & $4.2 \%$ & $42 \%$ \\
\hline BoE Equity & R2 000 & R. 500 & $1.0 \%$ & $1.0 \%$ & $10 \%$ & $1.0 \%$ & $1.0 \%$ & $5.8 \%$ & $6.0 \%$ & $6.1 \%$ & $6.1 \%$ & 6.150 \\
\hline Community Growth & R 500 & R 10000 & $0.0 \%$ & $0.0 \%$ & $00 \%$ & $0.0 \%$ & $0.5 \%$ & $5.8 \%$ & $6.0 \%$ & $6.0 \%$ & $6.1 \%$ & $6.1 \%$ \\
\hline Coronation High Growth & R 5000 & R 50000 & $1.0 \%$ & $1.0 \%$ & $1.0 \%$ & $1.0 \%$ & $1.0 \%$ & $0.0 \%$ & $6.1 \%$ & $6.0 \%$ & $6.0 \%$ & $6.0 \%$ \\
\hline Fairheads Equity & R 5000 & $R+000$ & & & & & $1.3 \%$ & & & & & $6.1 \%$ \\
\hline FNB Growth & R2 2000 & $R+000$ & & & & $0.0 \%$ & $0.0 \%$ & & & & $5.6 \%$ & $5.5 \%$ \\
\hline FT NIB LT Wealth Creator & R2 500 & R. 250 & & $0.8 \%$ & $0.8 \%$ & $0.8 \%$ & $0.8 \%$ & & $6.0 \%$ & $6.1 \%$ & E. $1 \%$ & $6.1 \%$ \\
\hline FT NIB P rime Select & R 5000 & R 100 & $1.0 \%$ & $1.0 \%$ & $1.0 \%$ & $1.0 \%$ & $1.0 \%$ & $5.9 \%$ & $6.0 \%$ & $6.1 \%$ & $6.1 \%$ & $3.0 \%$ \\
\hline FT NiB Quants Core Equity & R 2500 & R 1000 & & & & & $08 \%$ & & & & & $6.1 \%$ \\
\hline Futuregrowth Core Equity & R 10000 & & & & & $0.8 \%$ & $1.0 \%$ & & & & $1.1 \%$ & $1.1 \%$ \\
\hline Futuregrowth Pure Equily & R 500 & & $0.0 \%$ & $0.0 \%$ & $0.0 \%$ & $0.0 \%$ & $00 \%$ & $6.2 \%$ & $60 \%$ & $6.1 \%$ & $6.1 \%$ & $6.1 \%$ \\
\hline Gryphan Imp General Equity & R 2000 & R 200 & & & & & $1.8 \%$ & & & & & $5.0 \%$ \\
\hline Gryphon Imp SA Tracker & R 100 & R 100 & & $1.3 \%$ & $1.3^{6} \%$ & $1.35 \%$ & $1.3 \%$ & & $2.1 \%$ & $5.1 \%$ & $5.1 \%$ & $5.0 \%$ \\
\hline Investec Equity $\mathbf{R}$ & R 10000 & $R 100$ & $10 \%$ & $1.0 \%$ & $1.0 \%$ & $1.0 \%$ & $1,0 \%$ & $5.8 \%$ & $6.0 \%$ & $6.1 \%$ & $6.1 \%$ & 6.1\%: \\
\hline Investec Index R & R 10000 & & $0.4 \%$ & $0.4 \%$ & $0.4 \%$ & $0.4 \%$ & $0.4 \%$ & $5.18 \%$ & $6.0 \%$ & $0.1 \%$ & $3.9 \%$ & $0.6 \%$ \\
\hline Liberty Pros perity $\mathbf{R}$ & R2 000 & & $1.5 \%$ & $1.6 \%$ & $1.5 \%$ & $16 \%$ & $22 \%$ & $6.2 \%$ & $6.4 \%$ & $6.4 \mathrm{So}$ & $6.4 \%$ & B. $4 \%$ \\
\hline Liberty RSA Equity A & R. 2000 & $R 1000$ & & & & $2.2 \%$ & $2.7^{2} \%$ & & & & $6.1 \% \%$ & 6. $1 \%$ \\
\hline Liberty Wealthbuilder $\mathbf{R}$ & R 200 & & $1.6 \%$ & $1.8 \%$ & $1,8 \%$ & $1.8 \%$ & $2.2 \%$ & $5.2 \%$ & $6.3 \%$ & $6.4 \%$ & $6.4^{10 \%}$ & $5.3 \%$ \\
\hline m Cubed Equity FoF & $R 10000$ & R 500 & & & $1.5 \%$ & $1.5 \%$ & $05 \%$ & & & $6.2^{\%} \%$ & $6.2 \%$ & $6.1 \%$ \\
\hline Notropolitan General Equity & R 500 & R 100 & $1.0 \%$ & $1.0 \%$ & $1.0 \%$ & $1.0 \%$ & $1.0 \%$ & $6.1 \%$ & $6.1 \%$ & $6.1 \%$ & $6.1 \%$ & $6,0 \%$ \\
\hline Nedbank Growth & R 2000 & R 250 & & & $1.0 \%$ & $10 \%$ & $1.0 \%$ & & & $6.0 \%$ & $84 \%$ & $61 \%$ \\
\hline Nodbank Harlequin & R 2000 & & & & & $1.0 \%$ & $1.0 \%$ & & & & $6.1^{0 \prime}$ & $6.1 \%$ \\
\hline NIB A litude Equity FoF A & R 5000 & R 1000 & & & & $18 \%$ & $1.8 \%$ & & & & $6.1 \%$ & $5.9 \%$ \\
\hline NiB Horizon Equity Fof A & R 5000 & R 1000 & & & & $18 \%$ & $1.8 \%$ & & & & $6.0 \%$ & $5.9 \%$ \\
\hline Oat is Crescent Equity & R 2000 & R 500 & & & $0.0 \%$ & $0.0 \%$ & $0.0 \%$ & & & $5.6 \%$ & $5.5 \%$ & $5.5 \%$ \\
\hline Old Mutual investors & R 10000 & R 100 a & $1.0 \%$ & $1.0 \%$ & $1.0 \%$ & $1.0 \%$ & $1.0 \%$ & $6.0 \%$ & $6.1 \%$ & $6.2 \%$ & $6.2 \%$ & $6.2 \%$ \\
\hline Old Mutual Top Companles & R 10000 & & $10 \%$ & $1.0 \%$ & $1.0 \%$ & $1.0 \%$ & $1.0 \%$ & $6.0 \%$ & $6.1 \%$ & $6.2 \%$ & $6.2 \%$ & 6.25 \\
\hline Prudential Optimiser & R 10000 & $R 1000$ & & & & $1.5 \%$ & $1.5 \%$ & & & & $6.2 \%$ & 6.1 药 \\
\hline RMB Equity & R 5000 & & $1.0 \%$ & 1. ase & $1.0^{\circ} \mathrm{s}$ & $1.0 \%$ & $1.0 \%$ & $58 \%$ & $60 \%$ & $6.1 \%$ & $6.1 \%$ & $6.0 \%$ \\
\hline RMB Performance FoF & R5 000 & & & & $1.7 \%$ & $1.8 \%$ & $1.3 \%$ & & & $5.5 \%$ & $5.6 \%$ & $5.5 \%$ \\
\hline Sage Fund & R 1000 & R. 500 & $1.0 \%$ & $1,0 \%$ & $1.0 \%$ & $1.0^{\circ} \%$ & $1.0 \%$ & $6.0 \%$ & $6.0 \%$ & $6.1 \%$ & $6.2 \%$ & $6.1 \%$ \\
\hline Sanlam Future Trends & R 2000 & $R 200$ & & & $2.0 \%$ & $2.0 \%$ & 2. $.1 \%$ & & & $4.7 \%$ & $51 \%$ & $5.6 \%$ \\
\hline Sanlam General & R 1000 & $R 200$ & $1.0 \%$ & $1.0 \%$ & $1.0 \%$ & $10 \%$ & $1.0 \%$ & $5.4 \%$ & $6.0 \%$ & $6.1 \%$ & $6.2 \%$ & $6.1 \%$ \\
\hline Standard BK Aggreggive FoF & $\mathrm{R} 2000$ & & & & $1.5 \%$ & $1.5 \%$ & $2.0 \%$ & & & $4.9 \%$ & $5.4 \%$ & $5.6 \%$ \\
\hline Standard Bk Index R & R 2000 & & $0.0 \%$ & $0,0 \%$ & $0.0 \%$ & $0.0 \%$ & $0.0 \%$ & $5.7 \%$ & $3.7 \%$ & $5.7 \%$ & $5.7 \%$ & $5.7 \%$ \\
\hline Standard Bk Mutual R & $R 200$ 며 & $R 1000$ & $1.0 \%$ & $1.0 \%$ & $1.0 \%$ & $1.0 \%$ & $1.0 \%$ & $5.8 \%$ & 5.11\% & $6.0 \%$ & $6.0 \%$ & $5.8 \%$ \\
\hline Woolwarthg Unit Trust & R 500 & & & & & & $1.1 \%$ & & & & & $3.6 \%$ \\
\hline
\end{tabular}

(SOURCE: Lambrechts. 2003) 


\section{H. Spearman rank order correlations matrix}

\begin{tabular}{|c|c|c|c|c|c|c|c|c|c|c|c|c|c|}
\hline & Cash flows & $\begin{array}{l}\text { Shart-term } \\
\text { interest }\end{array}$ & $\begin{array}{l}\text { Long-term } \\
\text { intorosi }\end{array}$ & $\begin{array}{c}\text { Local market } \\
\text { returtis }\end{array}$ & $\begin{array}{c}\text { Intorntalional } \\
\text { market } \\
\text { returns }\end{array}$ & Fees & Returns & $\begin{array}{l}\text { Natural log } \\
\text { of fund sizo }\end{array}$ & Risk & $\begin{array}{l}\text { Excess } \\
\text { return }\end{array}$ & $\begin{array}{l}\text { Abnormal } \\
\text { returns }\end{array}$ & $\begin{array}{l}\text { Changos in } \\
\text { short-term } \\
\text { interest }\end{array}$ & $\begin{array}{l}\text { Changes in } \\
\text { long-term } \\
\text { intorosi }\end{array}$ \\
\hline Cash flows & 1.00 & & & & & & & & & & & & \\
\hline Sholt-tẹrm interrest & 0.17 & 1.00 & & & & & & & & & & & \\
\hline Long-term intorest & 0.19 & $0.75^{\circ}$ & 100 & & & & & & & & & & \\
\hline $\begin{array}{l}\text { Local markot } \\
\text { roturns }\end{array}$ & $0.71^{*}$ & 0.11 & -0.07 & 1.00 & & & & & & & & & \\
\hline $\begin{array}{l}\text { International } \\
\text { market retums }\end{array}$ & $0.60^{*}$ & $0.34^{*}$ & 0.24 & $0.53^{n}$ & 100 & & & & & & & & \\
\hline Fees & 0.08 & $0.57^{\star}$ & $0.69^{\circ}$ & -0.09 & $0.26^{*}$ & 1.00 & & & & & & & \\
\hline Roturns & $0.68^{*}$ & 0.19 & -007 & $0.95^{\star}$ & $0.5 T^{x}$ & -0.00 & 1.00 & & & & & & \\
\hline $\begin{array}{l}\text { Natural log of fund } \\
\text { sizo }\end{array}$ & -5.13 & $-0.59^{\circ}$ & $-0.75^{2}$ & 0.14 & -0.06 & -0.20 & 0.15 & 1.00 & & & & & \\
\hline Risk & .0 .10 & -0.21 & -0.18 & -0.03 & -0.13 & -0.22 & -0.09 & 0.13 & 1.00 & & & & \\
\hline Excoss roturns & $-0.52^{*}$ & d.t: & 0.03 & $-0.67^{A}$ & -021 & $0.26^{x}$ & $-0.44^{4}$ & -0.03 & -0.13 & 1.00 & & & \\
\hline Abnormal returns & -0.11 & 0.29 & .0 .00 & .0 .16 & 0.15 & 0.25 & 0.11 & 0.08 & $-0.27^{*}$ & $0.77^{*}$ & 1.00 & & \\
\hline $\begin{array}{l}\text { Changes in short. } \\
\text { torm intorest }\end{array}$ & -0.03 & 0.01 & 0.04 & 5.01 & -0.09 & 0.09 & 0.03 & 007 & 0.09 & -0.01 & 0.00 & 1.00 & \\
\hline $\begin{array}{l}\text { Changes in long- } \\
\text { term interest }\end{array}$ & $-0.26^{\star}$ & -0.03 & $0.27^{*}$ & $-0.43^{n}$ & -0.21 & 0.22 & $-0.43^{*}$ & -0.06 & 0.05 & $0.27^{*}$ & -0.02 & -0.19 & 100 \\
\hline
\end{tabular}




\section{Aggregated determinant time-series regression results}

Appendix I presents the aggregated regression results. Appendix I.1 presents the stepwise regression results based on the aggregated data adjusted for auto-correlation using the first-differencing approach. Appencices i.2 and I. 3 present the multivariate and stepwise regression results. based on data which were not adjusted for autocorrelation.

\section{I.1: Regression results between cash flows and the independent variables} using a stepwise regression technique based on data adjusted for autocorrelation using the first-differencing approach

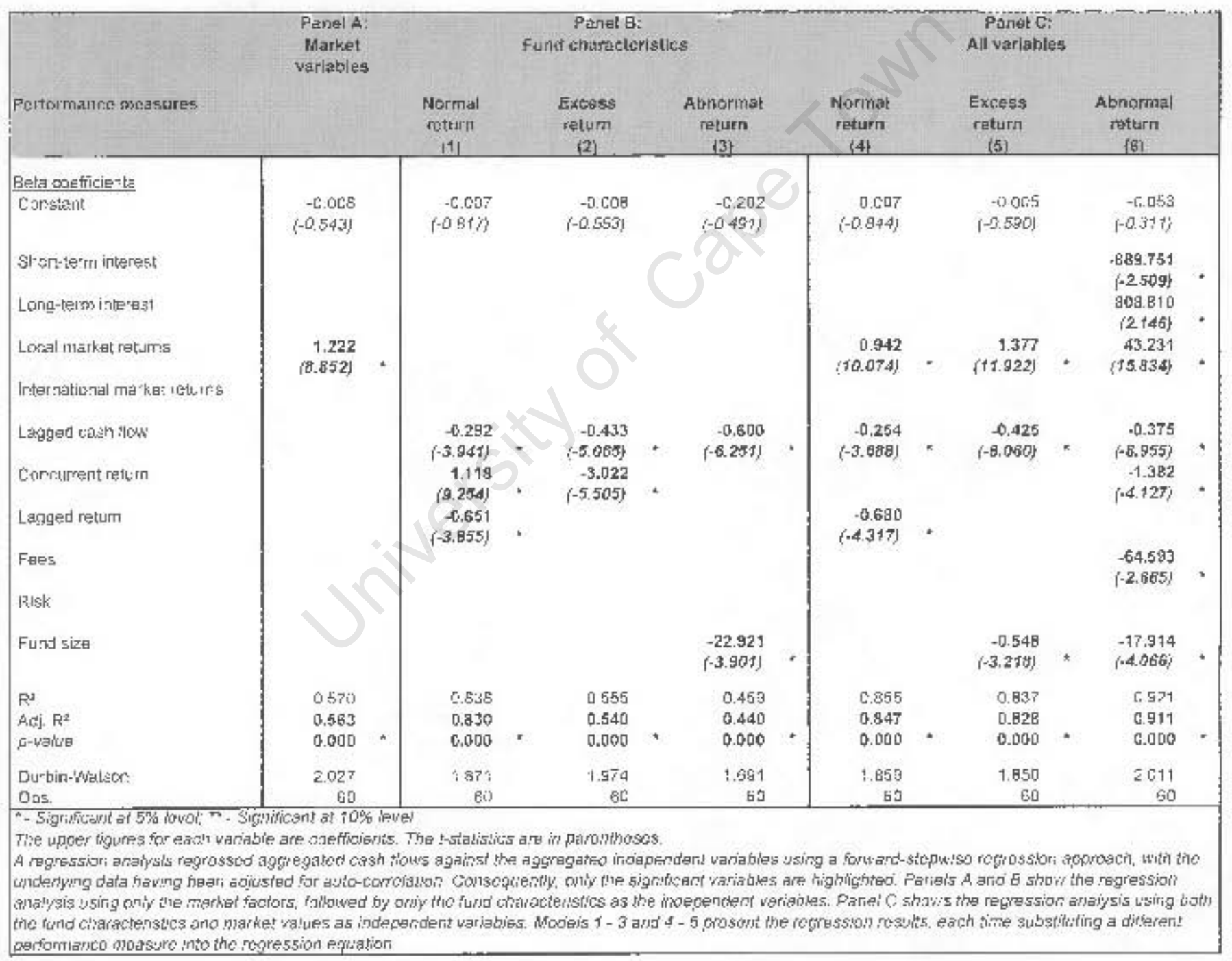




\section{I.2: Regression results between cash flows and the independent variables}

\section{using a multivariate regression technique based on data not adjusted for}

\section{auto-correlation}

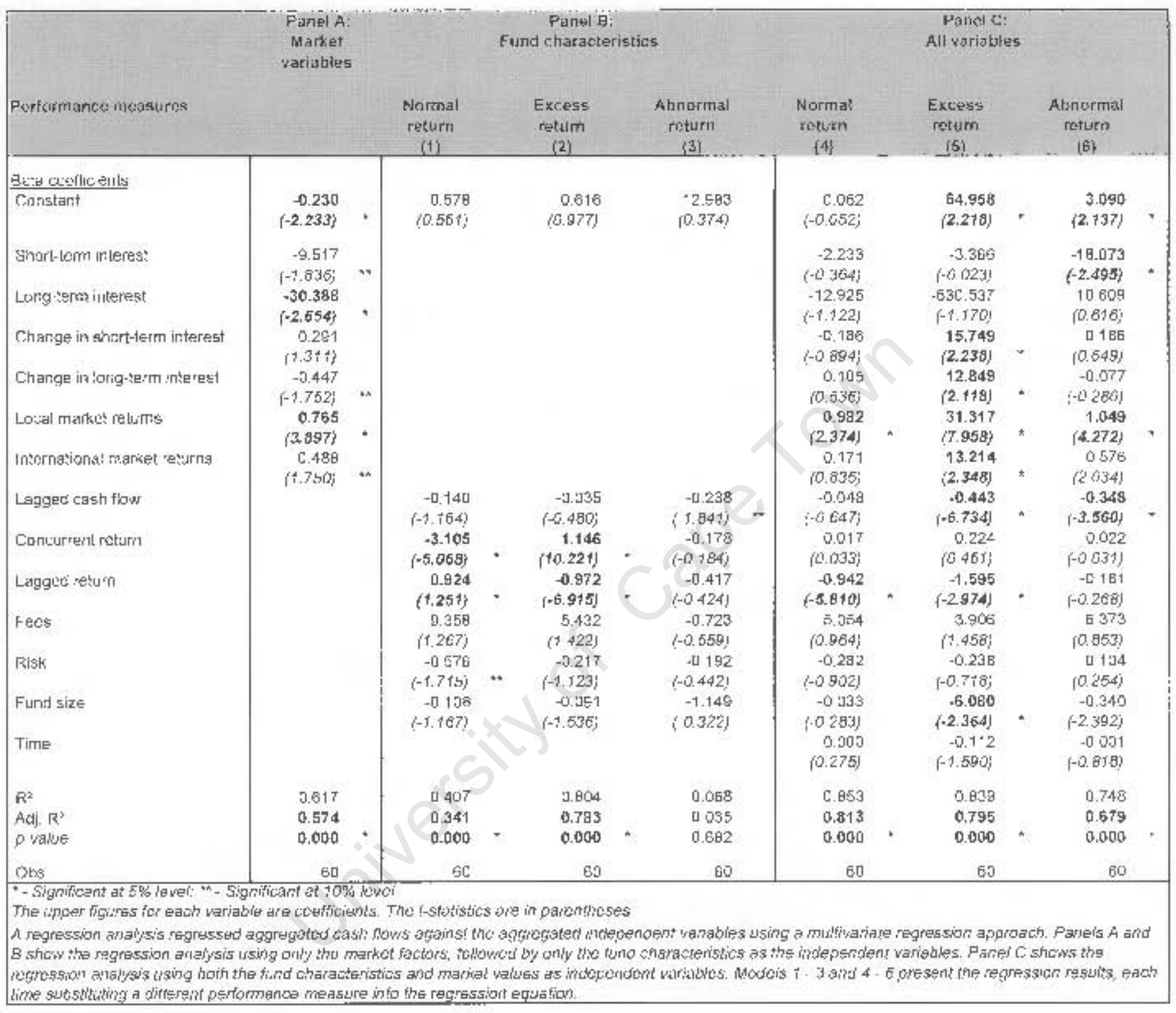




\section{I.3: Regression results between cash flows and the independent variables using a stepwise regression technique based on data not adjusted for auto- correlation}

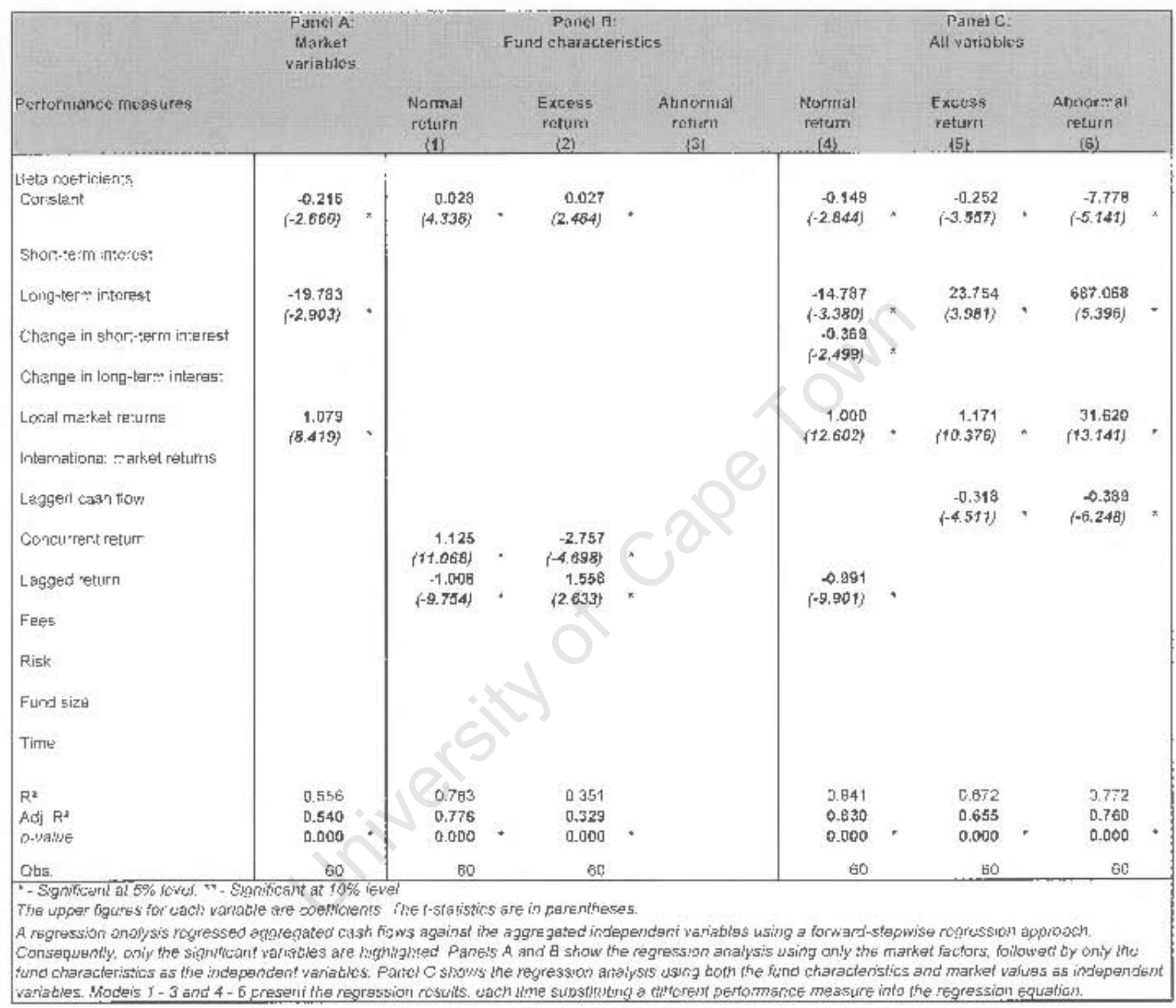




\section{J. Individual fund time-series regression analysis results}

J.1: Proportional number of significant regression coefficients based on a stepwise regression analysis approach

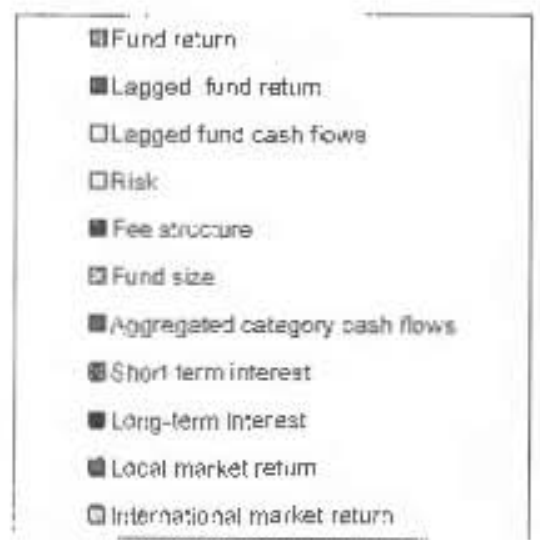

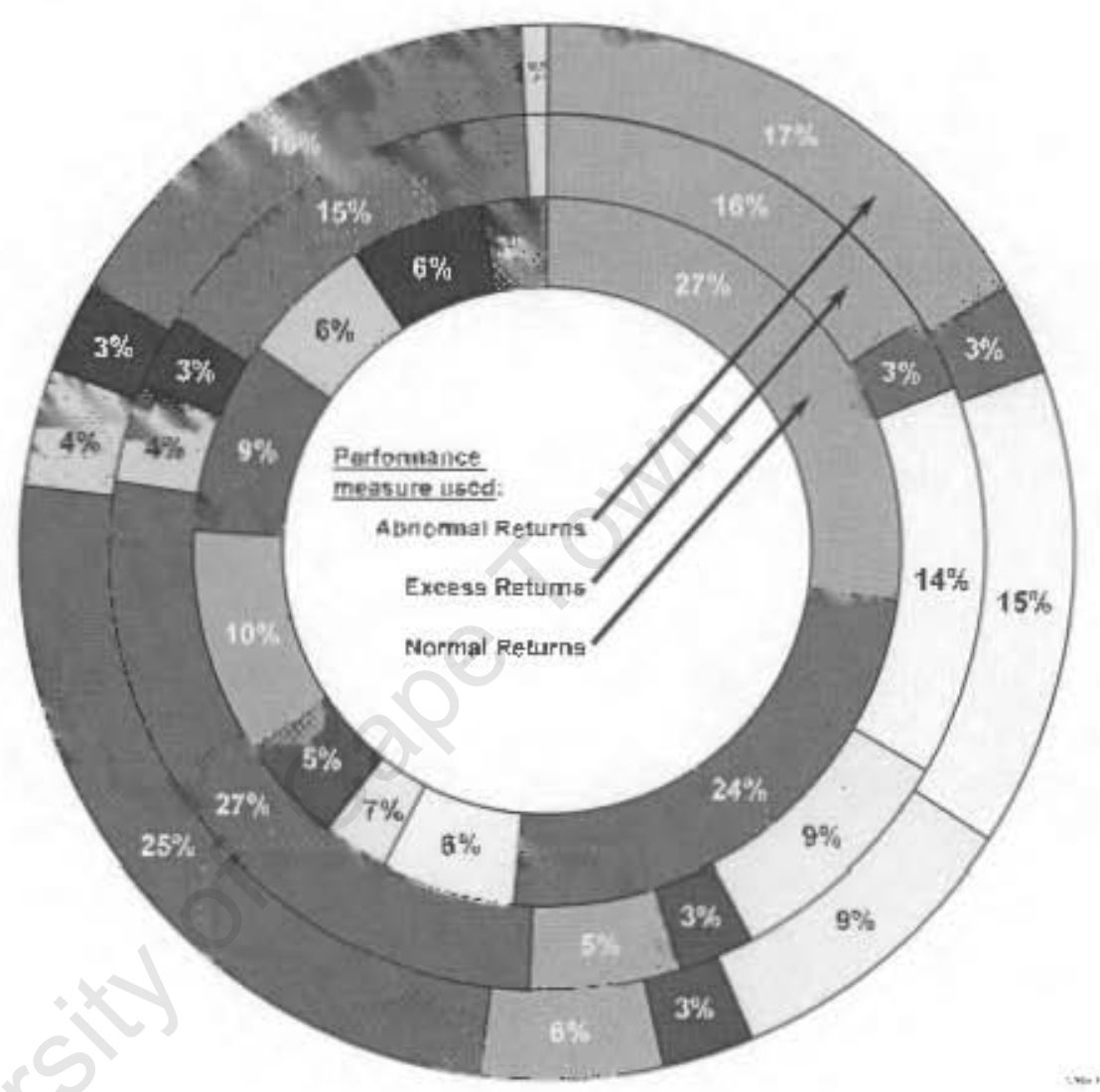

J.2: Summary results of the variables adding significant explanatory power towards explaining cash flows following a stepwise regression approach

\begin{tabular}{|c|c|c|c|c|c|c|}
\hline & \multicolumn{2}{|c|}{ Panel A: Noctual retum } & \multicolumn{2}{|c|}{ Panel B Excess retum } & \multicolumn{2}{|c|}{ Panel C: Abnormal return } \\
\hline & $\begin{array}{l}\text { Significant } \\
\text { Variables } \\
\end{array}$ & \%. & $\begin{array}{l}\text { Significant } \\
\text { Variables }\end{array}$ & 然 & $\begin{array}{l}\text { Signaficant } \\
\text { Variables }\end{array}$ & Ya \\
\hline Constant & 26 & $76 \%$ & 24 & $71 \%$ & 23 & $74^{0, i}$ \\
\hline Local inarket return & 3 & $\theta^{\prime \prime} \%$ & 17 & $50 \%$ & 17 & $55 \%$ \\
\hline International market relurn & - & $0 \%$ & 1 & $3 \%$ & 1 & $3 \%$ \\
\hline Short-term inlerest & 6 & $18 \%$ & 4 & $12 \mathrm{~s}$ & 4 & $13 \%$ \\
\hline Long-term interest & 5 & $18^{\circ} \%$ & 3 & $9 \%$ & 3 & $10 \%$ \\
\hline Fund return & 27 & $79 \%$ & 18 & $53 \%$ & 18 & $58 \%$ \\
\hline Lagged fund retum & 24 & $71 \%$ & 3 & $9 \%$ & 3 & $10 \%$ \\
\hline Lagged fund cash flows & 6 & $18 \%$ & 16 & $47 \%$ & 16 & $52 \%$ \\
\hline Aggregated category cash flows & 9 & $26 \%$ & 30 & $89 \%$ & 27 & $87 \%$ \\
\hline Fee structure & 5 & $15 \%$ & 3 & $9 \%$ & 3 & $10 \%$ \\
\hline Risk & 3 & $9 \%$ & 10 & $29 \%$ & 10 & $32 \%$ \\
\hline Fund size & 10 & $29 \%$ & 6 & $18 \%$ & $\theta$ & $19 \%$ \\
\hline Number of funds & 34 & & $\$ 4$ & & 31 & \\
\hline
\end{tabular}


J.3: Interaction between the independent variables at different levels of correlation following a stepwise regression approach

\begin{tabular}{|c|c|c|c|c|c|c|c|c|c|c|c|c|}
\hline & Add. $R^{t}$ & $\begin{array}{l}\text { Shart-term } \\
\text { unterest }\end{array}$ & $\begin{array}{l}\text { Long-termi } \\
\text { interest }\end{array}$ & $\begin{array}{l}\text { Cocal } \\
\text { markel } \\
\text { returtus }\end{array}$ & $\begin{array}{l}\text { Internatiaal } \\
\text { market coturms }\end{array}$ & $\begin{array}{l}\text { Lapged } \\
\text { fund casl } \\
\text { How }\end{array}$ & $\begin{array}{l}\text { Aggregatod } \\
\text { category cash } \\
\text { Mow }\end{array}$ & $\begin{array}{l}\text { Concuiteirt } \\
\text { tund teturn }\end{array}$ & $\begin{array}{l}\text { Lagged } \\
\text { fusd return }\end{array}$ & Tees & Rish & Fund size \\
\hline \multicolumn{13}{|c|}{ Pathel A: Namai rebarm } \\
\hline OS IHighesli & 9736 & 2 & 1 & T] & 9 & $\overline{2}$ & 2 & 9 & 9 & 5 & $\bar{\pi}$ & 3 \\
\hline ?Z & $9 ; 3$ & $i$ & 1 & 1 & $\ddot{z}$ & 1 & $i$ & 7 & 日 & i & 1 & 3 \\
\hline os & EE $z_{4}$ & 2 & 2 & 1 & is & 2 & 1 & 8 & 5 & a & 1 & 4 \\
\hline 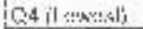 & $34 \%$ & $\therefore$ & $\therefore$ & 1 & $\therefore$ & 1 & t & i & ? & 1 & 1 & 1 \\
\hline \multicolumn{13}{|c|}{ Panel B: Excess rettirn } \\
\hline Q: (Higtests) & $5 ? 5$ & : & $\frac{5}{5}$ & 7 & $\frac{\pi}{6}$ & 7 & 9 & 8 & $\frac{2}{2}$ & 2 & $B$ & 3 \\
\hline 02 & 77 & 1 & 1 & 4 & 1 & 6 & 8 & 5 & $\ddot{z}$ & 1 & 5 & 2 \\
\hline oa & $B \equiv I_{i}$ & 1 & 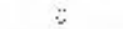 & 3 & 0 & $\Rightarrow$ & g & 5 & 0 & u & $i$ & 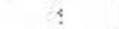 \\
\hline Q4 ILUWEE: & 74 & 2 & ju & 3. & 0. & 1 & 5 & u & 1 & 0 & $\therefore$ & 1 \\
\hline \multicolumn{13}{|c|}{ Panel C: Abinomal return } \\
\hline 0 ! $\mathrm{iH}$ nes: & $\mathrm{E} \cdot 2 \%$ & J & 2 & 7 & $\because$ & 6 & 8 & B & 2 & 2 & 5 & 2 \\
\hline 02 & $7 \%$ & 1 & 1 & 3 & 1 & $B$ & 7 & a. & 0 & 1 & 3 & 2 \\
\hline 03 & $71 \%$ & 0 & 0 & a & a & 3 & 8 & 5 & 0 & a & 1 & i \\
\hline Q1 Lom:-S: & $38 \%$ & 9 & 0 & 3 & a & 1 & 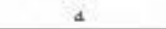 & 1 & 1 & a & 1 & 1 \\
\hline
\end{tabular}

J.4: Individual fund level findings using a multivariate regression analysis including all independent variables and the following performance measures

J.4.1: All variables: Normal return

J.4.2: All variables: Excess return

J.4.3: All variables: Abnormal return

J.5: Individual fund level findings using a forward-stepwise regression analysis including all independent variables and the following performance measures

J.5.1: Stepwise: Normal return

J.5.2: Stepwise: Excess return

J.5.3: Stepwise: Abnormal return

The results on the following tables are based on televant data having been adjusted for auto-correlation, using the first-differencing approach. 

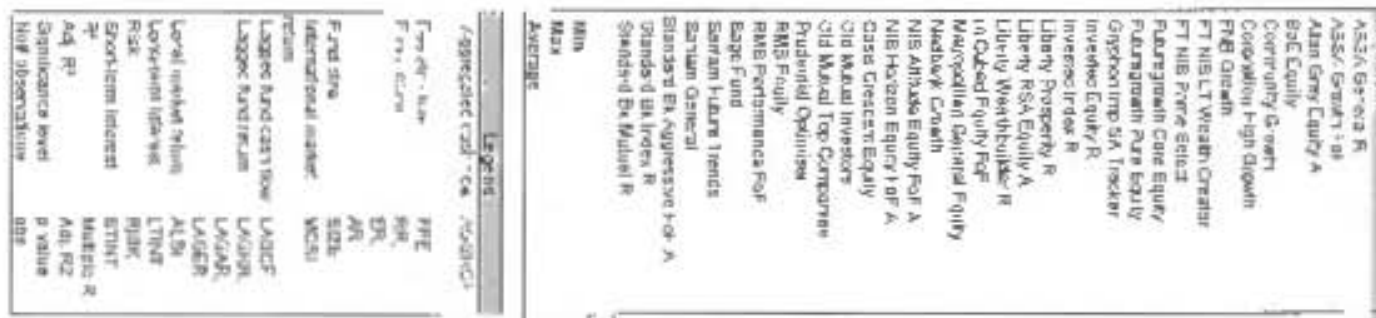

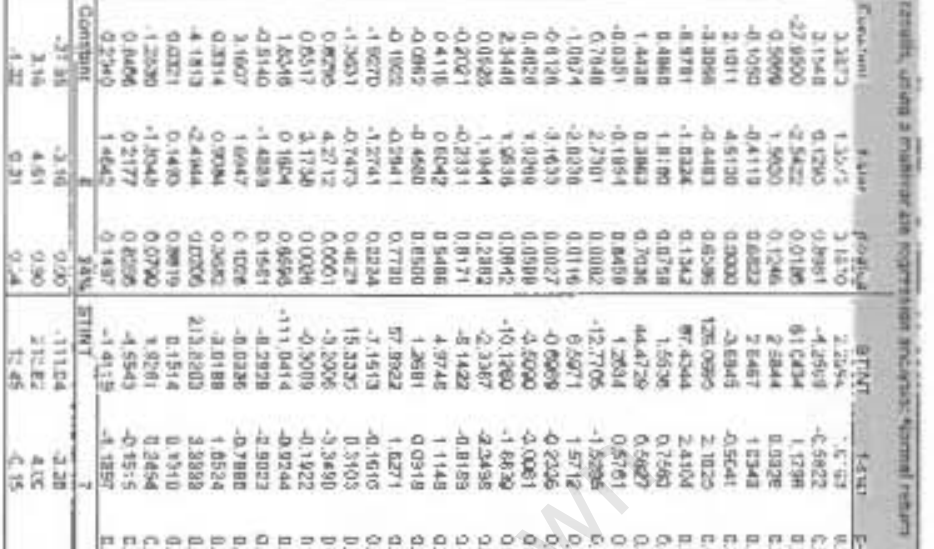

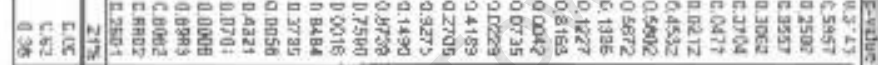

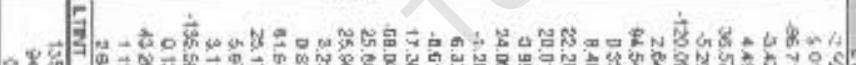

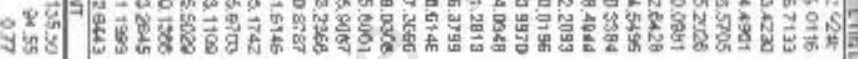

胥

으의.

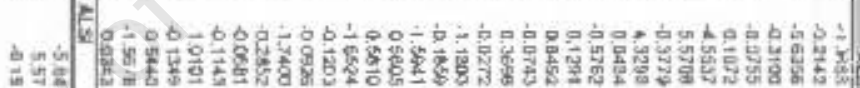

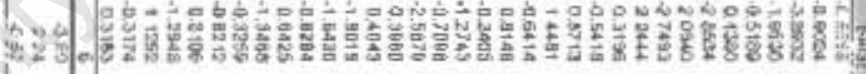

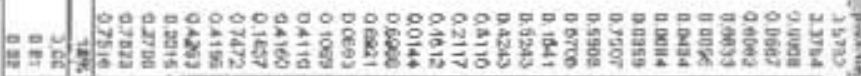

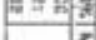

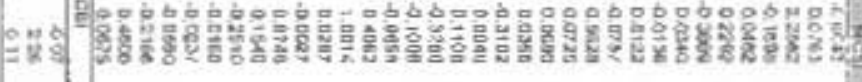

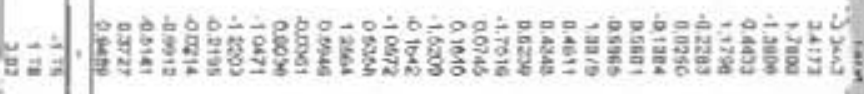

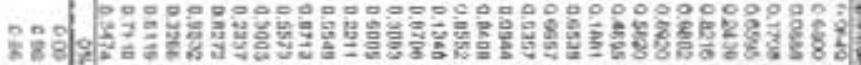
إ.

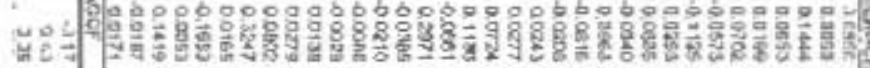

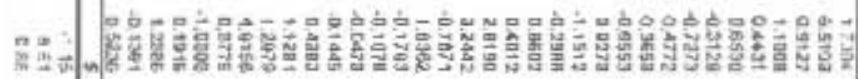
ด

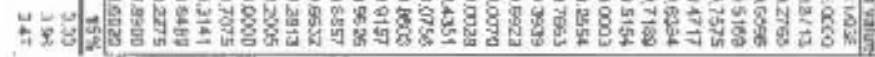




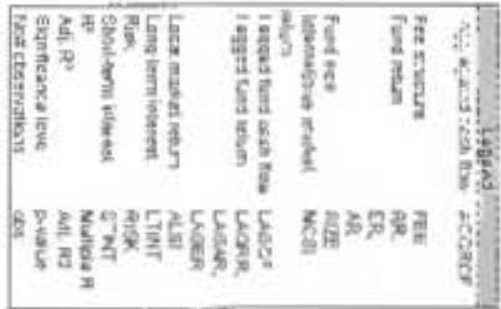

.

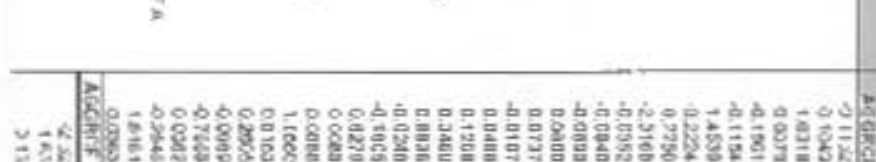
Ions it

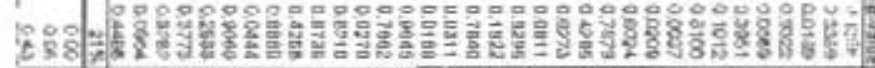
|

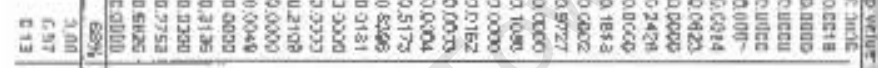

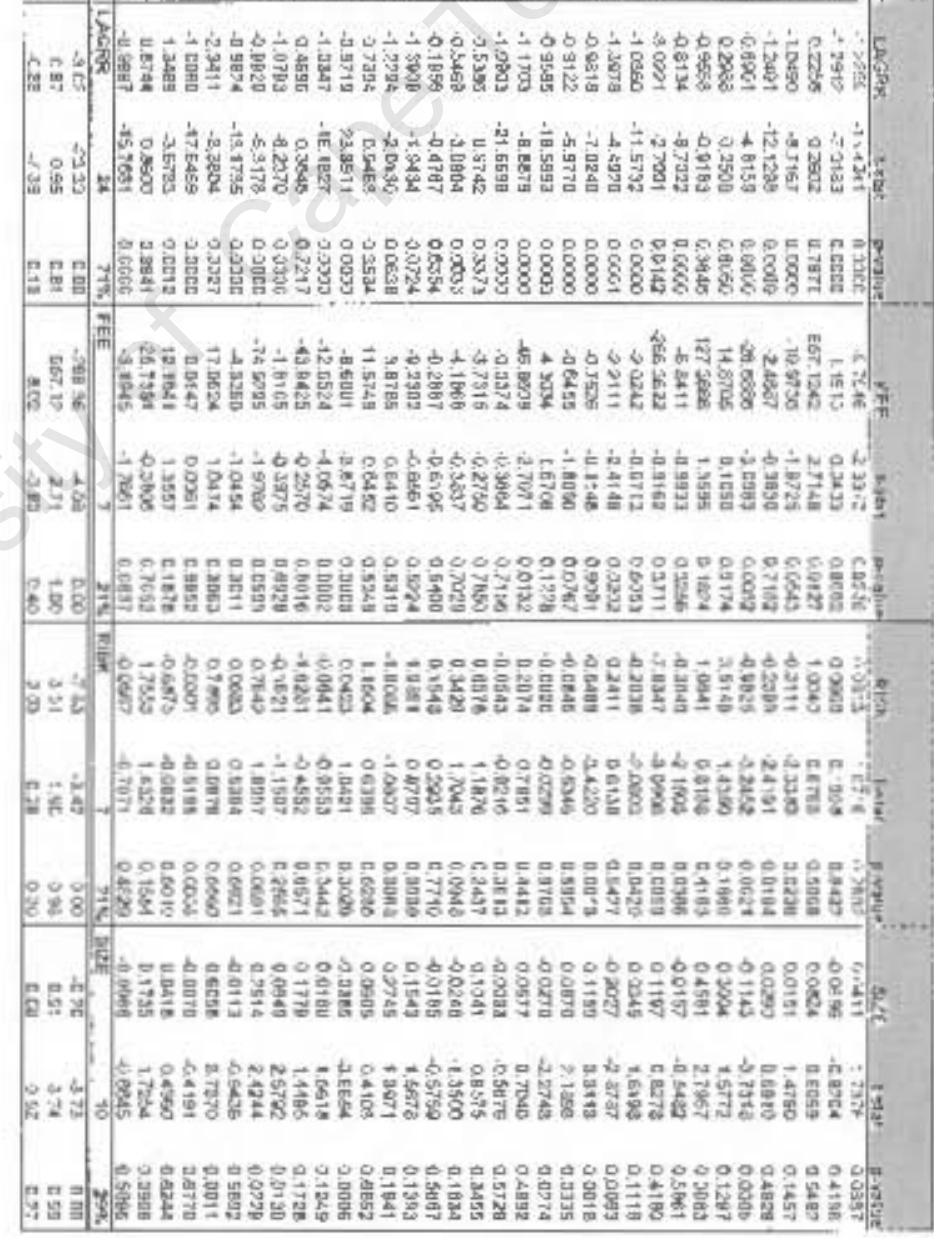




\begin{tabular}{|c|c|c|c|c|}
\hline \multicolumn{5}{|l|}{ 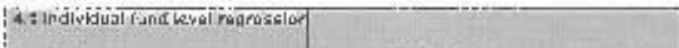 } \\
\hline Fundolamia & \multicolumn{2}{|c|}{ 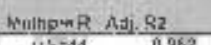 } & \multicolumn{2}{|c|}{ p.alu* cbs } \\
\hline 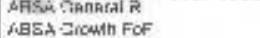 & $\int_{0 \rightarrow 101}$ & 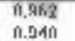 & cowed & \\
\hline Alingray Equty a & $\begin{array}{l}09117 \\
0917\end{array}$ & 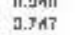 & n & 3 \\
\hline Eauty & & 0.920 & $0.0 \mathrm{nnn}$ & 60 \\
\hline Curnenty'somth & & 0.041 & 0.0000 & 60 \\
\hline Coronat on high Gmath & 03457 & 0.670 & c. .0000 & $\Leftrightarrow$ \\
\hline FNE GIOSTl: & 0.8456 & 0.500 & c.0010 & as \\
\hline FT MIE LT Wiesthl Sreater & 0.6271 & 0.256 & C.UA4: & 4" \\
\hline 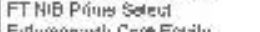 & & 0.928 & 6.0000 & $\approx$ \\
\hline 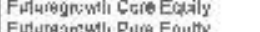 & 0000 & 0.457 & 6.0110 & s1 \\
\hline 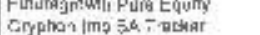 & 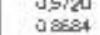 & 0 & 然, 00000 & \&s \\
\hline SWESTAC EnLilyR & 00570 & $\begin{array}{l}0,1090 \\
0,1997\end{array}$ & $\begin{array}{lll}80000 \\
00000\end{array}$ & 24 \\
\hline 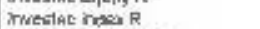 & 0.4514 & 0 & 0 & \\
\hline Jterty Picsosty R & 0.9950 & 0,977 & c nc00 & $\infty$ \\
\hline Jterty RE: Equilys & 09967 & 0.998 & G caod & 33 \\
\hline Lterty Weatricuber A & a.921 & 0.981 & c cono & $\Leftrightarrow$ \\
\hline & - .9523 & 0.681 & $a 0000$ & 4 \\
\hline a Equits & 0.9134 & 0.810 & c.ccce & कב \\
\hline & 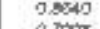 & 0.689 & c.cecc & \\
\hline 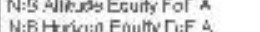 & 0 & 0.368 & 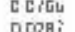 & 25 \\
\hline 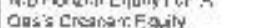 & 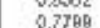 & 0.120 & 0.0069 & 35 \\
\hline Olf Mucial Invastors & $\Delta$ YIE & 0.29 & 00060 & 69 \\
\hline old kntwa iop corposires & 0.9894 & $0.97 \mathrm{~A}$ & cer.on & $\infty$ \\
\hline trusernal Lpomiser & a.9sit & 0.529 & 00755 & 26 \\
\hline & & 0.8в9 & Decer & 50 \\
\hline Imunce For & 0.80572 & 0.8077 & arcte & ${ }^{3} x^{2}>0$ \\
\hline & & 0.954 & a.coce & og \\
\hline Eardam Fl,bure Tnenos & 0.8559 & 0.557 & 000064 & se \\
\hline 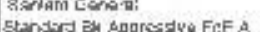 & $\begin{array}{ll}0.423 \\
0.8151\end{array}$ & 0.951 & 0000 & su \\
\hline \multirow{3}{*}{ 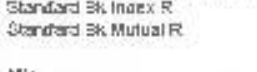 } & & $\begin{array}{l}0.716 \\
0.153\end{array}$ & ocents 15 & $\rightarrow \infty$ \\
\hline & & 0.97 & & \\
\hline & & & & \\
\hline Min & & c.76 & $\begin{array}{l}a \operatorname{coc} \\
0,0 \rightarrow\end{array}$ & \\
\hline & & & & \\
\hline
\end{tabular}

\begin{tabular}{|c|c|}
\hline Legrand & AESPCF \\
\hline 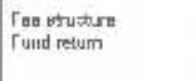 & $\begin{array}{l}F E E \\
P R \text {. } \\
\text { CR, }\end{array}$ \\
\hline Fund $G z \phi$ & $\begin{array}{l}\text { AR } \\
\text { SIII } \\
\text { NCB: }\end{array}$ \\
\hline 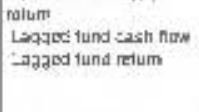 & $\begin{array}{l}\text { LAGCF } \\
\text { LASRR, } \\
\text { LAGQRR } \\
\text { LAGER }\end{array}$ \\
\hline 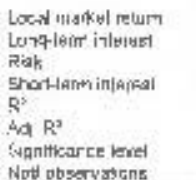 & 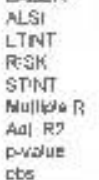 \\
\hline Hod obsarystans & \\
\hline
\end{tabular}




\begin{tabular}{|c|c|c|c|c|c|c|c|c|c|c|c|c|c|c|c|c|}
\hline \multicolumn{17}{|c|}{ 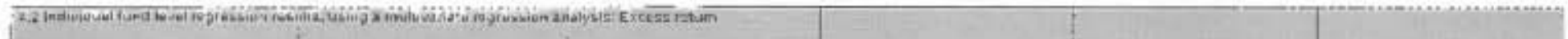 } \\
\hline \multirow{2}{*}{\multicolumn{2}{|c|}{ 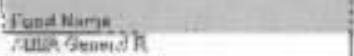 }} & Caratari & tetal & Hatoo: & $\sin x$. & 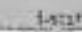 & funlue & LINUT & sobat & prour & $A \mid E$ & & & Mes: & & \\
\hline & & D.MNK & 29 & crati & 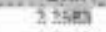 & ofis & 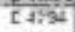 & Atein & 54540 & 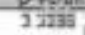 & Eक्डिक & 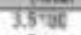 & cंज & ग्रिद & रान & एवयक्ष \\
\hline \multirow{2}{*}{\multicolumn{2}{|c|}{ 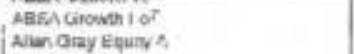 }} & -2.1230 & 6454 & $60 x^{2}$ & $-4 \cos 2$ & A soive & | & $-x \leq 5 e a 1$ & $-1 \mathrm{cms}$ & 31355. & onat & u.sac. & 50000 & uavi & ineso & 2354 \\
\hline & & 2752 & 25105 & $\cos 100$ & $\$ 13: 62$ & 1385 & $635 \% 2$ & $\$ 458 \pi g$ & $-1,7651$ & 0.0814 & $12 \%$ & 1230 & a.15ece & 2.0000 & lineso & 20920 \\
\hline \multicolumn{2}{|l|}{ B.E EquY } & 1.9181 & 1000 & 20004 & 20679 & 0.0529 & 0.5108 & 4.5166 & -10648 & 0.52904 & 00000 & 3649 & Dows & A.:64 & -10018 & a sace \\
\hline \multirow{2}{*}{\multicolumn{2}{|c|}{$\begin{array}{l}\text { Community Gronth } \\
\text { Cormation lition Grast }\end{array}$}} & onst & (2017 & Dass & $622 \mathrm{en}$ & 1. 1800 & 02411 & Q.4cas & 0.9423 & $12750 t$ & 0.3515 & 27765 & 0.000 & - पบ & oss: & 0.9pact \\
\hline & & 2584 & 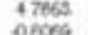 & 00000 & & 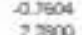 & a.sed & 37.2358 & $\begin{array}{ll}24: k \\
\text { apess }\end{array}$ & 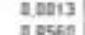 & 0.5623 & $\begin{array}{l}34268 \\
0.14\end{array}$ & 0,0095 & 0.0045 & 1 Doed & D.1238 \\
\hline \multicolumn{2}{|l|}{ 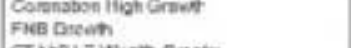 } & astia & 00006 & $\begin{array}{ll}0.3060 \\
02004\end{array}$ & $\begin{array}{l}13572865 \\
775013\end{array}$ & 232000 & 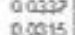 & $\begin{aligned} 4.1560 \\
-19208\end{aligned}$ & $\begin{array}{l}-0,0658 \\
-10600\end{array}$ & $\begin{array}{l}0.0560 \\
\text { sesen }\end{array}$ & 00914 & opena & (20, & 0.0146 & $\begin{array}{l}0 \times 21 \\
\text { gosse }\end{array}$ & $\begin{array}{l}0.702 \\
08093\end{array}$ \\
\hline \multirow{2}{*}{\multicolumn{2}{|c|}{ 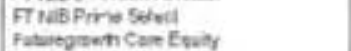 }} & 00501 & 12271 & $022 \pi 1$ & $\operatorname{lom}_{013 \pi}$ & .0017 & 000015 & $\begin{array}{l}-102750 \\
-24581\end{array}$ & - & ocest & $0 x 2$ & 25241 & Doing & 8018 & 0109 & orat \\
\hline & & (37) & 10012 & 0,3102 & 7.1560 & a $275 \mathrm{a}$ & (2003 & 123600 & $\pi=72$ & w wees & s.ses & 02860 & omiz & solut & 0.2537 & Doss \\
\hline \multicolumn{2}{|l|}{ 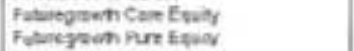 } & e01n & $005 \times$ & osset! & 60569 & 1.10270 & 01101 & 47002 & $-0,3505$ & o set: & 00012 & $306 n$ & gosan & tima & axcist. & 0.0004 \\
\hline \multicolumn{2}{|l|}{ Gopond ins se Tueter } & asent & $7 \operatorname{men}$ & Soony & +42170 & -121255 & 0.172 & 55061 & 0.2975 & ens & 0.005 & 8,0209 & $0,2 \mathrm{kn}$ ! & 0.050 & 0.052 & Q:34: \\
\hline \multicolumn{2}{|l|}{$\begin{array}{l}\text { thenens Ear yn } \\
\text { imetar indor : }\end{array}$} & Asate & 2517 & 0.0504 & asies & $211 x$ & 28534 & 20,3300 & 22118 & 8000 & $2 \cos 72$ & 3.3546 & 20001d & 9,173 & 0 mis: & eats: \\
\hline \multirow{2}{*}{\multicolumn{2}{|c|}{ 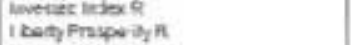 }} & ingen: & 9.9124 & 0.0017 & 29060 & 5.50 & 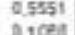 & & 2517 & Dorts & 24004 & 2,751 & gowery. & and & 0.012 & Donin \\
\hline & & 100 & 5000 & (25ins & $\begin{array}{lll}56284 \\
1651\end{array}$ & 1.803 & $\begin{array}{l}0.1020 \\
\text { sengs }\end{array}$ & $4+407$ & $\begin{array}{l}-0,4097 \\
1.49\end{array}$ & $\begin{array}{l}0.5006 \\
01041\end{array}$ & 0.45 & $\begin{array}{l}30021 \\
1,3150\end{array}$ & 0.45 & 0000 & and: & 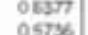 \\
\hline 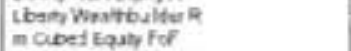 & 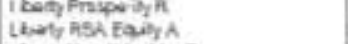 & 0078 & .6400 & $=\sin x$ & $3 \times 13$ & anden & 0.4857 & -0574 & $\begin{array}{l}14098 \\
.0095\end{array}$ & & 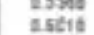 & $30 \%$ & tols & $0+\infty$ & am & 然 $057 x$ \\
\hline \multirow{2}{*}{\multicolumn{2}{|c|}{ 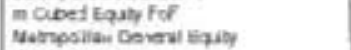 }} & avess & .00094 & 0.5505 & -89904 & - eave & 6.4199 & 227099 & $0=06 e^{2}$ & $0 \leq 28$ & 1.1230 & 2213 & 20241 & D.0314 & a.mi & -x215 \\
\hline & & aros & t.945: & 0.9012 & 27576 & emaco & Q.4675: & A.9457 & -1.1152 & 02703 & 6.5550 & $2 \mathrm{mon}$ & 0.0077 & 42202 & 12278 & ooss \\
\hline \multicolumn{2}{|l|}{ Nutirk costh } & $\Delta 18 \mathrm{sis}$ & a.,0215 & 0.2175 & 2.155 & oste & ¿984? & 255012 & esste & asoseg & 0.5428 & 1207 & 0.2392 & 81030 & $-0.232 x$ & o omat \\
\hline & & 0.2162 & $-4 \times 941$. & 0.7212 & t1ases & 0.0344 & 0.3973 & 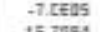 & -0.0952 & 0.2047 & Lapn & 1.150 & 0.2as! & $\$ .460$ & -04461 & angs! \\
\hline 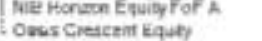 & & $\cos 27$ & -64922 & $\begin{array}{l}0.5614 \\
0.9393\end{array}$ & 40.9324 & -0.02157 & $\begin{array}{c}0.8234 \\
03034\end{array}$ & $\begin{array}{l}15.7054 \\
28.345\end{array}$ & 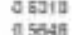 & 0.5519 & $\begin{array}{ll}0.068 \\
10528\end{array}$ & a.0983 & - 8.9322 & 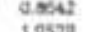 & 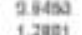 & 年, \\
\hline 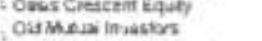 & & 1.1278 & - & ampa & $\begin{array}{l}12164010 \\
674,7\end{array}$ & $\begin{array}{l}0.052 \\
+\infty 6054\end{array}$ & $80+24$ & $\begin{array}{l}26.3454 \\
0.5947\end{array}$ & 20.5018 & $\begin{array}{l}0375 \\
09985\end{array}$ & $\begin{array}{l}16518 \\
80500\end{array}$ & $\begin{array}{l}2+127 \\
4+394\end{array}$ & g gerte & 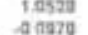 & 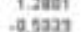 & $\begin{array}{l}02121 \\
0.9 x+1\end{array}$ \\
\hline 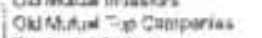 & & 10201 & , & 0,0057 & -0.1396 & 0.0044 & E9727 & 2.6121 & $\begin{aligned}-0.95 \mathrm{E}^{4} \\
-\end{aligned}$ & 0.7270 & $050 \% 5$ & 3.7. & 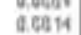 & - 11937 & -9essy & $\begin{array}{l}0.5 x 159 \\
0.5154\end{array}$ \\
\hline Prudorial Spliniour & & +6271 & 0,9702 & O.S4EE & -414.5993 & -1.1120 & $a=879$ & 93.7109 & 1.0014 & 81001 & อBร9 & 0.9071 & 04026 & 2.9078 & Q al142 & 0.194 \\
\hline PME Erity & & .92100 & $-0,3787$ & $0 \pi 06$ & $\ldots 199$ & 83349 & Do146 & 26.3955 & 2.8458 & 00055 & DTe4t & 275 & cc005 & a22006 & 0.0961 & 0.351 \\
\hline FMe Fertarmance $\mathrm{Fat}$ & & 52996 & tedos & $\alpha 0709$ & -145230 & -15512 & 0.1254 & 14. 4939 & 0. & a 9294 & $0 \pi \Delta 4$ & a. E4t3 & i. 4327 & .02139 & .018242 & 0.1010 \\
\hline Gage Fund & & .0 .1737 & 02273 & aesst & -.0845 & 0.1528 & 0.5314 & 9.268: & 6.5479 & (4) & D NESA & 4.7909 & 0.0000 & 20.0774 & . & 0.5504 \\
\hline Sanlam F-Anda Trants & & I ingas & -1.285 & $a, 0132$ & $+62.34+10$ & 2.2013 & 00072 & .724 .4428 & -1.9617 & 0.0001 & azast & ก เ 9.65 & प 3920 & 24143 & 0.2904 & a 742 \\
\hline Sarlam Gunenal & & isaya & 27413 & acoes & -1.5610 & $\Delta \mathrm{ASONO}$ & $0.004 \theta$ & toles & c.san?4 & 0.8677 & 0627 & 4 अ959 & 0.6001 & -0.0569 & a 3not & 0.7049 \\
\hline Sardud Ck Fog unains Fof A & & -24004 & -20470 & 00070 & 9.173t & 0.9802 & 0.3421 & 36.8150 & 2.3ana & Quzte & 0.002 & 1.00ae & c.324 & 0.0327 & 0.0647 & 0.040 \\
\hline Sarcerid Dh incan R & & -21168 & .05043 & 0.5020 & 2.2436 & 0.728 & 08374 & 2.1225 & 0.0454 & 1.9540 & 0.41546 & ¿. $452 \pi$ & abc2 & 0.5587 & 0.706 & 0,10068 \\
\hline 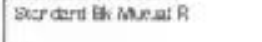 & & Q.7age & 2.1809 & 00042 & 42708 & $\frac{-10588}{4}$ & $\frac{023501}{1274}$ & $\frac{+3190}{\text { NT }}$ & BETSA & 0.5002, & 0 >5a19. & 3.9290 & 0.00003 & 0.078 & 0.4167 & 90735 \\
\hline Min & & -2754 & 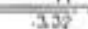 & 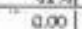 & $514 \overline{100}$ & -2.55 & & $13 \times 11$ & -1.96 & $\frac{1504}{0.00}$ & 0.34 & $\frac{10}{.696}$ & and & 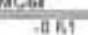 & 12 & तराणु \\
\hline $\operatorname{Mn} \pi$ & & 5.25 & 479 & $\Delta 96$ & 19234 & 2.06 & o. & 12305 & 341 & a. & 105 & 178 & a. & 220 & 7.76 & 100 \\
\hline Auerape & & 0.74 & oas & 0.4 & 1006 & הa1 & & 354 & $a, 32$ & 0.44 & 059 & 2.7 & 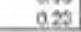 & 0.8 & 00 & 2.50 \\
\hline & & & & & & & & & & & & & & & & \\
\hline 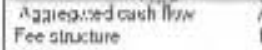 & $\begin{array}{l}A G \\
\mathrm{FE}\end{array}$ & & & & & & & & & & & & & & & \\
\hline Fidrotur: & & & & & & & & & & & & & & & & \\
\hline & & & & & & & & & & & & & & & & \\
\hline Itrat sex & & & & & & & & & & & & & & & & \\
\hline 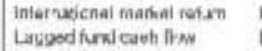 & $\begin{array}{l}\text { Masi } \\
\text { Wace }\end{array}$ & & & & & & & & & & & & & & & \\
\hline Lagratend retum & & & & & & & & & & & & & & & & \\
\hline & LAGER & & & & & & & & & & & & & & & \\
\hline Lowal man hin moun & & & & & & & & & & & & & & & & \\
\hline $\begin{array}{l}\text { Lonp inmm rinerst } \\
\text { s:sk }\end{array}$ & & & & & & & & & & & & & & & & \\
\hline Ghertienn wernat & $\min ^{-}$ & & & & & & & & & & & & & & & \\
\hline sq. & Mutiph $K$ & & & & & & & & & & & & & & & \\
\hline 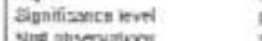 & & & & & & & & & & & & & & & & \\
\hline & & & & & & & & & & & & & & & & \\
\hline
\end{tabular}




\begin{tabular}{|c|c|c|c|c|c|c|c|c|c|c|c|c|}
\hline \multirow{2}{*}{\multicolumn{13}{|c|}{ 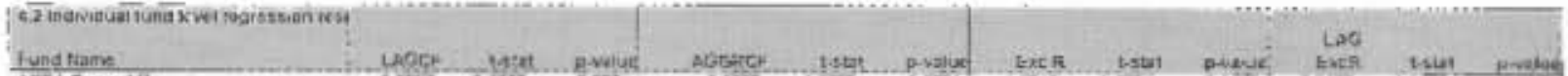 }} \\
\hline & & & gevertur & Abtert & t.tent & & Exc $\pi$ & tastor & & tite- & hiat. & \\
\hline AESG vioust For & 2,2058 & 24145 & $\cos _{2}$ & 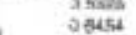 & 38:5: & & 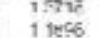 & $\begin{array}{l}53586 \\
21247\end{array}$ & $\cos _{0} \sin x$ & $\begin{array}{l}-3158 \\
0725 \\
-2725\end{array}$ & 1 the & 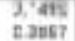 \\
\hline $\sin G$ & & किजा & \& 2072 | & & $19=$ & & 60 & 5.89 & conu & aot & Qevas & 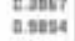 \\
\hline$E$ Egat & i.tses & -178 & tuntea & & & & & & 0.0000 & 0.160 & Q.eרse & \\
\hline Yomen & $022 z$ & 20063 & soiv? & & ess & & 1a. & 4.28 & D. & 2005 & 9.318 & $\pi, 7040$ \\
\hline then crom & $\begin{array}{l}A 11100 \\
A n e s\end{array}$ & Ascosu & Igtae & a.1984 & 13604 & & ascost & 25570 & 0.0126 & 21716 & oring & 0.6858 \\
\hline th & newes & asm & C.706 & 12400 & 1.112 & Q2076: & 5.3679 & $2762 \pi$ & 200014 & asipte & esin? & nom \\
\hline 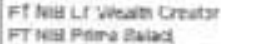 & 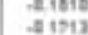 & $\begin{array}{l}4000 \\
1453\end{array}$ & 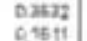 & O45I & ganina & 2.225 & 4 sesi & $-1,8455$ & Cons & $-1,964$ & $\rightarrow$ Aens & $\begin{array}{l}0.3620 \\
\text { Detsid }\end{array}$ \\
\hline 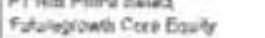 & nosem & 0,007 & 0.045 & $-0.52 \pi$ & ofthe & 0.5156 & 35060 & $\begin{array}{l}215150 \\
-1.4202\end{array}$ & cinto & 0.004 & $\operatorname{lin} 1$ & I.mo \\
\hline & asees & +1130 & 0.5609 & & 20052 & & & 24156 & {$[\cos 13$} & -2551 & 1 . & $e .15 x$ \\
\hline & & 2656 & 0.0102 & & & & & & c.3645 & .8974 & Avsen & enes \\
\hline & +2263 & & 0,0014 & 2010 & 20259 & & & 2204 & & eates & -16ase & oons \\
\hline & A, an: & 1928 & bos? & 2.5405 & 2., sint & e.60001. & 0.059 & $-0,0075$ & c91so & chase & 2.1274 & $20=5$ \\
\hline & stast & 20001 & - & asant & 20124 & gavas & abses & 18319 & $\cos 2$ & 0.0717 & 02107 & 0330 \\
\hline & 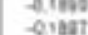 & $\begin{array}{l}1,0228 \\
-2817\end{array}$ & 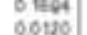 & $\begin{array}{l}\text { 9.5at } \\
\text { guts }\end{array}$ & ?ase & Davat & 2.2584 & 24734 & Conzo & 19972 & 1.560 & 20134 \\
\hline 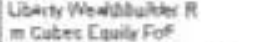 & 0.16 & 206 & $\begin{array}{l}00041 \\
0004\end{array}$ & & 41002 & 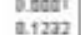 & & 39728 & $\begin{array}{l}60006 \\
60035\end{array}$ & $\begin{array}{l}\text { 2) } 1950 \\
0.159\end{array}$ & 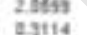 & 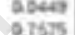 \\
\hline$m_{\text {Metap }}$ & & 10000 & 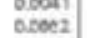 & sote & $\begin{array}{l}15001 \\
4 \pi 04\end{array}$ & $\begin{array}{l}212020 \\
0.0000\end{array}$ & & $\begin{array}{l}311204 \\
93154\end{array}$ & 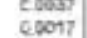 & $\begin{array}{l}0.159 \\
-122652\end{array}$ & 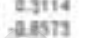 & i.jos \\
\hline & & & & & & & & & & 0.550 & D. 255 & e.tsi \\
\hline & 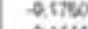 & & & & & & & & & . 2.354 & & Basio \\
\hline & & $\operatorname{acs} t$ & ose & & & & & & & -1.2333 & & asous \\
\hline & ons & 0.405 & C. & & 05010 & D.378s & & $2 . \operatorname{sen} 4$ & $\cos 25$ & ganoer & 0.5004 & 0.4065 \\
\hline & 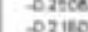 & $\begin{array}{l}4006 \\
2 \text { 2453 }\end{array}$ & $\begin{array}{ll}00008 \\
80044\end{array}$ & 800 & $\begin{array}{l}0.587 \\
57627\end{array}$ & ander & 13 & $\begin{array}{l}450200 \\
5 \times 9003\end{array}$ & $c 0000$ & $-0,1971$ & -10634 & 9.2055 \\
\hline & & 1,41 & $\begin{array}{l}0,00 \\
0.12\end{array}$ & sol. & 376 & $\begin{array}{l}9.0000 \\
0.2793\end{array}$ & $1,4.4$ & 5,80 & 8060 & 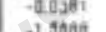 & - a.1217 & C. Suse \\
\hline & -1137 & 1,100 & & & 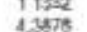 & & & & & Oats & & anti2 \\
\hline mance for & 0.306 & 22392 & & & 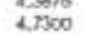 & & & & & & & 0 \\
\hline & Q ita & tim & & & & & & & $c 0$ & 0.2245 & & \\
\hline & A. & .1,9719 & 0.12 & BE & 0.2 & & 0.10 & Do & & $\begin{array}{r}-1.8197 \\
\end{array}$ & & \\
\hline & 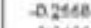 & .10927 & 0.0003 & & & & & & & D. 0040 & & \\
\hline & 00 & 0.04 & & esset & & & & & & -0.8 & & \\
\hline & $-0 \propto \infty$ & 0,0184 & 2804 & $1.47 ?$ & 2.5155 & 0.0153 & $0.888 \%$ & 0.20 & $\cos 202$ & - $t$-4452 & -2.0212 & E. DE14 \\
\hline Siendaru Br Menal R & & 2.3247 & 0.009 & 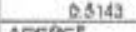 & 5.9980 & 0.00 & & 4.1050 & & & $-0.6 n 73$ & anges \\
\hline & & & & & & & & & $56 x-1$ & LQSE Exes: & & \\
\hline & & & & & Ser & & & & & & & \\
\hline & 023 & 191 & 0,0 & & 6.5 & & & & 84 & & & \\
\hline & -000 & - & 200 & 8,01 & 329 & 0 & & 200 & 0.17 & 0.44 & Q18 & \\
\hline
\end{tabular}

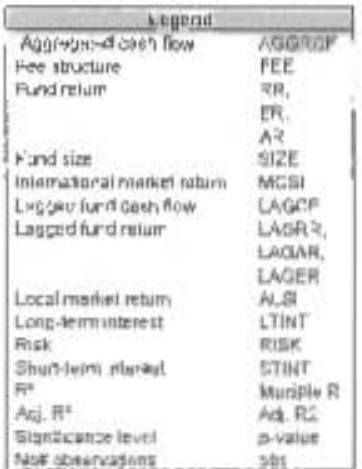




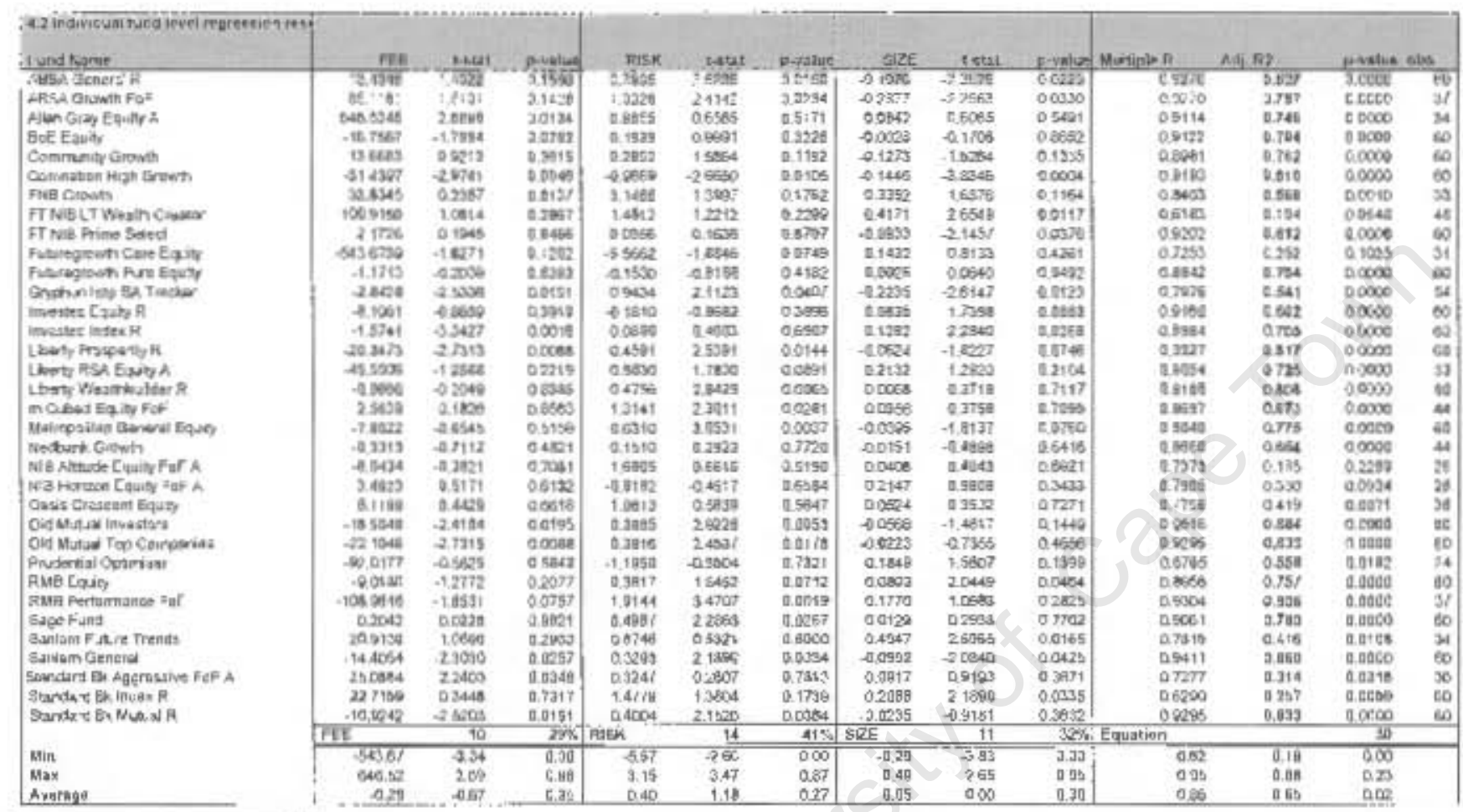

\begin{tabular}{|c|c|}
\hline \multicolumn{2}{|l|}{ Legent } \\
\hline 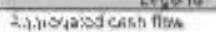 & उOH \\
\hline res aluediue & \\
\hline Funditium & \\
\hline & ${ }_{A R} R_{2}$ \\
\hline Fund aind & Sile \\
\hline Intamsienai ranct relurr & NCS \\
\hline Laepec And cash Hais & GAC: \\
\hline Lagueat ind reluin & IABsR, \\
\hline & Wote \\
\hline Locki makei retrm & A.si \\
\hline $\begin{array}{l}\text { Leng-lutrm ntarese } \\
\text { Ruk }\end{array}$ & 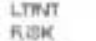 \\
\hline Shart iem irenst & SกN \\
\hline a & thitiple R \\
\hline 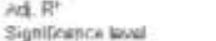 & halka \\
\hline 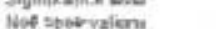 & \\
\hline
\end{tabular}




\begin{tabular}{|c|c|c|c|c|c|c|c|c|c|c|c|c|}
\hline \\
\hline \multicolumn{8}{|c|}{ 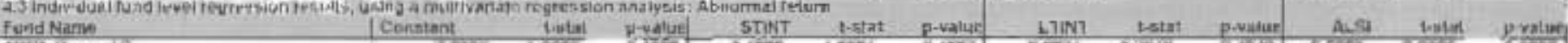 } & & & & & \\
\hline AESSGererain & D. & T.J3E: & 6.1856 & B.605 & 13001 & द. 1289 & मांखल & Shass & 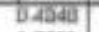 & 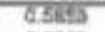 & 3.005 & \\
\hline AES: Gronth FaF & 0.4207 & 0.1876 & 2.8525 & -5.0295 & -0.3939 & 0.7045 & -63641 & $\Delta 3009$ & 0.7658 & $\$ 2250$ & -0.9054 & 0.5287 \\
\hline Alan Grag Equily $\lambda$ & -20.0703 & 27539 & 0019 & 905484 & 13097 & 0.2002 & -50.7575 & 1.2005 & 0.0657 & 02052 & 0.2205 & 0.5205 \\
\hline Bor Equats & 1.0120 & 1.7675 & 0.0009 & 41074 & 0.5789 & 0.3824 & 55250 & 0741 & 04585 & 0.3721 & 29396 & 0.0530 \\
\hline Conimuriti Grosam & 0.0000 & 01120 & 2.9113 & 64797 & 1.0306 & 8.3007 & 25105 & -0.5195 & $0.000 \mathrm{E}$ & 0.3158 & 17774 & 0.0957 \\
\hline Curonsson Hith Orowh & 2297 & 40726 & 0,0002 & 63359 & -12009 & 02324 & so.734a & 25066 & 0.0061 & 03012 & 16001 & 0.067 \\
\hline FNA Grown & $200 e n$ & -04117 & a68es & 1297459 & 21619 & 20008 & 96372 & -01260 & 0 esas & -0.50707 & -05241 & 0.0055 \\
\hline FT NIS LT Wenth Cragtar & .77050 & $\therefore 2 e 27$ & Q 1912 & RCOASE & 23559 & $0.023 B$ & -107.6170 & -1.7952 & Q.0000 & 0.4758 & Q4730 & 0.090 \\
\hline FT Nib Pime Sa गू & 0.7495 & 1.7975 & D0784 & 0.0077 & $0.028 \mathrm{e}$ & 9.9763 & -20000 & $-0.3 / 11$ & 0.7122 & ormat & 10402 & Q.9058 \\
\hline Fienngour Com Eahy & 39586 & 0.86te & 0.3974 & 12.230 & 0.1315 & Q.e267 & 125.983 & 1.7922 & 0.0976 & 0.2356 & 02170 & 0.6304 \\
\hline 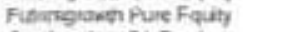 & .01158 & 04215 & D.6752 | & 4579 & 1.3125 & 0.1851 & $\rightarrow$ otess & -12130 & 0.2250 & D yoes & $2 \operatorname{sis4}$ & 0.0144 \\
\hline Gryphen ims SA Tracker & 0.06003 & 25090 & 00152 & -85618 & 0.8787 & 0.3645 & -20823 & $\Delta \sin \theta$ & 0.5006 & e. 1000 & 0260 & a.792s \\
\hline Mvester Fiquily R & .00212 & .00600 & D.8524 & $-1,0078$ & .02155 & 0.0012 & 165465 & $2 \cos 47$ & 0.0425 & DEOOF & 22747 & 0.0019 \\
\hline nyeseses inter $R$ & -0.8010 & semae & 0.0011 & 3.2732 & 0.8133 & 0.4250 & 24.3763 & 36005 & 0.065 & 0.4100 & 20067 & 0.0458 \\
\hline Lberty Pruspeity R & 1.4831 & 22258 & 00307 & 4330 & -13663 & 01974 & -5.6584 & 00022 & 63528 & 0.005 & 25000 & 00061 \\
\hline Lempy age [quily $\lambda$ & 0.9342 & $0.3 \times 62$ & 0.7310 & 5.3073 & -0408 & oess: & 40.396 & 1.3423 & $2 \log 2$ & 05106 & 1.4102 & Q.1707 \\
\hline Lberty Wealth & & 0.1234 & 0.002 & 87295 & -02102 & 08297 & 45004 & 06349 & 25824 & 0.5259 & 2.1005 & 00000 \\
\hline & & 0.746 & 0.4020 & $.000=8$ & -00598 & 0.9527 & 3.8718 & Q.1025 & o.819 & 0.6055 & & 0.2431 \\
\hline Mefacaila & & & 09400 & 12.1436 & 20067 & 0.0451 & -15127 & 0.6652 & 0.064 & 0.9241 & & 20049 \\
\hline Nedomin C & $-0.17 \% 5$ & 0.0064 & 0.064 & $\triangle 00723$ & $-0,0059$ & 0.9959 & 28.1800 & 0.9273 & Q3259 & 0.9306 & 0.7400 & 0.459 a \\
\hline Oestis & -1.28 & -80739 & 0.5006 & 92002 & 02045 & 0.8936 & 26.3720 & & 6.607 & 00101 & 00040 & बรन \\
\hline & 1.20 & 26546 & 0.016 & -25043 & -0.7252 & 0.4712 & 4.1409 & $0.5 \mathrm{ANT}$ & 05753 & 0.750 & 4.3465 & 0.0001 \\
\hline Ord Ms & & 22973 & 00025 & 30585 & 07970 & 0.4350 & $-7,7924$ & & 0.2100 & 04715 & 2.9514 & 0.0084 \\
\hline & & 9.7050 & Q4641 & .9 .5855 & -22389 & 00297 & $2804 \leqslant 2$ & 20127 & $D \infty 70$ & 0.5503 & 20704 & 0050 \\
\hline RMA PE & a.6 & 0.2550 & 0.7831 & 29762 & 01073 & 0.7604 & -11.2438 & 27509 & 0.4543 & 20007 & -0.01 & 9686 \\
\hline & Dod & 1.1933 & 0.4504 & -35733 & -1.0030 & 0.3208 & 2.1204 & Q.3487 & 0.7265 & 04807 & & 0014 \\
\hline Sariter & 3.00 & 2.0119 & 20561 & 2009550 & 3.2453 & 0.0036 & -135.3265 & -216 & 0.0412 & 0.8440 & a997 & 0.3073 \\
\hline 5enterm C & 1.3002 & 23652 & 20205 & $-0.15 a 0$ & $-0.049 t$ & 7.9610 & -0.2989 & -004 & 0.9507 & 05700 & 30436 & 0.0000 \\
\hline Standary & 2.0295 & .30278 & 0.0056 & 6.4042 & 0.0168 & $0.4 Z 20$ & $49.3 \geq 05$ & 23452 & acar & 0.5395 & 1.6706 & D.t072 \\
\hline & 2.51 & $-0,6462$ & 0.5212 & 3.AB? & -0.1119 & $29: 13$ & 192700 & 0.3907 & 0.977 & 1.2443 & 1.3527 & 0.1025 \\
\hline \multirow{2}{*}{ Starderd Bk Mutual R } & 0.3410 & 2565 & 00127 & $-1+37$ & a.3772 & 0.7378 & $\therefore .2200$ & $D=T 3 D$ & 0.5041 & D 4624 & 3.3260 & bol \\
\hline & Canchani & 10 & $32 \%$ & STINT & 5 & 1630 & LTINT & 6 & 195 & ALSI & 13 & 424 \\
\hline & 27 & $\sqrt{48}$ & 000 & & & 000 & & & & & & \\
\hline & & & a.95 & 201.00 & & 100 & 125. & & 0.96 & & 426 & \\
\hline avernge & .000 & 0.36 , & 038 & 15.76 & 0.31 & 0.49 & 0.12 & $0 \geqslant 5$ & 044 & 0.36 & 1.64 & \\
\hline
\end{tabular}

\begin{tabular}{|c|c|}
\hline Legraind & \\
\hline सं & लtatiner \\
\hline & \\
\hline Fund retum & \\
\hline & \\
\hline Furd aist & SIZE \\
\hline 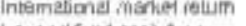 & MCSA \\
\hline Layped fund ogsin ADW & LAGCR \\
\hline 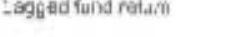 & LAORR \\
\hline & LAOEK \\
\hline Loosil markes return & ALSI \\
\hline Longten ni irtieres & LIINT \\
\hline Risk & Risk \\
\hline Stari-kerminirrest & STHAN \\
\hline & 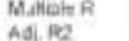 \\
\hline & $\begin{array}{l}\text { Adilez } \\
\text { preve }\end{array}$ \\
\hline 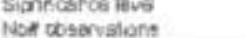 & ots \\
\hline
\end{tabular}




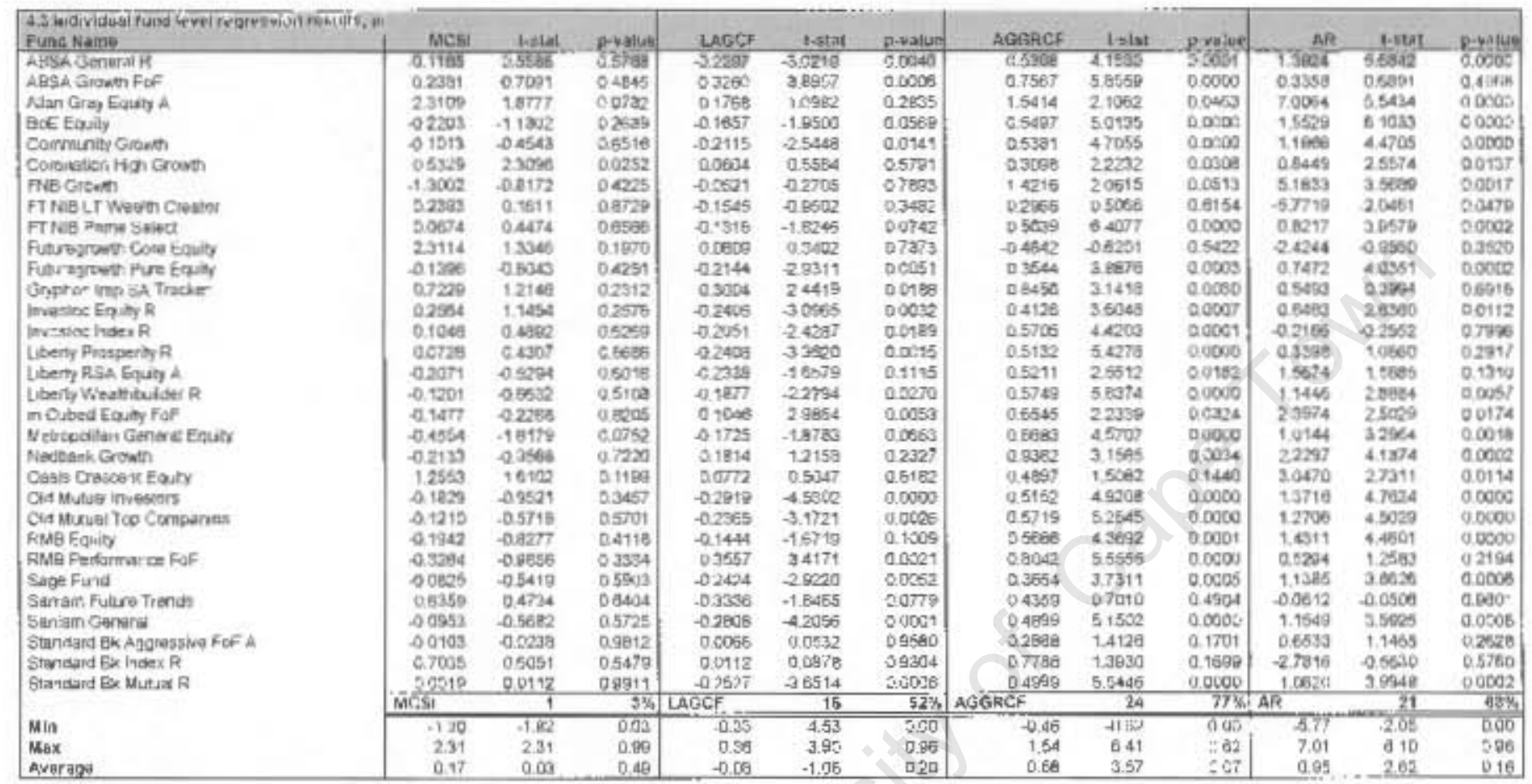

\begin{tabular}{|c|c|}
\hline Lefien: & \\
\hline Pagrogatad cask fism & MEs: \\
\hline Fae structurn & FEE \\
\hline Fund rearm & RR, \\
\hline & $\mathrm{Ag}$ \\
\hline Funt size & stze \\
\hline Intrerralianal r rathet rikum & MCsi \\
\hline lagged fund tath law & LACCF \\
\hline Lagyed fund retain & LAGRR, \\
\hline & $\begin{array}{l}\text { WhoAR, } \\
\text { LWGEB }\end{array}$ \\
\hline Local inisme-1 fetum & ALSI \\
\hline Laid-term interest & IINT \\
\hline Rleh & Bask \\
\hline Shon-tom interest & $\begin{array}{l}\text { STINT } \\
\text { Huste }\end{array}$ \\
\hline & Wutiphe R \\
\hline Aci $R^{t} t$ & ad, 12 \\
\hline 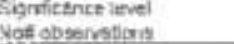 & $\begin{array}{l}\text { cosuce } \\
\text { cos }\end{array}$ \\
\hline
\end{tabular}




\begin{tabular}{|c|c|c|c|c|c|c|c|c|c|c|c|c|c|}
\hline \multirow{2}{*}{ 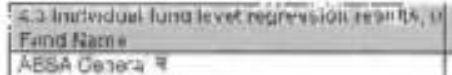 } & LAGAK & & & & & & & מ.ata & \multirow{2}{*}{$\frac{\text { p-value }}{\text { andw? }}$} & \multirow{2}{*}{ 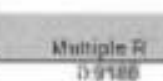 } & & & \\
\hline & .63951 & Falat & 5.1285 & 5375 & 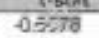 & 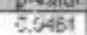 & $-0,505$ & 2724 & & & काजिए & & \\
\hline ARSA Grant = of & 10381 & 24494 & 0.2214 & -39502 & -00168 & o.sses: & -20600 & -04697 & 0.64251 & 0.9250 & 0.3025 & 20000 & z: \\
\hline Nor Gar Equhy A & 0.2307 & 0.1520 & 0.805 & 521,312a & 205900 & $0 \infty$ & 00696 & 0.6000 & 0.6158 & 09020 & & & \\
\hline BoE Equil & -0.1511 & -06505 & 0.5755 & -166998 & -1.9102 & 0.0512 & -00017 & Q. .060 & 091 & 0.9102 & 0.70 & & 50 \\
\hline whin & -04730 & -16519 & 1049 & 51641 & 0.3470 & Q.75: & 0.0837 & -0.7265 & Q40 & 0 Be & 07 & & 50 \\
\hline rowt & $-04 / 25$ & .13505 & a) 60 : & -246359 & 2.2478 & 200 & -0.1526 & 400 & 000 & 0.9 & 07 & & 50 \\
\hline FNBG & Q.ene? & 0,099 & 67723 & 135605 & 0,0951 & 0.92 & 0.3054 & 1.52 & 6 & o.e & & & sa \\
\hline ream crefort & .2 .7900 & 40000 & 0.3614 & 111.2849 & 1.2078 & 025 & 0.38 & 2.4ere & Dor & 000 & Q I9BA & Coesg & se \\
\hline FT MeO Pine Sirige & -0.4720 & 25041 & 00145 & .27441 & .02067 & 0.7008 & 000700 & 2.1539 & 0036 & $0 \mathrm{k260}$ & 0.0940 & 0.0000 & $\Leftrightarrow$ \\
\hline Funverow th Cure Eguts & 00204 & 0,0070 & OSA45: & .543260 & -1.4797 & 0.1525 & Q.1525 & 0.8135 & 04227 & $0600 / 4$ & 0.1200 & 0.254 & 21 \\
\hline Fanuenosen Furs Eqult & $-060 / 2$ & A717a & 00000 & 01765 & 0,0393 & Doger. & $0 \cos 2$ & 0.8919 & $0.3 \pi 5$ & 0.9028 & 0.235 & 0,0500 & 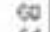 \\
\hline Gresten lep SA Truaker & 20005 & $-1,209$ & 0.2056 & -24930 & -2.2447 & nesson & -0.2179 & 2.3609 & $0.02 \times 3$ & 0.3416 & 0.5060 & 0,0000 & SA \\
\hline irveatse Eavalu R & $-0 \cos \theta$ & 23015 & 0.0212 & -12.8128 & -1.5060 & D.13es & 0.0612 & 1.7500 & 00002 & 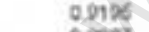 & 0,15 & 00000 & $\omega$ \\
\hline imvelde iniex 7 & 15176 & .1.2306 & 0.1895 & -1.5300 & -35001 & 0.0010 & 0.1225 & 25050 & 0.0160 & 00027 & $0.7 m$ & 00000 & to \\
\hline 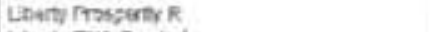 & .07622 & $2: 127$ & 0000 & -76.2230 & -21692 & 0,0350 & $-0,0582$ & -17192 & 000 se & 0.995 & 0.013 & 00000 & 60 \\
\hline Lbersy resh Eavy'A & 0.0919 & 0.294 & Q74a? & 45.8972 & -1.1979 & 0.2437 & 0.2484 & 14126 & $0171 \mathrm{~B}$ & Qsets & oesus & $D \cos 0$ & $3 a$ \\
\hline Lerny washocider of & $0 \operatorname{sen} x$ & -12734 & 0.2003 & 0.0115 & 0,0325 & 0.9742 & $0.0<01$ & 00072 & 09042 & $0.0 \mathrm{nas}$ & a reet & otoco & 60 \\
\hline in Cubed Eany Faf & 0.3052 & .0 .0222 & 0.6763 & $-10.2 \operatorname{sen} 1$ & -1.2652 & $020 \pi 7$ & $0.0 \mathrm{ecc}$ & 0.672 & 0 anso & 0.967 & cosite & D toto & 24 \\
\hline Marogotion ficners Equity & 4285 & 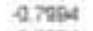 & 0.2272 & quess & $-0.06 \% 5$ & 0.9449 & $-0,0<\theta_{2}$ & -0 asns & 07501 & OBAST & 0.7406 & 00000 & $\infty$ \\
\hline Nethark Orswth & Q4ipes & 0.7504 & 0.4583 & -03215 & -osacts & 0.4899 & $-00: 02$ & 000720 & $a \leq 8$ & 00047 & 0.6712 & D.000 & 44 \\
\hline Casis Cresert Equily & 1.4156 & 1.2294 & 0.2304 & 10.7374 & 06230 & 0.5989 & 00400 & 0.3497 & 0.72 & 07814 & $0.4: 4 ?$ & 0.0027 & $\$ 6$ \\
\hline Od Mulual huesións" & -0.1530 & -2.5998 & 0.5815 & -177909 & -21888 & 0,0052 & -01003 & .27944 & 0.0074 & 00429 & 0.0063 & 0,0000 & 50 \\
\hline Ot Multas Too Conipentes & -23235 & .10005 & 0.2952 & -15.5496 & $-2: 3333$ & 0.0372 & -0.0285 & -0.8097 & 03674 & 0.9221 & O.A192 & 00000 & 60 \\
\hline RMG Equly & 05412 & .18700 & Q.1001 & 26408 & -0.0908 & 0,3267 & 0.0651 & 21734 & 0.03 & OA995 & 07572 & 00000 & 60) \\
\hline FMAB Fortermanos Fot & asers & 21822 & 0.0400 & -14.5450 & -0.2257 & 0.7774 & $0, t+4$ & 0.5409 & 0.73 & agnos & 0.7644 & 0,0000 & 37 \\
\hline Sage Fupd & .07290 & 2.4518 & 0.0178 & -10.9566 & -1.2430 & 0.2198 & -00662 & 07097 & 0.4802 & 0.9057 & 0.7022 & 0.0000 & 60 \\
\hline Sanban Futur = Trends & -1.0704 & .1 .2556 & 0.2218 & 24.1058 & 1.3184 & 0.2003 & $0,602 t$ & 26862 & 0.0132 & 0.7780 & 0.4550 & $0.00 \div A$ & 34 \\
\hline Ssnbir Genera & .02533 & -0.8072 & 20234 & -121340 & -1.9097 & 0.0520 & $-0: 02 \theta$ & -2.1282 & 9.0396 & 0,8959 & Qenes & anose & 60 \\
\hline 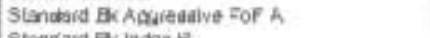 & .17150 & 3170 & ovioes & $23 \cos 3$ & 24673 & Q.02018 & 0.0727 & 0.8422 & 04075 & 07944 & otazs & 0.0011 & 36 \\
\hline \multirow{3}{*}{5 tendare ex Nuturai R } & -130419 & 25678 & 0.133 & 3า. 3552 & 0.4571 & 0.5425 & 0.1605 & 1.6313 & 0073 & 06104 & 0.2445 & 0.062 & 60 \\
\hline & .05121 & .19436 & 00577 ! & $=\frac{-11,2915}{10}$ & -2.5171 & $20 \mathrm{c} 11 \mathrm{~b}$ & -0067.3 & -1022 & D 1712 & OS281 & oassi & 0,000 & \\
\hline & HONR & & $29 \%$ & & 9 & & SIIZE & & \multirow{2}{*}{\multicolumn{2}{|c|}{\begin{tabular}{l|l}
324 & Equizion \\
540 & $0: 0$
\end{tabular}}} & & 30 & \\
\hline Mi: & .1364 & -4.72 & 500 & 243.29 & -451 & 000 & 42 & 4.05 & & & 0.75 & 8.00 & \\
\hline thax & 1.42 & 1.23 & 599 & 69331 & 2.98 & 099 & $\alpha \leq 0$ & 2.68 & 039 & 0114 & 0.7 & c:ix & \\
\hline Average & - 0.99 & $-1,38$ & DA & 384 & $-28 B$ & 0.37 & $0=2$ & -0.05 & 031 & Latai & aOB & cal & \\
\hline
\end{tabular}

\begin{tabular}{|c|c|}
\hline & \\
\hline 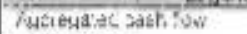 & SOCRCF \\
\hline Fés studu' & \\
\hline Find reym & RR, \\
\hline & $\mathrm{ER}_{\mathrm{E}}$ \\
\hline Finn s28 & SIZE \\
\hline 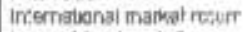 & $M C B$ \\
\hline Lagoed fund cash flow & ASCF \\
\hline Lapgeal fund rofum & IAGRA \\
\hline & $\begin{array}{l}\text { LAGNR, } \\
\text { iAGER }\end{array}$ \\
\hline & \\
\hline Long-tamm niteras & LTINT \\
\hline Rijik & Risk \\
\hline Sint-famn interest & sinvT \\
\hline & Willicie $\mathrm{F}$ \\
\hline Sili Re & Aol 122 \\
\hline Stanifranos leviol & Prave \\
\hline & \\
\hline
\end{tabular}




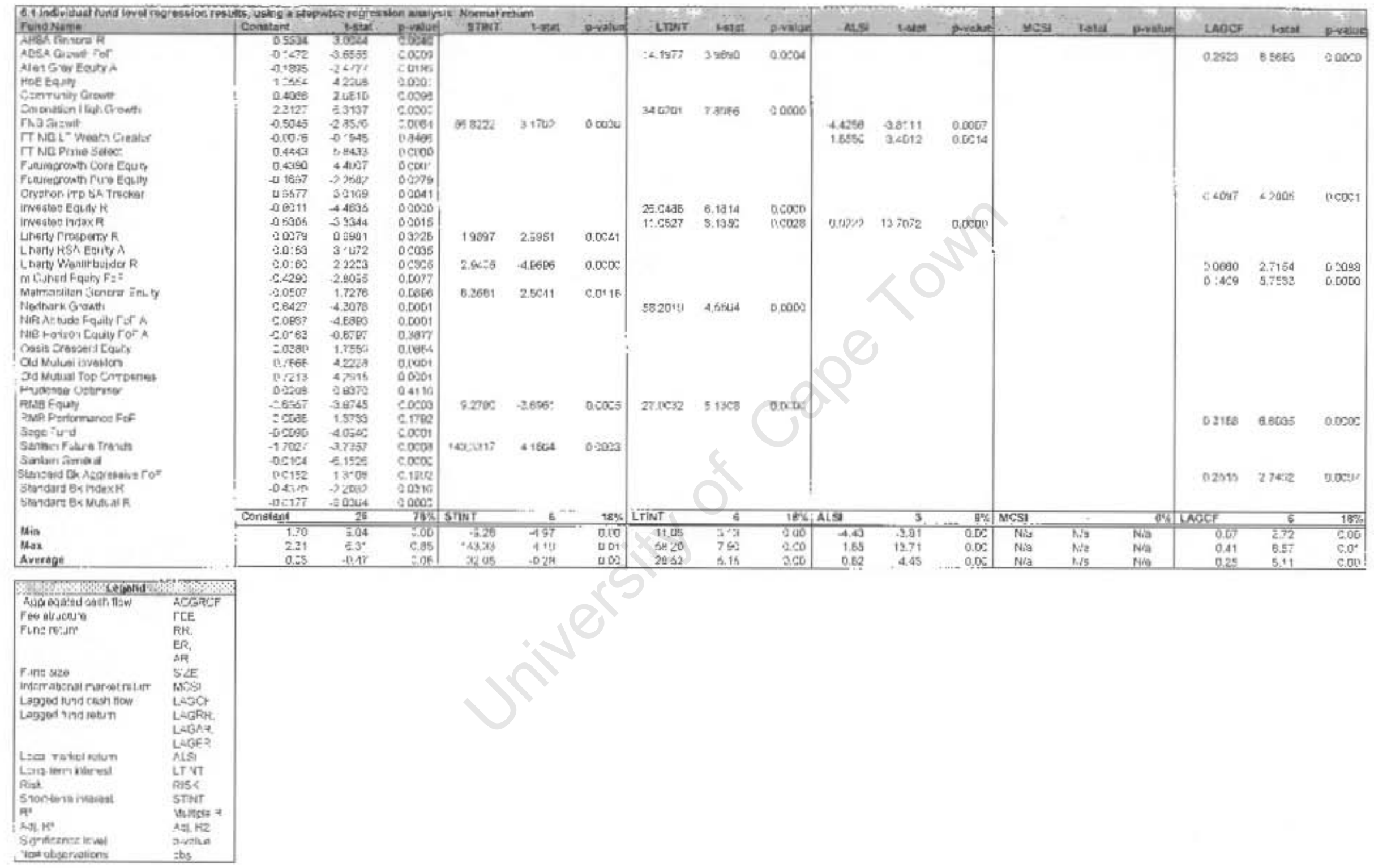




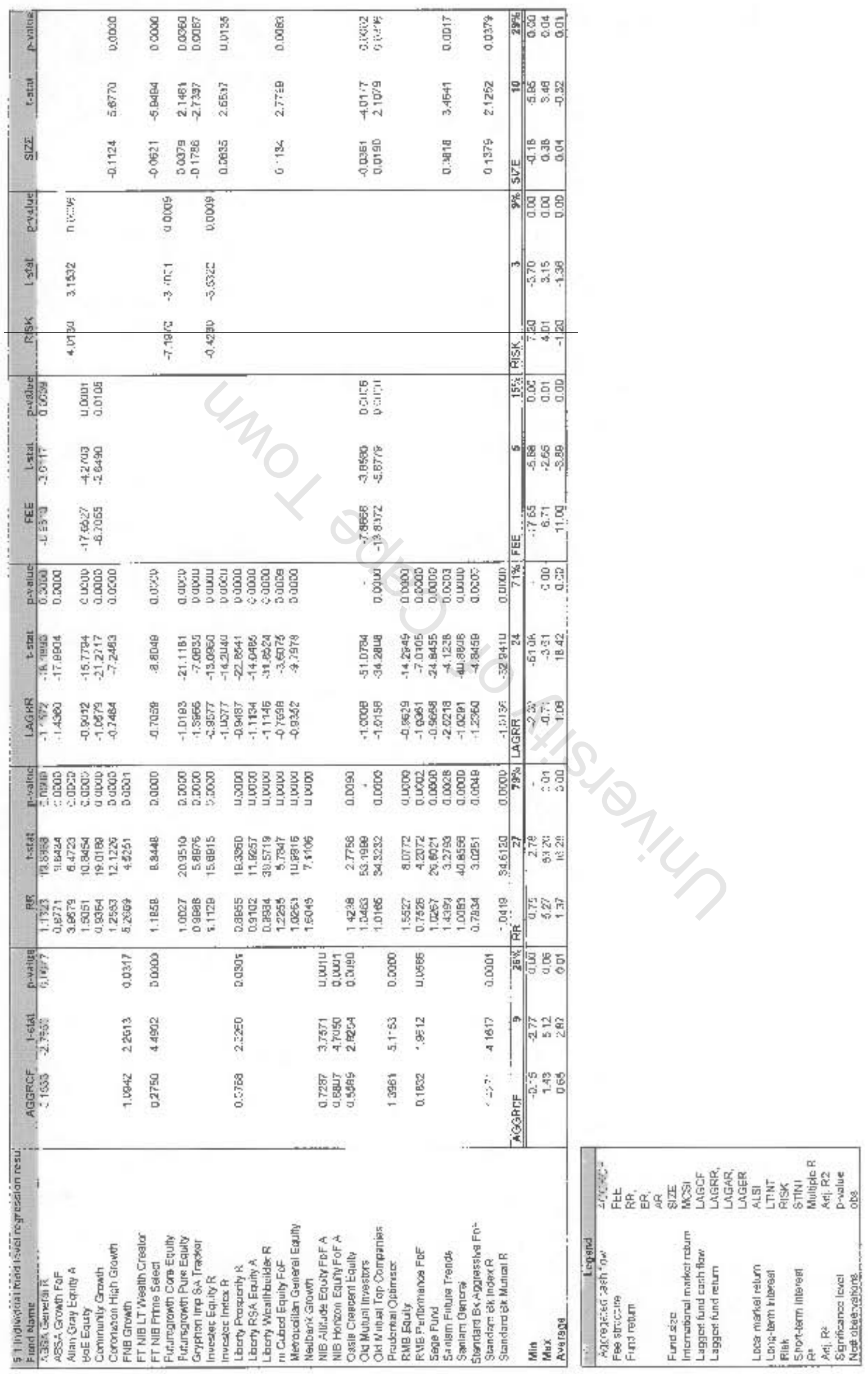




\begin{tabular}{|c|c|c|c|c|}
\hline 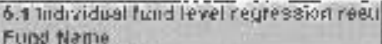 & & & & \\
\hline 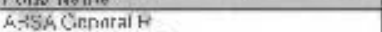 & 6 :ives & A(I). $0.96=$ & & \\
\hline MESA G Trath FoF & 08771 & 0.949 & 0.0000 & 37 \\
\hline Alan Gray Equity $A$ & 0.8086 & 0.632 & 0.0000 & \\
\hline ENE ERUY' & 0.0081 & 0.028 & 0.0000 & \\
\hline 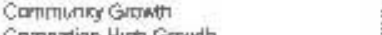 & 口细9 & 0.836 & 00030 & \\
\hline Counstion High Growth & 0.6417 & 0.874 & $\begin{array}{l}0.0600 \\
0.0050\end{array}$ & \\
\hline FNB Cromth & 0.8028 & 0.594 & 0.0050 & \\
\hline FT Nig LT Wealth Crastar & 0.4483 & [.:184 & 0.0014 & \\
\hline FT Nil Primt Salect & $0.96 \times 0$ & 0.926 & 0.0000 & \\
\hline 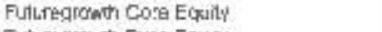 & ㅁ. & 0298 & 0.0008 & \\
\hline Fularegromoth Fure Fquy & 0.0587 & 0.936 & $0.000 \mathrm{xu}$ & \\
\hline Eypoticn Imif Sa Tracket & 0.6543 & 0.702 & $0.56[0$ & \\
\hline Liveskec Equily R & 0.8026 & 0.998 & 0.0000 & \\
\hline Mvestec Index R & 0.39525 & 0.898 & 9.00004 & \\
\hline Literty Progbenity $R$ & 0.9893 & 0.9 ה & 0.00000 & \\
\hline Leerty RSa Equity A & 0.8625 & 0.922 & 0.0000 & \\
\hline Lubery Waltreulicer $R$. & 0.9814 & 0.962 & 9.00004 & \\
\hline m Cutied Equity Fof & $0.04 \mathrm{dy}$ & 0.692 & 0.0000 & \\
\hline i Gararal Equity & 0.9000 & 0.601 & 0.0000 & \\
\hline Natorbonk & $0.77 \mathrm{EZ}$ & 0, ses & 4.0000 & \\
\hline$N E$ aitulude Equity $F \circ A$ & 0.0008 & 0.244 & 0.0510 & \\
\hline N: 3 Horran Enury FaF h & 0.6027 & 0.458 & 0.0001 & \\
\hline Osis Crescent Equity & $0.68<9$ & 0.451 & 0.0000 & \\
\hline Old Mulual Imustm?: & 0.9850 & 0.980 & 0.0000 & \\
\hline 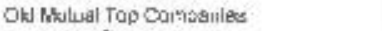 & 0.2867 & 0.976 & 0.0400 & \\
\hline Prurtami:al Ogúmikar & $0 . / 371$ & $0 \leqslant 78$ & 20000 & \\
\hline RMB & 0.9538 & 0.535 & 00000 & \\
\hline imances FoF & 04519 & 9.834 & 00000 & \\
\hline & 0.9771 & $0.5 ?$ & 200000 & \\
\hline am Fubure Treivg & D. 9078 & $0.5:$ & 0.0000 & \\
\hline n Getersl & [:.81B & 0.5 & D.00040 & \\
\hline Stgndera Bk, Agaresive FoF & $0.7 \$ 72$ & 0.533 & 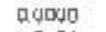 & \\
\hline \multirow{3}{*}{ 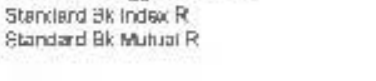 } & $0 \$ 170$ & 0242 & a 0 ond 1 & 80 \\
\hline & 09972 & 0.974 & $0<0<0$ & \\
\hline & \begin{tabular}{|l|} 
Equarloin \\
\end{tabular} & & 34 & \\
\hline Mir & & 0.08 & & \\
\hline & $1: 00$ & 0.89 & 000 & \\
\hline & D85 & 0.72 & $0: 0$ & \\
\hline
\end{tabular}

\begin{tabular}{|c|c|}
\hline Legpna & \\
\hline 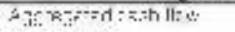 & FuLER- \\
\hline ;-AQ str.rDIIF & \\
\hline Fint retum & \\
\hline & ER. \\
\hline Funtlsize & SIZE \\
\hline 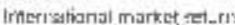 & MCSI \\
\hline Lapuld furd riven flew & LAGCF \\
\hline Laghed fund retum & LAGRR, \\
\hline & $\angle A \in A R$, \\
\hline & LAGER \\
\hline Loat rivaket ietum & \\
\hline Latu-derni irterast & LTINT \\
\hline & Risk \\
\hline short-tarm intaraat & STINT \\
\hline & Mutiple $F$ \\
\hline & 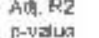 \\
\hline 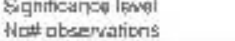 & obs \\
\hline
\end{tabular}




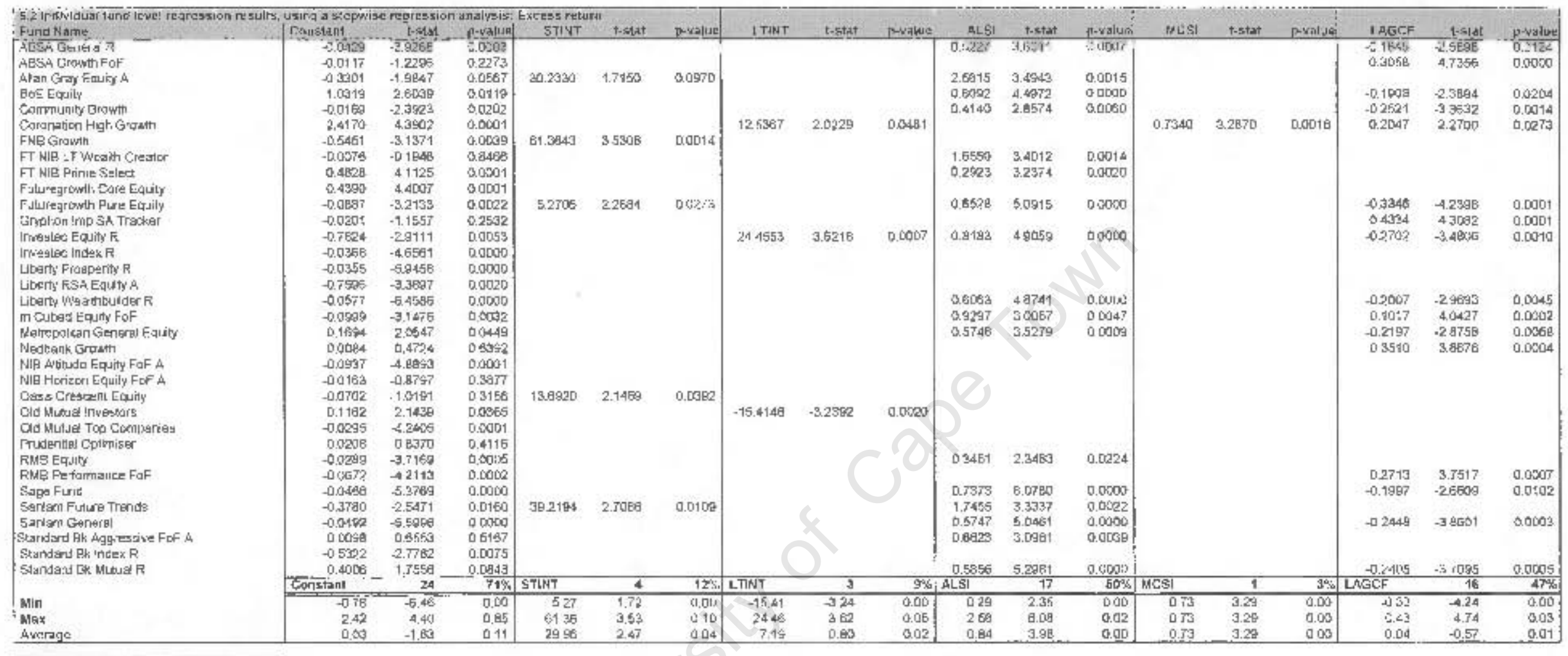

\begin{tabular}{|c|c|}
\hline Leygrid & \\
\hline 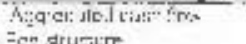 & engen: \\
\hline Fund relum & $\begin{array}{l}\text { RR, } \\
\text { ER }\end{array}$ \\
\hline & $A B$ \\
\hline 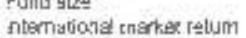 & MCSi \\
\hline LEafoed fund cast: for & LAGCF \\
\hline :agfed fund resurn & $\begin{array}{l}\text { LAGRR, } \\
\text { LAGAR, } \\
\text { LAEEFE }\end{array}$ \\
\hline LOC:31 marxat 'E.urn & $A L S S^{\circ}$ \\
\hline Lang-tem intorgst & LTNAT \\
\hline Fijk & Fisk \\
\hline $\begin{array}{l}\text { Stanterin imiteres } \\
\mathrm{R}^{2}\end{array}$ & $\begin{array}{l}\text { SFiNI } \\
\text { Mutipi= R }\end{array}$ \\
\hline Ad. $F^{3}$ & AG. R2 \\
\hline Sisinficances : & $\theta-v \theta h=0$ \\
\hline Natf abservahans & \\
\hline
\end{tabular}




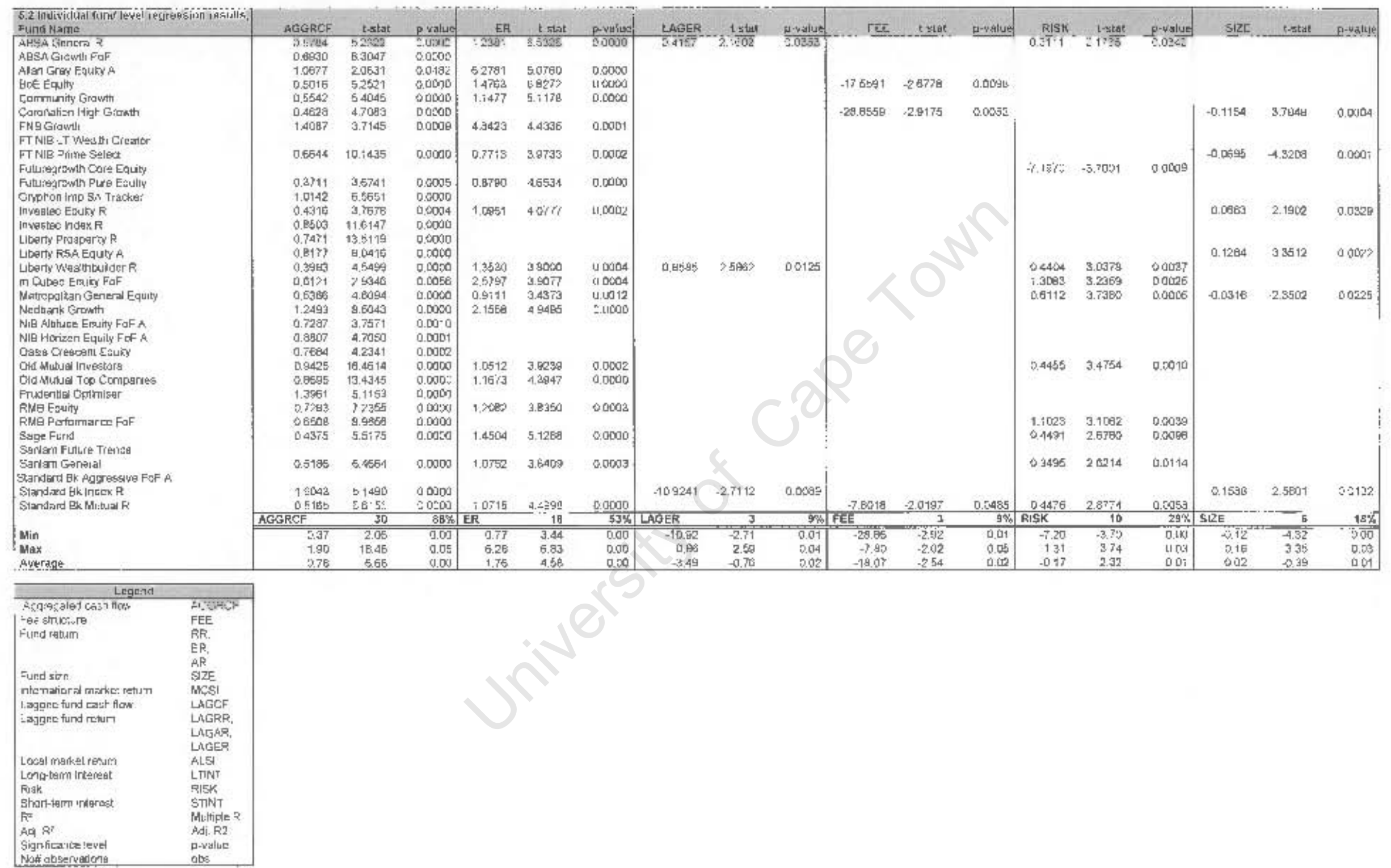




\begin{tabular}{|c|c|c|c|c|c|}
\hline 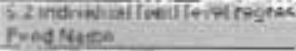 & ancesuls & & & fratere & \\
\hline & & 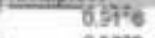 & 6.812 & 50000 & so \\
\hline LASA Cruath Fof & & 0.639 & $0,78 \%$ & oucap & as \\
\hline Nilan Gray Equity $A$ & & $0.84 ? ?$ & 0.620 & 00000 & 34 \\
\hline BoE Equity & & 0.5040 & 0.000 & $\begin{array}{l}6.0000 \\
800000\end{array}$ & \\
\hline $\begin{array}{l}\text { Cominumtry Grosth } \\
\text { Corongta Migh Growth }\end{array}$ & & $\begin{array}{l}0.8765 \\
0.0962\end{array}$ & $\begin{array}{l}0.755 \\
9.765\end{array}$ & $\begin{array}{l}0.0000 \\
0.01400\end{array}$ & . \\
\hline $\begin{array}{l}\text { HNE Brouth } \\
\text { inth }\end{array}$ & & 0.7842 & 0,593 & volous & \\
\hline FT Nia LT Weallh Creatar & & (1.448 & 0.184 & Dap14 & \\
\hline IT Nili Prime Seied & & d.eist & 0.623 & 00000 & \\
\hline Fulturegrowen Core Equity & & 05862 & 0.277 & Do00y & \\
\hline Tuluregtewth Purb Ecauthy & & 08248 & 0.763 & 00000 & \\
\hline Exychen ime SA Tracks & & 0.7573 & Q.491 & $0 \cos 0$ & \\
\hline bvatieo Equtres & & tisteat & O.ADS & 0,0050 & \\
\hline Invettec inces $R$ & & 0.8283 & 0.894 & 0.0000 & \\
\hline 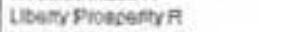 & & 0.8712 & 0.756 & 00000 & 00 \\
\hline LDENYFSK EquYA A & & Dละ5 & 0.605 & 00000 & 33 \\
\hline Ubarty Weatroudter $R$ & & 09156 & 2.920 & 0.0000 & $\omega$ \\
\hline in cuses toquty fof & & a & 0.700 & 0,0000 & \\
\hline Motoposutan Genereal Fquity & & 0.9921 & a.773 & 0.0000 & $\infty$ \\
\hline Nectsank Growth & & 0.3414 & 0.965 & 0.0000 & 44 \\
\hline Nil allode Equily FaF \& & & 0.6000 & 0344 & 0.0070 & 20 \\
\hline Nie Harizon Equily Fof A & & $0.6 \mathrm{R} 27$ & 0.459 & 0.0001 & 20 \\
\hline Oavis Credoant Equilly & & 0,5635 & 0,405 & a.dojol & ä \\
\hline Old Mueal Invegking & & 0.9191 & Q. .773 & 0.0000 & क \\
\hline OL Muna Tap Comparies & & 0,8760 & 0.39 & 0.0005 & 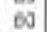 \\
\hline Prudentual Cofirniser & & 0.7371 & 0.622 & 0.0200 & \\
\hline RME Equaty & & 0.855 & 0.709 & 1.0200 & 50 \\
\hline 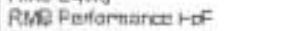 & & 0.9129 & 0.795 & 00400 & \\
\hline Eagn Furit & & 0.0020 & 0.796 & vocos & b) \\
\hline Strian Tulure Trends & & 0.6523 & 0.296 & 00002 & \\
\hline Estiatn Gerenti & & 0.9239 & OBst & 0.0000 & 60 \\
\hline 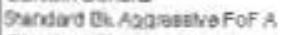 & & 0.032 & 0.197 & 00009 & s) \\
\hline 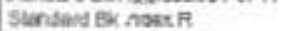 & & $\operatorname{cosecs}$ & 0.318 & 00000 & 00 \\
\hline 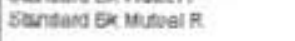 & & $6 \ln ^{2} 2$ & exese & $0<000$ & \\
\hline & & Equation & & & \\
\hline MNo & & 0.45 & $\overline{0.18}$ & 000 & \\
\hline & & $\log$ & 0.85 & $0 \infty$ & \\
\hline Averaye - & & 0.80 & $0 \in 4$ & 0,0 & \\
\hline 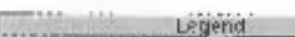 & & & & & \\
\hline 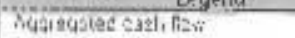 & AूSPCD & & & & \\
\hline $\begin{array}{l}\text { ret slinalue } \\
\text { Fures }\end{array}$ & & & & & \\
\hline Furnd recum & & & & & \\
\hline & $\begin{array}{l}\text { AR } \\
\text { SIZE }\end{array}$ & & & & \\
\hline international marketretum & & & & & \\
\hline Loppea fund cest tow & LAGC: & & & & \\
\hline Laxpood Nund ietum & $\begin{array}{l}\text { LAGRR } \\
\text { LAGAR }\end{array}$ & & & & \\
\hline & $\begin{array}{l}\text { LAGAR, } \\
\text { LAGER }\end{array}$ & & & & \\
\hline Loear mariet rocum & & & & & \\
\hline $\begin{array}{l}\text { Lomglem inzeest } \\
\text { Rist }\end{array}$ & $\begin{array}{l}\text { LTINT } \\
\text { PISK }\end{array}$ & & & & \\
\hline Shonlam inlereat & STINT & & & & \\
\hline $\begin{array}{l}R^{*} \\
A d \mid \cdot R^{\prime}\end{array}$ & $\begin{array}{l}\text { ANitbie } \\
\text { Adl } R 2\end{array}$ & & & & \\
\hline Sarneance leves & paralue & & & & \\
\hline Mou observations & & & & & \\
\hline
\end{tabular}




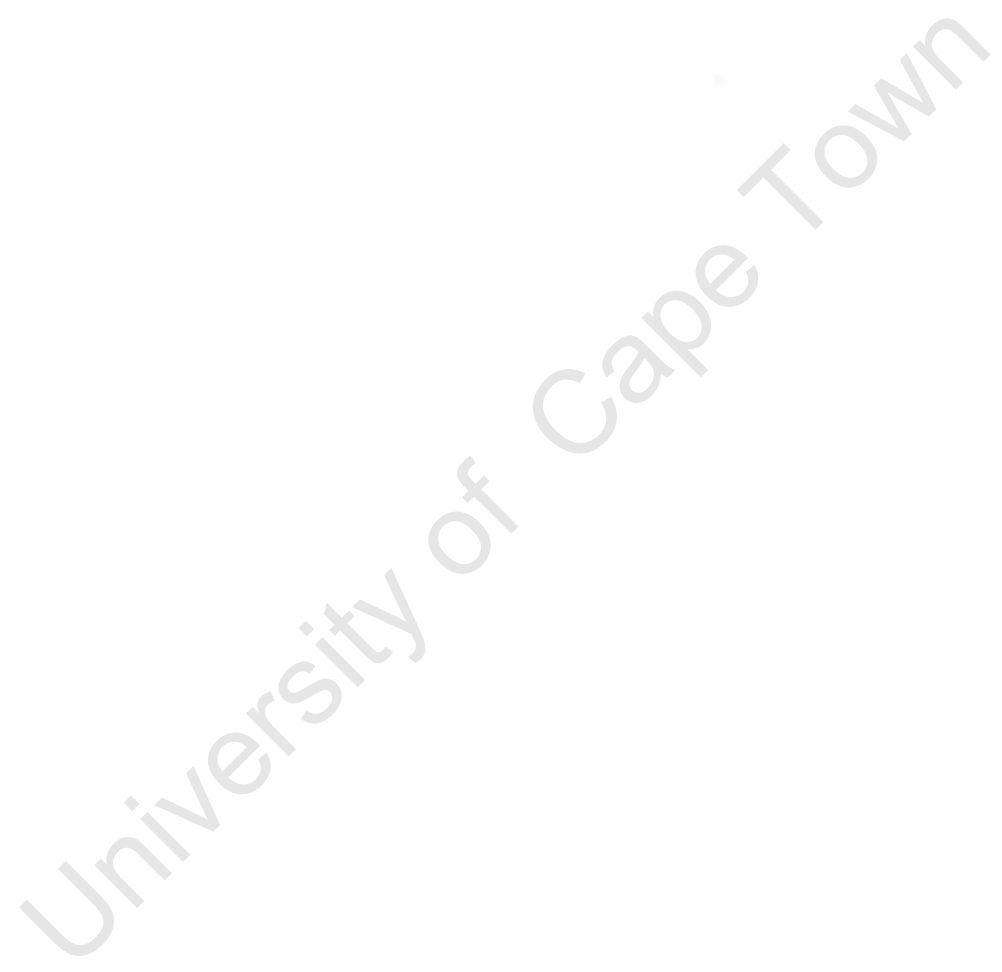




\begin{tabular}{|c|c|c|c|c|c|c|c|c|c|c|c|c|c|c|c|c|c|c|c|}
\hline \multicolumn{2}{|c|}{ 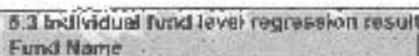 } & $\begin{array}{l}\text { 5. using r i topu } \\
\text { congtant }\end{array}$ & $\begin{array}{l}\text { Mso rapenti } \\
\text { totat: }\end{array}$ & $\begin{array}{l}\text { Ion andys } \\
\text { peralue }\end{array}$ & 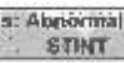 & retum & praluef & LTINT & $1-\sin \alpha$ & p-xaluen, & $\therefore$ ALS & - Istat: & pratase & acs. & tostat & Dratue & UAGCF & tostat & puvalueg \\
\hline & 0.0429 & 3.5265 & Bceos & & & & Fion & & & $\frac{A L S}{C 5227}$ & $\frac{1.5654}{3.5 \times 1^{2}}$ & $\frac{1-\cos \theta}{C-1}$ & & & & TAGCF & .2 .5658 & $\frac{\text { p.values }}{3.5124}$ \\
\hline \multicolumn{2}{|l|}{ 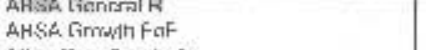 } & $\sin 17$ & -17796 & $c 273$ & & & & & & & & & & & & & c. 3150 & 4.7355 & 0.0000 \\
\hline \multicolumn{2}{|l|}{ Allse Gres' Exulty A } & $-c .35=1$ & $-1.54 \pm 2$ & ac567 & 307330 & $1.7 \% 6$ & $0,0147 \mathrm{c}$ & & & & 2.2615 & $34<3$ & U.G111.5 & & & & & & \\
\hline \multicolumn{2}{|l|}{ EoE Equity } & $1.03-5$ & 2.5039 & 20119 & & & & & & & C 6092 & $4.45 / 2$ & 0.0050 & & & & -6.1508 & 2.3691 & 1.0204 \\
\hline \multirow{2}{*}{\multicolumn{2}{|c|}{ Caromaluan High Growti }} & times & 23923 & $c 5202$ & & & & & & & G 4145 & $2 \mathrm{E5} 7 \mathrm{~A}$ & $6 . \cos 0$ & & & & -6.251 & - & $0.0 \times 14$ \\
\hline & & $2.11 \% 0$ & 4 अस्सार & $\cos 0^{\circ}$ & & & & $12.036 ?$ & 2.0229 & 0.0421 & & & & 0.73411 & 0.2073 & nino1a & $6.204 ?$ & $2.27 x$ & $012 / 3$ \\
\hline \multirow{2}{*}{\multicolumn{2}{|c|}{ FNa Gryonth }} & $0.045^{*}$ & $3.137^{2}$ & $\cos 3$ & $B^{\prime} .3 E 43$ & 3.5358 & G.C011 & & & & & & & & & & & & \\
\hline \multirow{2}{*}{\multicolumn{2}{|c|}{ 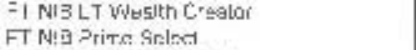 }} & - HIIIs? & $\therefore 14<8$ & PSAli:i & & & & & & & $1 € 55 \mathrm{C}$ & 34312 & c.ent14 & & & & & & \\
\hline & & 0.1828 & 11125 & cxo: & & & & & & & c.2923 & 3.2274 & $\operatorname{c.c020}$ & & & & & & \\
\hline \multicolumn{2}{|l|}{ 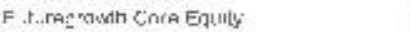 } & $\begin{array}{l}64350 \\
\sin 657\end{array}$ & $\begin{array}{l}\text { A } 4107 \\
3.2132\end{array}$ & $\begin{array}{l}3 \times 01 \\
3 \times 20\end{array}$ & $5 / 2 / 0^{6}$ & & $n(273)$ & & & & & $\therefore 1810$ & $\mathrm{ccosc}$ & & & & C. .346 & 4235 & 00001 \\
\hline \multirow{2}{*}{\multicolumn{2}{|c|}{ 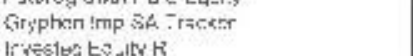 }} & $-6.625^{\circ}$ & -1.155 & 03532 & $52 / 0 ; i$ & 2.25000 & 06773 & & & & 60573 & (1)ाजि & 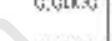 & & & & 0.1332 & $1.30 \mathrm{~s} 2$ & i., 15001 \\
\hline & & $+176 \% 4$ & $-201 \div$ & $5 \times 62^{2}$ & & & & $2<.403$ & 3.6216 & 5) $0 \times 07$ & $\mathrm{G}$ stea & $\angle C S 9$ & $c \cos c$ & & & & $-.27 \mathrm{C} 2$ & A das: & 0.0510 \\
\hline \multicolumn{2}{|l|}{ lisusta lindox R } & -.0358 & $-1.5056^{\circ}$ & 20000 & & & & & & & & & & & & & & & \\
\hline \multirow{2}{*}{\multicolumn{2}{|c|}{$\begin{array}{l}\text { Libe-y troserity } R \\
\text { Liberly } R \$ \text { Equily } A\end{array}$}} & -00365 & $-5 \equiv 456$ & 5 seno & & & & & & & & & & & & & & & \\
\hline & & 0.7656 & 3.3997 & 20020 & & & & & & & & & & & & & & & \\
\hline \multicolumn{2}{|l|}{ Literls whallibis ant R } & -00577 & \& 450 i & $5 \times 10$ & & & & & & & c fantis & $\angle 874 ;$ & cense & & & & $-c .2 \times 7$ & -29650 & 0.0545 \\
\hline in C_ked tyuly FoF & & $-c .0950$ & $-3 \cdot 1 / 6$ & 20232 & & & & & & & C.\#Z29? & $3.005 !$ & $\mathrm{SCOH} /$ & & & & G.1017 & $4.6<87$ & $1111 x_{2}$ \\
\hline 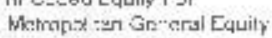 & & C. 1005 & $\geqslant 05<7$ & 30449 & & & & & & & 55725 & $3.57 \%$ & 56059 & & & & $-0.21+17$ & 2.9759 & 0.0058 \\
\hline Nedbsnk Limath & & $\cos 2$ & {$[4 / \% 4$} & $2.62 \mathrm{kig}$ & & & & & & & & & & & & & C. $35^{2} \mathrm{U}$ & 3. $9170:$ & $00 \times<<$ \\
\hline Ousis C:everil Cqu:y & & GG:02 & $\therefore 5 \times 91$ & 03156 & 13.6920 & 2.1159 & $\operatorname{ccs}=2$ & & & & & & & & & & & & \\
\hline 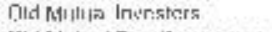 & & $2 \cdot 162$ & $\hat{2} \cdot 43 ! 4$ & $\| 12+2 \div 5$ & & & & $-1\lfloor i<<4 k j$ & 32508 & nion & & & & & & & & & \\
\hline Uld Mutua! Tos CoTDen:A\& & & 50295 & -12405 & $0.00<1$ & & & & & & & & & & & & & & & \\
\hline RMD [qu:y & & 55089 & 37109 & 0.0205 & & & & & & & 2\$45: & 2.3443 & $\operatorname{cc} 2224$ & & & & & & \\
\hline RMB Perfinten:e FnF & & $5, \infty 6: 2$ & -12113 & $\{11 \times 2 \times 2$ & & & & & & & & & & & & & 22713 & 37517 & $\mathrm{n} 00 \mathrm{C}$ \\
\hline Sags Fu-d & & -29295 & $-5,37 \mathrm{Eg}$ & 0.0000 & & & & & & & $0 / 3 / 3$ & E.uren & 3000 & & & & $0.198 r$ & $-2 \operatorname{se} i t \mathrm{i}$ & ance \\
\hline Qurilanil Fufure Trentids & & 2389 & $254 \div 1$ & $0.0 \cdot 80$ & $39.2 \cdot 92$ & 27085 & c.c10s & & & & $\because 455$ & 3.3337 & $5 \times 22$ & & & & & & \\
\hline gan|arm Gereral & & $\partial(4: 42$ & $-5.5: x_{i} f_{3}$ & $00 \times \mathrm{xi}$ & & & & & & & if $5: 47$ & $50<1$ & $3 \times 50$ & & & & $a>42$ & $3 \mathrm{seO}^{-}$ & $000 \times 3$ \\
\hline S:erdarc Nik Aasesene tof & & c:c0:4 & 1. $6 ! 43$ & $\begin{array}{ll}0 . u^{*} \in r \\
0.007\end{array}$ & & & & & & & 0.6423 & Jinge 1 & $3 \times 39$ & & & & & & \\
\hline 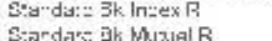 & & $\begin{array}{l}-\mathrm{c} 5 \mathrm{322} \\
54 \mathrm{H}) \mathrm{a}\end{array}$ & $\begin{array}{r}-2.7762 \\
1756 f_{i}\end{array}$ & 00649 & & & & & & & $0.5955_{i}$ & 529011 & $0 \times 000$ & & & & $-52 \angle x \leq$ & $37 C 95$ & 0.0005 \\
\hline Count & & Lonstant & 23 & $74 \%$ & STINT & 4 & $13 x$ & LTINT & 3 & $10 \%$ & ALSi & 17 & $55 \%$ & MCSI & 1 & $3 \%$ & $\mathrm{AGCF}$ & 18 & $82 \%$ \\
\hline Min & & 0.79 & -6.46 & $\cos$ & $-\overline{5.27}$ & 1.72 & $0.05]$ & 1541 & 3.24 & $0 \ddot{0}-$ & C.29 & $=2 \overline{3}$ & -0.05 & $=0.73$ & 3.29 & $0.0 \%$ & $-1,30$ & -1.24 & $5 \hat{\mathrm{c}}$ \\
\hline Max & & $2<2$ & 441 & egs & $f_{i}^{-} 3 *$ & 353 & is 19 & 24 4: & $3 n_{0}^{2}$ & is 155 : & $2 \Sigma_{f i}$ & $B: A$ & 002 & 073 & 029 & $0.0 \mathrm{c}$ & 0.43 & 2.74 & 50 \\
\hline Average & $\ldots \ldots$. & 0.113 & $-1 . \bar{\infty}$ & $\ldots=0$ ? & 2006 & $2.4 i$ & 0.04 & $7: \xi$ & 0.80 & $-0.0 \mathrm{z}$ & $c .2 \pm$ & _. 3.58 & 0.113 & 0,73 & 3.79 & 003 & 054 & .0 .53 & 531 \\
\hline Loganct & & & & & & & & & & & & & & & & & & & \\
\hline 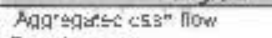 & AGGRCT & & & & & & & & & & & & & & & & & & \\
\hline$\Gamma=0$ sthucure. & FEF & & & & & & & & & & & & & & & & & & \\
\hline furd relum & & & & & & & & & & & & & & & & & & & \\
\hline & $\mathrm{AH}$ & & & & & & & & & & & & & & & & & & \\
\hline$F u-d \leqslant I \theta$ & SIZE & & & & & & & & & & & & & & & & & & \\
\hline Irrlenkyl arlis Irarket return & $M C \leqslant 1$ & & & & & & & & & & & & & & & & & & \\
\hline 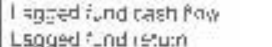 & $\begin{array}{l}\text { LAGCF } \\
\text { IAGRR }\end{array}$ & & & & & & & & & & & & & & & & & & \\
\hline & $\begin{array}{l}\text { LACRR } \\
\text { LAC:AR, }\end{array}$ & & & & & & & & & & & & & & & & & & \\
\hline$L=\Rightarrow$ tarkercelum & LAEER & & & & & & & & & & & & & & & & & & \\
\hline 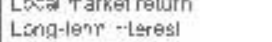 & $\begin{array}{l}\text { ALS: } \\
\text { ATINT }\end{array}$ & & & & & & & & & & & & & & & & & & \\
\hline Riek & $\mathrm{kl} \& \mathrm{~K}$ & & & & & & & & & & & & & & & & & & \\
\hline Shart-term intr'se: & STIN: & & & & & & & & & & & & & & & & & & \\
\hline$a_{3}^{4} b_{3}$ & Mutrize K & & & & & & & & & & & & & & & & & & \\
\hline Ad $R^{2}$ & $\begin{array}{l}\text { A-j R2 } \\
\text { p-velue }\end{array}$ & & & & & & & & & & & & & & & & & & \\
\hline Nüt gogsristcons & obs & & & & & & & & & & & & & & & & & & \\
\hline
\end{tabular}



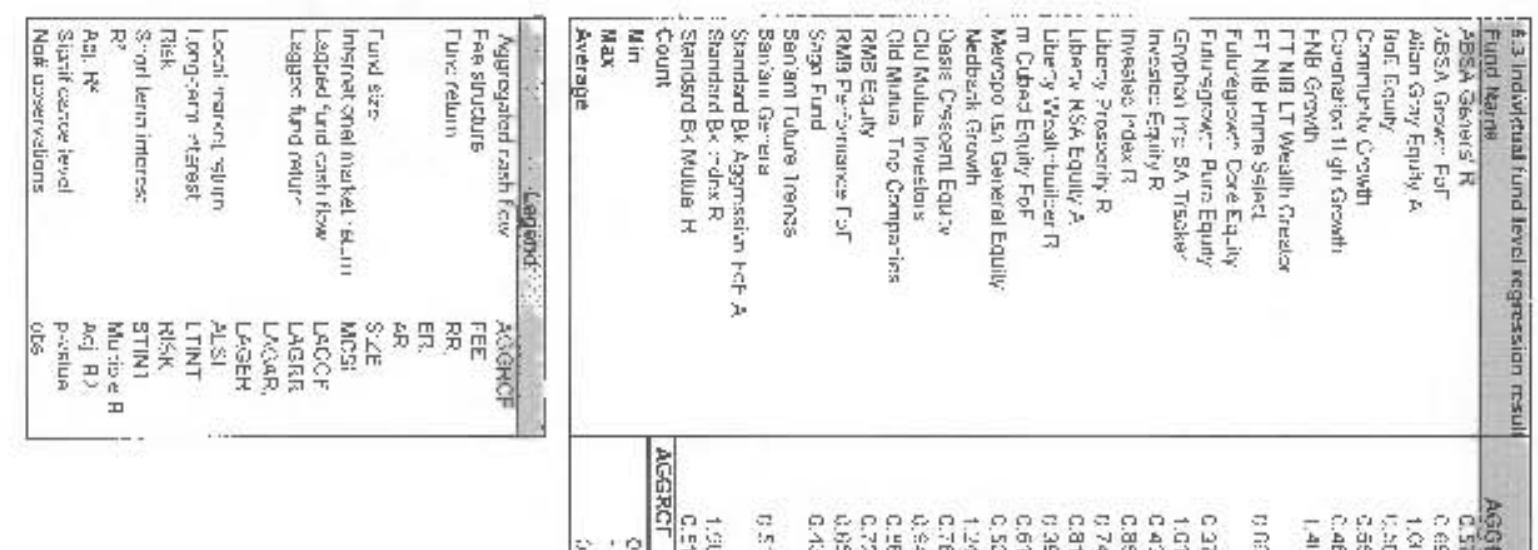

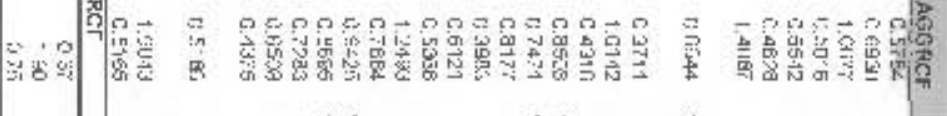

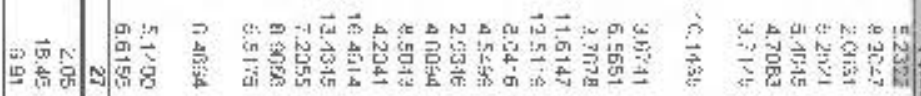

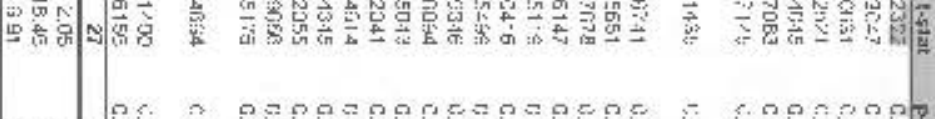

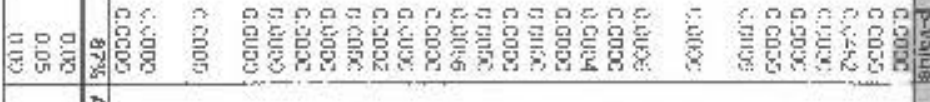

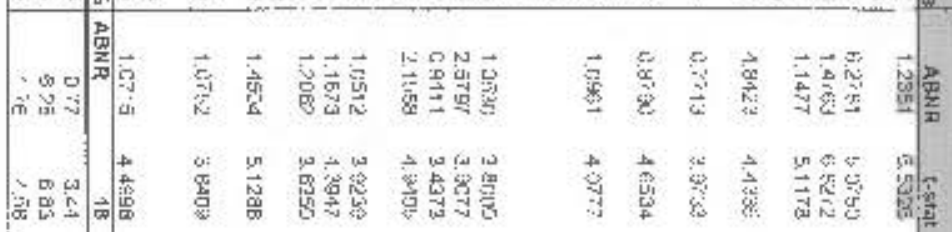

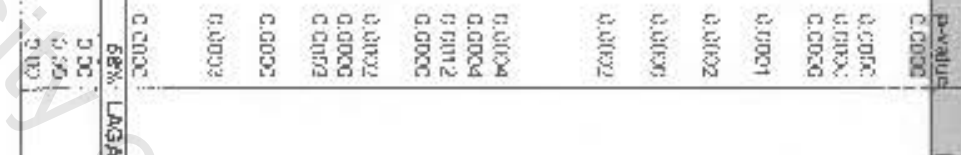

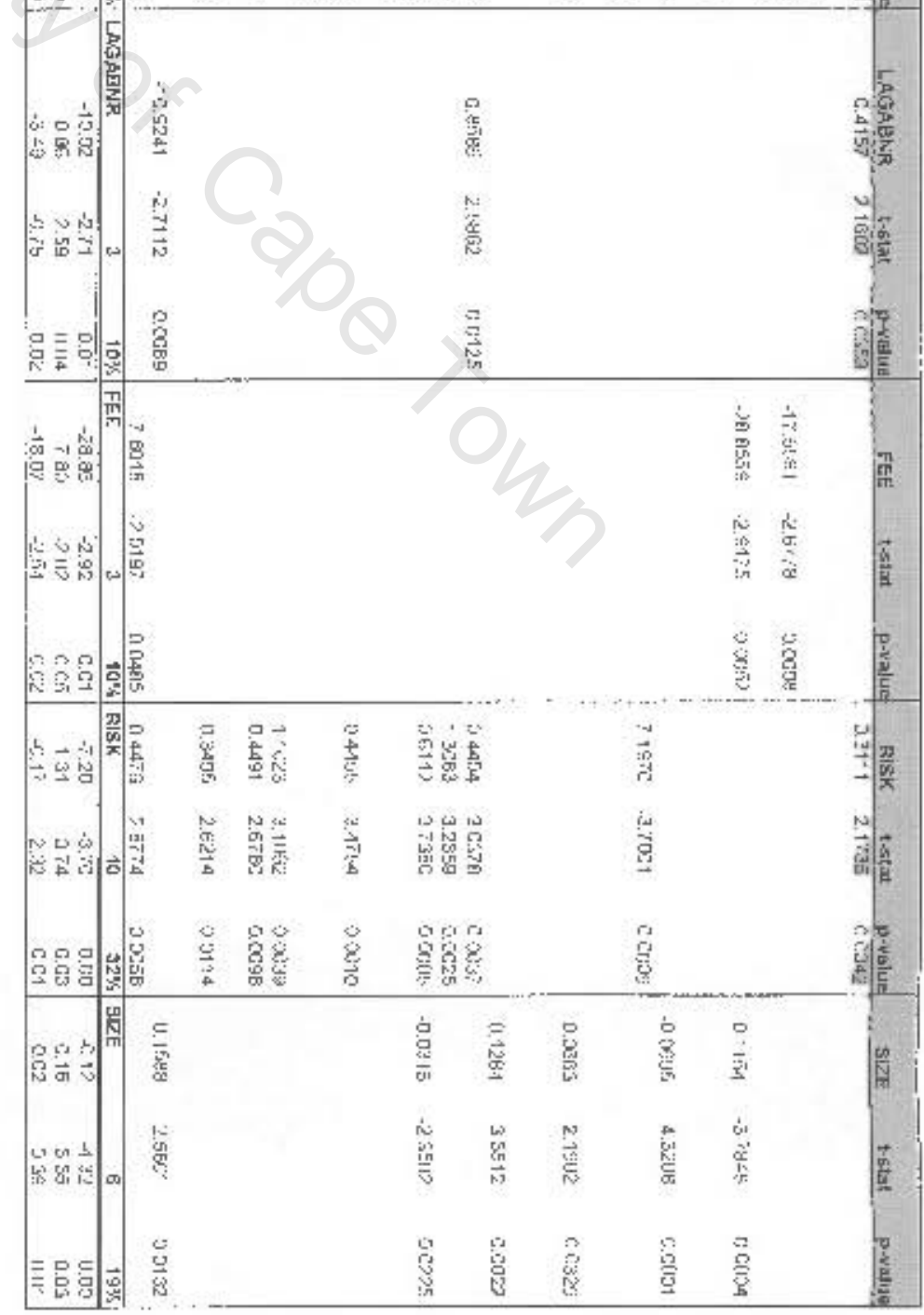




\begin{tabular}{|c|c|c|c|c|}
\hline 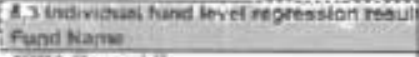 & Dultipie R & Adj 82 & parite of & \\
\hline 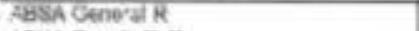 & 0.8116 & Qsinz & कod & खाम \\
\hline ABSA Geoth FI" & D.8599 & $0.76 \mathrm{~s}$ & 0,000 & \\
\hline Allan Gray Cqu:y A & 0 Aat7 & 0.665 & 00000 & 31 \\
\hline Rat Equky & 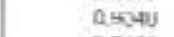 & ososo & 00000 & so \\
\hline Conininity Urast & 0.8795 & 0.755 & QQu⿰亻⿻上丨 & $\Rightarrow$ \\
\hline Caranatio- If gh Growth & D.6592 & 0705 & 20000 & 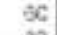 \\
\hline FNe Crowih & $0734 \%$ & 0,591 & 00000 & $x a$ \\
\hline FF NID I T Weath Gereitor & 0.4483 & c.184 & 0.0014 & aล \\
\hline F? Nit Pririe Solest & $09 \div 36$ & 0.823 & 00000 & ec \\
\hline Fusegroan Cord Equity & D.s.es & c.297 & 8.6000 & 31 \\
\hline Finidegarow:-Pure tquery & 0 Q 498 & 0.763 & 00005 & 0 \\
\hline Gryuher tis $3 A$ Tiacher & $0.00 / 5$ & 0.461 & $\sec 00$ & 54 \\
\hline Invastae squity $\mathrm{R}$ & 09584 & 0.805 & 00005 & ec \\
\hline Investa: index $\mathrm{R}$ & $0.83 \mathrm{ES}$ & 0.694 & 00000 & \#s \\
\hline I Eeriy Prasparity $\mathrm{H}$ & 0 0712 & 0.765 & 00000 & so \\
\hline Leerty RSA Esuity A & 0.6206 & $0.6 \mathrm{E} \mathrm{B}$ & socus & 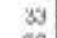 \\
\hline Learly Woitt tuildar $\mathrm{A}$ & $09=56$ & 0.920 & 00005 & sc \\
\hline TC Cubed tsults tor & $0.65 / 1$ & 0.700 & soous & 14 \\
\hline 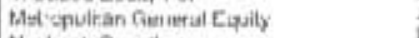 & 0.6951 & 0.773 & ว0005 & 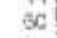 \\
\hline Nanterk 6 rowth & $0.641=$ & 0.685 & 50005 & 44 \\
\hline Obat: Conce-1 Eyury & 0.6395 & $0.4 C B$ & 35001 & $3 e$ \\
\hline Qe M.tinal investers & $\Delta R_{i}{ }_{1} 1$ & 0.433 & 5000 & Dat \\
\hline $\mathrm{C}$ a Mulual IO Cotranes & U.875C & 0.757 & 30000 & 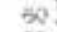 \\
\hline RQAl Eusiry & 0.8508 & 0.700 & 20000 & to \\
\hline FeAd Pentornarten Fof & 0.9509 & 0.599 & a $\alpha<0$ & a7 \\
\hline Sage runa & u.gue & 0.756 & $0.00 x 00$ & \\
\hline Soniluxi, ruhuet T ents & 0.6563 & 0396 & $D 0002$ & $x$ \\
\hline Sentam Gerentral & 0.9204 & . 2.051 & anco & 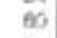 \\
\hline Searsars bl ropens of rot $A$ & $c .40 \div 2$ & 3198 & 0.0009 & \\
\hline Stanclacid Be midex $R$ & c. 5936 & 2316 & 0.0000 & 6.) \\
\hline Domerane hik Menial R & 6904,3 & Q.ess & 80000 & B5 \\
\hline Coumt & Equation & & $x$ & \\
\hline Mia & $=-215$ & dT & 0.00 & \\
\hline & $3: 0$ & cats & $\mathrm{cco}$ & \\
\hline Averages & 251 & 0.48 & 900 & \\
\hline
\end{tabular}

\begin{tabular}{|c|c|}
\hline Legentad & \\
\hline sapragafor cas- 10 w & dogker \\
\hline 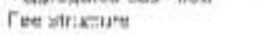 & FFF \\
\hline$F^{*}, 4$ motilyer & FR. \\
\hline & [R. \\
\hline & \\
\hline rurdsze & IIZL \\
\hline Iriles-atondi parkel relum & MC:S \\
\hline I ariged f.nd cash tiow & LATGCF \\
\hline Layaged f.nudirim & LNGRR \\
\hline & LAGAAF, \\
\hline Loval retertintur- & \\
\hline 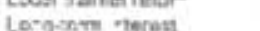 & Aat \\
\hline Pote & PISK: \\
\hline S-val lemn inesed & SIENI \\
\hline & Mulio $\equiv R$ \\
\hline Aa is & Ad $\mathrm{B}$ ? \\
\hline Sigaif arum level & Dezalie \\
\hline 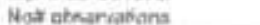 & \\
\hline
\end{tabular}

